\title{
$\triangle 1$ \\ Radionuclide-Chelating Agent Complexes in Low-Level Radioactive Decontamination Waste; Stability, Adsorbtion and Transport Potential
}

Pacific Northwest National Laboratory

U.S. Nuclear Regulatory Commission Office of Nuclear Regulatory Research Washington, DC 20555-0001 


\section{AVAILABILITY OF REFERENCE MATERIALS IN NRC PUBLICATIONS}

\section{NRC Reference Material}

As of November 1999, you may electronically access NUREG-series publications and other NRC records at NRC's Public Electronic Reading Room at www.nrc.gov/NRC/ADAMS/index.html.

Publicly released records include, to name a few, NUREG-series publications; Federal Register notices; applicant, licensee, and vendor documents and correspondence; NRC correspondence and internal memoranda; bulletins and information notices; inspection and investigative reports; licensee event reports; and Commission papers and their attachments.

NRC publications in the NUREG series, NRC regulations, and Title 10, Energy, in the Code of Federal Regulations may also be purchased from one of these two sources.

1. The Superintendent of Documents

U.S. Government Printing Office

Mail Stop SSOP

Washington, DC 20402-0001

Internet: bookstore.gpo.gov

Telephone: 202-512-1800

Fax: 202-512-2250

2. The National Technical Information Service Springfield, VA 22161-0002

mww.ntis.gov

$1-800-553-6847$ or, locally, 703-605-6000

A single copy of each NRC draft report for comment is available free, to the extent of supply, upon written request as follows:

Address: Office of the Chief Information Officer, Reproduction and Distribution

Services Section

U.S. Nuclear Regulatory Commission

Washington, DC 20555-0001

E-mail: DISTRIBUTION@nrc.gov

Facsimile: $301-415-2289$

Some publications in the NUREG series that are posted at NRC's Web site address

www.nrc.gov/NRC/NUREGS/indexnum.html

are updated periodically and may differ from the last

printed version. Although references to material found on a Web site bear the date the material was accessed, the material available on the date cited may subsequenily be removed from the site.

\section{Non-NRC Reference Material}

Documents available from public and special technical libraries include all open literature items, such as books, journal articles, and transactions, Federal Register notices, Federal and State legislation, and congressional reports. Such documents as theses, dissertations, foreign reports and translations, and non-NRC conference proceedings may be purchased from their sponsoring organization.

Copies of industry codes and standards used in a substantive manner in the NRC regulatory process are maintained at-

The NRC Technical Library

Two White Flint North

11545 Rockville Pike

Rockville, MD 20852-2738

These standards are available in the library for reference use by the public. Codes and standards are usually copyrighted and may be purchased from the originating organization or, if they are American National Standards, from-

American National Standards Institute 11 West $42^{\text {nd }}$ Street

New York, NY 10036-8002

www.ansi.org

$212-642-4900$

Legally binding regulatory requirements are stated only in laws; NRC regulations; licenses, including technical specifications; or orders, not in NUREG-series publications. The views expressed in contractor-prepared publications in this series are not necessarily those of the NRC.

The NUREG series comprises (1) technical and administrative reports and books prepared by the staff (NUREG-XXXX) or agency contractors (NUREG/CR-XXXX), (2) proceedings of conferences (NUREG/CP-XXXX), (3) reports resulting from international agreements (NUREG//A-XXXX), (4) brochures (NUREG/BR-XXXX), and (5) compilations of legal decisions and orders of the Commission and Atomic and Satety Licensing Boards and of Directors' decisions under Section 2.206 of NRC's regulations (NUREG-0750).

DISCLAIMAER: This report was prepared under an international cooperative agreement for the exchange of technical information. Neither the U.S. Government nor any agency thereof, nor any employee, makes any warranty, expressed or implied, or assumes any legal liability or responsibility for any third party's use, or the results of such use, of any information, apparatus, product or process disclosed in this publication, or represents
that its use by such third party would not infringe privately owned rights. 
NUREG/CR-6758

PNNL-13774

\section{Radionuclide-Chelating Agent Complexes in Low-Level Radioactive Decontamination Waste; Stability, Adsorbtion and Transport Potential}

Manuscript Completed: February 2002

Date Published: February 2002

Prepared by:

R.J. Serne, K.J. Cantrell, C.W. Lindenmeier, A.T. Owen, I.V. Kutnyakov, R.D. Orr, and A.R. Felmy

Pacific Northwest National Laboratory

P.O.Box 999

Richland, WA 99352

P.R. Reed, NRC Project Manager

Prepared for:

Division of Systems Analysis and Regulatory Effectiveness

Office of Nuclear Regulatory Research

U.S. Nuclear Regulatory Commission

Washington, DC 20555-0001

NRC Job Code $L 1155$

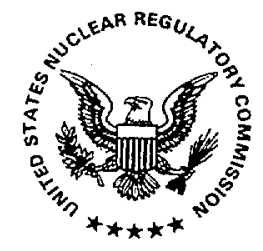




\begin{abstract}
Leach data for cement solidified spent resins from reactor decontamination suggests that maximum concentrations of organic ligands range from $2 \times 10^{-3}$ to $10^{-4} \mathrm{M}$ for picolinic acid and $3 \times 10^{-4}$ to $10^{-5} \mathrm{M}$ for EDTA. Cement leachates may release higher concentrations of organic ligands and lower concentrations of contaminant transition metals than the leachates of spent resins disposed directly in high integrity containers because the free hydroxide produced by cement leaching acts as a regenerating solution for the anion exchange resins, thus releasing the organic ligands and anionic complexes.

Speciation calculations were conducted to determine the significance of organic complexing agents in facilitating transport of radionuclides leached from buried waste forms through soil. The results of these speciation calculations can be condensed to the following conclusions. The potential for EDTA to mobilize metals is highest for divalent cations, and moderate for trivalent actinides. Picolinate appears to have significant potential to mobilize only $\mathrm{Ni}^{2+}$ and $\mathrm{Co}^{2+}$. It is important to recognize that speciation predictions ignore the influence of soil adsorption and biodegradation reactions that will compete with and destroy, respectively, the radionuclide/ligand complexes and thus potentially release the metals/ radionuclides to act as free ions.
\end{abstract}

In batch and flow-through adsorption studies, picolinate concentrations have to be $>10^{-4} \mathrm{M}$ to significantly lower the adsorption of divalent transition metals (Ni and $\mathrm{Co}$ ). For the metals $\mathrm{Sm}^{3+}, \mathrm{Th}^{4+}, \mathrm{NpO}_{2}^{+}, \mathrm{UO}_{2}{ }^{2+}$, and oxidized $\mathrm{Pu}$, the picolinate concentration must be $>10^{-3} \mathrm{M}$ before adsorption decreases. EDTA forms strong complexes with divalent transition metals and can stop adsorption of $\mathrm{Ni}$ and $\mathrm{Co}$ when EDTA solution concentrations are $\geq 10^{-5} \mathrm{M}$. EDTA complexes with oxycations such as $\mathrm{NpO}_{2}^{+}, \mathrm{UO}_{2}{ }^{2+}$, and oxidized $\mathrm{Pu}$ are much weaker. Adsorption tests suggest that EDTA concentrations would have to be $>10^{-3} \mathrm{M}$ to have adverse effects on non-transition metal/radionuclide adsorption onto most soils in contact with leachates at common $\mathrm{pH}$ 's.

Excepting divalent transition metal complexes, most picolinate and ETDA-metal complexes appear to be labile (readily dissociated) during interactions with soils. As complexes migrate from the disposal facility, dilution and interaction with competing cations in the pore fluids and adsorption reactions will result in dissociation of all but the strongest or most kinetically recalcitrant complexes. It appears that the enhanced migration of cationic metals/radionuclides-organic ligand complexes may be limited to a few unique conditions. Conditions that promote enhanced migration include high concentrations of organic ligands, low concentrations of competing cations, alkaline $\mathrm{pH}$, organic ligands with slow biodegradation rates and kinetically inert and very strong ligand-metal stability constants.

At high $\mathrm{pH}$ values such as that created by cementitious wastes, mobilization of $\mathrm{Ni}^{2+}$ and $\mathrm{Co}^{2+}$ by EDTA becomes very significant and adsorption by soils and sediments is essentially zero. Thus we recommend that mixtures of metal/radionuclides and chelating agents (particularly EDTA) should not be co-disposed with high $\mathrm{pH}$ materials such as cement. This also indicates that cementitious waste forms are not a suitable disposal option for mixtures of transition metal/radionuclides and strongly binding chelating agents such as EDTA. For weaker binding organic complexants such as picolinate, citrate, and oxalate, co-disposal of decontamination wastes and concrete should be acceptable. 


\section{Contents}

Abstract $\ldots \ldots \ldots \ldots \ldots \ldots \ldots \ldots \ldots \ldots \ldots \ldots \ldots \ldots \ldots \ldots \ldots \ldots \ldots \ldots \ldots \ldots \ldots \ldots \ldots \ldots$

Foreword $\ldots \ldots \ldots \ldots \ldots \ldots \ldots \ldots \ldots \ldots \ldots \ldots \ldots \ldots \ldots \ldots \ldots \ldots \ldots \ldots \ldots \ldots \ldots \ldots$

Acknowledgments $\ldots \ldots \ldots \ldots \ldots \ldots \ldots \ldots \ldots \ldots \ldots \ldots \ldots \ldots \ldots \ldots \ldots \ldots \ldots \ldots \ldots$

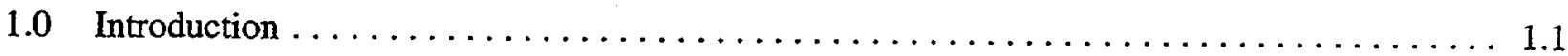

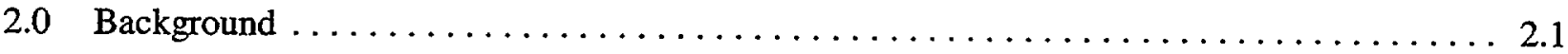

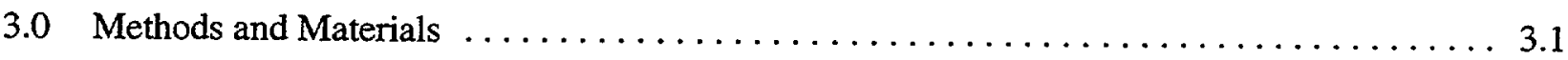

3.1 Speciation Calculation Methods and Assumptions $\ldots \ldots \ldots \ldots \ldots \ldots \ldots \ldots \ldots$

3.2 Experimental Methods for Batch Adsorption $\ldots \ldots \ldots \ldots \ldots \ldots \ldots \ldots \ldots$

3.3 Experimental Methods for Column Adsorption $\ldots \ldots \ldots \ldots \ldots \ldots \ldots \ldots$

4.0 Speciation Calculations $\ldots \ldots \ldots \ldots \ldots \ldots \ldots \ldots \ldots \ldots \ldots \ldots \ldots \ldots \ldots \ldots \ldots$

4.1 Speciation in Initial Cement Dominated Leachates $\ldots \ldots \ldots \ldots \ldots \ldots \ldots \ldots .1$

4.2 Speciation in $\mathrm{pH}$ Adjusted Leachates from Cement Waste Forms $\ldots \ldots \ldots \ldots .3$

4.3 Speciation of Non-Solidified Decontamination Waste Leachate . . . . . . . . . . 4.19

4.4 Speciation of $\mathrm{pH}$ Adjusted Non-Solidified Decontamination Waste Leachate $\ldots \ldots 4.20$

5.0 Adsorption Results and Discussion $\ldots \ldots \ldots \ldots \ldots \ldots \ldots \ldots \ldots \ldots \ldots \ldots \ldots \ldots \ldots$

5.1 Batch Adsorption Experiments $\ldots \ldots \ldots \ldots \ldots \ldots \ldots \ldots \ldots \ldots \ldots \ldots \ldots \ldots .1$

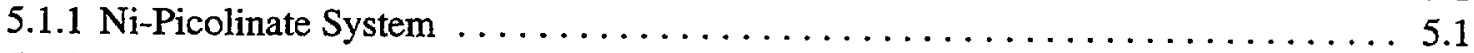

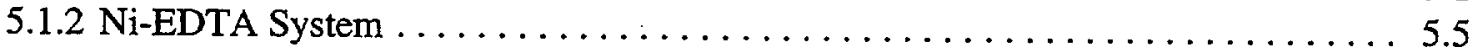

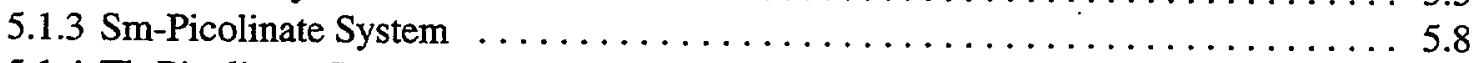

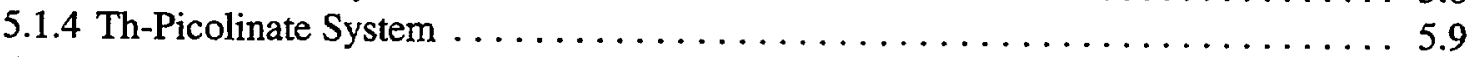

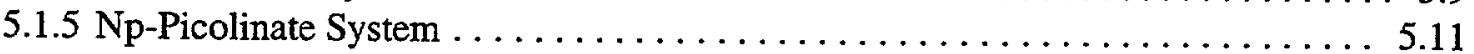

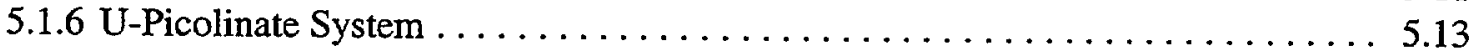

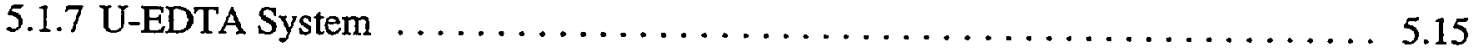

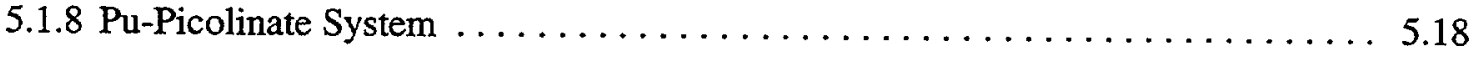

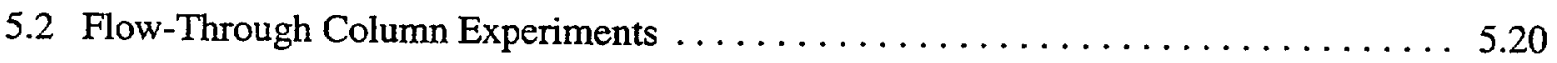


6.0 Summary and Recommendations $\ldots \ldots \ldots \ldots \ldots \ldots \ldots \ldots \ldots \ldots \ldots \ldots \ldots \ldots \ldots \ldots \ldots \ldots \ldots \ldots$

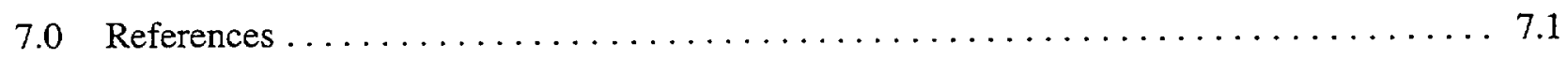

Appendix A - Thermodynamic Data . . . . . . . . . . . .

Appendix B - Kd Values as a Function of $\mathrm{pH}$ for Batch Adsorption Experiments .......... B.1

\section{Figures}

4.1 Speciation Distribution for Trivalent Actinides in Peach Bottom Leachate $\ldots \ldots \ldots . .4$

4.2 Speciation Distribution for Cobalt in Peach Bottom Leachate $\ldots \ldots \ldots \ldots \ldots \ldots \ldots .5$

4.3 Speciation Distribution for Manganese in Peach Bottom Leachate $\ldots \ldots \ldots \ldots \ldots \ldots . .5$

4.4 Speciation Distribution for Nickel in Peach Bottom Leachate $\ldots \ldots \ldots \ldots \ldots \ldots$

4.5 Speciation Distribution for Plutonium in Peach Bottom Leachate $\ldots \ldots \ldots \ldots \ldots \ldots$

4.6 Speciation Distribution for Zinc in Peach Bottom Leachate $\ldots \ldots \ldots \ldots \ldots \ldots \ldots .7$

4.7 Speciation Distribution for Picolinic Acid in Peach Bottom Leachate $\ldots \ldots \ldots \ldots .7$

4.8 Speciation Distribution for Trivalent Actinides in Pilgrim Leachate $\ldots \ldots \ldots \ldots \ldots . . \ldots$

4.9 Speciation Distribution for Cobalt in Pilgrim Leachate $\ldots \ldots \ldots \ldots \ldots \ldots \ldots \ldots \ldots$

4.10 Speciation Distribution for Manganese in Pilgrim Leachate $\ldots \ldots \ldots \ldots \ldots \ldots \ldots \ldots .10$

4.11 Speciation Distribution for Nickel in Pilgrim Leachate $\ldots \ldots \ldots \ldots \ldots \ldots \ldots \ldots \ldots$

4.12 Speciation Distribution for Strontium in Pilgrim Leachate $\ldots \ldots \ldots \ldots \ldots \ldots \ldots \ldots .11$

4.13 Speciation Distribution for Zinc in Pilgrim Leachate $\ldots \ldots \ldots \ldots \ldots \ldots \ldots \ldots \ldots .11$

4.14 Speciation Distribution for EDTA in Pilgrim Leachate $\ldots \ldots \ldots \ldots \ldots \ldots \ldots \ldots \ldots .12$

4.15 Speciation Distribution for DTPA in Pilgrim Leachate $\ldots \ldots \ldots \ldots \ldots \ldots \ldots \ldots \ldots .12$

4.16 Speciation Distribution for Trivalent Actinides in Millstone Leachate . . . . . . . . 4.13

4.17 Speciation Distribution for Cobalt in Millstone Leachate $\ldots \ldots \ldots \ldots \ldots \ldots \ldots \ldots .13$ 
4.18 Speciation Distribution for Manganese in Millstone Leachate $\ldots \ldots \ldots \ldots \ldots \ldots \ldots .14$

4.19 Speciation Distribution for Nickel in Millstone Leachate $\ldots \ldots \ldots \ldots \ldots \ldots \ldots .14$

4.20 Speciation Distribution for Strontium in Millstone Leachate $\ldots \ldots \ldots \ldots \ldots \ldots \ldots$

4.21 Speciation Distribution for Zinc in Millstone Leachate $\ldots \ldots \ldots \ldots \ldots \ldots \ldots \ldots$

4.22 Speciation Distribution for Plutonium in Millstone Leachate $\ldots \ldots \ldots \ldots \ldots \ldots \ldots$

4.23 Speciation Distribution for EDTA in Millstone Leachate $\ldots \ldots \ldots \ldots \ldots \ldots \ldots$

4.24 Speciation Distribution for Trivalent Actinides in Cooper Leachate . . . . . . . . . . 4.17

4.25 Speciation Distribution for Nickel in Cooper Leachate $\ldots \ldots \ldots \ldots \ldots \ldots \ldots \ldots \ldots$

4.26 Speciation Distribution for Oxalic Acid in Cooper Leachate $\ldots \ldots \ldots \ldots \ldots \ldots \ldots .18$

4.27 Speciation Distribution for Oxalic Acid in Brunswick Leachate . . . . . . . . . . 4.19

4.28 Speciation Distribution for $\mathrm{Cr}^{3+}$ in Non-Solidified Leachate $\ldots \ldots \ldots \ldots \ldots \ldots \ldots \ldots .21$

4.29 Speciation Distribution for $\mathrm{Am}^{3+}$ in Non-Solidified Leachate $\ldots \ldots \ldots \ldots \ldots \ldots \ldots .21$

4.30 Speciation Distribution for $\mathrm{Co}^{2+}$ in Non-Solidified Leachate $\ldots \ldots \ldots \ldots \ldots \ldots \ldots .22$

4.31 Speciation Distribution for $\mathrm{Mn}^{2+}$ in Non-Solidified Leachate $\ldots \ldots \ldots \ldots \ldots \ldots \ldots .22$

4.32 Speciation Distribution for $\mathrm{Ni}^{2+}$ in Non-Solidified Leachate $\ldots \ldots \ldots \ldots \ldots \ldots \ldots \ldots .23$

4.33 Speciation Distribution for $\mathrm{Zn}^{2+}$ in Non-Solidified Leachate $\ldots \ldots \ldots \ldots \ldots \ldots \ldots$

4.34 Speciation Distribution for EDTA in Non-Solidified Leachate $\ldots \ldots \ldots \ldots \ldots \ldots \ldots .24$

5.1 Percent Adsorption of $\mathrm{Ni}^{2+}$ on 1.2\% Iron Oxide Coated Sand as a Function of $\mathrm{pH}(0.5 \mathrm{~g}$ soil $/ 30 \mathrm{ml}, 0.003$ molar $\mathrm{Ca}\left[\mathrm{ClO}_{4}\right]_{2}$ solution, with an initial $\mathrm{Ni}^{2+}$ concentration of $\left.10^{-5} \mathrm{M}\right) \ldots 5.1$

5.2 Percent Adsorption of $\mathrm{Ni}^{2+}$ and Picolinate on 1.2\% Iron Oxide Coated Sand as a Function of $\mathrm{pH}\left(0.5 \mathrm{~g}\right.$ soil $/ 30 \mathrm{ml}, 0.003$ molar $\mathrm{Ca}\left[\mathrm{ClO}_{4}\right]_{2}$ solution, with initial concentrations of $\mathrm{Ni}^{2+}$ and picolinate of $10^{-5} \mathrm{M}$ and $10^{-3} \mathrm{M}$, respectively) $\ldots \ldots \ldots \ldots \ldots \ldots \ldots \ldots \ldots \ldots \ldots \ldots \ldots \ldots \ldots$

5.3 Percent Adsorption of $\mathrm{Ni}^{2+}$ and Picolinate on 1.2\% Iron Oxide Coated Sand as a Function of $\mathrm{pH}\left(0.5 \mathrm{~g}\right.$ soil $30 \mathrm{ml}, 0.003$ molar $\mathrm{Ca}\left[\mathrm{ClO}_{4}\right]_{2}$ solution, with initial concentrations of $\mathrm{Ni}^{2+}$ and picolinate of $10^{-5} \mathrm{M}$ and $10^{-4} \mathrm{M}$, respectively) 
5.4 Percent Adsorption of $\mathrm{Ni}^{2+}$ and Picolinate on 1.2\% Iron Oxide Coated Sand as a Function of $\mathrm{pH}\left(0.5 \mathrm{~g}\right.$ soil $/ 30 \mathrm{ml}, 0.003$ molar $\mathrm{Ca}\left[\mathrm{ClO}_{4}\right]_{2}$ solution, with initial concentrations of $\mathrm{Ni}^{2+}$

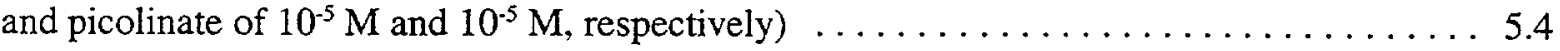

5.5 Percent Adsorption of $\mathrm{Ni}^{2+}$ and Picolinate on Milford Soil as a Function of $\mathrm{pH}(0.5 \mathrm{~g}$ soil/ $30 \mathrm{ml}, 0.003$ molar $\mathrm{Ca}\left[\mathrm{ClO}_{4}\right]_{2}$ solution, with initial concentrations of $\mathrm{Ni}^{2+}$ and picolinate of

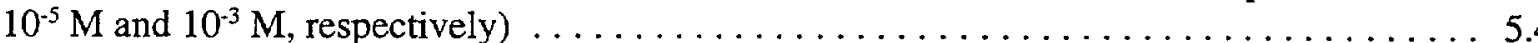

5.6 Percent Adsorption of $\mathrm{Ni}^{2+}$ (as measured by $\mathrm{Ni}-63$ tracer and ICP methods) and Picolinate on Milford Soil as a Function of $\mathrm{pH}\left(0.5 \mathrm{~g}\right.$ soil/30 ml, 0.003 molar $\mathrm{Ca}\left[\mathrm{ClO}_{4}\right]_{2}$ solution, with initial concentrations of $\mathrm{Ni}^{2+}$ and picolinate of $10^{-5} \mathrm{M}$ and $10^{-5} \mathrm{M}$, respectively) $\ldots \ldots \ldots .5$

5.7 Percent Adsorption of $\mathrm{Ni}^{2+}$ and EDTA on 1.2\% Iron Oxide Coated Sand as a Function of $\mathrm{pH}\left(0.5 \mathrm{~g}\right.$ soil $/ 30 \mathrm{ml}, 0.003$ molar $\mathrm{Ca}\left[\mathrm{ClO}_{4}\right]_{2}$ solution, with initial concentrations of $\mathrm{Ni}^{2+}$

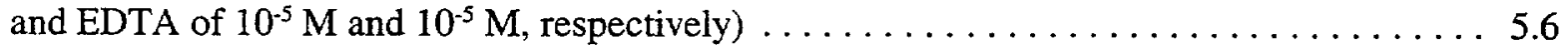

5.8 Percent Adsorption of $\mathrm{Ni}^{2+}$ and EDTA on Milford Soil as a Function of $\mathrm{pH}(0.5 \mathrm{~g}$ soil $30 \mathrm{ml}, 0.003$ molar $\mathrm{Ca}\left[\mathrm{ClO}_{4}\right]_{2}$ solution, with initial concentrations of $\mathrm{Ni}^{2+}$ and EDTA of

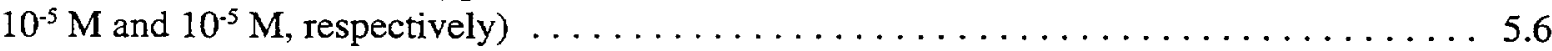

5.9 Percent Adsorption of $\mathrm{Ni}^{2+}$ and EDTA on LK-1 Soil as a Function of $\mathrm{pH}(0.5 \mathrm{~g}$ soil/ $30 \mathrm{ml}, 0.003$ molar $\mathrm{Ca}\left[\mathrm{ClO}_{4}\right]_{2}$ solution, with initial concentrations of $\mathrm{Ni}^{2+}$ and EDTA of

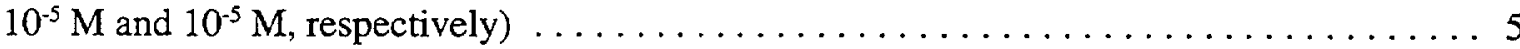

5.10 Percent Adsorption of $\mathrm{Ni}^{2+}$ and EDTA on MNC-7 Soil as a Function of $\mathrm{pH}(0.5 \mathrm{~g}$ soil/ $30 \mathrm{ml}, 0.003$ molar $\mathrm{Ca}\left[\mathrm{ClO}_{4}\right]_{2}$ solution, with initial concentrations of $\mathrm{Ni}^{2+}$ and EDTA of

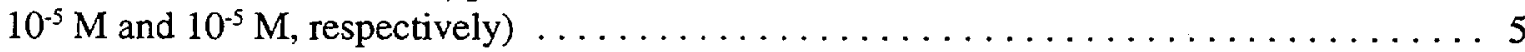

5.11 Percent Adsorption of $\mathrm{Sm}^{3+}$ and Picolinate on 1.2\% Iron Oxide Coated Sand as a Function of $\mathrm{pH},\left(0.5 \mathrm{~g}\right.$ soil $/ 30 \mathrm{ml}, 0.003$ molar $\mathrm{Ca}\left[\mathrm{ClO}_{4}\right]_{2}$ solution, with initial concentrations of $\mathrm{Sm}^{3+}$

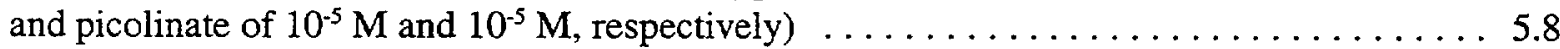

5.12 Percent Adsorption of $\mathrm{Sm}^{3+}$ and Picolinate on Milford Soil as a Function of $\mathrm{pH}(0.5 \mathrm{~g}$ soily $30 \mathrm{ml}, 0.003$ molar $\mathrm{Ca}\left[\mathrm{ClO}_{4}\right]_{2}$ solution, with initial concentrations of $\mathrm{Sm}^{3+}$ and picolinate of

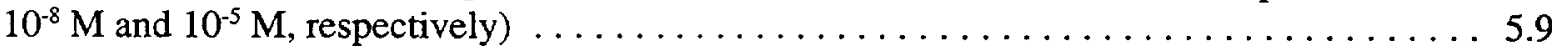

5.13 Percent Adsorption of $\mathrm{Sm}^{3+}$ and Picolinate on Milford Soil as a Function of $\mathrm{pH}$ $\left(0.5 \mathrm{~g}\right.$ soil $/ 30 \mathrm{ml}, 0.003$ molar $\mathrm{Ca}\left[\mathrm{ClO}_{4}\right]_{2}$ solution, with initial concentrations of $\mathrm{Sm}^{3+}$ and picolinate of $10^{-5} \mathrm{M}$ and $10^{-5} \mathrm{M}$, respectively)

5.14 Percent Adsorption of $\mathrm{Th}^{4+}$ and Picolinate on $1.2 \%$ Iron Oxide Coated Sand as a Function of $\mathrm{pH}\left(0.5 \mathrm{~g}\right.$ soil $/ 30 \mathrm{ml}, 0.003$ molar $\mathrm{Ca}\left[\mathrm{ClO}_{4}\right]_{2}$ solution, with initial concentrations of $\mathrm{Th}^{4+}$ and picolinate of $10^{-5} \mathrm{M}$ and $10^{-5} \mathrm{M}$, respectively) $\ldots \ldots \ldots \ldots \ldots \ldots$ 
5.15 Percent Adsorption of $\mathrm{Th}^{4+}$ and Picolinate on Milford Soil as a Function of $\mathrm{pH}$ $\left(0.5 \mathrm{~g}\right.$ soil $/ 30 \mathrm{ml}, 0.003$ molar $\mathrm{Ca}\left[\mathrm{ClO}_{4}\right]_{2}$ solution, with initial concentrations of $\mathrm{Th}^{4+}$ and picolinate of $10^{-5} \mathrm{M}$ and $10^{-5} \mathrm{M}$, respectively) $\ldots \ldots \ldots \ldots \ldots \ldots \ldots \ldots \ldots \ldots \ldots \ldots \ldots \ldots$

5.16 Percent Adsorption of $\mathrm{NpO}_{2}{ }^{+}$on $1.2 \%$ Iron Oxide Coated Sand as a Function of pH $\left(0.5 \mathrm{~g}\right.$ soil $/ 30 \mathrm{ml}, 0.003$ molar $\mathrm{Ca}\left[\mathrm{ClO}_{4}\right]_{2}$ solution, with an initial $\mathrm{NpO}_{2}+$ concentration of $6.7 \times 10^{-7} \mathrm{M}$ )

5.17 Percent Adsorption of $\mathrm{NpO}_{2}{ }^{+}$and Picolinate on 1.2\% Iron Oxide Coated Sand as a Function of $\mathrm{pH}\left(0.5 \mathrm{~g}\right.$ soil $/ 30 \mathrm{ml}, 0.003$ molar $\mathrm{Ca}\left[\mathrm{ClO}_{4}\right]_{2}$ solution, with initial concentrations of $\mathrm{NpO}_{2}{ }^{+}$and picolinate of $6.7 \times 10^{-7} \mathrm{M}$ and $10^{-5} \mathrm{M}$, respectively)

5.18 Percent Adsorption of $\mathrm{NpO}_{2}{ }^{+}$on Milford Soil as a Function of $\mathrm{pH}(0.5 \mathrm{~g} \mathrm{soil} / 30 \mathrm{ml}$, 0.003 molar $\mathrm{Ca}\left[\mathrm{ClO}_{4}\right]_{2}$ solution, with an initial $\mathrm{NpO}_{2}{ }^{+}$concentration of $6.7 \times 10^{-7} \mathrm{M}$ )

5.19 Percent Adsorption of $\mathrm{NpO}_{2}^{+}$and Picolinate on Milford Soil as a Function of $\mathrm{pH}$ $\left(0.5 \mathrm{~g}\right.$ soil $/ 30 \mathrm{ml}, 0.003$ molar $\mathrm{Ca}\left[\mathrm{ClO}_{4}\right]_{2}$ solution, with initial concentrations of $\mathrm{NpO}_{2}^{+}$ and picolinate of $6.7 \times 10^{-7} \mathrm{M}$ and $10^{-5} \mathrm{M}$, respectively)

5.20 Percent Adsorption of $\mathrm{UO}_{2}{ }^{2+}$ and Picolinate on 1.2\% Iron Oxide Coated Sand as a Function of $\mathrm{pH}\left(0.5 \mathrm{~g}\right.$ soil $/ 30 \mathrm{ml}, 0.003$ molar $\mathrm{Ca}\left[\mathrm{ClO}_{4}\right]_{2}$ solution, with initial concentrations of $\mathrm{UO}_{2}{ }^{2+}$ and picolinate of $10^{-5} \mathrm{M}$ and $10^{-3} \mathrm{M}$, respectively)

5.21 Percent Adsorption of $\mathrm{UO}_{2}{ }^{2+}$ and Picolinate on Milford Soil as a Function of $\mathrm{pH}$ $\left(0.5 \mathrm{~g}\right.$ soil/ $30 \mathrm{ml}, 0.003$ molar $\mathrm{Ca}\left[\mathrm{ClO}_{4}\right]_{2}$ solution, with initial concentrations of $\mathrm{UO}_{2}{ }^{2+}$

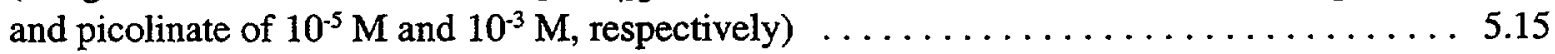

5.22 Percent Adsorption of $\mathrm{UO}_{2}{ }^{2+}$ and EDTA on 1.2\% Iron Oxide Coated Sand as a Function of $\mathrm{pH}\left(0.5 \mathrm{~g}\right.$ soil $/ 30 \mathrm{ml}, 0.003$ molar $\mathrm{Ca}\left[\mathrm{ClO}_{4}\right]_{2}$ solution, with initial concentrations of $\mathrm{UO}_{2}{ }^{2+}$ and EDTA of $10^{-5} \mathrm{M}$ and $10^{-5} \mathrm{M}$, respectively) $\ldots \ldots \ldots \ldots \ldots \ldots .16$

5.23 Percent Adsorption of $\mathrm{UO}_{2}{ }^{2+}$ and EDTA on Milford Soil as a Function of $\mathrm{pH}$ $\left(0.5 \mathrm{~g}\right.$ soil $/ 30 \mathrm{ml}, 0.003$ molar $\mathrm{Ca}\left[\mathrm{ClO}_{4}\right]_{2}$ solution, with initial concentrations of $\mathrm{UO}_{2}{ }^{2+}$ and EDTA of $10^{-5} \mathrm{M}$ and $10^{-5} \mathrm{M}$, respectively)

5.24 Percent Adsorption of $\mathrm{UO}_{2}{ }^{2+}$ and EDTA on LK-1 Soil as a Function of $\mathrm{pH}(0.5 \mathrm{~g}$ soil/ $30 \mathrm{ml}, 0.003$ molar $\mathrm{Ca}\left[\mathrm{ClO}_{4}\right]_{2}$ solution, with initial concentrations of $\mathrm{UO}_{2}{ }^{2+}$ and EDTA

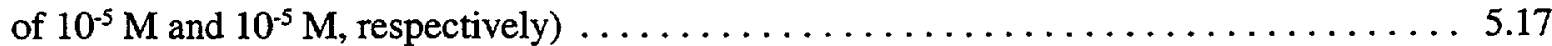

5.25 Percent Adsorption of $\mathrm{UO}_{2}{ }^{2+}$ and EDTA on MNC-7 Soil as a Function of pH ( $0.5 \mathrm{~g}$ soil/ $30 \mathrm{ml}, 0.003$ molar $\mathrm{Ca}\left[\mathrm{ClO}_{4}\right]_{2}$ solution, with initial concentrations of $\mathrm{UO}_{2}{ }^{2+}$ and EDTA of $10^{-5} \mathrm{M}$ and $10^{-5} \mathrm{M}$, respectively) $\ldots \ldots \ldots \ldots \ldots \ldots \ldots \ldots \ldots \ldots \ldots \ldots \ldots \ldots \ldots \ldots \ldots \ldots \ldots \ldots \ldots .18$

5.26 Percent Adsorption of Pu on Milford Soil as a Function of $\mathrm{pH}(0.5 \mathrm{~g}$ soil/30 ml, $0.003 \mathrm{molar}$ $\mathrm{Ca}\left[\mathrm{ClO}_{4}\right]_{2}$ solution, with an initial $\mathrm{Pu}$ concentration of $\left.6.7 \times 10^{-7} \mathrm{M}\right) \ldots \ldots \ldots \ldots \ldots \ldots$ 
5.27 Percent Adsorption of Pu and Picolinate on Milford Soil as a Function of $\mathrm{pH}(0.5 \mathrm{~g}$ soil/ $30 \mathrm{ml}, 0.003$ molar $\mathrm{Ca}\left[\mathrm{ClO}_{4}\right]_{2}$ solution, with initial concentrations of $\mathrm{Pu}$ and picolinate of

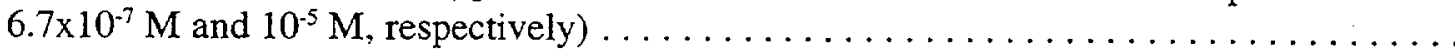

5.28 Percent Adsorption of Pu and Picolinate on Milford Soil as a Function of $\mathrm{pH}(0.5 \mathrm{~g}$ soil $30 \mathrm{ml}, 0.003$ molar $\mathrm{Ca}\left[\mathrm{ClO}_{4}\right]_{2}$ solution, with initial concentrations of $\mathrm{Pu}$ and picolinate of

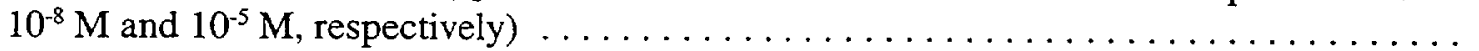

5.29 Flow Through Column Results for $\mathrm{Ni}^{2+}$ and Picolinate Through 1.2\% Iron Oxide Coated Sand (influent solution 0.003 molar $\mathrm{Ca}\left[\mathrm{ClO}_{4}\right]_{2}$ with initial concentrations of $\mathrm{Ni}^{2+}$ and picolinate of $10^{-6} \mathrm{M}$ and $10^{-4} \mathrm{M}$, respectively)

5.30 Flow Through Column Results for $\mathrm{Ni}^{2+}$ and Picolinate Through Milford Soil (influent solution 0.003 molar $\mathrm{Ca}[\mathrm{ClO} 4])_{2}$ with initial concentrations of $\mathrm{Ni}^{2+}$ and picolinate of

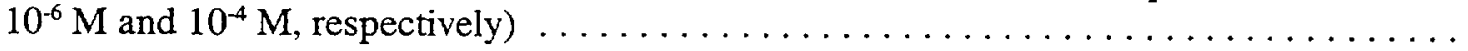

5.31 Flow Through Column Results for $\mathrm{Ni}^{2+}$ and Picolinate Through Milford Soil (influent solution 0.003 molar $\mathrm{Ca}[\mathrm{ClO} 4])_{2}$ with initial concentrations of $\mathrm{Ni}^{2+}$ and picolinate of

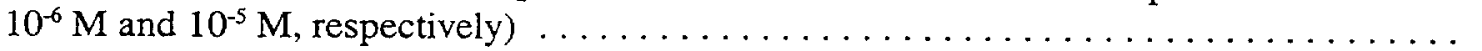

5.32 Flow Through Column Results for $\mathrm{Ni}^{2+}$ and EDTA Through 1.2\% Iron Oxide Coated Sand (influent solution 0.003 molar $\mathrm{Ca}\left[\mathrm{ClO}_{4}\right]_{2}$ with initial concentrations of $\mathrm{Ni}^{2+}$ and EDTA of $10^{-5} \mathrm{M}$ and $10^{-5} \mathrm{M}$, respectively)

5.33 Flow Through Column Results for $\mathrm{Ni}^{2+}$ and EDTA Through Milford Soil (influent solution 0.003 molar $\mathrm{Ca}\left[\mathrm{ClO}_{4}\right]_{2}$ with initial concentrations of $\mathrm{Ni}^{2+}$ and EDTA of $10^{-5} \mathrm{M}$ and $10^{-5} \mathrm{M}$, respectively)

5.34 Flow Through Column Results for Pu and Picolinate Through Milford Soil (influent solution 0.003 molar $\mathrm{Ca}\left[\mathrm{ClO}_{4}\right]_{2}$ with initial concentrations of $\mathrm{Pu}$ and picolinate of $10^{-7} \mathrm{M}$ and $10^{-4} \mathrm{M}$, respectively)

\section{Tables}

3.1 Starting Concentrations of Chelating Agents and Metals Used in Equilibrium Modeling of Cementitious Waste Form Leachates $\ldots \ldots \ldots \ldots \ldots \ldots \ldots \ldots \ldots \ldots \ldots \ldots \ldots$

3.2 Major Ion Concentrations in Synthetic Hanford Groundwater, Before, and After Equilibration with Portlandite

3.3 Major Ion Concentrations in Non-Solidified Decontamination Waste Leachates 
3.4 Chemical and Particle Size Characteristics of the Soils $\ldots \ldots \ldots \ldots \ldots \ldots \ldots \ldots \ldots$

3.5 Physical Properties of Experimental Columns $\ldots \ldots \ldots \ldots \ldots \ldots \ldots \ldots \ldots \ldots \ldots$

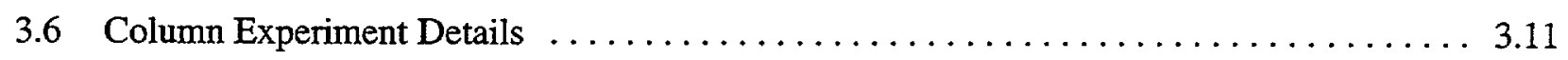

4.1 Percent Distribution of Picolinate Complexes in LOMI Leachates in Equilibrium

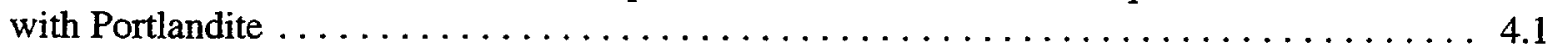

4.2 Percent Distribution of EDTA and DTPA Complexes in NS-1 Pilgrim Leachates in

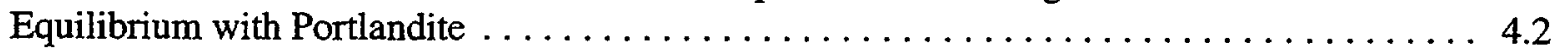

4.3 Percent Distribution of EDTA Complexes in CAN-DECON Millstone Leachates in Equilibrium with Portlandite $\ldots \ldots \ldots \ldots \ldots \ldots \ldots \ldots \ldots \ldots \ldots \ldots \ldots \ldots \ldots \ldots \ldots$

4.4 Speciation Distribution of Dissolved Radionuclides and Metals Calculated for NonSolidified Decontamination Waste Leachate $\ldots \ldots \ldots \ldots \ldots \ldots \ldots \ldots \ldots \ldots \ldots \ldots \ldots \ldots \ldots \ldots .20$ 


\section{Foreword}

This contractor technical report was prepared by Pacific Northwest National Laboratory ${ }^{1}$ (PNNL) under their DOE Interagency Work Order (JCN L1155) with the Radiation Protection, Environmental Risk and Waste Management Branch, Division of Systems Analysis and Regulatory Effectiveness, Office of Nuclear Regulatory Research, U.S. Nuclear Regulatory Commission.

The report is the final contractor report documenting PNNL's research results on radionuclide-chelating complexes from studies performed with decontamination waste collected from operating nuclear power stations and disposed in a low-level waste disposal facility.

The PNNL research study was undertaken to support licensing needs for assessing radionuclide migration in soils under conditions where radionuclides combine with chelating agents to form radionuclide-chelate complexes which could enhance radionuclide migration in soil and increase dose as described in the Statement of Considerations to 10 CFR Part 61. This PNNL report provides data and information on chemical species, adsorption and behavior in typical soils for many radionuclide-chelating complexes found in the leachates of decontamination. Speciation distributions for radionuclides and organic complexing agents were calculated with chemical thermodynamic computer codes using the chemical composition of actual leachates. Both batch and flow experiments were used to obtain adsorption coefficients for the radionuclides, organic ligands and complexes. The report also provides the chemical thermodynamic data used in chemical codes to calculate the chemical species, and identifies areas where important thermodynamic data to calculate radionuclide-chelating chemical species are needed. Research results provided by the PNNL report are expected to be used for assessing the migration of radionuclide complexes in site-specific performance assessments as described in "A Performance Assessment Methodology for Low-Level Radioactive Waste Disposal Facilities," NUREG-1573.

This report is not a substitute for NRC regulations, and compliance is not required. The approaches and/or methods described in this NUREG/CR report are provided for information only. Publication of this report does not necessarily constitute NRC approval or agreement with the information contained herein. Use of product or trade names is for identification purposes only and does not constitute endorsement by the NRC or Pacific Northwest National Laboratory.

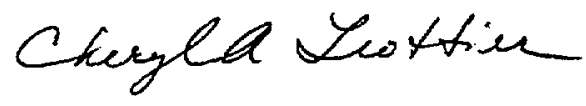

Cheryl A. Trottier, Chief

Radiation Protection, Environmental Risk and Waste Management Branch

Division of Systems Analysis and Regulatory Effectiveness

Office of Nuclear Regulatory Research

(1) Pacific Northwest National Laboratory is operated for the U.S. Department of Energy by Battelle Memorial Institute under contract DE-AC06-76RL01830. 


\section{Acknowledgments}

We would like to thank and acknowledge Dr. Daniel I. Kaplan of Westinghouse Savannah River Company, Aiken, South Carolina who provided independent technical peer review of this report. We also wish to thank and acknowledge Dr. Phil R. Reed of the United States Nuclear Regulatory Commission, Division of Systems Analysis and Regulatory Effectiveness, Washington, D.C. for collating all the technical and editorial comments from NRC staff. We also acknowledge Dr. Reed's sustained support, technical guidance and many fruitful discussions on commercial reactor operations during the life-time of this project.

We also wish to thank Ms. Lila M. Andor with Pacific Northwest National Laboratory's Publications Design Group for producing the camera ready version of this technical report. 


\subsection{Introduction}

Organic complexes of radionuclides have been implicated in several instances as enhancing the mobility of radionuclides such as ${ }^{60} \mathrm{Co},{ }^{238} \mathrm{Pu},{ }^{241} \mathrm{Am}$, and ${ }^{90} \mathrm{Sr}$ from shallow-land burial grounds at Oak Ridge, Tennessee (Means et al. 1978; Means and Alexander 1981) and at Maxey Flats, Kentucky (Polzer et al. 1982; O'Donnell 1983; Dayal et al. 1986). Organic chelates, such as EDTA and picolinic acid, have also been shown to leach from solidified decontamination wastes from nuclear power stations (McIsaac and Mandler 1989). Thus, chelating agents present in decontamination wastes could enhance the migration of radionuclides away from sites where such wastes are disposed.

Because of the possibility of enhanced migration federal regulations (10 CFR Part 61 "Licensing Requirements for Land Disposal of Radioactive Wastes") within subpart D require waste generators and disposal site owners to take consideration and document handling and disposal details for waste that includes chelating agents. Within 10 CFR 61 two sections in particular explicitly give guidance, Section 61.2 defines what types of chemicals are considered to be "chelating agents" and Section 21.12 discusses the types of information that licensees must provide in requests to dispose of such wastes.

Chemical decontamination is an effective means of removing the build-up of activated metals and other radioactive components that can occur in the cooling systems of nuclear power plants. This build-up of radioactive elements is primarily associated with corrosion products, such as $\mathrm{Fe} / \mathrm{Ni}$ chromites, chromic oxides, $\mathrm{Ni}$ ferrites, and ferric oxides, which are deposited as films in the cooling systems. Removal of such oxide films can significantly reduce the occupational radiation exposure received by personnel while performing maintenance tasks and improve the thermal hydraulic performance of the cooling system.

Three principal chemical decontamination processes are currently used: the low-oxidation-state metal ions (LOMI) process (Shaw and Wood 1985; Swan et al. 1987; Smee et al. 1986), the CAN-DEREM process (Speranzini et al. 1990); and the CITROX process. Two other processes are less commonly used: the DOW NS-1 process (McIsaac and Mandler 1989) and the CAN-DECON process (Speranzini et al. 1990). Some decontamination processes are typically used in conjunction with pre-oxidation steps. These steps involve alternate applications of reducing/complexing agents to dissolve the Fe-oxide coatings and to complex the released radionuclides, and of strong oxidizing agents (such as alkaline permanganate) to oxidize $\mathrm{Cr}$ present in the $\mathrm{Fe} / \mathrm{Ni}$ chromites and to loosen or break up these deposits. The added reducing or complexing agents and oxidizing solutions are then removed by either cation- or anion-exchange resins. These resins constitute the principal waste from the decontamination process and were commonly mixed with cement for stabilization (in the 1980's) and then disposed. Current disposal practices emphasize placing the solidified wastes or dewatered resins directly in high-integrity containers prior to burial in licensed shallow land disposal facilities.

The principal organic chelating/complexing agents present in the decontamination solutions, listed with their associated process, are as follows: 1) citric acid-oxalic acid (CITROX), 2) formic acid-picolinic acid (LOMI), 3) citric acid-ethylenediaminetetraacetic acid (EDTA) (CAN-DEREM), and 4) citric and oxalic acids and diethylenetriaminepentaacetic acid (DTPA) and EDTA (DOW NS-1). This study is principally 
concerned with the radionuclides and chelating agents that can be leached from the disposed wastes and the potential for these chelates to enhance or retard migration of the leached radionuclides through surrounding soils and sediments.

The radionuclides and metal ions of primary concern include neutron activation products (isotopes of Co, $\mathrm{Cr}, \mathrm{Fe}, \mathrm{Mn}$, and $\mathrm{Ni}$ ), fission products ( $\mathrm{Cs}, \mathrm{Sb}$, and $\mathrm{Sr}$ ), actinide elements ( $\mathrm{U}, \mathrm{Am}, \mathrm{Cm}, \mathrm{Np}$, and $\mathrm{Pu}$ ), and major components of groundwaters and soils (e.g., $\mathrm{Al}, \mathrm{Ca}, \mathrm{Mg}$ ). The major cations present in the groundwaters are important because they can displace the hazardous radionuclides from the organic chelates.

To address the effects of the chelates on the leaching and migration of radionuclides from disposal facilities requires knowledge of 1 ) the quantities of chelates and metals that potentially could be leached; 2) the ability of the chelates to bind the released metals in aqueous solution; 3) the ability of surrounding soils or sediments to adsorb the chelates or radionuclide-chelate complexes; and 4) the identification of processes, such as biodegradation, that can break down or degrade the released chelates.

A previously published review was conducted to evaluate current state of knowledge of the effects of chelates on the leaching and migration of radionuclides from buried nuclear wastes (Serne et al. 1996). The review includes four sections: decontamination concerns and treatment and disposal of spent resins, aqueous complexation of radionuclides, adsorption of chelates and radionuclide-chelate complexes, and biodegradation of chelates and radionuclide chelate complexes. All of these factors are important in determining the potential for the chelating agents to affect the leaching of buried waste and the migration of radionuclides in soils and sediments. The section on the aqueous complexation of radionuclides includes a review of the data available for performing thermodynamic equilibrium calculations and a review of analytical methods for identifying radionuclide-organic complexation. In addition, two sections were included that discuss chemical models/codes that use the thermodynamic and adsorption data to predict radionuclide fate and review literature where organic chelating agents have been suspected of causing enhanced migration, respectively.

Following the cited review, speciation calculations were conducted to determine the potential significance of organic chelating/complexing agents in facilitating transport of radionuclides from the waste forms and through soil and aquifer materials. The results and discussion of the speciation calculations are included in this report (Section 4). The speciation calculations were performed using thermodynamic equilibrium calculations to determine the contribution of the organic chelating/complexing agents to the speciation scheme of the important radionuclides and stable metals in the leachates from cement solidified waste and dewatered spent ion exchange resins. Actual leachate data from tests conducted at the Idaho National Engineering and Environmental Laboratory (INEEL) were used to determine the concentrations used in the model calculations. Initially the leachate solutions from cementitious waste forms have a high $\mathrm{pH}$, which results from reactions with portland cement. The chemical evolution of these leachates can be expected to follow two pathways. If the leachates are contained within the waste site with an impermeable barrier, the high $\mathrm{pH}$ solutions could be neutralized by carbonic acid from the diffusion of $\mathrm{CO}_{2}$ from the atmosphere or soil gas. Impermeable barriers are prone to failure and as a result may eventually leak. If the leachates flow through the soil column, it is expected that the $\mathrm{pH}$ will decrease due to the natural buffering capacity of the soil. To simulate these $\mathrm{pH}$ neutralization processes, the speciation calculations were conducted as a function of $\mathrm{pH}$. Similar thermodynamic calculations for unsolidified dewatered resins were performed on the only data set available (CAN-DEREM spent resins leached in 
simulated groundwater). We make no claims that the results of these speciation calculations based on the few data sets available cover the whole range of possible leachate concentrations that might exist now or in the future at licensed shallow land burial facilities. However, the calculations are representative of the highest concentration of organic ligands found to date in laboratory leaching studies.

After the speciation calculations were completed, laboratory adsorption experiments were conducted. Both batch and column experiments were performed. The results and discussion of this work is presented in Section 5. Section 6 presents the conclusions of this project and recommendations and Section 7 lists the references cited. Two appendices are included, the first contains the thermodynamic data used to perform the speciation calculations discussed in Section 4 and the second contains the $\mathrm{K}_{d}$ values for the organic ligands and metals as a function of $\mathrm{pH}$ for the batch adsorption tests shown in Section 5 . 


\subsection{Background}

A variety of chemical decontamination processes are used to remove the build-up of radionuclides and corrosion products from the cooling systems of nuclear power plants. All of these decontamination processes use one or more chelating agents that can include; ethylenediaminetetraacetic acid (EDTA), picolinic acid, oxalic acid, citric acid, and less frequently, diethylenetriaminepentaacetic acid (DTPA), to complex the released radionuclides. The complexed radionuclides and any excess uncomplexed chelates are then removed onto cation-, anion-, and mixed bed ion exchange resins. The U.S. Nuclear Regulatory Commission (NRC), as defined in 10 CFR 61, is responsible for regulating the disposal of such wastes, including providing regulatory criteria for the co-disposal of organic chelating agents that have the potential to enhance the migration of radionuclides away from disposal sites.

One of the principal pathways for radionuclides migrating away from a disposal site is contact with infiltrating recharge water. The presence of chelating agents in the buried wastes could enhance the subsequent migration of radionuclides in groundwaters if 1) sufficient quantities of chelating agents can leach from the buried wastes, 2) the leached chelating agents form strong radionuclide-chelate complexes, 3 ) the chelating agents or the radionuclide-chelate complexes do not adsorb to soils or sediments, and 4) the leached chelating agents or radionuclide-chelate complexes do not undergo degradation processes, such as biodegradation, that destroy the chelating agents.

Earlier a literature review was published (Serne et al. 1996) that focused on the following areas: 1) the nature and composition of reactor decontamination solutions; 2) the leaching chemistry of solidified decontamination wastes; 3 ) the aqueous complexation of radionuclides, including the thermodynamic data available for calculating the stability of radionuclide-chelate complexes and analytical methods for identifying specific radionuclide-chelate complexes; 4) the adsorption of chelating agents and metalchelate complexes in soils or specific soil components (i.e., oxides and clay minerals); and 5) the biodegradation of the chelates and radionuclide-chelate complexes present in decontamination solutions. A summary of the major findings of this review is presented below.

From the review of the leaching and decontamination chemistry studies, it appears that the principal decontamination processes used in the mid-1990's were the following: 1) the low-oxidation-state metal ions (LOMI) process (used in about 65 percent of power plant decontaminations performed in the mid 1990 's), which uses picolinic and formic acid; 2) the CAN-DEREM process, which uses EDTA and citric acid; and 3) the CITROX process, which uses citric and oxalic acids. Based upon the few studies of decontamination wastes identified in the literature, it appears that organic chelating agents can leach moderately from solidified cements and can increase radionuclide and transition-metal leach rates by factors of 10 to 100 . The resulting leach rates still appear to be low, possibly because of the importance of $\mathrm{pH}$-dependent precipitation reactions. In addition, some of these waste forms appear to be physically unstable in low-ionic-strength solutions. Only one set of leach studies of unsolidified (dewatered) spent resins is available in work recently performed at INEEL on three spent resins obtained from a CANDEREM process used at Indian Point nuclear reactor. The three resins were leached using static experiments where simulated groundwater was mixed with dewatered spent ion exchange resins at a mass ratio of $\sim 10: 1$ groundwater to resin. The leachates were separated from the resin aliquots after $\sim 37$ and $\sim 90$ days of contact. Detailed radionuclide measurements were performed on all leachates and 
complete cation and anion measurements were performed on selected leachates. Organic ligand measurements in the leachate were performed using ion chromatography. EDTA was found in the leachate from only one resin type. The preliminary results for the chemical composition of the leachate from the one resin that contained EDTA were recently shared with us such that some speciation calculations could be performed to allow comparison with the cement solidified waste form leachates. The calculations are shown in Section 4. More details on the leach tests will be published by INEEL (Doug Akers, INEEL, personal communication Oct.-Nov. 2001).

The review of the thermodynamic data available for aqueous complexation reactions of chelates with metals and radionuclides focused on tabulating the data for metal-chelate complexes of EDTA, DTPA, picolinic acid, oxalic acid, and citric acid with selected radionuclides (i.e., neutron activation products, fission products, and actinides). A critical evaluation of these data was not performed because several such reviews have been published. Few data more recent than the latest critical review (i.e., Martell and Smith 1989) were found. Therefore, the majority of the data were compiled from the published critical reviews. As expected, this tabulation revealed that a large amount of data is available for transition-metal complexes with all of the ligands of interest in this study, although fewer data are available for DTPA and picolinic acid than for the other chelates. Unfortunately, far fewer data are available for the actinidechelate complexes that could be present in the decontamination wastes. Based upon these data, it appears that the most important (thermodynamically stable) complexes involve EDTA and picolinate. Oxalate and citrate do not appear to be present in sufficiently high concentrations or to be sufficiently strong chelating agents to form important metal-chelate complexes.

Successful detection of radionuclide-chelate complexes in leachate solutions is very challenging at the low concentrations of chelates and metals found in the reviewed studies. All the published studies only include data on cement solidified spent resins while current practice is to dispose of the spent resins directly in high integrity containers. It is not possible to predict from the published studies what the expected concentrations/radioactivity of the chelating agents, stable metals and radionuclides would be in leachates from the dewatered resins themselves. Although appropriate analytical procedures are still being developed, some promising techniques are becoming available such as liquid chromatography/mass spectrometry (LC/MS). Such direct analytical determinations, once passed the development stage, could complement the thermodynamic calculations in identifying the specific radionuclide-chelate complexes of concern. At the present time these sophisticated analytical procedures are neither routine or economical.

Available research on the adsorption of EDTA, oxalate and citrate and their metal complexes to soils and specific soil components, such as hydrous oxides were reviewed in the previous project (Serne et al. 1996) and more recently in Davis et al. (2000). The following summary was mainly extracted from Serne et al. (1996). Less work has been done on DTPA, and only a few studies have been conducted with picolinic acid see Serne et al. 1996). The adsorption of these chelates and their metal complexes, especially on oxides, can be highly $\mathrm{pH}$-dependent and all of the chelates can undergo what is termed "ligand-like" adsorption (i.e., adsorption of the chelates is strongest at low $\mathrm{pH}$, decreases rapidly in the neutral $\mathrm{pH}$ region, and can be negligible at high $\mathrm{pH}$ [>8]). In general, relatively high concentrations of oxalate and citrate are required to complex and mobilize metal ions in soils or soil components.

These adsorption/desorption reactions for oxalate and citrate complexes do not appear to have any significant kinetic hindrance, and there is little or no evidence for the adsorption of oxalate-metal or citrate-metal complexes. Owing to the stronger stability of EDTA-metal aqueous complexes at higher $\mathrm{pH}$ 
values, EDTA can reduce metal adsorption onto soils or soil components. However, there is very good evidence for the adsorption of EDTA-metal complexes, particularly on Fe and Al oxides. This metalchelate adsorption can retard, rather than enhance, the migration of radionuclides in soils and sediments. In addition, certain metal-EDTA complexes, most notably Co-EDTA, appear to be kinetically inert and do not react rapidly with other competing ions in solution. These factors make it especially difficult to predict quantitatively the effects of EDTA on radionuclide transport in soils or sediments. Similar effects appear to be possible for the adsorption of DTPA, or possibly DTPA-metal complexes, although the data are much more limited. In the case of picolinate, very few studies have been conducted, and it is difficult to reach general conclusions. However, based on the few studies that have been done, it appears that adsorption of picolinate-metal complexes does not occur because both the amine and carboxylate functional groups of the picolinate ion prefer to bond to the adsorbent surface leaving no binding site on the ligand to adsorb metals, and that the formation of kinetically inert picolinate-metal complexes is unlikely. That is, when adsorption does occur, the picolinate molecule uses both of its binding sites to bond with the solid surface in preference to remaining bonded to the metal in the aqueous complex. However, further research in this area is warranted.

A variety of factors can influence the biodegradation of chelating agents and metal (radionuclide)-chelate complexes: 1) the presence of microorganisms capable of degrading the chelates; 2) the adsorption of the chelates to soils or sediments; 3 ) the aqueous speciation or complexation of the chelates; and 4) specific groundwater conditions, such as the $\mathrm{pH}$ and the organic carbon content of the water. In general, it appears that because citrate and oxalate are naturally present in some environmental systems, microorganisms capable of degrading these acids should be generally present. Picolinate is not normally present in the environment, but natural structural pyridine analogs do exist, suggesting that picolinatedegradative pathways should also exist. There is no natural structural analog for EDTA in environmental systems, and this fact may account for EDTA's general recalcitrance to biodegradation in many environmental systems.

The need for an accurate and adequately complete water analysis as input data is one of the most important factors needed to obtain accurate thermodynamic modeling predictions. Inadequate solution characterization resulting from incomplete analysis of all significant constituents and a lack documentation of the sampling and analytical uncertainties are common problems. As with most computer modeling predictions, the common adage "garbage in equals garbage out," also applies to the application of chemical equilibrium models to aqueous speciation and mass transfer calculations. In the rare cases when the user has a complete and accurate water analysis other limitations include 1) an inadequate conceptual model that ignores the existence of certain aqueous species, sorbed species, and/or solids containing elements and/or ligands of interest (such as complexation of metals by dissolved natural organic compounds); 2) the lack of thermodynamic data for known aqueous species, sorbed species, and/or solids of interest; 3) the lack of internal consistency between parameters within a single thermodynamic database as well as between databases used by different models, and 4) inadequate theoretical understanding and formulation of certain processes, such as absence of models and/or data for sorption, kinetic rates, and solid solution; calculations in high-ionic strength solutions; and disequilibrium between redox couples.

Because thermodynamic databases are a critical component to model accurately aqueous speciation and solubility in soil/water systems, the more knowledgeable the user is with a model's database in terms of the completeness and accuracy of its data, the more likely the results will be correct. Unfortunately, most users cannot be experts with respect to the measurement and derivation of thermodynamic data nor can 
they afford to do a critical review of thermodynamic data for all aqueous species and solids containing elements of interest to their modeling applications. In these cases, the user should thoroughly document the database used when reporting results of aqueous speciation and solubility modeling calculations.

At present, the geochemical codes MINTEQ and HYDRAQL appear to have the most robust adsorption algorithms and most complete databases for organic ligand-radionuclide complexes. These codes were used in thermodynamic speciation modeling endeavors associated with this project.

Field data that show significant concentrations of radionuclides migrating with an apparent anomalously enhanced rate away from disposal units are scarce. No such studies are available for commercial lowlevel disposal facilities. At two defense waste facilities (Chalk River, Ontario and Oak Ridge, Tennessee) enhanced ${ }^{60} \mathrm{Co}$ migration has been observed beyond 50 meters from the burial trenches. In the former instance the cobalt appears to be associated with natural dissolved organics from neighboring swamps. In the latter case the cobalt appears to be bound to EDTA, likely present in the original waste stream.

The work presented in this document includes speciation calculations of radionuclide chelate interactions as a function of $\mathrm{pH}$ and laboratory adsorption results conducted using batch and column techniques. 


\subsection{Methods and Materials}

\subsection{Speciation Calculation Methods and Assumptions}

Speciation calculations were conducted to determine the potential significance of organic chelating/ complexing agents in facilitating transport of radionuclides leached from cement solidified decontamination waste and through soil and aquifer materials. One set of calculations were also performed for leachate contacting a spent resin from the CAN-DEREM process with simulated groundwater based on the chemical composition recently obtained under contract with INEEL.

Potential impacts for organic complexes were assessed using thermodynamic equilibrium calculations to determine the contribution of the organic chelating/complexing agents to the speciation scheme of the important radionuclides and stable metals in the leachates. Initially the leachate solutions from cementitious waste forms have a high $\mathrm{pH}$, which results from reactions with portland cement. The chemical evolution of these leachates can be expected to follow two pathways. If the leachates, are contained within the waste site with a water impermeable barrier, the high $\mathrm{pH}$ solutions could be neutralized by carbonic acid from the diffusion of $\mathrm{CO}_{2}$ from the atmosphere or soil gas. After the barriers degrade, waste leachates percolate into the soil column. For this scenario, the $\mathrm{pH}$ will decrease due to the natural buffering capacity of the soil. To simulate these processes, speciation calculations were conducted as a function of $\mathrm{pH}$. In these calculations it was assumed that the three principal soil components affecting $\mathrm{pH}$ and the subsequent speciation of important radionuclides and chelating agents are calcite, amorphous ferric hydroxide and gibbsite. That is, the soil system was simplified to consist of these three solids. The soil gas was maintained as a closed system; that is the partial pressure of carbon dioxide was allowed to vary with $\mathrm{pH}$ while maintaining equilibrium with calcite. It is well known that cement environments are not in equilibrium with air (Criscenti et al. 1996). In the calculations dissolution/precipitation of these three solids was included; however, adsorption reaction to these three solids was not included.

The chemical equilibrium code HYDRAQL (Papelis et al. 1988) was used to perform the speciation calculations for the cement leachates and MIMEQL+ (Schecher and McAvoy 1998) was used to perform the calculations on the leachate from the dewatered CAN-DEREM resin. Most of the stability constants for the organic chelating/complexing agents used as decontaminating agents were not included in either codes database. Therefore, the thermodynamic database file for each code was modified to include the organically chelated/complexed species needed to perform the calculations. Most organic-radionuclide/ metal stability constant values incorporated into the database were estimated from the compilation listed in Appendix A (Serne et al. 1996). Krupka and Serne (1998) was used as the source of Pu(IV) stability constants for inorganic complexes. Unfortunately, no stability constants for key organic ligands and the more oxidized forms of $\mathrm{Pu}[\mathrm{Pu}(\mathrm{V})$ and $\mathrm{Pu}(\mathrm{VI})]$ are available. Thermodynamic data added to the two codes databases were adjusted to zero ionic strength using the Davies equation. The thermodynamic database used in the calculations from both codes and reported in this document is attached as Appendix A, for completeness.

The chelate, radionuclide, corrosion product and common groundwater ion concentrations selected for the speciation modeling calculations were based on a review of decontamination waste form leachate data (Serne et al. 1996). Most of this data was produced by researchers at the Idaho National Engineering 
and Environmental Laboratory (INEEL). Laboratory work was conducted with several decontamination waste streams and cementitious, solidified decontamination waste forms from commercial reactors. Leach experiments and physical stability tests were conducted. Details of this work can be found in McIsaac and Akers (1991), Morcos et al. (1992), Akers et al. (1993a,b; 1994a,b), McIsaac and Mandler (1989), McIsaac et al. (1991,1992) and McIsaac (1993). The most important decontamination processes from a waste disposal perspective are LOMI, CAN-DEREM and CITROX. A total of six cementitious leachates were selected for the modeling analysis which were expected to be representative of any leachates derived from the LOMI, CAN-DEREM and CITROX processes. In general, the concentrations of the chelating agents and metals used in the speciation calculations were selected to be the highest values measured in any of the INEEL leachates for a given waste form. INEEL used the ANSU/ANS 16.1 leach protocol (ANS 1986) for the leach tests on cement solidified resins. ANSI/ANS 16.1 calls for frequent exchanges of the leachate such that equilibrium concentrations are not guaranteed. Thus one leach test of a given specimen typically produced 7 to 10 or more leachate solutions. We attempted to use the highest concentrations observed in the leach tests.

For the one set of leach tests conducted on dewatered spent resins from the CAN-DEREM process static leach tests were performed. Two contact times were chosen $\sim 27$ and $\sim 93$ days. The test results for the longer time period were used to choose the leachate composition that was speciated versus $\mathrm{pH}$.

Two LOMI leachates from solidified cement wastes were modeled. These are referred to as the James A. FitzPatrick and Peach Bottom waste-form leachates. Leachate data for cement solidified CANDEREM process resins are not currently available, however, leachates from two other processes were selected as alternates. The first leachate was derived from the CAN-DECON process which is a precursor of the CAN-DEREM process and is very similar with the exception that it contains oxalic acid. The CAN-DECON leachate is referred to as Millstone. The second leachate was derived from the NS-1 process (which is no longer used). Waste ion-exchange resin derived from the NS-1 process contained similar concentrations of EDTA and citric acid as the CAN-DECON process but also contains DTPA (Table 12, Akers et al. 1994b). This leachate is referred to as the Pilgrim leachate. The two CITROX leachates modeled are Brunswick and Cooper. Total solution concentrations of the chelating agents and metals used to conduct the speciation calculations for the leachates from the cement solidified wastes are listed in Table 3.1.

Table 3.2 lists the chemical composition of Hanford groundwater before and after equilibration with cement. The composition of the simulated Hanford groundwater in Table 3.2 was combined with the products in Table 3.1 to perform the speciation calculations. The comparable leachate composition, including the major common cations and anions from the groundwater for the one data set for dewatered spent resins leached in simulated groundwater are shown in Table 3.3. Dewatered resins are generally disposed in high integrity containers (either high density polyethylene or plastic lined steel containers). 
Table 3.1. Starting Concentrations of Chelating Agents and Metals Used in Equilibrium Modeling of Cementitious Waste Form Leachates (moles/liter)

\begin{tabular}{|l|l|l|l|l|l|l|}
\hline \multicolumn{1}{|c|}{ Facility } & FitzPatrick & $\begin{array}{c}\text { Peach } \\
\text { Bottom }\end{array}$ & \multicolumn{1}{|c|}{ Pilgrim } & Millstone & Brunswick & \multicolumn{1}{c|}{ Copper } \\
\hline $\begin{array}{c}\text { Decon } \\
\text { Process }\end{array}$ & \multicolumn{1}{|c|}{ LOMI } & \multicolumn{1}{c|}{ LOMI } & \multicolumn{1}{c|}{ NS-1 } & $\begin{array}{c}\text { CAN- } \\
\text { DECON }\end{array}$ & \multicolumn{1}{c|}{ CITROX } & CITROX \\
\hline Picolinate & $1.6 \times 10^{-3}$ & $2.9 \times 10^{-4}$ & 0.0 & 0.0 & 0.0 & 0.0 \\
\hline Citrate & 0.0 & 0.0 & $1.1 \times 10^{-5}$ & $2.6 \times 10^{-5}$ & $2.8 \times 10^{-5}$ & $2.7 \times 10^{-7}$ \\
\hline EDTA & 0.0 & 0.0 & $2.6 \times 10^{-5}$ & $2.7 \times 10^{-4}$ & 0.0 & 0.0 \\
\hline Oxalate & 0.0 & 0.0 & $1.7 \times 10^{-4}$ & $1.1 \times 10^{-4}$ & $3.9 \times 10^{-6}$ & $1.2 \times 10^{-4}$ \\
\hline DTPA & 0.0 & 0.0 & $2.5 \times 10^{-6}$ & 0.0 & 0.0 & 0.0 \\
\hline Co & $1.0 \times 10^{-10}$ & $3.1 \times 10^{-7}$ & $1.0 \times 10^{-10}$ & $7.3 \times 10^{-7}$ & $7.3 \times 10^{-6}$ & $4.8 \times 10^{-6}$ \\
\hline $\mathrm{Ni}$ & $1.6 \times 10^{-6}$ & $9.2 \times 10^{-7}$ & $2.9 \times 10^{-5}$ & $1.1 \times 10^{-6}$ & $5.3 \times 10^{-6}$ & $1.0 \times 10^{-4}$ \\
\hline $\mathrm{Zn}$ & $1.0 \times 10^{-10}$ & $7.6 \times 10^{-7}$ & $1.0 \times 10^{-10}$ & $1.0 \times 10^{-10}$ & $1.0 \times 10^{-10}$ & $1.0 \times 10^{-10}$ \\
\hline
\end{tabular}

Table 3.2. Major Ion Concentrations (total) in Synthetic Hanford Groundwater, Before, and After Equilibration with Portlandite

\begin{tabular}{|l|c|c|}
\hline \multicolumn{1}{|c|}{ Constituent } & Before & After \\
\hline $\mathrm{Ca}$ & $2.63 \times 10^{-2}$ & $2.63 \times 10^{-2}$ \\
\hline $\mathrm{K}$ & $3.76 \times 10^{-3}$ & $3.76 \times 10^{-3}$ \\
\hline $\mathrm{Mg}$ & $8.20 \times 10^{-3}$ & $1.30 \times 10^{-7}$ \\
\hline $\mathrm{Na}$ & $2.04 \times 10^{-2}$ & $2.04 \times 10^{-2}$ \\
\hline $\mathrm{CO}_{3}$ & $2.72 \times 10^{-2}$ & $7.00 \times 10^{-6}$ \\
\hline $\mathrm{Cl}$ & $1.81 \times 10^{-2}$ & $1.81 \times 10^{-2}$ \\
\hline $\mathrm{NO}_{3}$ & $3.20 \times 10^{-5}$ & $3.20 \times 10^{-5}$ \\
\hline $\mathrm{SO}_{4}$ & $1.68 \times 10^{-2}$ & $1.68 \times 10^{-2}$ \\
\hline $\mathrm{pH}$ & 8.9 & 12.3 \\
\hline
\end{tabular}


Various solutions were used in experiments at INEEL to determine the leachability of the FitzPatrick and Brunswick waste forms including synthetic Hanford and Barnwell groundwaters, seawater and deionized water. The speciation calculations for these two wastes were performed only for leachates which used Hanford groundwater. The other waste forms (Peach Bottom, Millstone, Pilgrim and Cooper) were leached only in deionized water. Because the cement dominates the leachate composition there is little difference in the leachate composition from the deionized water, Hanford, or Barnwell groundwaters. Thus we believe the speciation calculations of the INEEL leachates from cement solidified wastes would apply for any typical groundwater contacting solidified cementitious spent decontamination resins. Seawater was not considered further because disposal sites planned in the United States will not be influenced by seawater. In general a conservative approach was taken (calculations were conducted to determine the highest possible impact of the chelating agents for each leachate solution). This was accomplished by conducting the speciation calculations using concentrations of stable metals and chelating/complexing agents which approximated the highest values measured in leachates from each waste form. The radionuclide concentrations measured in the leachates are at trace concentrations (a concentration of $1 \times 10^{-10} \mathrm{M}$ was assumed for modeling purposes). Because the major ion concentrations of the cement solidified waste form leachates were not measured in the INEEL work, they were assumed to be that of synthetic Hanford groundwater (Table 5, McIsaac et al. 1991) in equilibrium with portlandite. Major ion concentrations (total) in Hanford groundwater and synthetic Hanford groundwater in equilibrium with portlandite (calculated with HYRDAQL) are shown in Table 3.2. Equilibration of Hanford groundwater with portlandite results in the removal of nearly all the carbonate and most of the magnesium. This is due to precipitation of calcite and brucite, respectively. The calcium lost from precipitation of calcite is replaced by dissolution of portlandite.

Subsequent speciation calculations for the cement solidified waste leachates were conducted as a function of $\mathrm{pH}$ from 4 to 12 in increments of $0.4 \mathrm{pH}$ units. In each of these calculations the solution was assumed to be in contact with $0.01 \mathrm{~mole} / \mathrm{L}$ each of calcite $\left(\mathrm{CaCO}_{3}[\mathrm{~s}]\right)$, amorphous iron hydroxide $\left(\mathrm{Fe}[\mathrm{OH}]_{3}[\mathrm{am}]\right)$, and gibbsite $\left(\mathrm{Al}[\mathrm{OH}]_{3}[\mathrm{~s}]\right)$. These solids were allowed to dissolve or precipitate as necessary to maintain equilibrium. They represent major constituents in most sediments that rapidly react with solutions that percolate through sediments. Adsorption was not included in the calculations.

Recently a leaching experiment on non-solidified decontamination waste material (spent ion-exchange resin) from the CAN-DEREM process was conducted at INEEL. The measured composition of one of these leachate solution is shown in Table 3.3. Measurements include $\mathrm{pH}$, major cations and anions and chelating agents. For the leachate from the dewatered CAN-DEREM process resin the measured $\mathrm{pH}$ was 7.49 but for completeness we varied the $\mathrm{pH}$ from 6 to 10 for comparison purposes. We again kept the leachate in contact with the same finite masses of calcite, amorphous iron oxide and gibbsite to represent the reactions with soil. Once again adsorption was not included in the calculations. 


\begin{tabular}{|l|c|c|c|}
\hline \multicolumn{5}{|c|}{ Table 3.3. Major Ion Concentrations in Non-Solidified Decontamination } \\
Waste Leachates
\end{tabular}

Significant differences are apparent between these results and those of the cement solidified wastes (Table 3.1). The major differences occur in the concentrations of transition metals leached from the non-solidifed waste. High concentrations of $\mathrm{Ni}^{2+}, \mathrm{Cr}^{3+}$, and $\mathrm{Mn}^{2+}$ were measured in the non-solidified waste leachate. For the cement solidified waste leachates, $\mathrm{Ni}^{2+}$ concentrations were generally low and $\mathrm{Cr}^{3+}$, and $\mathrm{Mn}^{2+}$ were below the detection limit likely because of precipitation reactions at the high $\mathrm{pH}$ in cement leachates. In the non-solidified waste leachates EDTA was the only chelating agent detected in this leachate solution. The measured concentration was similar to that of the cement solidified CANDECON waste leachate.

To estimate the effect of changes in $\mathrm{pH}$ and contact with natural soil components on the speciation of the metals and radionuclides in the waste leachate, additional speciation calculations were conducted on the leachate from the dewatered spent resin waste. These calculations were conducted by maintaining equilibrium with $0.01 \mathrm{~mole} / \mathrm{L}$ each of calcite, amorphous iron hydroxide, and gibbsite. The $\mathrm{pH}$ was adjusted between 6 and 10. The solubility of $\mathrm{Cr}^{3+}$ was assumed to be controlled by $\mathrm{Cr}(\mathrm{OH})_{3}(\mathrm{am})$. 


\subsection{Experimental Methods for Batch Adsorption}

A series of batch adsorption experiments were conducted with $\mathrm{Ni}^{2+}, \mathrm{Sm}^{3+}, \mathrm{Th}^{4+}, \mathrm{NpO}_{2}{ }^{+}, \mathrm{UO}_{2}{ }^{2+}$, and $\mathrm{PuO}_{2}{ }^{2+}$. These metals and radionuclides were selected to be representative of metals and radionuclides in leachates with oxidation states that ranged from +2 to +6 . This range in oxidation states covers the total range of possibilities for metals that form moderate to strong complexes with organic ligands. Two chelating agents were included in the study; picolinate and EDTA. The speciation calculations shown in Section 4 indicated that these were the two most important chelating agents. Three well-characterized natural soils and a Fe-coated sand were available from another project so to maximize the amount of adsorption testing that could be done for the available budget they were used as representative adsorbents. Several of the chosen adsorbents are also similar to soils at existing or currently inactive commercial low-level waste disposal sites. Characterization data from the other project for these soils are reported in Table 3.4. The $<2 \mathrm{~mm}$ size fraction from each of the soils was used in all experiments. The first soil (identified as MNC-70) is classified as clayey, kaolinitic, thermic Typic Hapludult. The MNC-70 soil has a slightly acidic $\mathrm{pH}$, low organic carbon, no carbonate, a moderately low cation exchange capacity and moderately high iron (ferric) content. This soil is representative of well-weathered soils from the humid Southeastern United States. The second soil (identified as LK-1) is classified as a fine, montmorillonitic, thermic, Vertic Argiudoll. The LK-1 soil has a near neutral $\mathrm{pH}$, moderate organic carbon, slight trace of carbonate and a relatively high cation exchange capacity consisting of mostly alkaline-earth cations and a moderate iron oxide content. This soil is representative of soils from a temperate climate such as the Midwestern United States. The third soil (identified as Milford-1) is from the Ultisol order collected at a depth of 2 meters from a glacio-fluvial gravel sediment pit exposing the lower Columbia formation located in Delaware.

The Fe-coated sand is a synthetic soil created by using a natural quartz sand which was acid washed to remove metals and then coating the sand with ferric oxyhydroxide. The iron oxyhydroxide gel was first synthesized by hydrolysis of a $0.24 \mathrm{~mol} / \mathrm{L}$ solution of ferric chloride solution (Zachara et al. 1987). This was accomplished by adjusting the solution $\mathrm{pH}$ to approximately 7.5 with $\mathrm{CO}_{2}$-free sodium hydroxide. The gel was equilibrated approximately 24 hours. After this the gel was mixed with the sand and allowed to age for approximately 4 days. The $\mathrm{pH}$ of the solution was maintained at 6.5 to 7.0 , and washed daily with $0.1 \mathrm{mmol} / \mathrm{L} \mathrm{NaCl}$ solution. The coated material was then filtered in a large Buchner funnel and dried in a forced air oven at $35 \circ \mathrm{C}$. This synthetic soil is similar to the sand, with enriched hydrous oxides contents, near the commercial burial ground at the Hanford reservation.

Prior to performing each adsorption experiment, the soils were pre-equilibrated in a 0.003 Molar $\mathrm{Ca}\left(\mathrm{ClO}_{4}\right)_{2}$ solution at $\mathrm{pH}$ values between 4 and 9 at $\mathrm{pH}$ intervals of approximately $0.5 \mathrm{pH}$ units. The calcium perchlorate is a simple non-interacting electrolyte used to simulate a simple groundwater that will not add complications to the study of organic-radionuclide complex interactions with representative soils. In most experiments, approximately $0.5 \mathrm{gm}$ of soil was added to $30 \mathrm{ml}$ of solution; however, for the nickel adsorption experiments using the LK-1 soil, a ratio of approximately $2 \mathrm{gm}$ of soil was added to $30 \mathrm{ml}$ of 


\begin{tabular}{|c|c|c|c|c|c|c|c|}
\hline \multirow[b]{2}{*}{ Soil Type } & \multirow[b]{2}{*}{ pH in $\mathrm{H}_{2} \mathrm{O}$} & \multicolumn{3}{|c|}{ Carbon (\%) } & \multicolumn{3}{|c|}{ Particle Distribution (\%) } \\
\hline & & Total C & Organic C & Inorg. C & Clay & Silt & Sand \\
\hline $\mathrm{MNC}-70$ & 5.33 & 0.07 & 0.07 & 0.00 & 28 & 48 & 24 \\
\hline LK-1 & 6.94 & 0.39 & 0.28 & 0.11 & 46 & 44 & 10 \\
\hline Milford-1 & 4.91 & 0.035 & 0.035 & 0.00 & $<1$ & $<1$ & 100 \\
\hline Fe-Coated & N/A & 0.00 & 0.00 & 0.00 & $<1$ & $<1$ & 100 \\
\hline \multicolumn{8}{|c|}{ Exchangeable Cations (meq/100 g) } \\
\hline & Al & $\mathbf{B a}$ & $\mathbf{C a}$ & $\mathbf{M g}$ & $\mathbf{K}$ & $\mathbf{N a}$ & $\mathbf{L a}$ \\
\hline MNC-70 & 0.27 & 0.07 & 0.17 & 0.94 & 0.12 & 0.2 & 0.54 \\
\hline LK-1 & 0.00 & 0.05 & 16 & 7.17 & 0.28 & 1.68 & $<0.05$ \\
\hline Milliford-1 & Total 4.91 & & & & & & \\
\hline Fe-Coated & N/A & & & & & & \\
\hline \multicolumn{8}{|c|}{ Fe Content (wt. \%) } \\
\hline & \multicolumn{3}{|c|}{$\mathrm{Fe}(\mathrm{II})$} & \multicolumn{2}{|c|}{$\mathrm{Fe}(\mathrm{III})$} & \multicolumn{2}{|c|}{ Fe (total) } \\
\hline $\mathrm{MNC}-70$ & \multicolumn{3}{|c|}{0.31} & \multicolumn{2}{|c|}{4.77} & \multicolumn{2}{|c|}{5.08} \\
\hline LK-1 & \multicolumn{3}{|c|}{0.2} & \multicolumn{2}{|c|}{3.38} & \multicolumn{2}{|c|}{3.58} \\
\hline Milford-1 & \multicolumn{3}{|c|}{--} & \multicolumn{2}{|l|}{--} & \multicolumn{2}{|c|}{0.30} \\
\hline Fe-Coated & \multicolumn{3}{|c|}{-} & \multicolumn{2}{|l|}{-} & \multicolumn{2}{|c|}{1.23} \\
\hline
\end{tabular}

solution to obtain a better measure of adsorption from the change in concentrations between the influent and effluent solutions. For tests where there is low adsorption it is difficult to get good data if there is not measurable removal of the adsorbate after contact with the soil. One obvious positive step is to add more soil until the difference in the concentrations of the adsorbate between the beginning and end of the test is readily measurable. The $\mathrm{pH}$ was adjusted over a period of several days to a few weeks by addition of acid $\left(\mathrm{HClO}_{4}\right)$ or base $\left(\mathrm{CO}_{2}\right.$ free $\left.\mathrm{NaOH}\right)$ until the $\mathrm{pH}$ drift was less than $0.5 \mathrm{pH}$ units over a 24 hour period. The $\mathrm{pH}$ adjustments and equilibrations were conducted in an inert atmosphere chamber $\left(\mathrm{N}_{2}\right.$ glovebox) to maintain $\mathrm{CO}_{2}$-free conditions. Once the slurry $\mathrm{pH}$ had stabilized, the solution was removed and fresh $0.003 \mathrm{M}$ calcium perchlorate solution at the desired $\mathrm{pH}$ was added to the tubes while still in the chamber. A small aliquot of concentrated radiolabeled stock solution was then added to the tubes.

For EDTA-metal complex adsorption experiments, stock solutions containing the equal molar concentration $\left(1.5 \times 10^{-3} \mathrm{M}\right)$ of EDTA and metal $\left(\mathrm{UO}_{2}{ }^{2+}\right.$ or $\left.\mathrm{Ni}^{2+}\right)$ were added together. EDTA in these stock 
solutions was spiked with ${ }^{14} \mathrm{C}$-labeled EDTA. The stock solutions containing nickel were spiked with ${ }^{63} \mathrm{Ni}$. After all reagents and tracers were added to the stock solutions, they were adjusted to a pH of 7.0. The final concentration of both EDTA and metal in the experiments (slurries of soil and simplified groundwater, $\mathrm{Ca}\left[\mathrm{ClO}_{4}\right]_{2}$ ) was $10^{-5} \mathrm{M}$. Following the addition of the EDTA-metal complex solutions, the vials were gently agitated for $16 \mathrm{hr}$ at which time the tests were stopped. Each vial was then centrifuged at $2,500 \mathrm{rpm}$ for 20 minutes, the $\mathrm{pH}$ measured, and an aliquot of the supernate removed and filtered with a $0.2 \mu \mathrm{m}$ syringe filter. The filtered supernate was used for liquid scintillation counting and/or uranium analysis. The adsorption experiments were run in duplicate and blanks (solution only) were run for each pH. Liquid scintillation counting was conducted with a Wallac OY Inc. model 1415 liquid scintillation counter (Turku, Finland). Uranium was determined by laser-phosphorimetry (Chemchek Instruments Inc., Richland, Washington).

In addition to the EDTA-metal adsorption experiments, adsorption experiments were also conducted with picolinate-metal complexes. For these experiments, the following metals were used: $\mathrm{Ni}^{2+}, \mathrm{Sm}^{3+}$ [analog for trivalent actinides], $\mathrm{Th}^{4+}$ [analog for quadrivalent actinides], $\mathrm{NpO}_{2}{ }^{+}, \mathrm{UO}_{2}{ }^{2+}$, and $\mathrm{PuO}_{2}{ }^{2+}$. These experiments were generally conducted in the same manner as the previous experiments with $\mathrm{UO}_{2}{ }^{2+}$ and $\mathrm{Ni}^{2+}$ and EDTA. In some cases, different chelate to metal ratios were used. Only iron oxide coated sand and Milford soil were used as adsorbents in the picolinate-metal adsorption experiments. ${ }^{14} \mathrm{C}$-labeled picolinate was added as a tracer to determine picolinate adsorption. For the picolinate- $\mathrm{Sm}^{3+}$ adsorption experiments, a beta emitting tracer was used $\left({ }^{151} \mathrm{Sm}^{3+}\right)$ to determine $\mathrm{Sm}^{3+}$ adsorption. For $\mathrm{PuO}_{2}{ }^{2+}$ an alpha emitting tracer was used $\left({ }^{239} \mathrm{PuO}_{2}{ }^{2+}\right)$. ${ }^{239} \mathrm{Pu}$ was measured using liquid scintillation counting. For the $\mathrm{NpO}_{2}{ }^{+}$and $\mathrm{Th}^{4+}$ experiments gamma emitting tracers were used $\left({ }^{237} \mathrm{NpO}_{2}{ }^{+}\right.$and $\left.{ }^{228} \mathrm{Th}^{4+}\right)$. In the $\mathrm{Th}^{4+}$ experiments, ${ }^{232} \mathrm{Th}^{4+}$ was added to maintain the required mass concentration. Gamma spectroscopy was conducted with a high performance (60\% efficient) germanium detector (Oxford, Inc.).

In one of the nickel-picolinate adsorption experiments, nickel was measured independently with Inductively Coupled Plasma - Optical Emission Spectrometer (ICP-OES) (Perkin Elmer 3300 Dual View). This was done to compare the results with the tracer techniques and verify their accuracy.

For the Pu experiments, the source of the $\mathrm{Pu}$ spiking solution was ${ }^{239} \mathrm{Pu}$ in $\mathrm{HNO}_{3}$ with an indeterminate oxidation state (an unknown mixture of $+3,+4,+5,+6$ ). We transformed this mixed spike into the most oxidized state ( +6 oxidation state) because the most common disposal environments are oxidizing and $\mathrm{Pu}$ in its higher oxidation states is expected to be more mobile. We transformed the mixed $\mathrm{Pu}$ spike to the +6 state by taking an aliquot of our standard solution and heating it to dryness. The ${ }^{239} \mathrm{Pu}$ was redissolved in $8 \mathrm{M} \mathrm{HNO}_{3}$ and reduced to $\mathrm{a}+4$ state using $\mathrm{H}_{2} \mathrm{O}_{2}$. This solution again was heated to dryness and redissolved in $8 \mathrm{M} \mathrm{HNO}_{3} . \mathrm{NaBiO}_{3}$ was then added and the solution vial was sealed and heated. The solution was periodically checked by UV-vis spectrometry until the oxidation reaction was complete. Again the solution was heated to dryness and brought back up in $0.1 \mathrm{M} \mathrm{HClO}_{4}$. This step was repeated twice to ensure complete removal of excess $\mathrm{HNO}_{3}$. The +6 oxidation state was verified by UV-vis spectrometry. The oxidation state of the standard was checked periodically. 
For the picolinate ${ }^{239} \mathrm{Pu}$ adsorption experiments, an aliquot of the +6 oxidation state ${ }^{239} \mathrm{Pu}$ standard was then combined with a ${ }^{14} \mathrm{C}$ labeled picolinate spiking solution to achieve an equal molar concentration of 1.0 $\times 10^{-4} \mathrm{M}$. The $\mathrm{pH}$ of the spiking solution was then adjusted to 7.0 and allowed to equilibrate for 24 hours. Prior to addition of the spike to the adsorption vials, the Pu oxidation state was verified as being +6 .

Because of the high activity of the ${ }^{239} \mathrm{Pu}$, a decision was made to run the adsorption tests with a final equal molar ${ }^{239} \mathrm{Pu} /$ picolinate concentration of $1.0 \times 10^{-6} \mathrm{M}$. These same concentrations of chelate and radionuclide were also used in the ${ }^{237} \mathrm{~Np}$ experiments (all other previous tests were run at an equal molar concentration of $1.0 \times 10^{-5} \mathrm{M}$ ). In these experiments, the beta spectra for the ${ }^{14} \mathrm{C}$ was swamped out by

${ }^{241} \mathrm{Pu}$ impurity in our stock ${ }^{239} \mathrm{Pu}$ solution; resulting in poor data quality for the picolinate concentrations. An additional adsorption experiment was conducted at a molar ratio of 1000:1 picolinate to $\mathrm{Pu}$ to allow for better resolution of the ${ }^{14} \mathrm{C}$ labeled picolinate concentrations and to determine the effects of a large excess of picolinate on adsorption. The $1000: 1$ series has $10^{-5} \mathrm{M}$ picolinate and $10^{-8} \mathrm{M}^{239} \mathrm{Pu}$ concentrations.

\subsection{Experimental Methods for Column Adsorption}

Following the batch adsorption experiments, six column adsorption experiments were conducted to establish whether changing the soil to solution ratio dramatically and introducing hydrologic transport would affect the adsorption properties of the organic-nuclide complexes. In the disposal environment the soil to leachate ratio will be much greater than in the batch tests and flow will occur that can change the fluid composition from that observed in the batch tests where reaction products can not be transported away.

The six columns with dimensions of approximately $2.6 \mathrm{~cm}$ diameter by $18.4 \mathrm{~cm}$ length (see Table 3.5 ) were packed with air-dry sediments using a vibrating wand to homogeneously shake sediment as it was poured slowly into the column in a continuous fashion. Known sediment weights were used to attain a desired bulk density [1.5 to $\left.1.7 \mathrm{~g} / \mathrm{cm}^{3}\right]$ on final packing. The packing was visually inspected to verify that a relatively homogeneous bedding structure was obtained. From the known column dimensions (column volume), weight of sediment, and measured particle density for each sediment, the porosity of each column could be calculated. The values are shown in Table 3.5. As a check on the porosity, the columns were reweighed after they were filled with the background electrolyte. Assuming the density of the dilute background electrolyte is $1.00 \mathrm{~g} / \mathrm{cm}^{3}$, the volume of water added is a measure of the porosity. As shown in Table 3.5 [table columns 7 and 11], the measured and calculated porosity are the same for each packed column, essentially corroborating all the measurements/calculations. Flow was established in an up flow direction in each column to attempt to maintain saturated conditions. Prior to the start of each adsorptiondesorption experiment, the columns were equilibrated with the background electrolyte [0.003 Molar 


\begin{tabular}{|c|c|c|c|c|c|c|c|c|c|c|c|}
\hline $\begin{array}{c}\text { Column } \\
\#\end{array}$ & Soil & $\begin{array}{c}\text { Wt. of } \\
\text { Empty } \\
\text { Column, } \\
\mathrm{g}\end{array}$ & $\begin{array}{c}\text { Wt. of } \\
\text { Column } \\
\text { and Soil, g }\end{array}$ & $\begin{array}{l}\text { Wt. of } \\
\text { Soil, g }\end{array}$ & $\begin{array}{c}\text { Wt. of } \\
\text { Column, } \\
\text { Soil and } \\
\mathrm{H}_{2} \mathrm{O}, \mathbf{g}\end{array}$ & $\begin{array}{c}\text { Volume } \\
\text { of } \\
\text { Pores, g }\end{array}$ & \begin{tabular}{|} 
Length of \\
Soil \\
Column, \\
cm
\end{tabular} & $\begin{array}{l}\text { Volume } \\
\text { of Soil } \\
\text { Column } \\
\mathrm{cm}^{3}, \mathrm{ml}\end{array}$ & $\begin{array}{c}\text { Bulk } \\
\text { Density, } \\
\text { g/cm }\end{array}$ & Porosity & $\begin{array}{c}\text { Particle } \\
\text { Density, } \\
\text { g/cm }^{3}\end{array}$ \\
\hline 1 & Milliford & 136.99 & 302.37 & 165.38 & 328.80 & 26.43 & 18.40 & 98.67 & 1.68 & 0.27 & 2.29 \\
\hline 2 & Milliford & 138.13 & 302.96 & 164.83 & 329.50 & 26.54 & 18.35 & 98.40 & 1.68 & 0.27 & 2.29 \\
\hline 3 & Milliford & 136.48 & 302.89 & 166.41 & 330.28 & 27.39 & 18.40 & 98.67 & 1.69 & 0.28 & 2.33 \\
\hline 4 & Milliford & 137.34 & 302.98 & 165.64 & 330.14 & 27.16 & 18.40 & 98.67 & 1.68 & 0.28 & 2.32 \\
\hline 5 & $\mathrm{Fe}$ coated & 136.83 & 282.58 & 145.75 & 318.50 & 35.92 & 18.40 & 98.67 & 1.48 & 0.36 & 2.32 \\
\hline 6 & Fe coated & 136.83 & 283.39 & 146.56 & 320.40 & 37.01 & 18.50 & 99.20 & 1.48 & 0.37 & 2.36 \\
\hline
\end{tabular}

$\left.\mathrm{Ca}\left(\mathrm{ClO}_{4}\right)_{2} ; \mathrm{pH} \sim 7\right]$ for $\sim 8-16 \mathrm{hrs}$ ( 1 to 2 pore volumes) to "pre-equilibrate" the sediment with the solution. In the Milford soil tests for columns 3 and 4, the sediment was first equilibrated with dilute $\mathrm{NaOH}$ to simulate cement leachate interactions.

The flow rate in each column was controlled by a constant flow rate hospital grade peristalic pump to be approximately $3.4 \mathrm{~mL} / \mathrm{min}$ for the Milford soil columns and $4.5 \mathrm{~mL} / \mathrm{min}$ for the iron coated sand columns. These volumetric flow rates equate to 3 pore volumes per day (or 8 hour residence time). A pore volume is the volume of fluid needed to fill the void space (porosity) in the column. After this "pre-conditioning," the same simple background electrolyte solution containing known concentrations of the metal/ radionuclide and organic ligand spiked with appropriate metal and ${ }^{14} \mathrm{C}$ tracers were injected into the columns for up to 10-15 days at the same flow rate. The $\mathrm{pH}$ of the influent solution was adjusted to $\mathrm{pH}$ $7.5 \pm 0.5$ before contacting the sediments. Breakthrough curves for the tracers were generated from measurements of aliquots of effluent taken every few hours during the injection period. In some cases, injection of the metal/radionuclide and tracers laden simple electrolyte was discontinued and further flushing was continued with the background electrolyte to study the desorption of the tracers. It was discovered after the first few column tests with the Milford soil that Milford soil has a net weak acidic nature (porewater $\mathrm{pH}$ is $\sim 4.9$ ). It was found that the column effluents from the first two columns was approximately 5, at which there is appreciable adsorption of the metal-ligand complexes and the free ligand. The major goal for the column tests was to explore environments in which the batch tests had shown little adsorption of the ligand and metal-ligand complex. We were concerned that the relatively strong adsorption in the first two Milford soil columns had been exacerbated by the acidic $\mathrm{pH}$. Therefore the latter two Milford tests on columns 3 and 4 were preflushed with several pore volumes of weak sodium hydroxide solution prior to equilibrating with the background electrolyte. As a result, neutralization capacity of the natural acidity in the Milford soil was overshot to simulate reaction with cement leachate such that once the metal-ligand-radiotracer solutions were injected, the effluent $\mathrm{pH}$ for the last two Milford columns remained close to 9.8 during the entire test. Based on the batch tests at $\mathrm{pH} 9.8$ 
metal-organic complexes and the free ligand should show insignificant adsorption. Thus it was felt that the last two Milford soil column tests would represent "worst case" enhanced transport for complexes in a cement leachate dominated column. The column experiments specifics are described in Table 3.6.

\begin{tabular}{|l|c|c|l|}
\hline \multicolumn{5}{|c|}{ Soil } & Ligand (M) & Metal & \multicolumn{1}{|c|}{ Comments } \\
\hline FeOX-sand & Picolinate $\left(10^{-4}\right)$ & Ni $\left(10^{-6}\right)$ & $\begin{array}{l}\text { Tracer for 29 PV, flush for 15 more; pH } ~ 6.7 \text { for 20 } \\
\text { PV then increased to 7.4 }\end{array}$ \\
\hline Miliford & Picolinate $\left(10^{-4}\right)$ & Ni $\left(10^{-6}\right)$ & $\begin{array}{l}\text { Tracer for 30 PV then flush for 12 more PV; pH } \\
\text { dropped by soil to } ~ 5 \text { throughout test except for a } \\
\text { few spikes up to pH } ~ 7 \text { near 25 and 30 PV }\end{array}$ \\
\hline Miliford & Picolinate $\left(10^{-5}\right)$ & Ni $\left(10^{-6}\right)$ & $\begin{array}{l}\text { Tracer for 30 PV then stop column: soil dropped the } \\
\text { effluent pH to } ~ 5 \text { throughout the test }\end{array}$ \\
\hline Miliford & Picolinate $\left(10^{-4}\right)$ & Pu $\left(10^{-7}\right)$ & $\begin{array}{l}\text { Soil flushed with weak NaOH to get rid of acid } \\
\text { buffering capacity; tracer for 49 PV then flush for } \\
\text { 31 more PV; effluent pH stayed near 9.8 for whole } \\
\text { test }\end{array}$ \\
\hline FeOX-sand & EDTA $\left(10^{-5}\right)$ & Ni $\left(10^{-5}\right)$ & $\begin{array}{l}\text { Tracer for 49 PV then flush for 20 more PV; pH } \\
\text { remained near 7.5 throughout test }\end{array}$ \\
\hline Miliford & EDTA $\left(10^{-5}\right)$ & Ni $\left(10^{-5}\right)$ & $\begin{array}{l}\text { Soil flushed with weak NaOH to get rid of acid } \\
\text { buffering capacity; tracer for 47 PV then flush for } \\
\text { 31 more PV; effluent pH stayed near 9.8 for whole } \\
\text { test }\end{array}$ \\
\hline
\end{tabular}

Three nickel-picolinate column experiments were performed. One nickel-picolinate column adsorption experiment was completed with the iron oxide coated sand using $\mathrm{Ni}$ at $1 \times 10^{-6} \mathrm{M}$ and picolinate at $1 \mathrm{x}$ $10^{-4} \mathrm{M}$. Two nickel-picolinate column adsorption experiments were conducted with Milford soil and $\mathrm{Ni}$ concentrations at $1 \times 10^{-6} \mathrm{M}$ and picolinate concentrations at $1 \times 10^{-4} \mathrm{M}$ and $1 \times 10^{-5} \mathrm{M}$, respectively. One Pu-picolinate experiment was performed with Milford soil at a Pu concentration of $1 \times 10^{-7} \mathrm{M}$ and a picolinate concentration of $1 \times 10^{-4} \mathrm{M}$. Two Ni-EDTA column adsorption experiments were conducted, one with iron oxide coated sand and one with Milford soil. In both cases, the Ni and EDTA concentrations were $1 \times 10^{-5} \mathrm{M}$. As in the batch experiments, radioactive tracers were used to track the adsorption of both the metals and the chelating agents.

After each column experiment was finished, the column was disassembled and the packed sediment was sliced into $2 \mathrm{~cm}$ thick layers. This soil material was then extracted with $1.0 \mathrm{M}$ nitric acid so that a mass balance of the tracer could be conducted. A 5-to-1 weight ratio of nitric acid to soil was used for the 
extraction step. The extractions were conducted in centrifuge tubes that were placed on a tube rotator overnight. The extractions were conducted twice, each time for 16 to $24 \mathrm{hrs}$ and the quantity of tracer extracted in the two extractions was combined to get the total mass of metal and organic ligand extracted from the sediment. The quantity of tracer transported through the column in the Ca perchlorate solutions was added to the quantity of extractable tracer. This total was compared to the total quantity of tracer injected into the column to determine a mass balance. If the mass balance agreed to within $10 \%$, the data were considered to be reliable and the column test a success. 


\subsection{Speciation Calculations}

\subsection{Speciation in Initial Cement Dominated Leachates}

Significant complexation of metals/radionuclides by organic chelating/complexing agents is predicted for several of the leachates from cement solidified decontamination wastes (assumes equilibrium with portlandite, Table 4.1). The percent distribution of the picolinate complexes in the LOMI leachates (Peach Bottom and FitzPatrick) are shown in Table 4.1. Picolinate complexes were the dominate species for $\mathrm{Co}^{2+}$ and $\mathrm{Ni}^{2+}$ in the FitzPatrick leachates. For the rest of the radionuclides and metals complexation by picolinate was unimportant. The balance of the species for $\mathrm{Am}^{3+}, \mathrm{Co}^{2+}, \mathrm{Fe}^{3+}, \mathrm{Mn}^{2+}, \mathrm{Ni}^{2+}, \mathrm{Pu}^{3+}, \mathrm{Pu}^{4+}$, and $\mathrm{Zn}^{2+}$ not listed in Table 4.1, were hydrolysis species. For $\mathrm{Sr}^{2+}$ the remaining species were free $\mathrm{Sr}^{2+}$, $\mathrm{SrOH}^{+}$, and $\mathrm{SrSO}_{4}{ }^{\circ}$. $\mathrm{Cs}^{+}$was essentially uncomplexed. The major differences between the FitzPatrick and Peach Bottom leachates were the concentrations of picolinate and nickel. The picolinate and nickel concentrations used in the Peach Bottom leachate calculations were $2.9 \times 10^{-4} \mathrm{M}$ and $9.2 \times 10^{-7} \mathrm{M}$, respectively, and $1.6 \times 10^{-3} \mathrm{M}$ and $1.6 \times 10^{-6} \mathrm{M}$ in the FitzPatrick leachate. These differences may reflect the fact that the FitzPatrick waste forms crumbled during the leach testing whereas the Peach Bottom samples remained intact.

\begin{tabular}{|c|c|c|}
\hline \multicolumn{3}{|c|}{$\begin{array}{c}\text { Table 4.1. Percent Distribution of Picolinate Complexes in LOMI } \\
\text { Leachates (Peach Bottom and FitzPatrick) in Equilibrium with } \\
\text { Portlandite (pH 12.3) }\end{array}$} \\
\hline Radionuclide or Metal & Peach Bottom & FitzPatrick \\
\hline $\mathrm{Am}^{3+}$ & 0.0 & 0.0 \\
\hline $\mathrm{Cs}^{+}$ & 0.0 & 0.0 \\
\hline $\mathrm{Co}^{2+}$ & 0.0 & 59.7 \\
\hline $\mathrm{Fe}^{3+}$ & 0.0 & 0.0 \\
\hline $\mathrm{Mn}^{2+}$ & 0.0 & 1.3 \\
\hline $\mathrm{Ni}^{2+}$ & 1.8 & 94.3 \\
\hline $\mathrm{Pu}^{3+}$ & 0.0 & 0.0 \\
\hline $\mathrm{Pu}^{4+}$ & 0.0 & 0.0 \\
\hline $\mathrm{Sr}^{2+}$ & 0.0 & 0.0 \\
\hline $\mathrm{Zn}^{2+}$ & 0.0 & 0.0 \\
\hline & & \\
\hline
\end{tabular}


The percent distribution of complexes in the initial Pilgrim leachate (in equilibrium with portlandite) that contains EDTA and DTPA are given in Table 4.2. Complexation of radionuclides/metals with citric acid and oxalic acid was insignificant in the Pilgrim leachates. For $\mathrm{Am}^{3+}, \mathrm{Pu}^{3+}$, and $\mathrm{Sr}^{2+}$ complexes with DTPA are the dominant species. $\mathrm{Cs}^{+}$and $\mathrm{Fe}^{3+}$ were essentially uncomplexed by organic ligands. A small to moderate amount of organic (both EDTA and DTPA) complexation occurred for $\mathrm{Co}^{2+}, \mathrm{Mn}^{2+}$, and $\mathrm{Zn}^{2+}$. The balance of the species not included in Table 4.2 for $\mathrm{Co}^{2+}, \mathrm{Fe}^{3+}, \mathrm{Mn}^{2+}, \mathrm{Ni}^{2+}$, and $\mathrm{Zn}^{2+}$ were hydrolysis complexes. $\mathrm{Cs}^{+}$exists in the leachates essentially as the free ion.

Significant complexation by organic ligands also is predicted for some of the radionuclides in the Millstone (CAN-DECON process) leachates. $\mathrm{Mn}^{2+}, \mathrm{Ni}^{2+}, \mathrm{Sr}^{2+}$, and $\mathrm{Zn}^{2+}$ were dominated by EDTA or mixed OH-EDTA complexes (Table 4.3). Complexation by citrate and oxalate was insignificant in the Millstone leachates. For $\mathrm{Am}^{3+}, \mathrm{Co}^{2+}, \mathrm{Fe}^{3+}, \mathrm{Pu}^{3+}$, and $\mathrm{Pu}^{4+}$ hydrolysis was strong enough to dominate the speciation scheme for these ions. $\mathrm{Cs}^{+}$again remained essentially as the free ion.

Predictions for CITROX leachates for Brunswick and Cooper cement solidified waste forms show that metals/radionuclides should not be complexed to any significant extent by organic chelating agents in the initial leachate solutions. The speciation scheme of all of the radionuclides, studied with the exception of $\mathrm{Cs}^{+}$and $\mathrm{Sr}^{2+}$ were dominated by hydrolysis. $\mathrm{Cs}^{+}$occurred in these leachates as the free ion. $\mathrm{Sr}^{2+}$ was mostly free, but about $30 \%$ occurred as sulfate complexes.

Table 4.2. Percent Distribution of EDTA and DTPA Complexes in NS-1 Pilgrim Leachates in Equilibrium with Portlandite ( $\mathrm{pH}$ 12.3)

\begin{tabular}{|c|c|c|c|c|}
\hline Radionuclide or Metal & \% M-EDTA & \% M(OH)-EDTA & \% M-DTPA & Total \\
\hline $\mathrm{Am}^{3+}$ & 0.0 & 0.0 & 87.3 & 87.3 \\
\hline $\mathrm{Cs}^{+}$ & 0.0 & 0.0 & 0.0 & 0.0 \\
\hline $\mathrm{Co}^{2+}$ & 0.0 & 59.7 & 7.2 & 10.9 \\
\hline $\mathrm{Fe}^{3+}$ & 0.0 & 0.0 & 0.0 & 0.0 \\
\hline $\mathrm{Mn}^{2+}$ & 19.6 & 0.0 & 2.7 & 22.3 \\
\hline $\mathrm{Ni}^{2+}$ & 0.0 & 0.0 & 0.0 & 0.0 \\
\hline $\mathrm{Pu}^{3+}$ & 0.0 & 0.0 & 87.3 & 87.3 \\
\hline $\mathrm{Pu}^{4+}$ & 0.0 & 0.0 & 0.0 & 0.0 \\
\hline $\mathrm{Sr}^{2+}$ & 32.7 & 0.0 & 61.9 & 94.6 \\
\hline $\mathrm{Zn}^{2+}$ & 0.0 & 44.6 & 0.0 & 44.6 \\
\hline
\end{tabular}




\begin{tabular}{|c|c|c|c|}
\hline \multicolumn{4}{|c|}{$\begin{array}{c}\text { Table 4.3. Percent Distribution of EDTA Complexes in CAN-DECON } \\
\text { Millstone Leachates in Equilibrium with Portlandite (pH 12.3) }\end{array}$} \\
\hline Radionuclide or Metal & \% M-EDTA & \% M(OH)-EDTA & Total \\
\hline $\mathrm{Am}^{3+}$ & 21.4 & 0.0 & 21.4 \\
\hline $\mathrm{Cs}^{+}$ & 0.0 & 0.0 & 0.0 \\
\hline $\mathrm{Co}^{2+}$ & 30.7 & 0.0 & 30.7 \\
\hline $\mathrm{Fe}^{3+}$ & 0.0 & 0.0 & 0.0 \\
\hline $\mathrm{Mn}^{2+}$ & 72.8 & 0.0 & 72.8 \\
\hline $\mathrm{Ni}^{2+}$ & 32.5 & 63.3 & 95.8 \\
\hline $\mathrm{Pu}^{3+}$ & 21.4 & 0.0 & 21.4 \\
\hline $\mathrm{Pu}^{4+}$ & 0.0 & 0.0 & 0.0 \\
\hline $\mathrm{Sr}^{2+}$ & 98.5 & 0.0 & 98.5 \\
\hline $\mathrm{Zn}^{2+}$ & 0.0 & 89.5 & 89.5 \\
\hline
\end{tabular}

\subsection{Speciation in pH Adjusted Leachates from Cement Waste Forms}

By decreasing the $\mathrm{pH}$ and maintaining equilibrium with calcite, amorphous iron hydroxide, and gibbsite at a total finite concentration of $0.01 \mathrm{~mole} / \mathrm{L}$ each, significant alterations in the equilibrium speciation were found to occur in the leachates. Although this scenario is used to simulate the consequences of interactions between the cement dominated leachate with a typical soil, these calculations are also generally applicable for a situation where the leachate is contained within the waste site and is neutralized with carbonic acid. Influx of carbon dioxide is not likely to reduce the $\mathrm{pH}$ below 8 and in nearly all instances, the speciation of the major chelating agents is not affected by $\mathrm{Fe}^{3+}$ or $\mathrm{Al}^{3+}$ complexation (see later discussion) at these high $\mathrm{pH}$ values. Significant complexation of the chelating agents with $\mathrm{Ca}^{2+}$ does occur between $\mathrm{pH} 12$ and 8; however, because the concentration of $\mathrm{Ca}^{2+}$ in equilibrium with both portlandite and calcite are essentially the same (see Table 3.2), the speciation results discussed below are applicable to both the soil percolation-neutralization scenario and the $\mathrm{CO}_{2}$ gas diffusion neutralization scenario that were described in Section 3.1.

The following figures portray the speciation calculation results for the various leachates as the $\mathrm{pH}$ is lowered from high values $(>12)$ found in the environments dominated by cement. For each figure, the $y$ axis is the percent of the total metal/radionuclide/chelating agent and the $\mathrm{x}$ axis is $\mathrm{pH}$. (An) represents trivalent actinides $\left(\mathrm{Pu}^{3+}, \mathrm{Am}^{3+}\right.$, and $\left.\mathrm{Cm}^{3+}\right)$, other metals and radionuclides use their appropriate elemental symbol. The ligands are represented as $(\mathrm{OH})$ for hydroxide (hydrolysis) species, (In) for all other inorganic ligands such as $\mathrm{Cl}^{-}, \mathrm{SO}_{4}{ }^{2-}, \mathrm{CO}_{3}{ }^{2-}$ as well as the free radionuclide/metal, (Pic) for picolinate, (Cit) for citrate, $(\mathrm{Ox})$ for oxalate, (EDTA) for ethylenediaminetetraactetate, and (DTPA) for diethylenetriaminepentaacetate. The subscript $(\mathrm{x})$ signifies that several species are present that were 
summed to give a total. This was done to keep the figures from becoming excessively cluttered. Most often the subscript is used to indicate the sum of a series of hydrolysis species, such as $\mathrm{AmOH}_{2}{ }^{+}$, $\mathrm{Am}(\mathrm{OH})_{2}{ }^{+}$, and $\mathrm{Am}(\mathrm{OH})_{3}{ }^{0}$. In other cases, the speciation modeling calculations predict that more than one organic ligand (chelating agent) may attach to a metal atom to form $\mathrm{ML}, \mathrm{ML}_{2}, \mathrm{ML}_{3}$, etc., or in some cases a mixed species such as MLOH.

Results of the LOMI Peachbottom equilibrium speciation calculations for a number of radionuclides are illustrated in Figures 4.1 through 4.6. From Figure 4.1, it is apparent that complexation of the trivalent actinides $\left(\mathrm{Am}^{3+}\right.$ and $\left.\mathrm{Pu}^{3+}\right)$ by picolinate in the Peachbottom leachates is relatively minor, peaking near $20 \%$ between $\mathrm{pH}$ values of 5 and 9 . Similar behavior is observed for $\mathrm{Mn}^{2+}$ (Figure 4.3). For $\mathrm{Co}^{2+}, \mathrm{Ni}^{2+}$, and $\mathrm{Zn}^{2+}$ (Figures 4.2,4.4,4.6), picolinate complexes dominate the speciation scheme throughout most of the $\mathrm{pH}$ range studied. At high $\mathrm{pH},>11$ for $\mathrm{Co}^{2+},>11.5$ for $\mathrm{Ni}^{2+}$, and $>9.5$ for $\mathrm{Zn}^{2+}$, hydrolysis dominates the speciation. $\mathrm{Sr}^{2+}$ was not significantly complexed by picolinate. For $\mathrm{Pu}^{4+}$ (Figure 4.5) picolinate complexes are not important. Carbonate complexes dominate the speciation scheme of $\mathrm{Pu}^{4+}$ up $\mathrm{pH} 8.3$; beyond this $\mathrm{pH}$ hydrolysis dominates. Figure 4.7 shows the speciation scheme of picolinic acid in the Peachbottom leachates, as a function of $\mathrm{pH}$. $\mathrm{CaPic}^{+}$and free picolinate are the major species of picolinic acid from $\mathrm{pH} 12$ down to 5 . Below $\mathrm{pH} 5$ protonation of picolinate increases as the $\mathrm{pH}$ decreases. A small amount of the $\mathrm{Fe}(\mathrm{OH}) \mathrm{Pic}^{+}$species is also observed to occur.

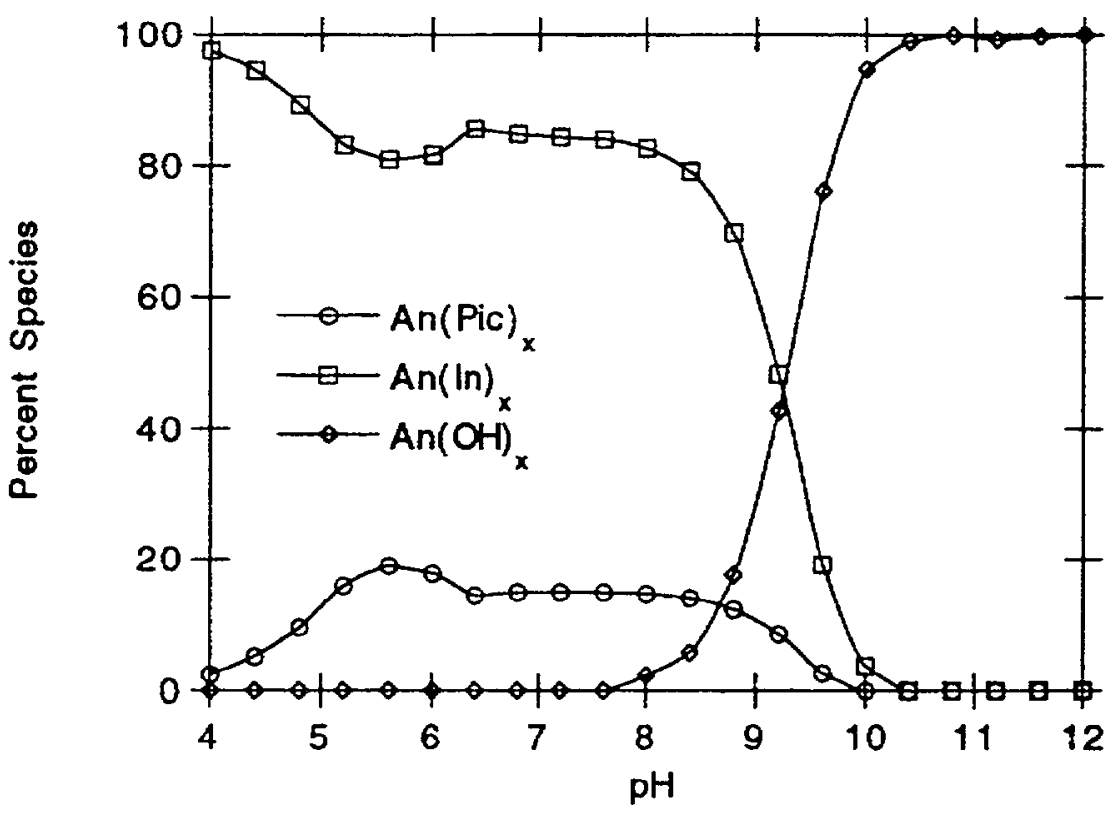

Figure 4.1. Speciation Distribution for Trivalent Actinides in Peach Bottom (LOMI) Leachate 


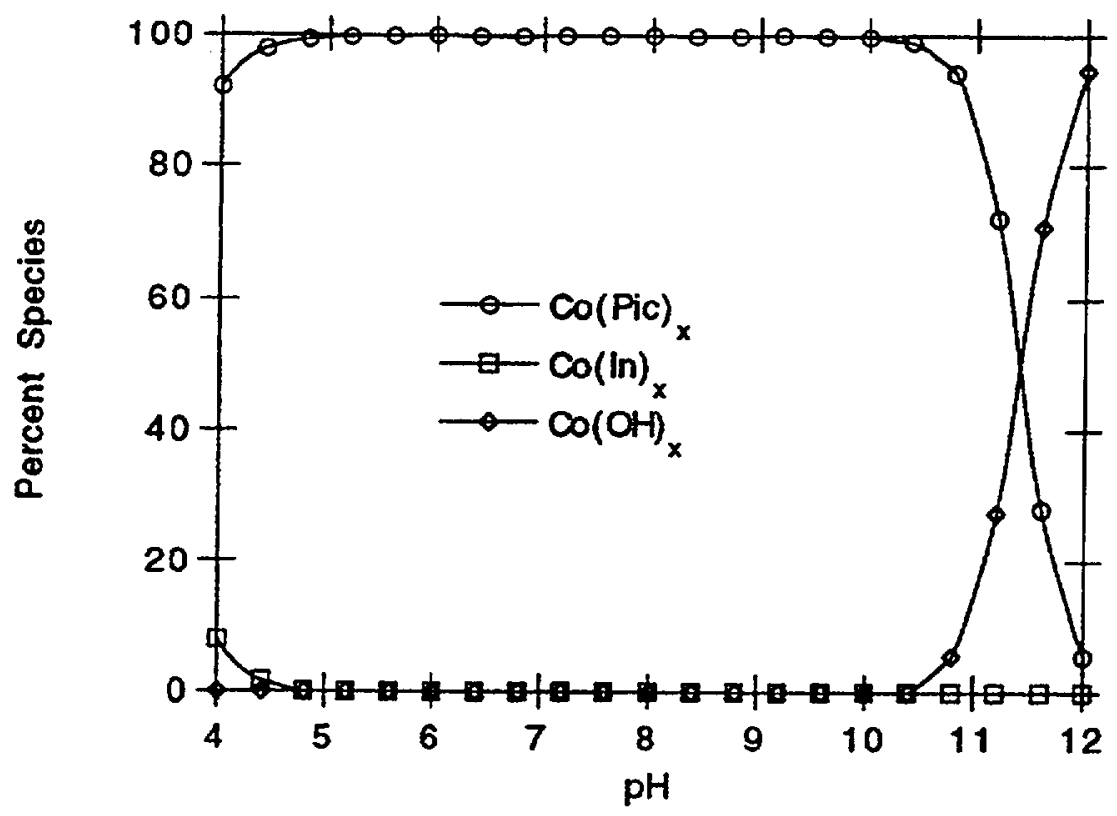

Figure 4.2. Speciation Distribution for Cobalt in Peach Bottom (LOMI) Leachate

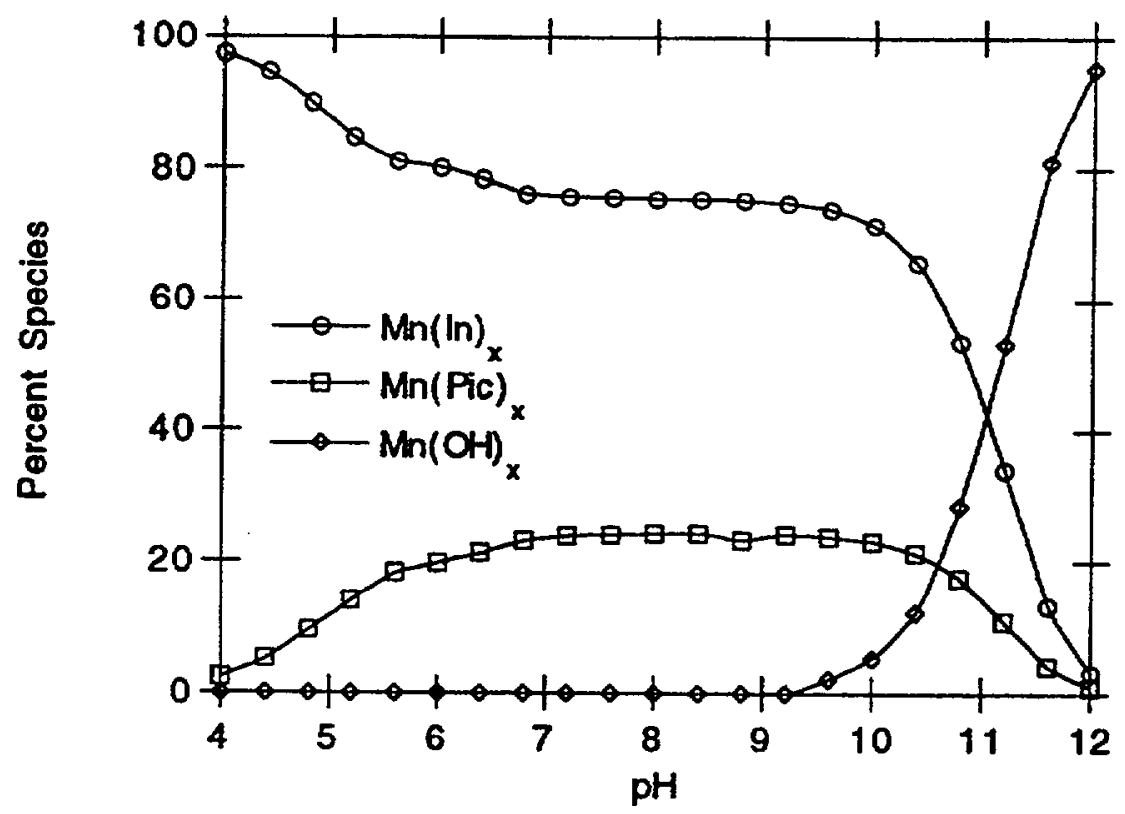

Figure 4.3. Speciation Distribution for Manganese in Peach Bottom (LOMI) Leachate 


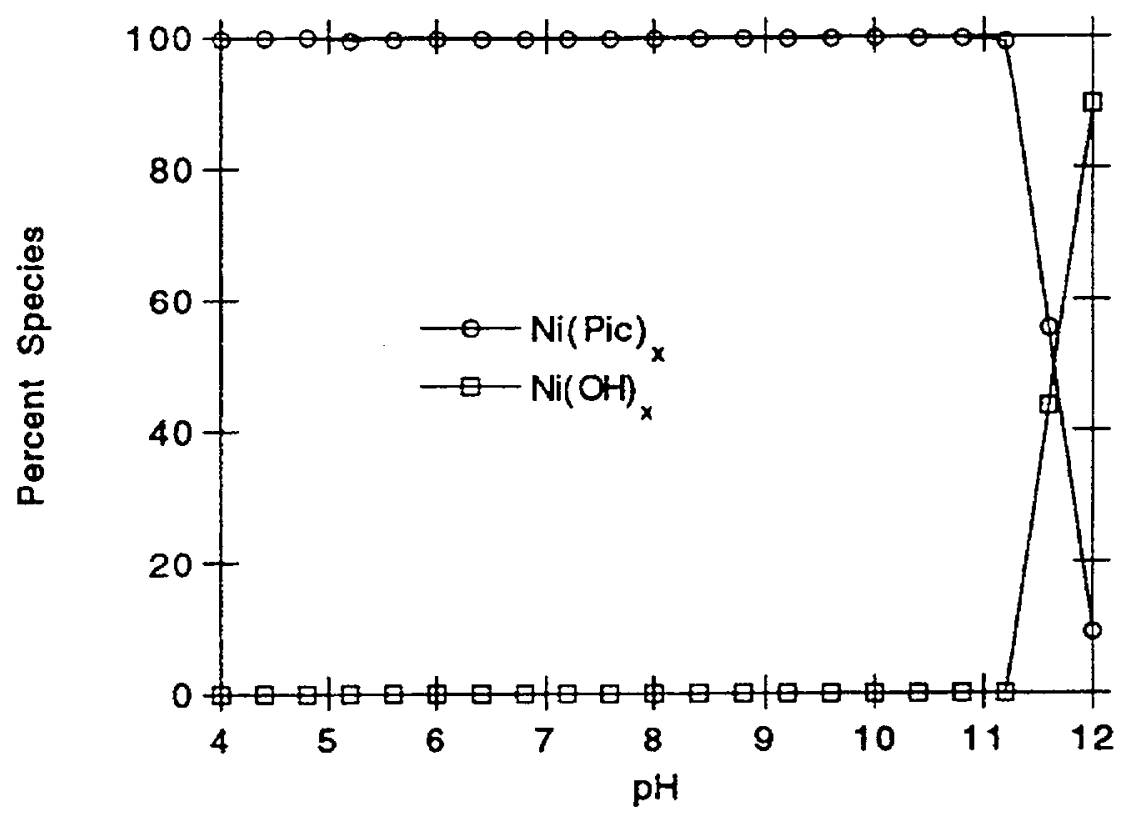

Figure 4.4. Speciation Distribution for Nickel in Peach Bottom (LOMI) Leachate

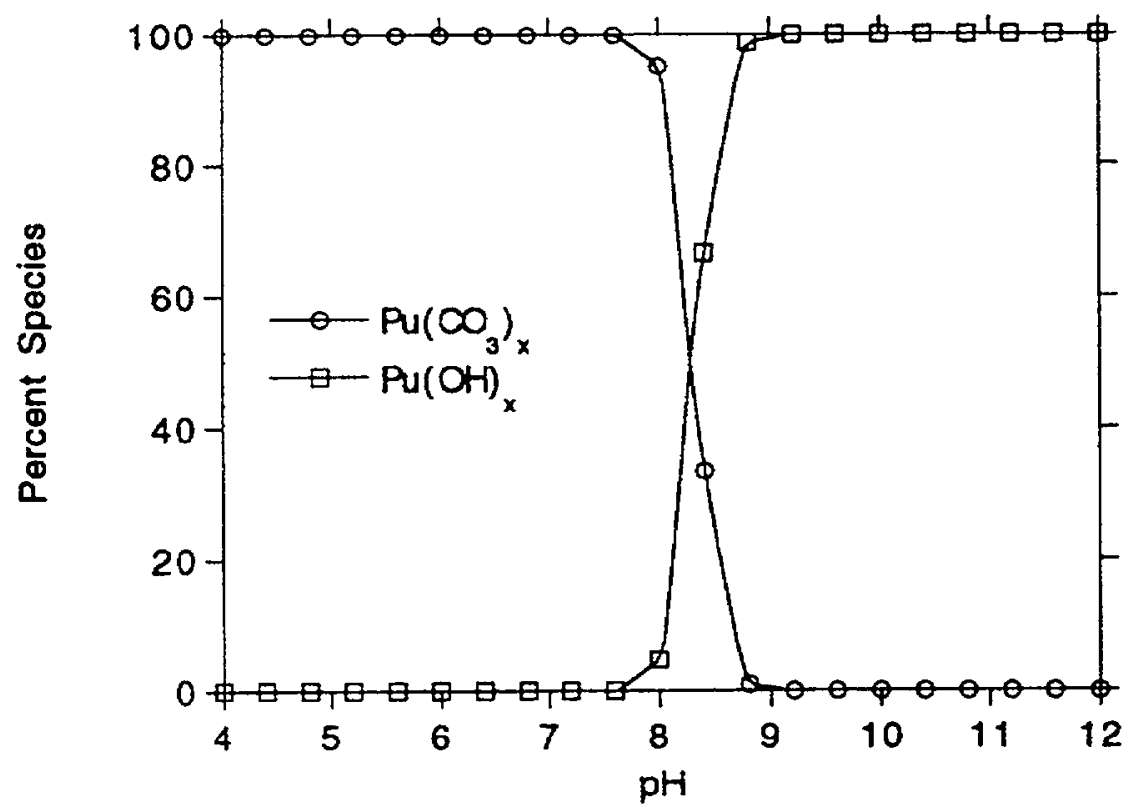

Figure 4.5. Speciation Distribution for Plutonium (IV) in Peach Bottom (LOMI) Leachate 


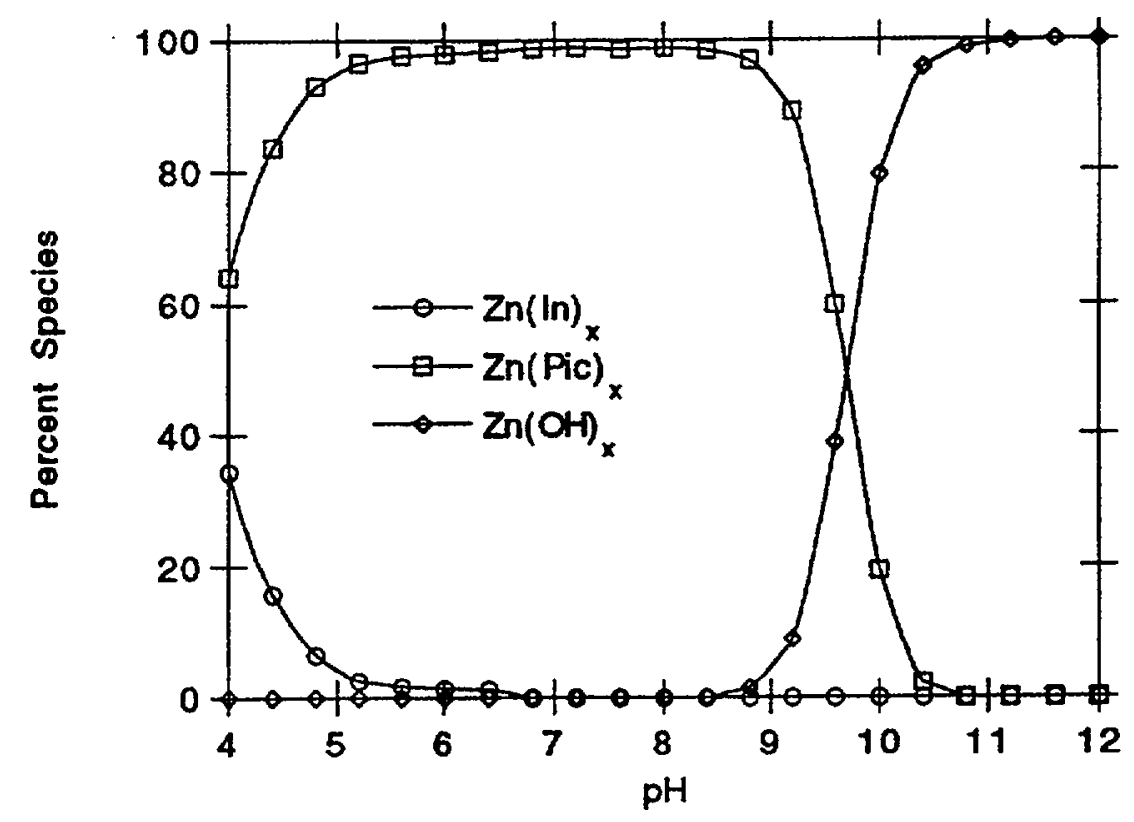

Figure 4.6. Speciation Distribution for Zinc in Peach Bottom (LOMI) Leachate

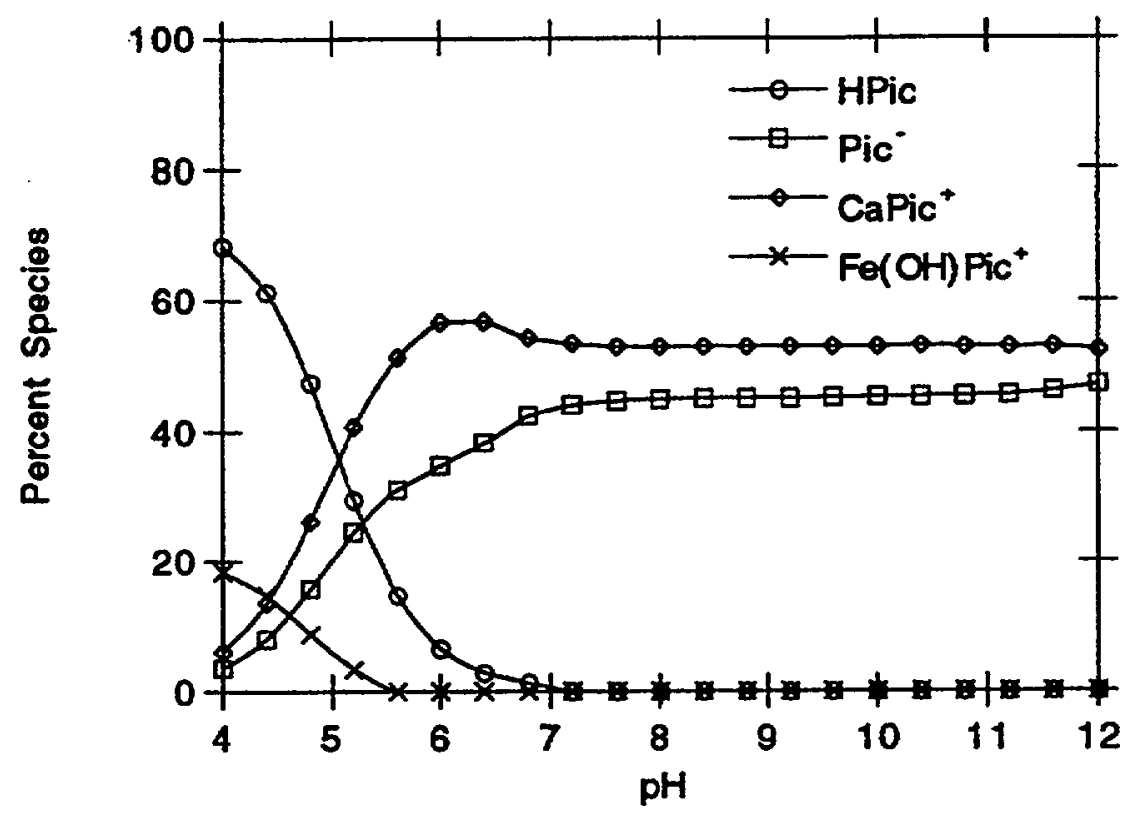

Figure 4.7. Speciation Distribution for Picolinic Acid in Peach Bottom (LOMI) Leachate 
In general, the speciation of the radionuclides in the LOMI FitzPatrick leachates are similar to those of Peachbottom leachates. Because of the higher picolinate concentrations in the FitzPatrick leachates the importance of picolinate complexation is even greater than for Peachbottom. In the case of the trivalent actinides $\left(\mathrm{Am}^{3+}\right.$ and $\mathrm{Pu}^{3+}$ ) picolinate complexation increases to a peak of near $70 \%$ between $\mathrm{pH}$ values of 5 and 9 . $\mathrm{Mn}^{2+}$ complexation with picolinate peaked at about $66 \%$. For $\mathrm{Co}^{2+}, \mathrm{Ni}^{2+}$, and $\mathrm{Zn}^{2+}$, the dominance of picolinate complexes shifted to higher $\mathrm{pH}$ values. For $\mathrm{Co}^{2+}$ and $\mathrm{Ni}^{2+}$, picolinate complexes dominated at all $\mathrm{pH}$ values. For $\mathrm{Zn}^{2+}$, hydrolysis begins to dominate the speciation above $\mathrm{pH} 10.5$.

In the NS-1 Pilgrim leachate, trivalent actinide $\left(\mathrm{Am}^{3+}\right.$ and $\mathrm{Pu}^{3+}$ ) speciation (Figure 4.8 ) is dominated by complexation with chelating agents from $\mathrm{pH} 12$ down to $\mathrm{pH} 5$. Below this $\mathrm{pH}$, inorganic species begin to dominate the trivalent actinide speciation scheme. The DTPA complex is the dominant species from $\mathrm{pH}$ 12 to $\mathrm{pH} 8$. Oxalate complexes dominate from $\mathrm{pH} 8$ to about 5. For $\mathrm{Co}^{2+}$, (Figure 4.9) complexes with EDTA and DTPA are the dominant species from $\mathrm{pH} 11.8$ to $\mathrm{pH}$ 9. For $\mathrm{Mn}^{2+}$ (Figure 4.10), the EDTA complex is dominant from $\mathrm{pH} 12$ down to 10. For $\mathrm{Ni}^{2+}$ (Figure 4.11), NiEDTA ${ }^{2-}$ is the most important species in the $\mathrm{pH}$ range of 5 to 11 . Above $\mathrm{pH} \mathrm{11}$, hydrolysis becomes the dominant species. Below $\mathrm{pH}$ 5 , free $\mathrm{Ni}^{2+}$ and inorganic complexes of $\mathrm{Ni}^{2+}$ dominate. Organic complexation of strontium (Figure 4.12) is dominant above $\mathrm{pH} 10.5$. Below $\mathrm{pH} 10.5$ complexation of strontium with EDTA and DTPA falls off rapidly and free $\mathrm{Sr}^{2+}$ and inorganic complexes predominate. $\mathrm{Pu}^{4+}$ speciation is not affected by organic complexation in the Pilgrim leachates. For zinc (Figure 4.13), EDTA complexes (ZnEDTA ${ }^{2-}$ and $\left.\mathrm{Zn}(\mathrm{OH}) \mathrm{EDTA}^{3-}\right)$ dominate the speciation scheme from $\mathrm{pH} 12$ down to $\mathrm{pH} 9$. Below $\mathrm{pH} 8, \mathrm{Zn}$ in predominantly in the form of inorganic species and free zinc. The speciation schemes of EDTA and DTPA are illustrated in Figures 4.14 and 4.15. For both EDTA and DTPA, complexes with $\mathrm{Ca}^{2+}$ are the dominant species from $\mathrm{pH} 12$ down to nearly $\mathrm{pH} 11$. Nickel chelates dominate the speciation of EDTA from $\mathrm{pH} 11$ to approximately $\mathrm{pH} 5$ and $\mathrm{pH} 11$ to $\mathrm{pH} 7$ for DTPA. $\mathrm{Fe}^{3+}$ chelates dominate below these $\mathrm{pH}$ values.

Organic complexation in the CAN-DECON Millstone leachate is significantly greater than for the Pilgrim leachate. This is due primarily to the higher EDTA concentrations (Table 3.1). For nearly all of the radionuclides $\left(\mathrm{Am}^{3+}, \mathrm{Pu}^{3+}, \mathrm{Co}^{2+}, \mathrm{Mn}^{2+}, \mathrm{Ni}^{2+}, \mathrm{Sr}^{2+}, \mathrm{Zn}^{2+}\right.$, Figures 4.16-4.21), EDTA complexes dominate the speciation scheme from $\mathrm{pH} 12$ down to $\mathrm{pH} 6.5$ or below. Only for $\mathrm{Pu}^{4+}$ is organic complexation relatively insignificant. From $\mathrm{pH} 12$ down to $5.5 \mathrm{Pu}^{4+}$ is dominated by hydrolysis and carbonate complexation (Figure 4.22). From pH 5.5 to 4.0 citrate complexes dominate the $\mathrm{Pu}^{4+}$ speciation scheme. In the Millstone leachates chelates with calcium dominate the EDTA speciation scheme from pH 12 to 7 ; below this $\mathrm{pH}$, chelates with $\mathrm{Fe}^{3+}$ are the dominant species for EDTA as shown in Figure 4.23.

With a few exceptions both CITROX leachates, Cooper and Brunswick, have relatively little organic complexation of the radionuclides. The most significant complexation was determined for the trivalent actinides and nickel in the Cooper leachate. Oxalate complexes comprised nearly $90 \%$ of the species distribution for $\mathrm{Am}^{3+}$ and $\mathrm{Pu}^{3+}$ (Figure 4.24) between $\mathrm{pH} 5$ and 9 . Oxalate complexes accounted for approximately $28 \%$ of nickel species from pH 5.5 to 9 in the Cooper leachates (Figure 4.25). The speciation scheme of oxalate in the Cooper leachate is illustrated in Figure 4.26. $\mathrm{Ca}^{2+}$ chelates are the 


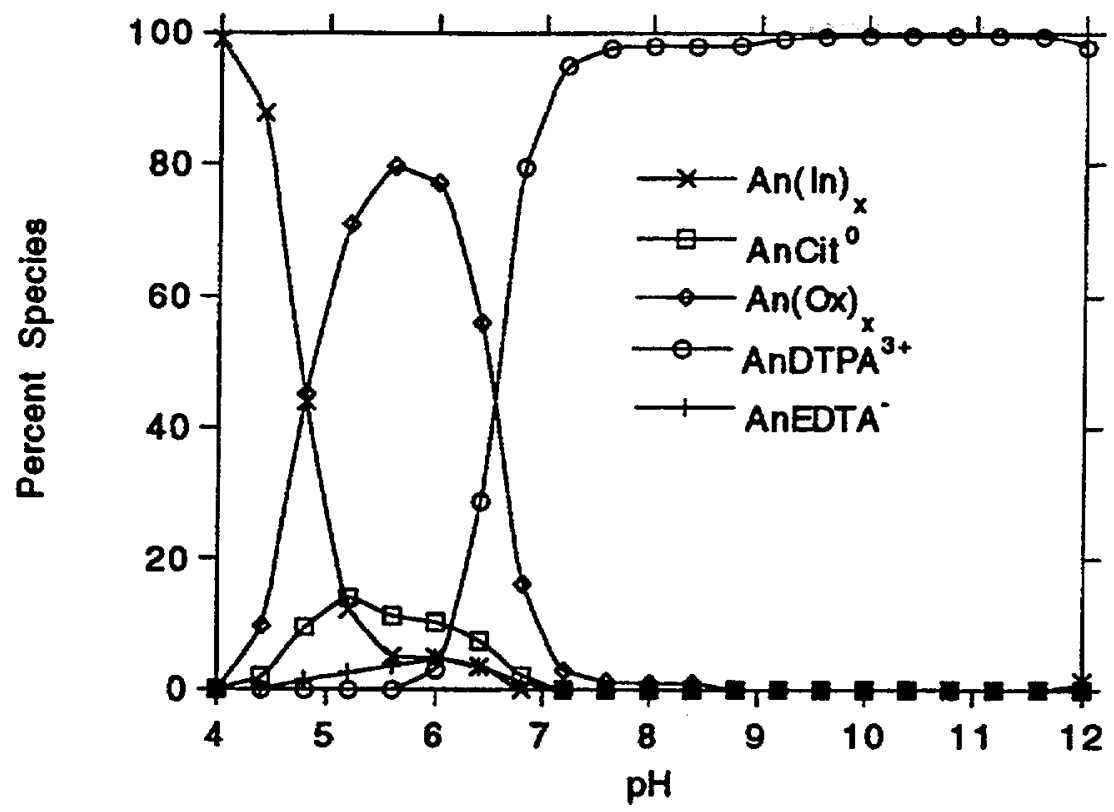

Figure 4.8. Speciation Distribution for Trivalent Actinides in Pilgrim (NS-1) Leachate

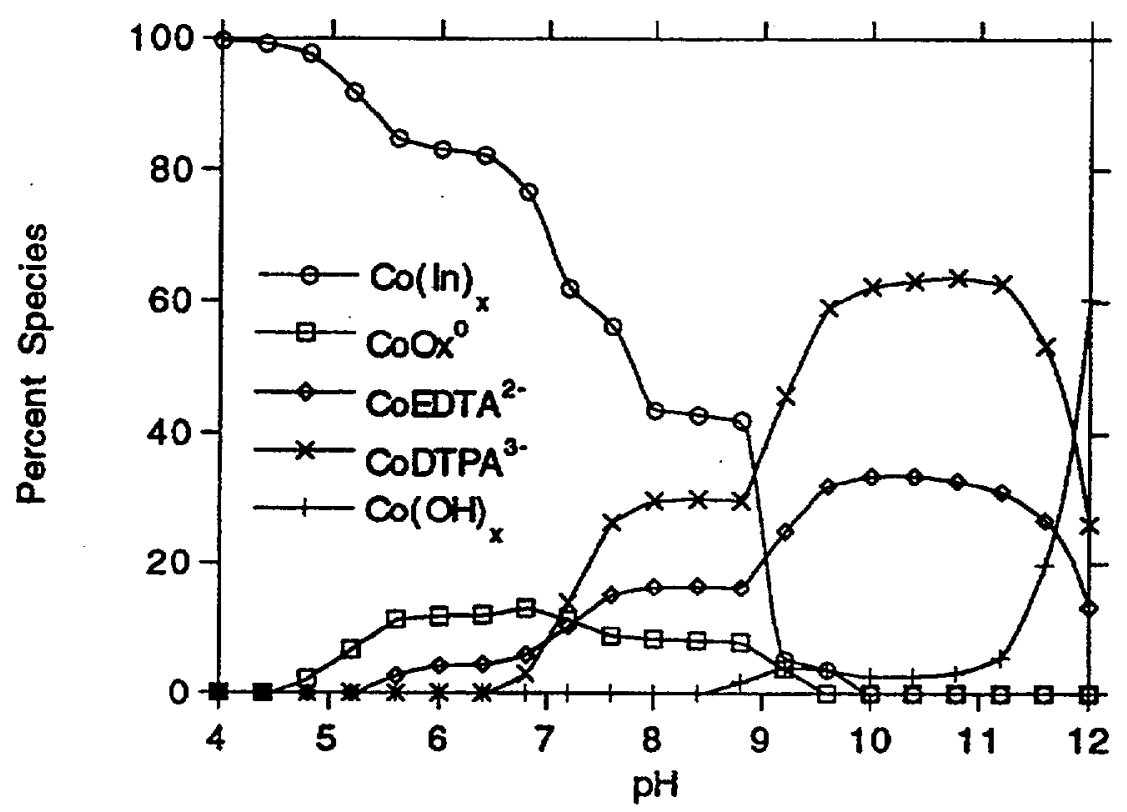

Figure 4.9. Speciation Distribution for Cobalt in Pilgrim (NS-1) Leachate 


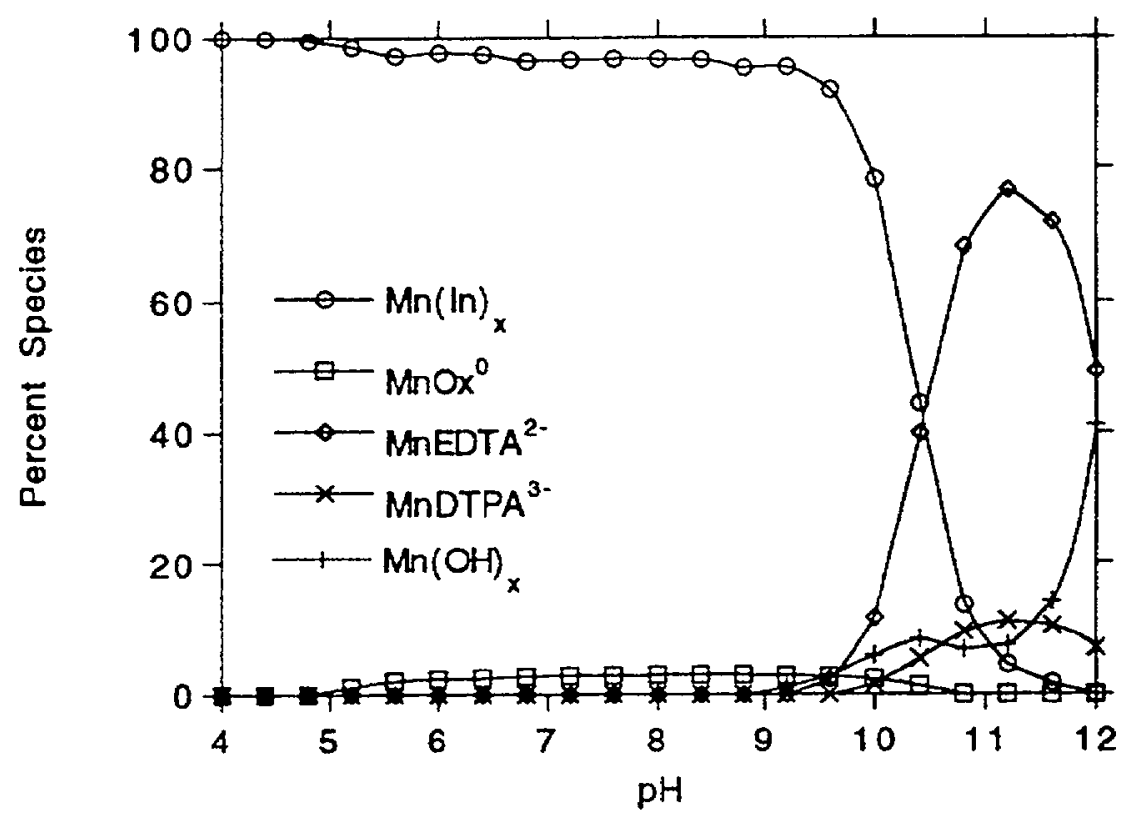

Figure 4.10. Speciation Distribution for Manganese in Pilgrim (NS-1) Leachate

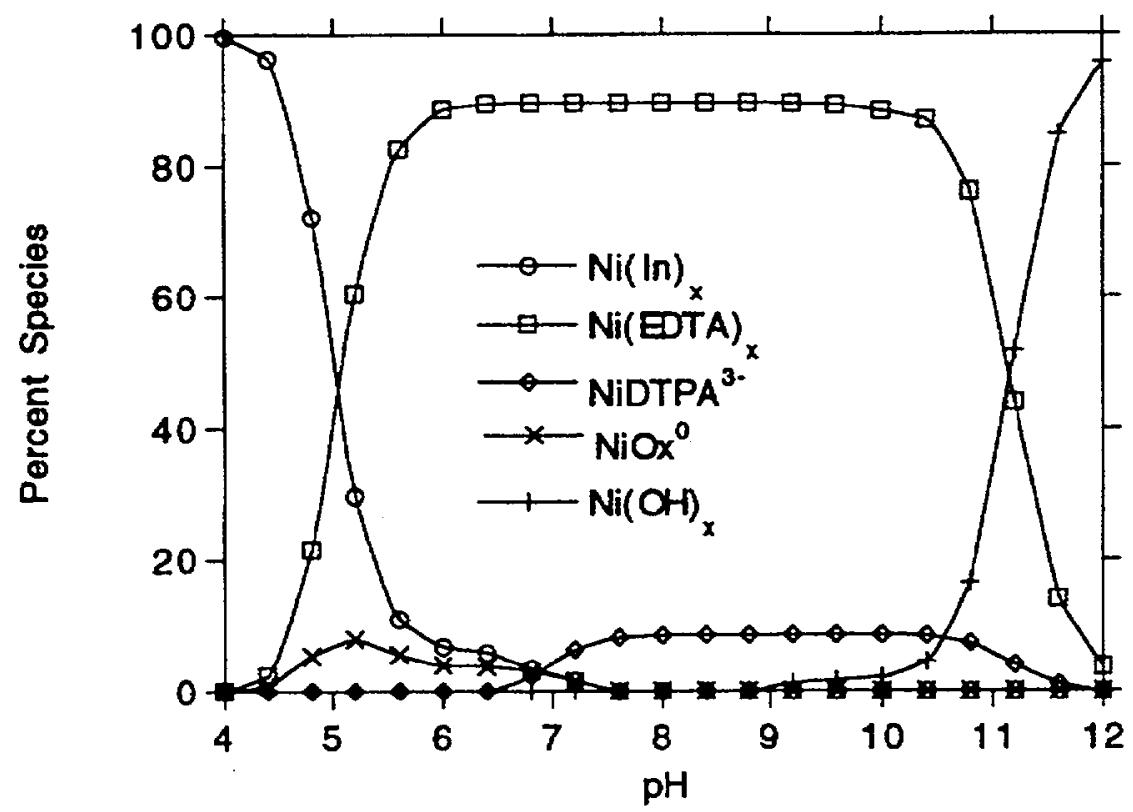

Figure 4.11. Speciation Distribution for Nickel in Pilgrim (NS-1) Leachate 


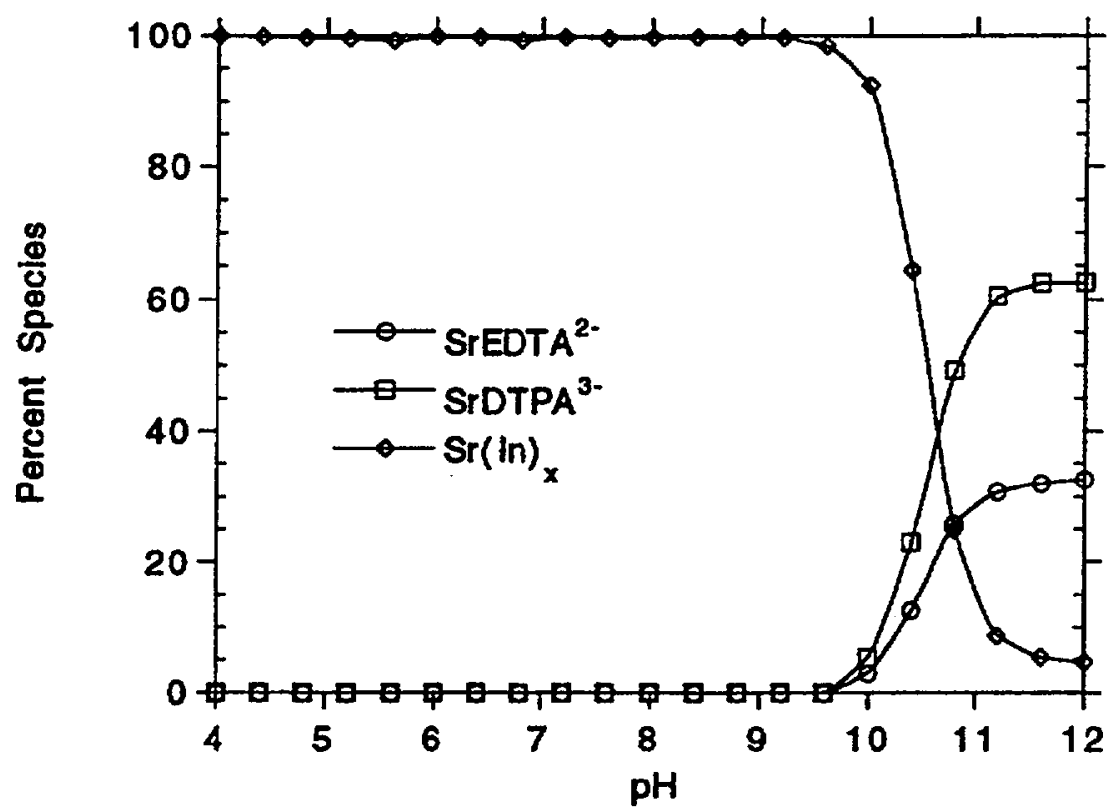

Figure 4.12. Speciation Distribution for Strontium in Pilgrim (NS-1) Leachate

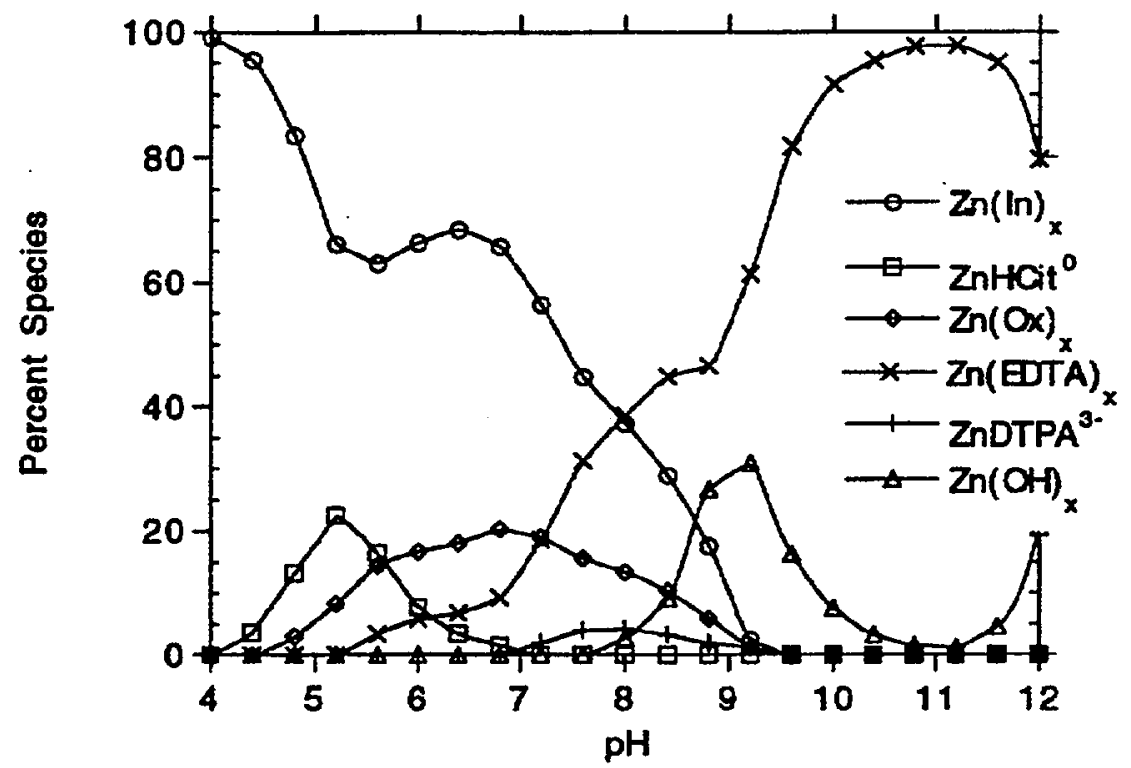

Figure 4.13. Speciation Distribution for Zinc in Pilgrim (NS-1) Leachate 


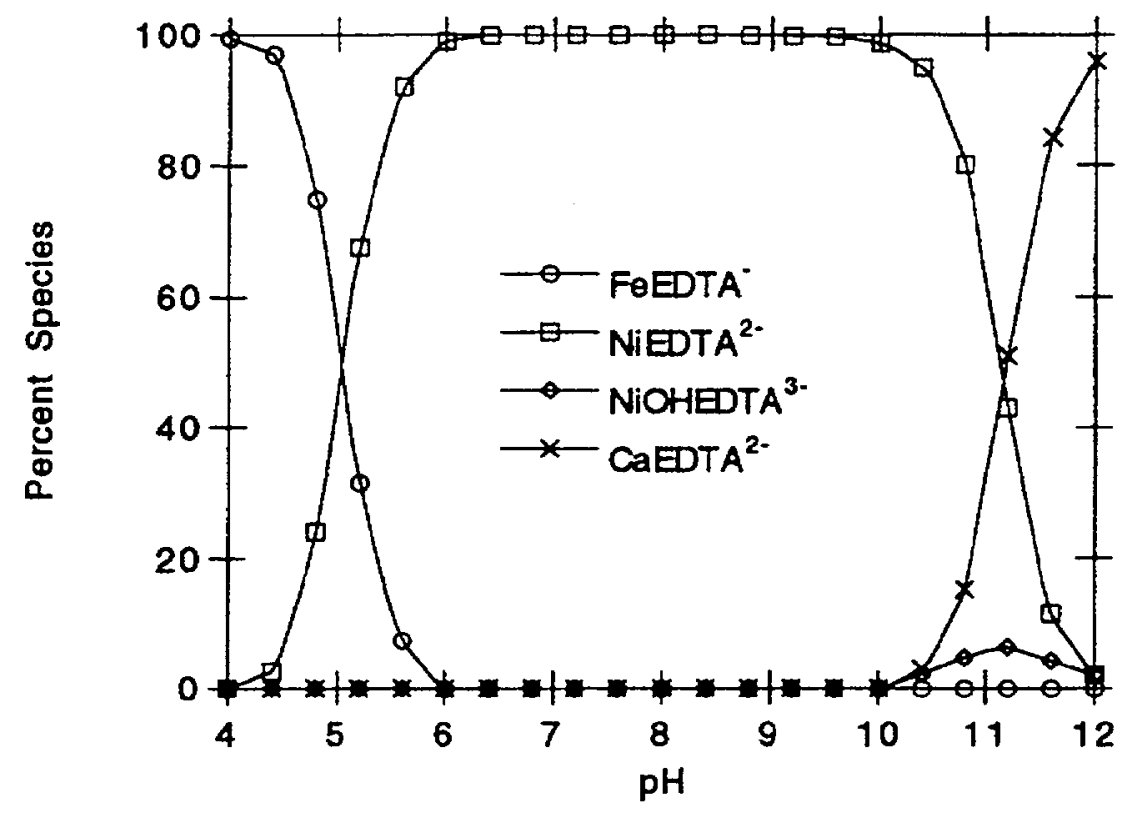

Figure 4.14. Speciation Distribution for EDTA in Pilgrim (NS-1) Leachate

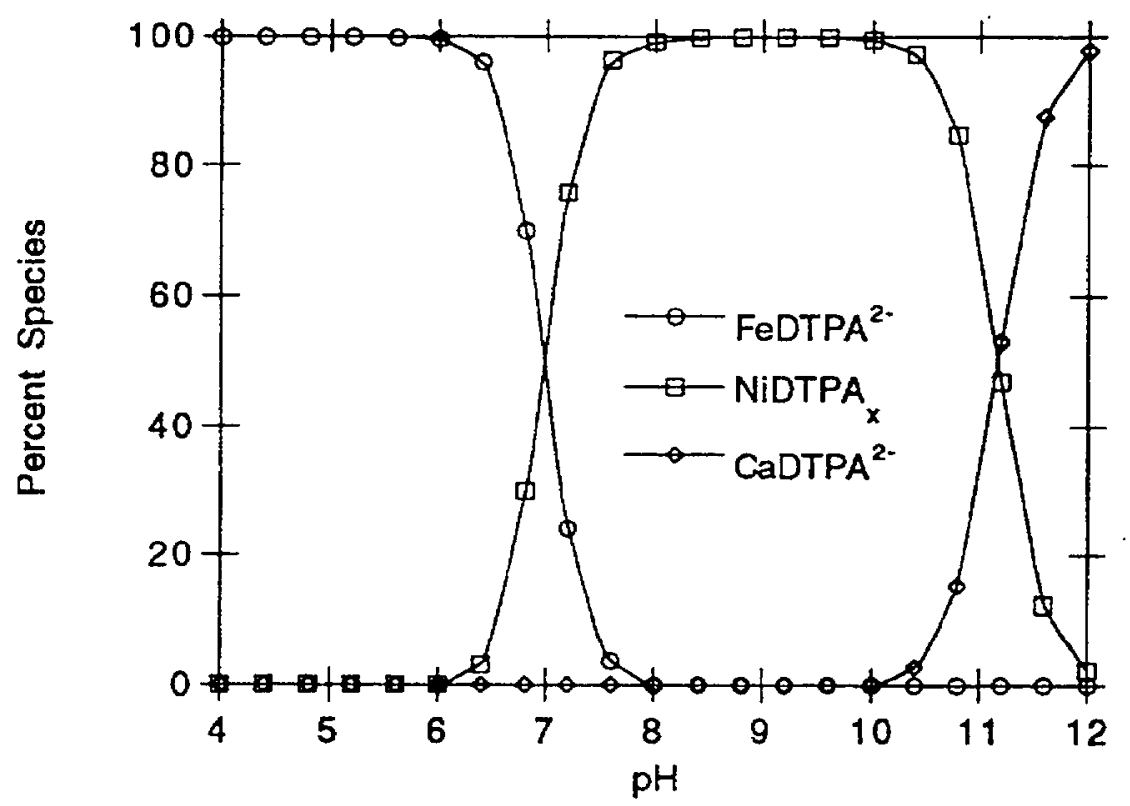

Figure 4.15. Speciation Distribution for DTPA in Pilgrim (NS-1) Leachate 


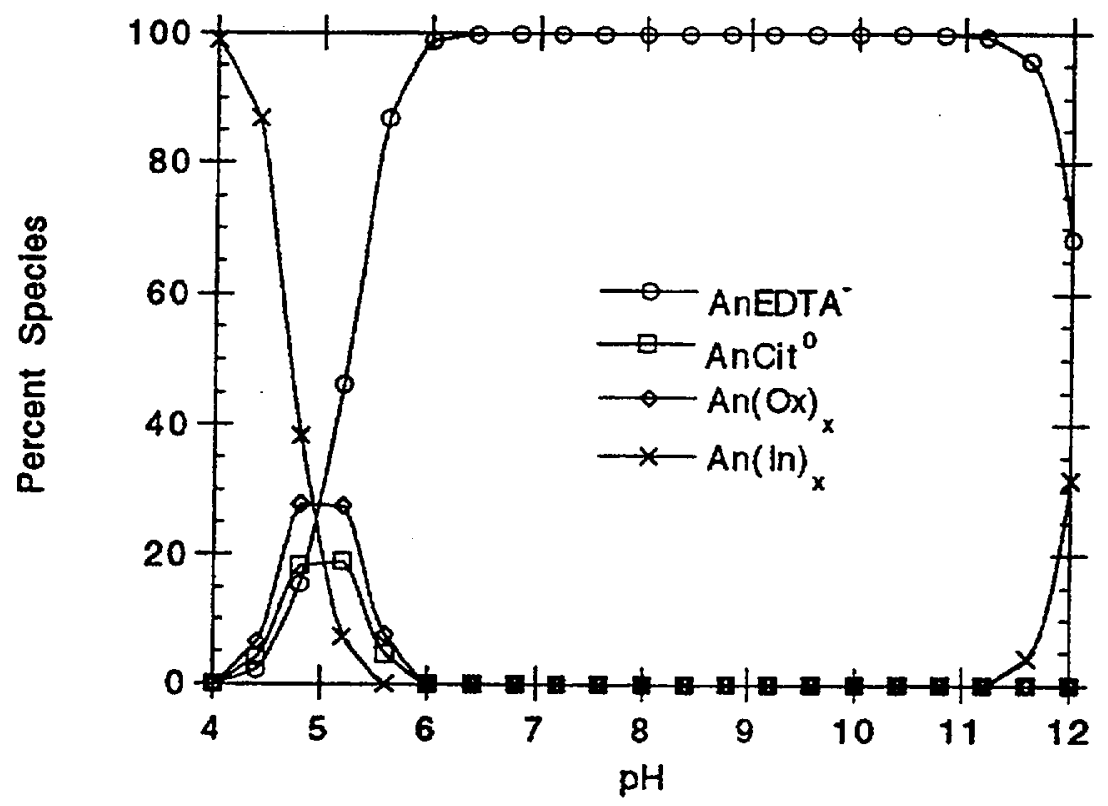

Figure 4.16. Speciation Distribution for Trivalent Actinides in Millstone (CITROX) Leachate

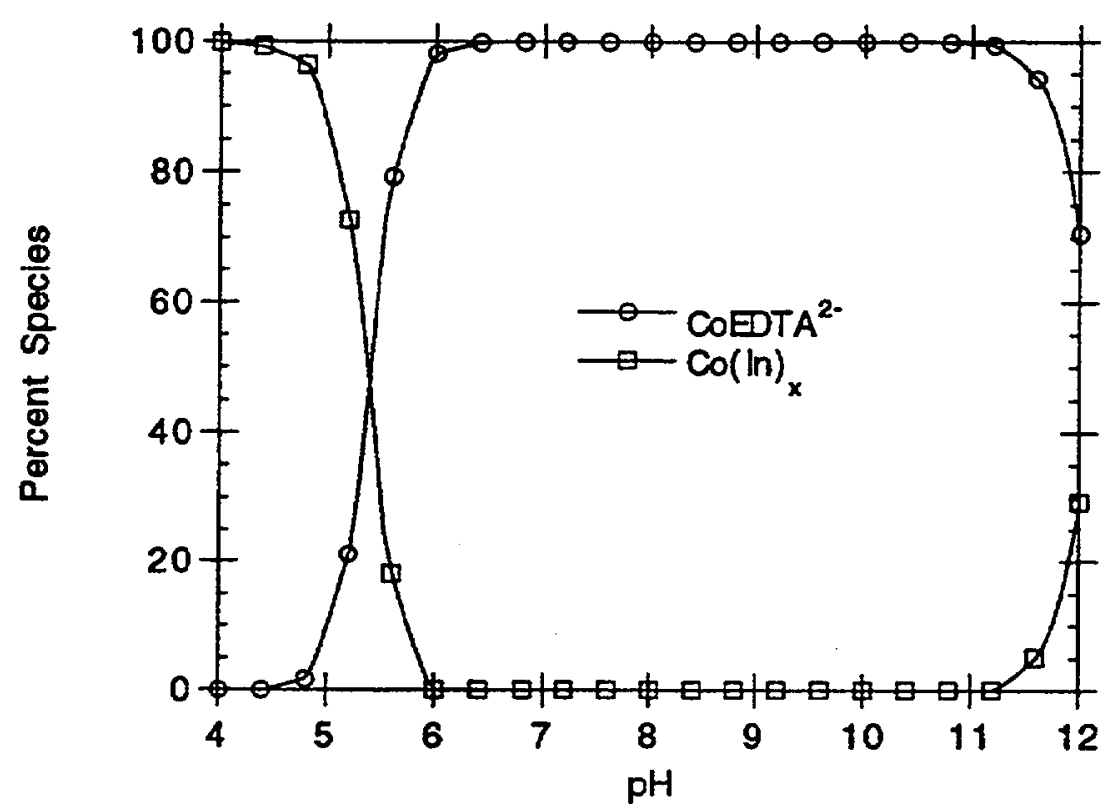

Figure 4.17. Speciation Distribution for Cobalt in Millstone (CAN-DECON) Leachate 


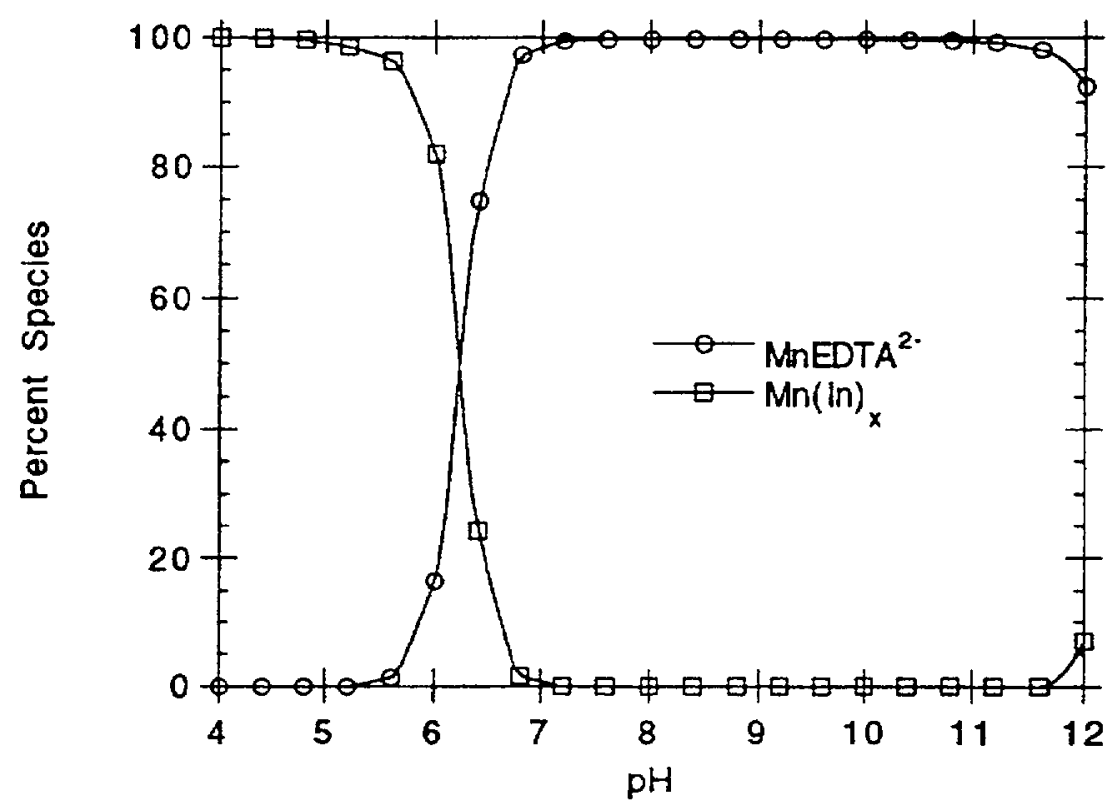

Figure 4.18. Speciation Distribution for Manganese in Millstone (CAN-DECON) Leachate

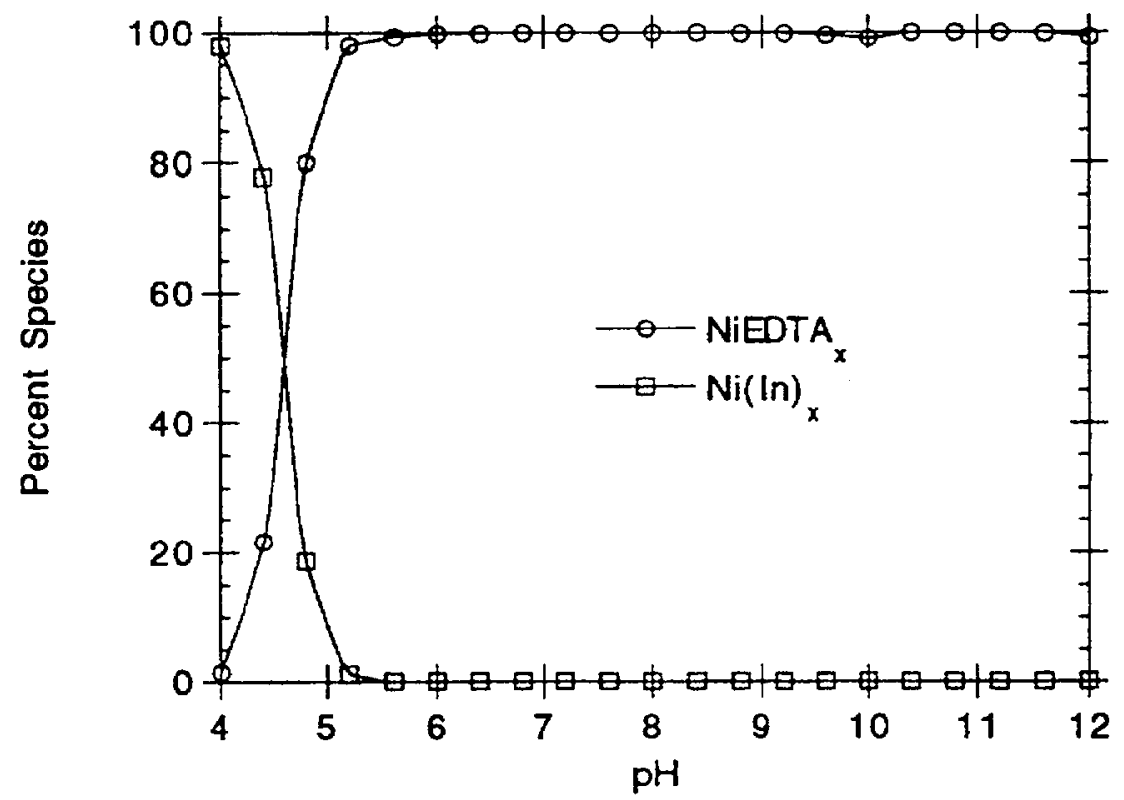

Figure 4.19. Speciation Distribution for Nickel in Millstone (CAN-DECON) Leachate 


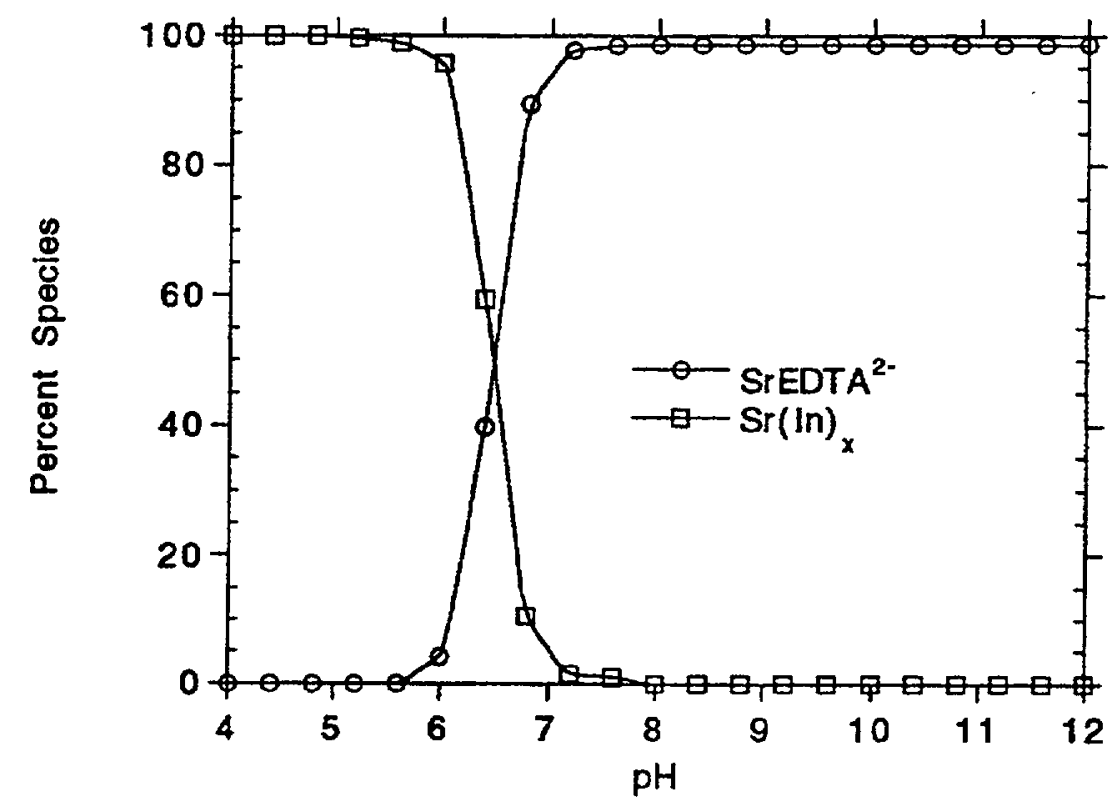

Figure 4.20. Speciation Distribution for Strontium in Millstone (CAN-DECON) Leachate

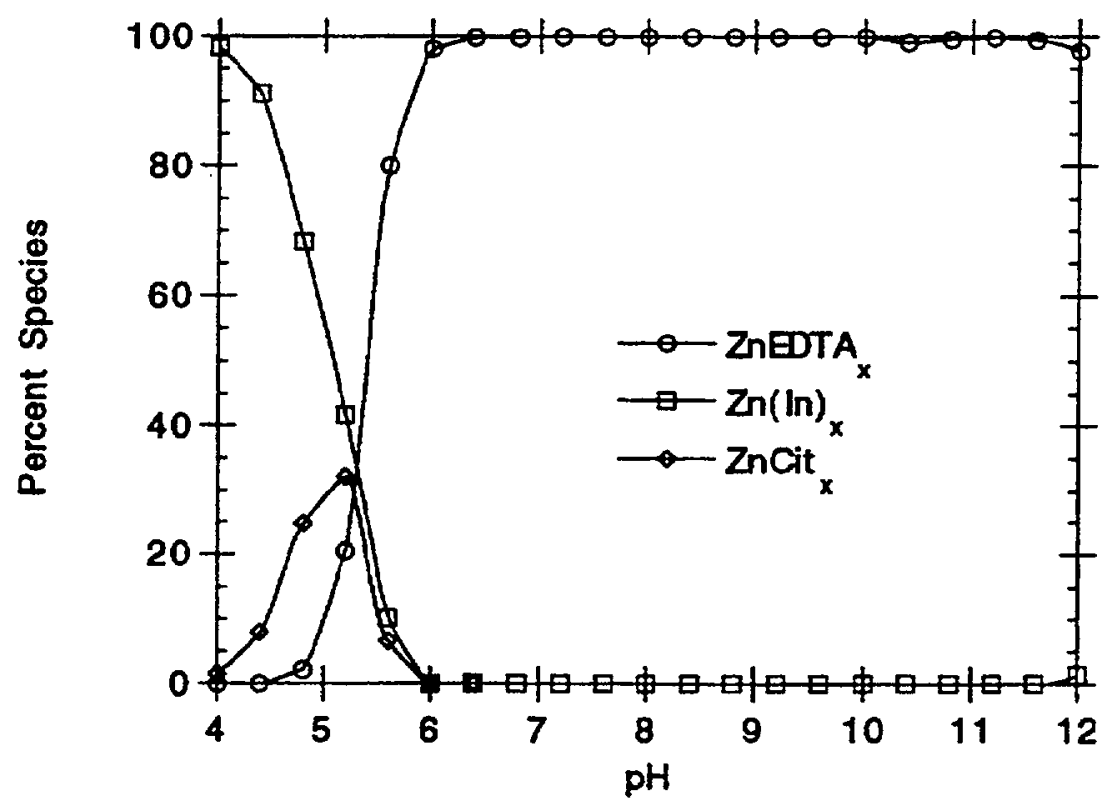

Figure 4.21. Speciation Distribution for Zinc in Millstone (CAN-DECON) Leachate 


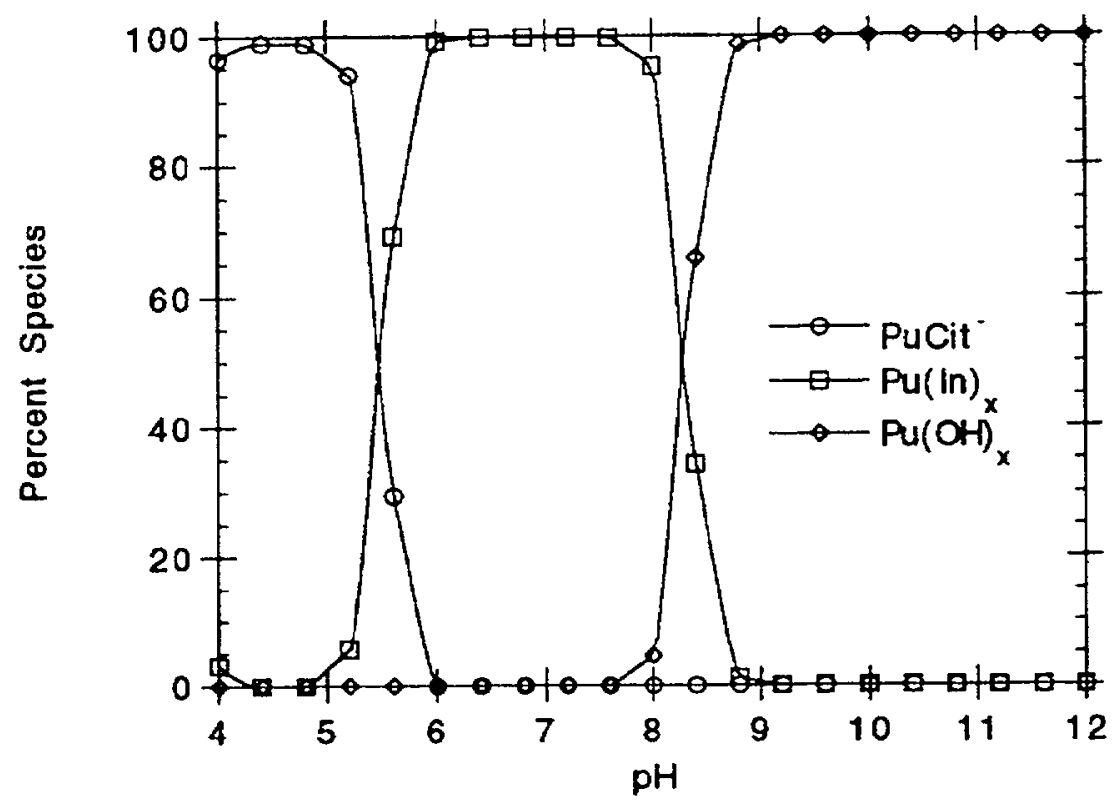

Figure 4.22. Speciation Distribution for Plutonium (IV) in Millstone (CAN-DECON) Leachate

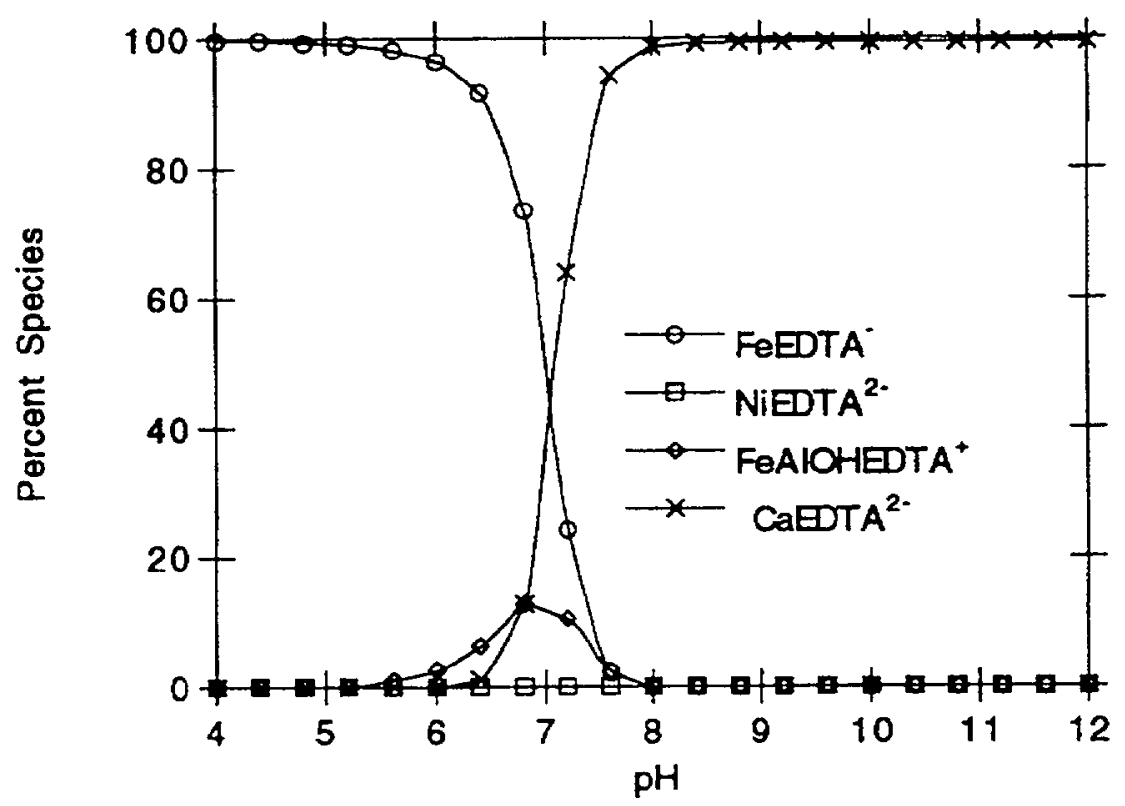

Figure 4.23. Speciation Distribution for EDTA in Millstone (CAN-DECON) Leachate 


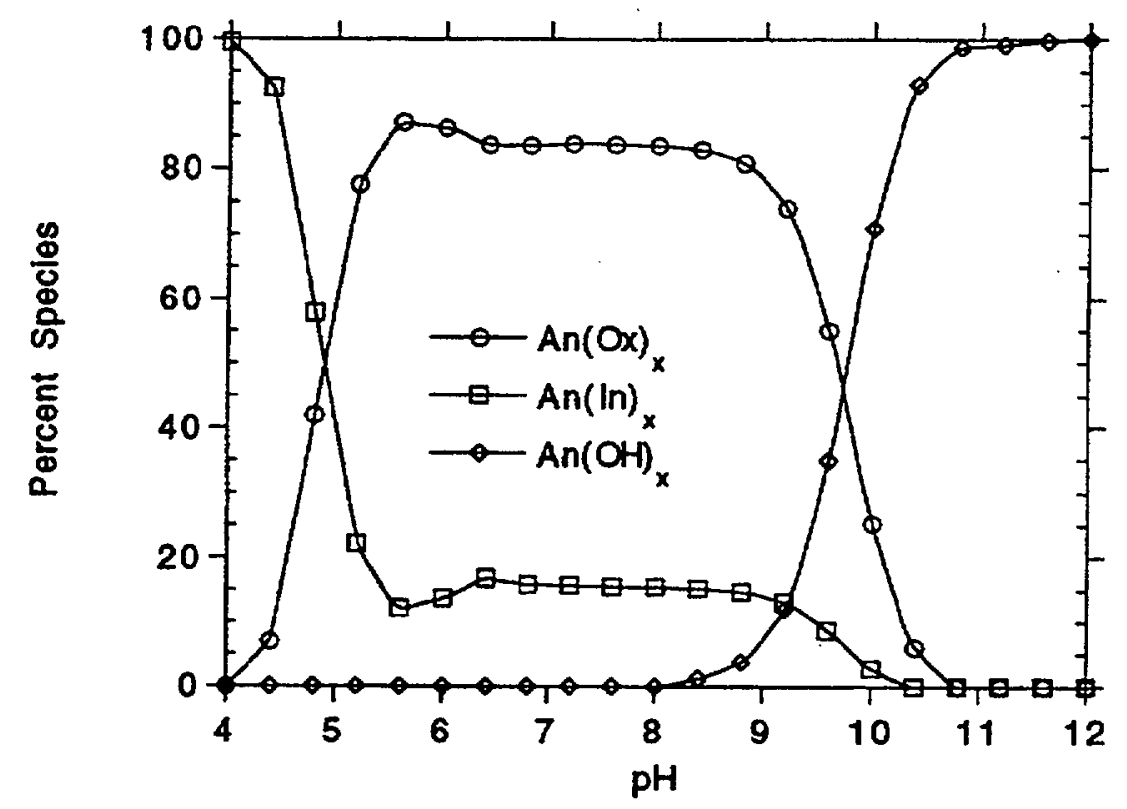

Figure 4.24. Speciation Distribution for Trivalent Actinides in Cooper (CITROX) Leachate

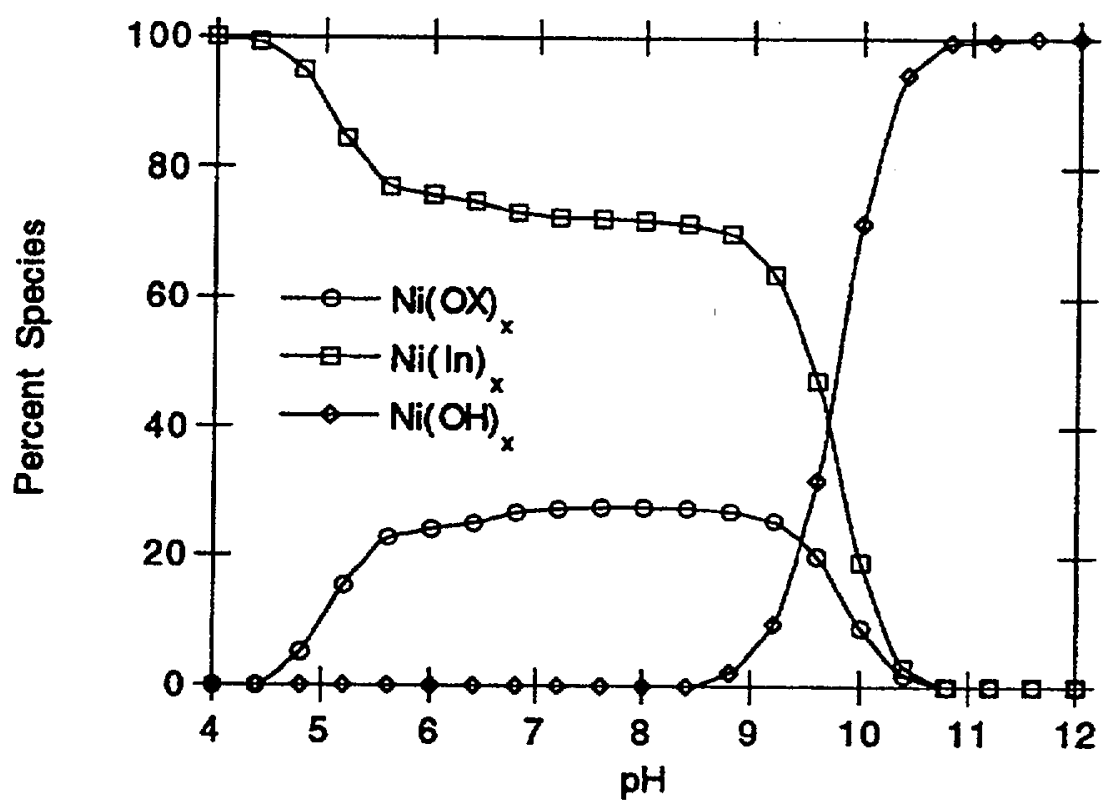

Figure 4.25. Speciation Distribution for Nickel in Cooper (CITROX) Leachate 


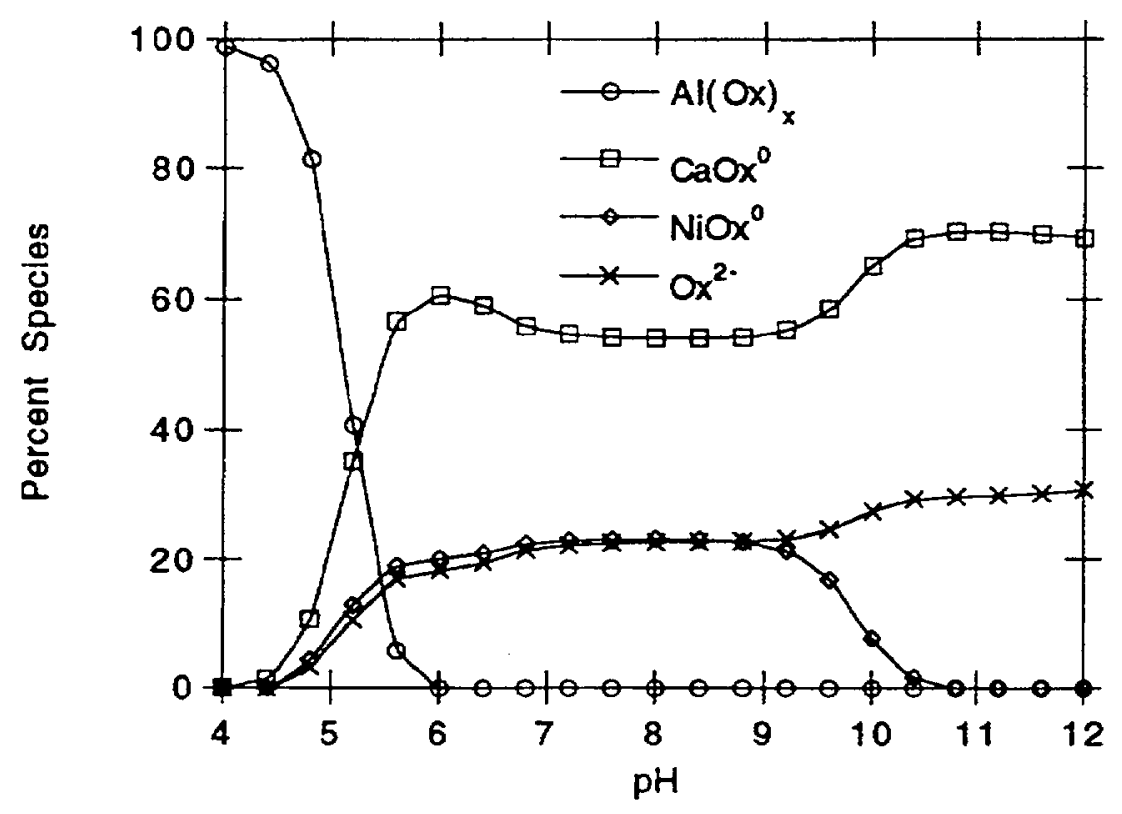

Figure 4.26. Speciation Distribution for Oxalic Acid in Cooper (CITROX) Leachate

dominant species with smaller contributions from $\mathrm{NiOx}{ }^{0}$ and free oxalate from $\mathrm{pH} 12$ to approximately $\mathrm{pH}$ 5. $\mathrm{AlOx}^{+}$is the dominant oxalate species below $\mathrm{pH} 5$.

The Brunswick leachates had significantly lower concentrations of oxalate than the Cooper leachates (despite the fact that both waste forms dissaggregated into small pieces during leaching) and except for the trivalent actinides very little organic complexation occurred in the Brunswick leachates (Figure 4.27). Chelates with oxalate formed nearly $60 \%$ of the $\mathrm{Am}^{3+}$ and $\mathrm{Pu}^{3+}$ species in the Brunswick leachates and citrate complexes were significant from $\mathrm{pH} 9$ to 10 .

The results of the equilibrium speciation calculations conducted in this section indicate that for many radionuclides and stable metals, the degree of complex formation with organic chelating/ complexing agents in waste form leachates is significant. In many cases, they are the dominant species. Equilibration with portlandite results in leachates with very high $\mathrm{pH}$ values. The resulting high concentrations of $\mathrm{OH}^{-}$ can, in many cases, effectively compete with the organic ligands and increase the tendency of the radionuclides/metals to precipitate. Note that anion exchange resins are frequently regenerated using $\mathrm{NaOH}$ solutions. In effect cement leachate may be acting as a regenerant, causing the release of anionic complexes and free anionic ligands from the spent resins. The results indicate that chelating/complexing agents could play a significant role in mobilizing radionuclides co-disposed with these agents in low-level waste sites, especially at $\mathrm{pH}$ values below 10 . 


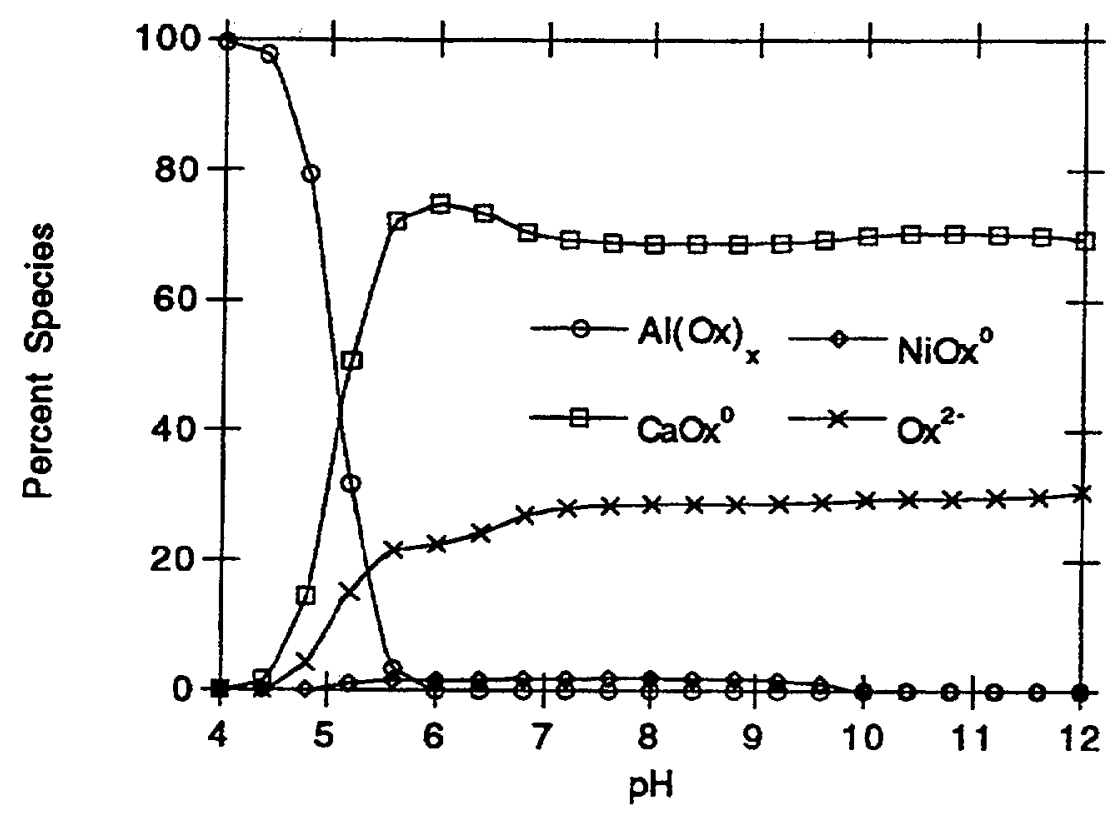

Figure 4.27. Speciation Distribution for Oxalic Acid in Brunswick (CITROX) Leachate

\subsection{Speciation of Non-Solidified Decontamination Waste Leachate}

Table 4.4 shows the calculated speciation distribution for radionuclides and metals of interest. The distribution is presented in terms of the two major EDTA complexes and the total of the free or inorganic complexes. If the metal was not measured above the detection limit (see Table 3.3), the radionuclide or metal was taken to have a concentration of $1.0 \times 10^{-10} \mathrm{M}$ for purposes of the speciation calculations, as was done for previous speciation calculations for cement leachates. Effectively we assumed Am, Cs, $\mathrm{Pu}^{3+}$, and $\mathrm{Pu}^{4+}$ were present in the leachates at $10^{-10} \mathrm{M}$ and all others were present at concentrations shown in Table 3.3.

From the results presented in Table 4.4, it is apparent that EDTA dominates the speciation scheme of $\mathrm{Am}^{3+}, \mathrm{Co}^{2+}, \mathrm{Fe}^{3+}, \mathrm{Ni}^{2+}, \mathrm{Pu}^{3+}$, and $\mathrm{Cr}^{3+}$. Note that $1.4 \times 10^{-5}$ moles/liter (13\%) of $\mathrm{Cr}^{3+}$ was calculated to precipitate as $\mathrm{Cr}(\mathrm{OH})_{3}(\mathrm{am})$. EDTA accounts for fractional speciation of $\mathrm{Mn}^{2+}$ and $\mathrm{Zn}^{2+}$ (7\% and 23\%, respectively). $\mathrm{Cs}^{+}, \mathrm{Pu}^{4+}$, and $\mathrm{Sr}^{2+}$ remain uncomplexed by EDTA under these conditions. Based on the results of Table 4.4 it is apparent that an excess of metals relative to EDTA occurs in the leachate solution. As a result, complexation by EDTA will preferentially occur with the metals that have the largest equilibrium stability constants. For example, the three transition metals that occur in the leachate at relatively high concentration $\left(\mathrm{Cr}^{3+}, \mathrm{Ni}^{2+}\right.$, and $\left.\mathrm{Mn}^{2+}\right)$ have EDTA stability constants $(\log \mathrm{K})$ of $35.7,20.3$, and 15.8 , respectively. Both dissolved $\mathrm{Cr}^{3+}$ and $\mathrm{Ni}^{2+}$ are essentially completely complexed by EDTA, but only a small percentage of $\mathrm{Mn}^{2+}$ is complexed by EDTA. This is because the dissolved $\mathrm{Cr}^{3+}$ and $\mathrm{Ni}^{2+}$ bind $2.28 \times 10^{-4}$ moles/liter of EDTA, leaving only $1.6 \times 10^{-5}$ moles/liter EDTA left to bind with $\mathrm{Mn}^{2+}$ and other metals present at very low concentrations $\left(<10^{-6} \mathrm{M}\right)$. 


\begin{tabular}{|c|c|c|c|}
\hline \multicolumn{3}{|c|}{$\begin{array}{c}\text { Table 4.4. Speciation Distribution of Dissolved Radionuclides and Metals } \\
\text { Calculated for Non-Solidified Decontamination }\end{array}$} \\
\hline $\begin{array}{c}\text { Radionuclide or } \\
\text { Metal }\end{array}$ & \% M-EDTA & $\begin{array}{c}\text { \% M(OH)- } \\
\text { EDTA }\end{array}$ & $\begin{array}{c}\text { \% Free or Inorganic } \\
\text { Complexes }\end{array}$ \\
\hline $\mathrm{Am}^{3+}$ & 100 & 0 & 0 \\
\hline $\mathrm{Cs}^{+}$ & 0 & 0 & 100 \\
\hline $\mathrm{Co}^{2+}$ & 93.1 & 0 & 6.9 \\
\hline $\mathrm{Fe}^{3+}$ & 16.1 & 83.2 & 0.7 \\
\hline $\mathrm{Mn}^{2+}$ & 6.6 & 0 & 03.4 \\
\hline $\mathrm{Ni}^{2+}$ & 100 & 0 & 0 \\
\hline $\mathrm{Pu}^{3+}$ & 100 & 0 & 100 \\
\hline $\mathrm{Pu}^{4+}$ & 0 & 0 & 100 \\
\hline $\mathrm{Sr}^{2+}$ & 0 & 0 & 77.2 \\
\hline $\mathrm{Zn}^{2+}$ & 22.8 & 0 & 0 \\
\hline $\mathrm{Cr}^{3+}$ & 37.4 & 62.6 & 0 \\
\hline
\end{tabular}

\subsection{Speciation of $\mathrm{pH}$ Adjusted Non-Solidified Decontamination Waste Leachate}

Speciation distribution plots for $\mathrm{Cr}^{3+}, \mathrm{Am}^{3+}, \mathrm{Co}^{2+}, \mathrm{Mn}^{2+}, \mathrm{Ni}^{2+}, \mathrm{Zn}^{2+}$ and EDTA are presented in Figures 4.28 through 4.34. In Figure 4.28, the speciation distribution of $\mathrm{Cr}^{3+}$ is shown. At low pH Cr-EDTA- dominates. As the $\mathrm{pH}$ increases, $\mathrm{Cr}(\mathrm{OH}) \mathrm{EDTA}^{2-}$ becomes increasingly important and peaks at about 7.5. At $\mathrm{pH} 7 \mathrm{Cr}(\mathrm{OH})_{3}(\mathrm{am})$ begins to precipitate. As this precipitation occurs, EDTA is released and becomes available to complex other metals.

$\mathrm{Am}^{3+}$ speciation is shown in Figure 4.29 and is dominated by the Am-EDTA-species for the entire $\mathrm{pH}$ range. Carbonate complexes make a small contribution to the speciation of scheme of $\mathrm{Am}^{3+}$ at $\mathrm{pH} 7$ and 10.

The speciation scheme of $\mathrm{Co}^{2+}$ is illustrated in Figure 4.30. At pH $6 \mathrm{Co}^{2+}$ occurs mostly as the free ion while about $42 \%$ occurs as the Co-EDTA ${ }^{2-}$ complex. As the $\mathrm{pH}$ increases the Co-EDTA ${ }^{2-}$ complex becomes increasingly dominant. At $\mathrm{pH}$ values above 6.5 the Co-EDTA ${ }^{2-}$ complex is the dominant species. Above $\mathrm{pH} 9.5, \mathrm{COOH}^{+}$makes a minor contribution to the speciation scheme. 


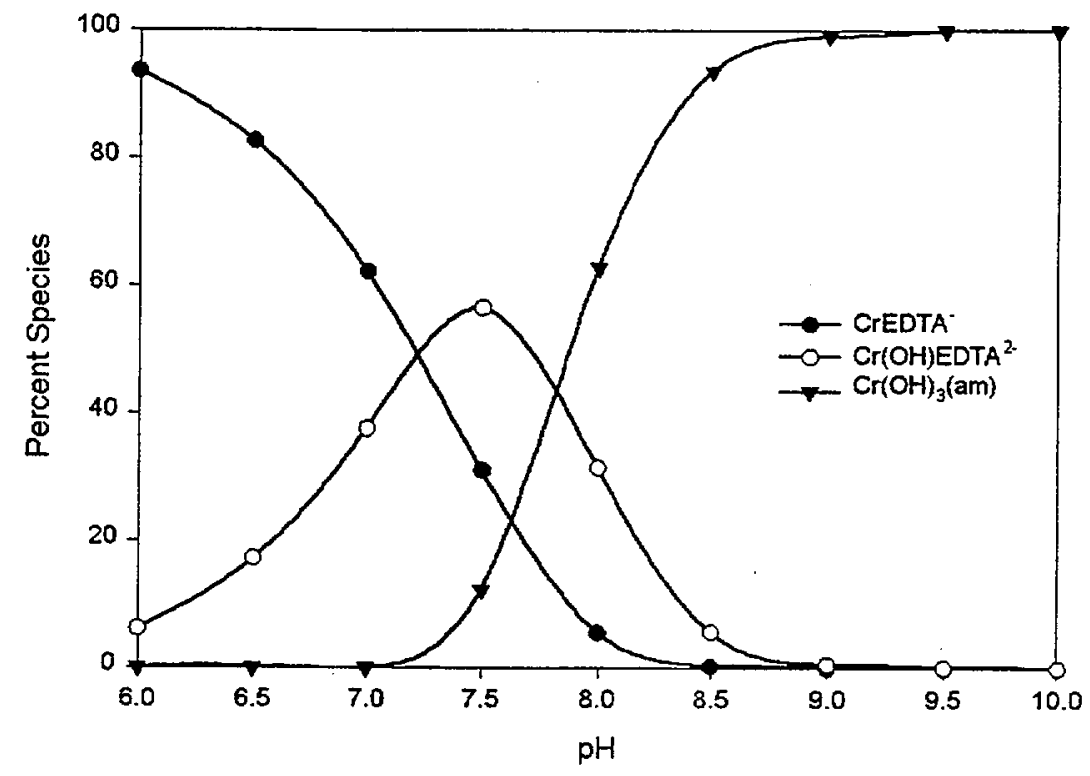

Figure 4.28. Speciation Distribution for $\mathrm{Cr}^{3+}$ in Non-Solidified Leachate

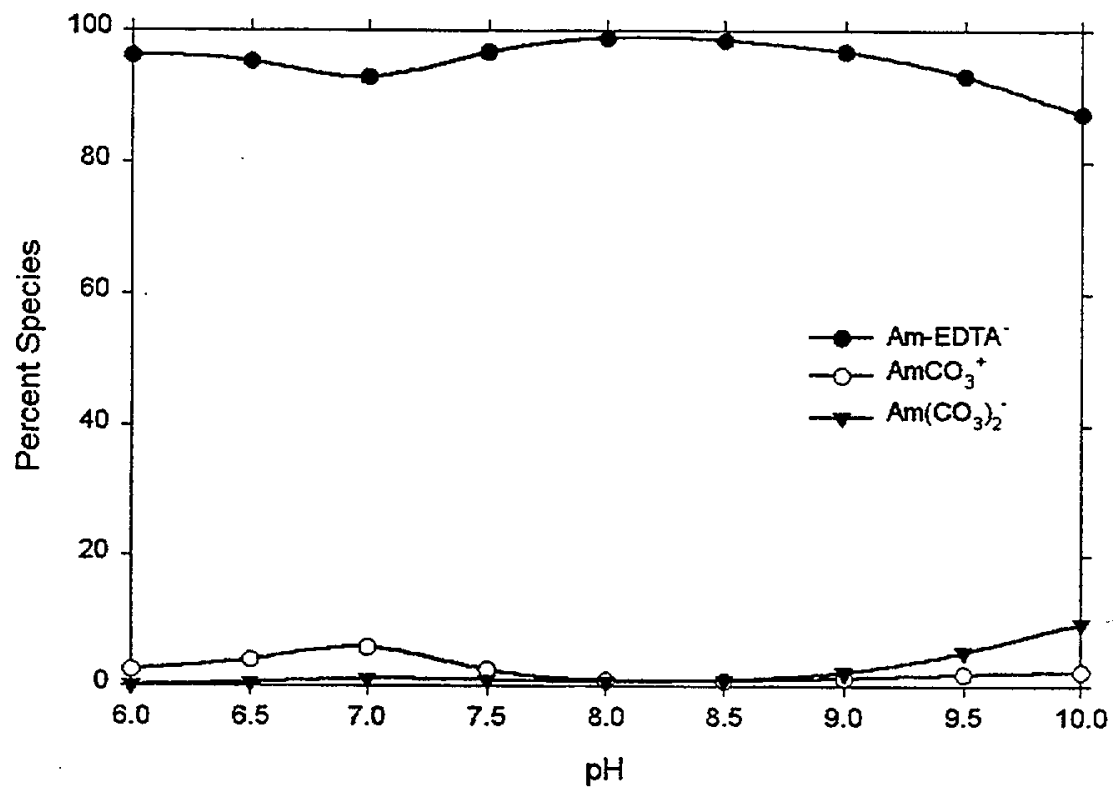

Figure 4.29. Speciation Distribution for $\mathrm{Am}^{3+}$ in Non-Solidified Leachate 


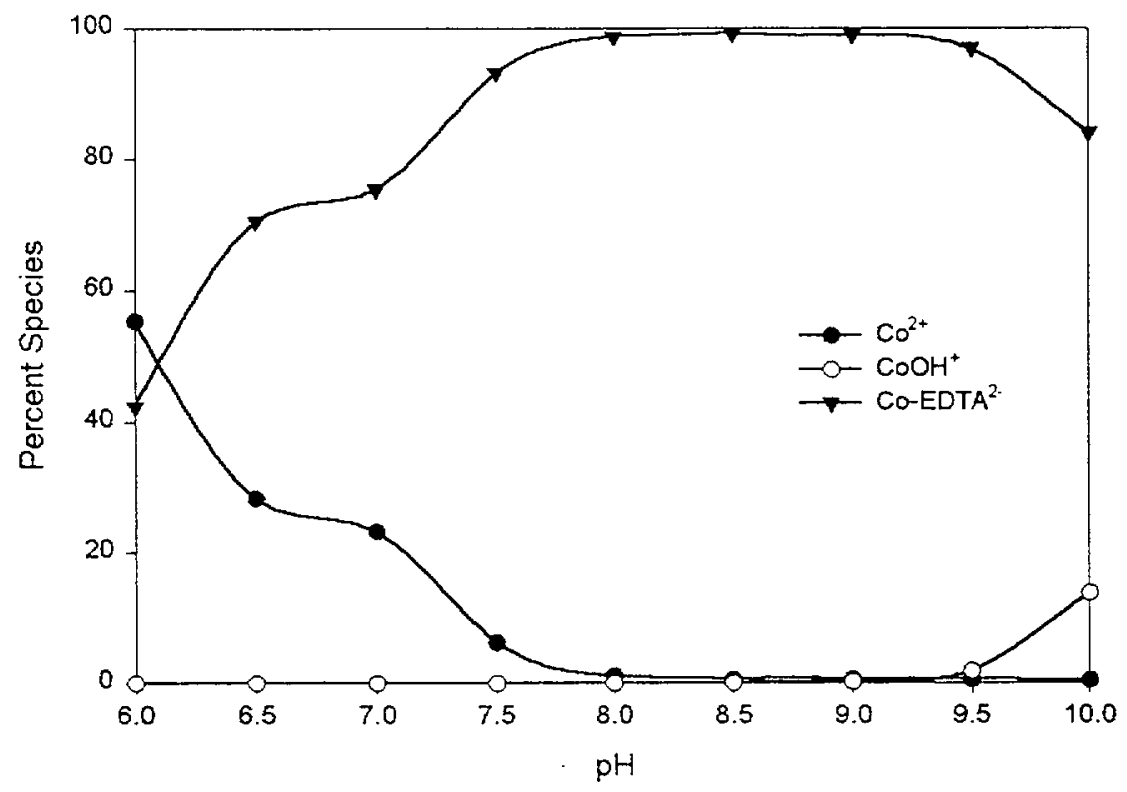

Figure 4.30. Speciation Distribution for $\mathrm{Co}^{2+}$ in Non-Solidified Leachate

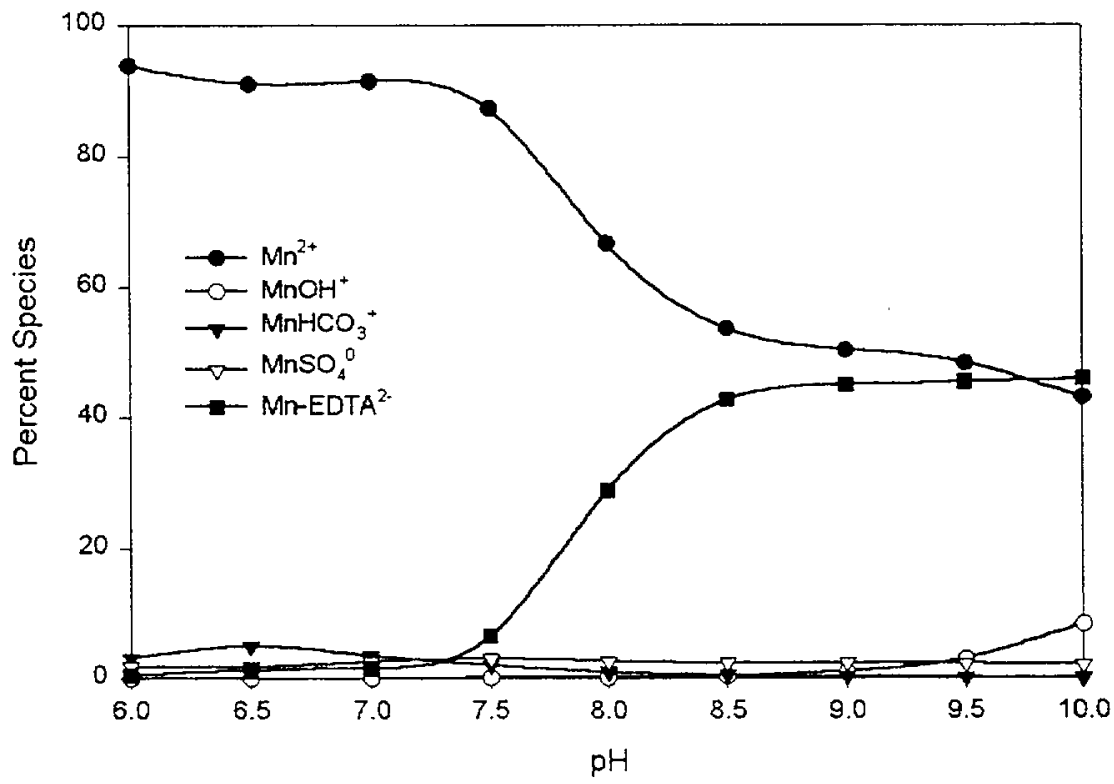

Figure 4.31. Speciation Distribution for $\mathrm{Mn}^{2+}$ in Non-Solidified Leachate 


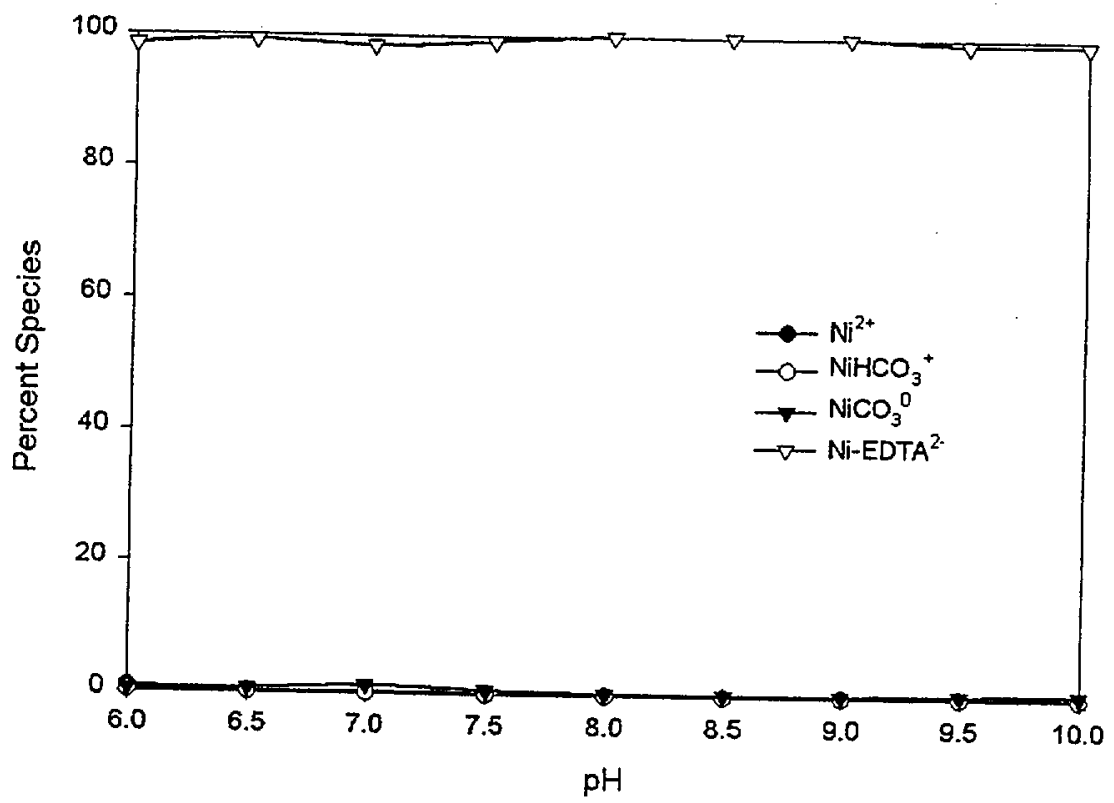

Figure 4.32. Speciation Distribution for $\mathrm{Ni}^{2+}$ in Non-Solidified Leachate

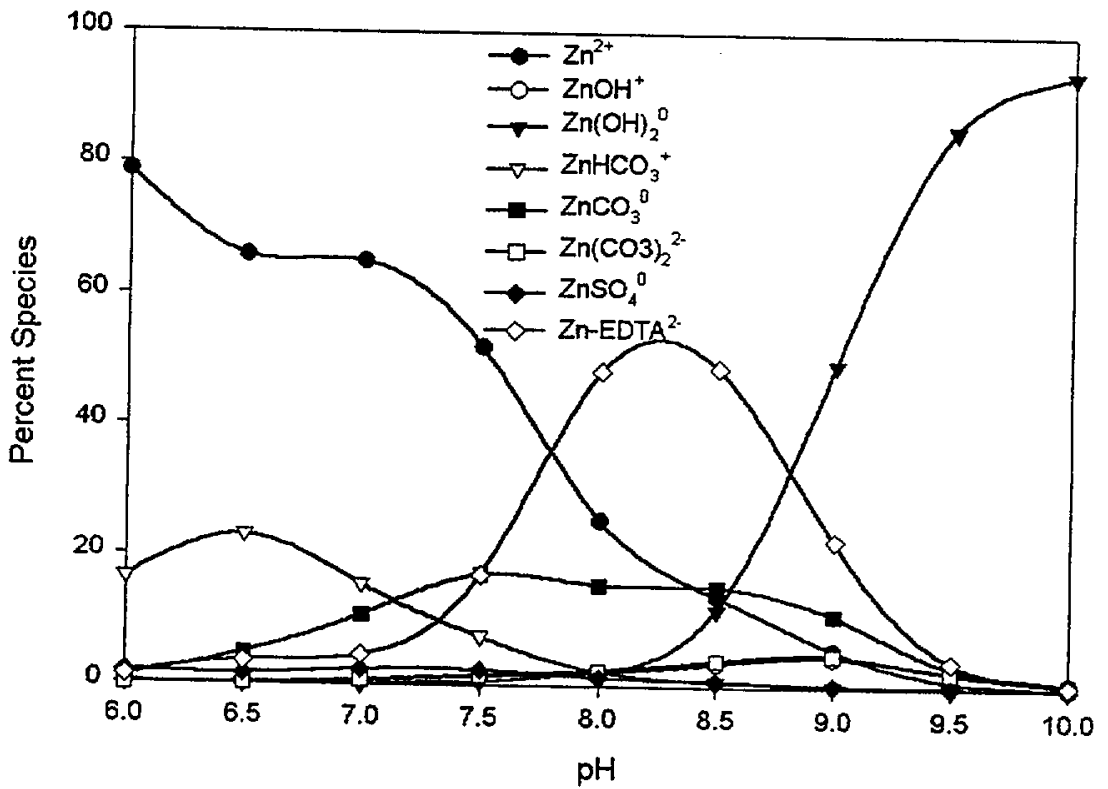

Figure 4.33. Speciation Distribution for $\mathrm{Zn}^{2+}$ in Non-Solidified Leachate 


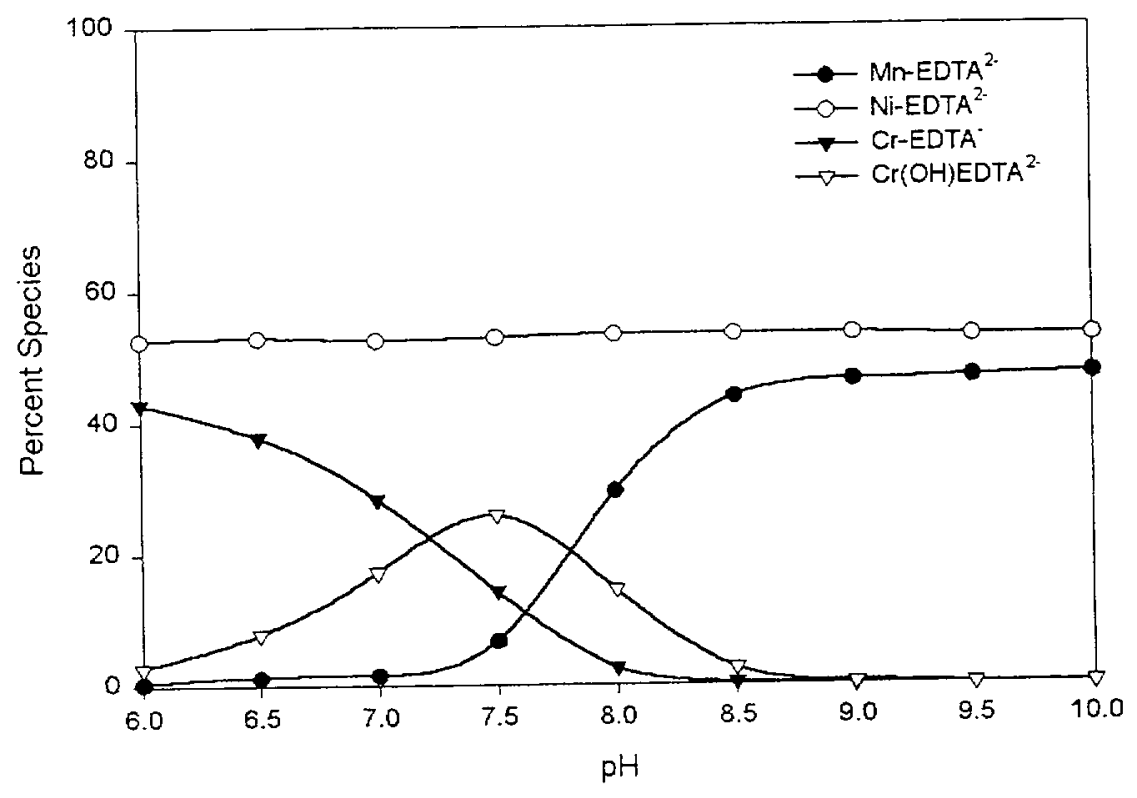

Figure 4.34. Speciation Distribution for EDTA in Non-Solidified Leachate

The distribution of $\mathrm{Mn}^{2+}$ species is exhibited in Figure 4.31. At $\mathrm{pH}$ values below 7.5 the free $\mathrm{Mn}^{2+}$ ion is the dominant species. As the $\mathrm{pH}$ increases, complexation by EDTA increases. At $\mathrm{pH}$ values above 8.5 about $45 \%$ of the $\mathrm{Mn}^{2+}$ is complexed by EDTA. This increase in the complexation of $\mathrm{Mn}^{2+}$ by EDTA with $\mathrm{pH}$ is due to release of EDTA complexed with $\mathrm{Cr}^{3+}$ as $\mathrm{Cr}(\mathrm{OH})_{3}(\mathrm{am})$ begins to precipitate. Minor amounts of various inorganic complexes with $\mathrm{Mn}^{2+}$ also occur.

Speciation of $\mathrm{Ni}^{2+}$ is shown in Figure 4.32 and is dominated by the $\mathrm{Ni}-\mathrm{EDTA}^{2-}$ complex at all $\mathrm{pH}$ values. $\mathrm{Zn}^{2+}$ speciation is presented in Figure 4.33. At the lower $\mathrm{pH}$ values $\mathrm{Zn}^{2+}$ occurs mostly as the free ion. A significant contribution to the speciation scheme of $\mathrm{Zn}^{2+}$ by the $\mathrm{Zn}-\mathrm{EDTA}{ }^{2-}$ complex occurs in the $\mathrm{pH}$ range of about 7.5 to 9 . Above $\mathrm{pH} 9 \mathrm{Zn}(\mathrm{OH})_{2}{ }^{0}$ becomes increasingly dominant. Minor contributions to the speciation scheme also occur below $\mathrm{pH} 9.5$ from various inorganic species.

The speciation distribution of EDTA is shown in Figure 4.34. The Ni-EDTA ${ }^{2-}$ complex makes up about $53 \%$ of the EDTA speciation throughout the $\mathrm{pH}$ range of interest. At pH 6 the Cr-EDTA complex makes up about $43 \%$ of the EDTA species. As the pH increases to 7.5, the Cr-EDTA complex is partially converted to the $\mathrm{Cr}(\mathrm{OH}) \mathrm{EDTA}^{2-}$ complex. Above this $\mathrm{pH} \mathrm{Cr}(\mathrm{OH})_{3}(\mathrm{am})$ begins to precipitate and $\mathrm{Mn}-\mathrm{EDTA}^{2-}$ replaces the $\mathrm{Cr}-\mathrm{EDTA}^{-}$and $\mathrm{Cr}(\mathrm{OH}) \mathrm{EDTA}^{2-}$ complexes.

The speciation of $\mathrm{Pu}^{3+}$ (not shown) is the same as that for $\mathrm{Am}^{3+} \cdot \mathrm{Cs}^{+}$and $\mathrm{Sr}^{2+}$ are uncomplexed throughout the $\mathrm{pH}$ range of 6 to 10 . $\mathrm{Fe}^{3+}$ remains precipitated as amorphous iron hydroxide, $\mathrm{Al}^{3+}$ remains precipitated as gibbsite, and $\mathrm{Pu}^{4+}$ is precipitated as $\mathrm{Pu}(\mathrm{OH})_{2} \mathrm{CO}_{3}(\mathrm{~s})$, throughout the $\mathrm{pH}$ range of 6 to 10 . 


\subsection{Adsorption Results and Discussion}

\subsection{Batch Adsorption Experiments}

\subsubsection{Ni-Picolinate System}

Nickel adsorption onto iron oxide coated sand as a function of $\mathrm{pH}$ in the absence of any complexing ligand is shown in Figure 5.1. The figure shows the typical cationic adsorption behavior expected for nickel (e.g., Bryce et al. 1994; Coughlin and Stone 1995; Dzombak and Morel 1989). Cationic type behavior on variable charged surfaces such as hydrous ferric oxides (HFO) arises from the amphoteric nature of the hydroxyl groups associated with the surface (e.g., $=\mathrm{FeOH},=\mathrm{FeO}^{-},=\mathrm{FeOH}_{2}^{+}$). As the $\mathrm{pH}$ of the solution in contact with the surface decreases, the hydronium ion $\left(\mathrm{H}_{3} \mathrm{O}^{+}\right.$, simplified as $\left.\mathrm{H}^{+}\right)$concentration increases. This increase in hydronium ion results in protonation of these surface sites and an increase in the net positive charge on the oxide surface. As the $\mathrm{pH}$ increases these same sites become increasingly deprotonated resulting in a net negative charge on the surface. As a result of this phenomenon, typical adsorption behavior for free cations exhibits near zero adsorption at low $\mathrm{pH}$, followed by an increase in adsorption with $\mathrm{pH}$ to nearly $100 \%$ within a relatively narrow $\mathrm{pH}$ range. The $\mathrm{pH}$ range where this "adsorption edge" occurs depends on the affinity between the metal ion and the surface of interest. For a free anion, the behavior is nearly the opposite, with nearly $100 \%$ adsorption occurring at low pH and adsorption dropping off with increasing $\mathrm{pH}$ as the number of available positive surface sites decreases.

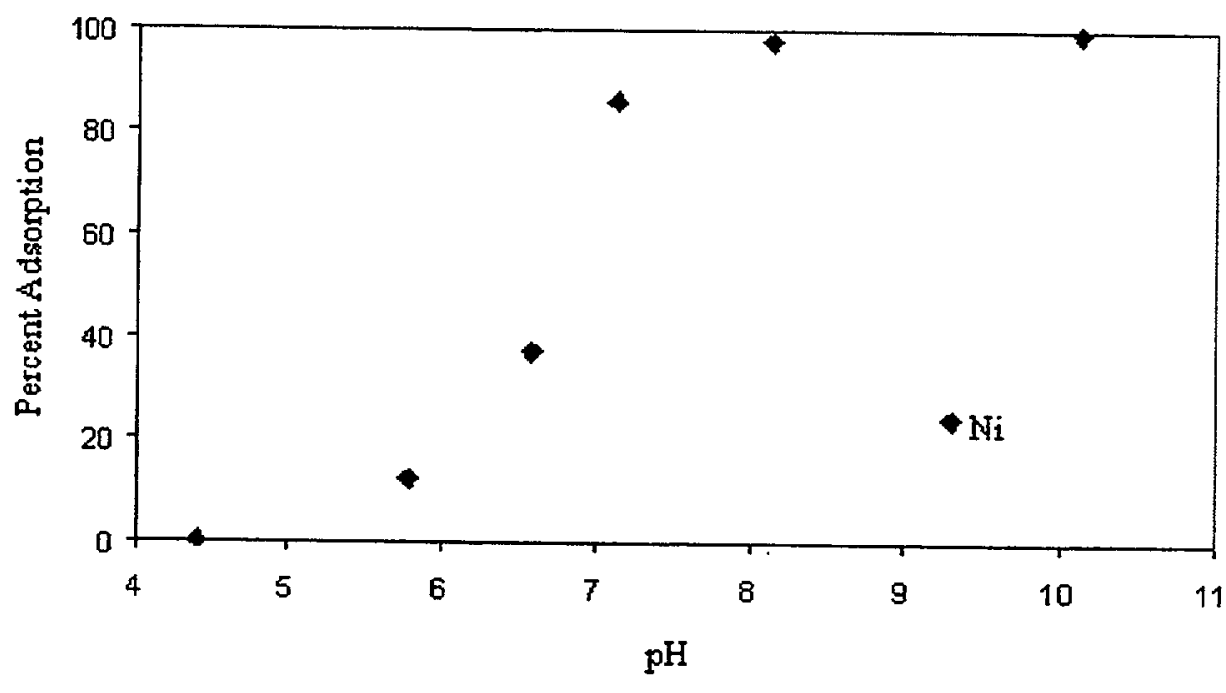

Figure 5.1. Percent Adsorption of $\mathrm{Ni}^{2+}$ on $1.2 \%$ Iron Oxide Coated Sand as a Function of pH $\left(0.5 \mathrm{~g}\right.$ soil $/ 30 \mathrm{ml}, 0.003$ molar $\mathrm{Ca}\left[\mathrm{ClO}_{4}\right]_{2}$ solution, with an initial $\mathrm{Ni}^{2+}$ concentration of $10^{-5} \mathrm{M}$ ) 
Figure 5.2 illustrates the affect of addition of picolinate at a concentration of $10^{-3} \mathrm{M}$ to the adsorption behavior of $\mathrm{Ni}$ present at $10^{-5} \mathrm{M}$. Adsorption of both nickel and picolinate are illustrated. Essentially no nickel adsorption is observed and very little if any picolinate is adsorbed. These results indicate that the quantity of picolinate in solution greatly exceeded the adsorption capacity of the iron oxide coated sand. For example, the maximum adsorption capacity of hydrous ferric oxide for EDTA at pH 4.5 was determined to be $0.0049 \mathrm{~mol} / \mathrm{mol}$ of $\mathrm{Fe}$ (Szescody et al. 1994). For the experiment illustrated in Figure 5.2, this would equate to a maximum adsorption capacity for picolinate of $1.0 \times 10^{-6}$ moles (assuming two moles of picolinate could adsorb for every mole of EDTA that could be adsorbed). The total quantity of picolinate in the experiment was $3.0 \times 10^{-5}$ moles $\left[10^{-3} \mathrm{M} \cdot 0.03\right.$ liters], indicating that a maximum of about $3 \%$ of the picolinate $\left[10^{-6} \div 3 \times 10^{-5}\right]$ could have been adsorbed. The combination of high stability constants for nickel picolinate complexes and high concentration of picolinate resulted in essentially complete complexation of the nickel, preventing adsorption of free nickel. For the conditions of this experiment the dominant nickel species are $\mathrm{NiL}_{2}{ }^{0}$ and $\mathrm{NiL}_{3}$, where $\mathrm{L}$ - represents the negatively charged picolinate ion. Because the high concentration of picolinate overwhelmed the adsorption capacity of the iron oxide sand, adsorption of the nickel picolinate complexes was also prevented.

When the concentration of picolinate is reduced by an order of magnitude, typical anionic adsorption behavior was observed (Figure 5.3). In this case, the greatest degree of picolinate adsorption was observed at the lowest $\mathrm{pH}$ values. This is consistent with the concentration of positive surface sites increasing with decreasing $\mathrm{pH}$. The concentration of picolinate is still high enough to cause the nickel to remain predominately in the form of nickel picolinate complexes and prevent the adsorption of nickel.

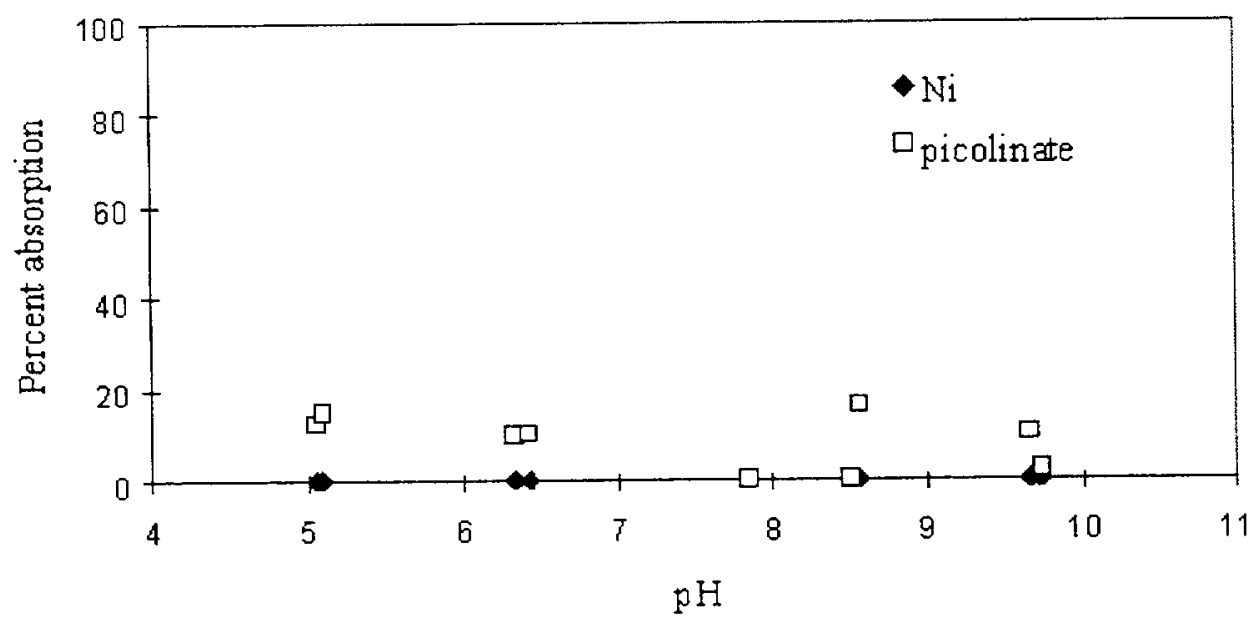

Figure 5.2. Percent Adsorption of $\mathrm{Ni}^{2+}$ and Picolinate on 1.2\% Iron Oxide Coated Sand as a Function of $\mathrm{pH}\left(0.5 \mathrm{~g}\right.$ soil $/ 30 \mathrm{ml}, 0.003$ molar $\mathrm{Ca}\left[\mathrm{ClO}_{4}\right]_{2}$ solution, with initial concentrations of $\mathrm{Ni}^{2+}$ and picolinate of $10^{-5} \mathrm{M}$ and $10^{-3} \mathrm{M}$, respectively) 


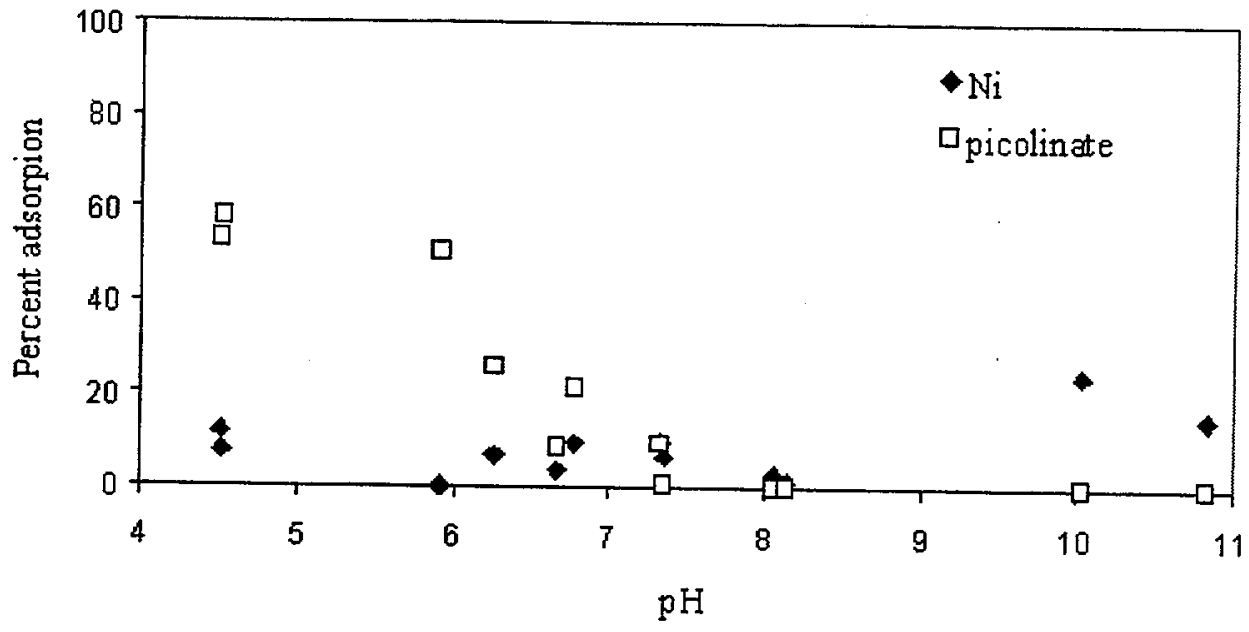

Figure 5.3. Percent Adsorption of $\mathrm{Ni}^{2+}$ and Picolinate on $1.2 \%$ Iron Oxide Coated Sand as a Function of $\mathrm{pH}\left(0.5 \mathrm{~g}\right.$ soil $/ 30 \mathrm{ml}, 0.003 \mathrm{molar} \mathrm{Ca}\left[\mathrm{ClO}_{4}\right]_{2}$ solution, with initial concentrations of $\mathrm{Ni}^{2+}$ and picolinate of $10^{-5} \mathrm{M}$ and $10^{-4} \mathrm{M}$, respectively)

When the concentration of picolinate is reduced by another order of magnitude [to $10^{-5} \mathrm{M}$ ], the situation changes again (Figure 5.4). In this case, picolinate illustrates the typical anionic adsorption behavior at low $\mathrm{pH}$ values, but additional adsorption is observed at higher $\mathrm{pH}$ values (unlike a typical anion). The nickel shows cationic adsorption behavior, but the adsorption is suppressed at $\mathrm{pH}$ values between 7 and 9 , relative to that observed in Figure 5.1. These observations are consistent with a moderate or low degree of complexation of nickel by picolinate and adsorption of nickel and possibly positively charged nickel picolinate complexes [ $\left.\mathrm{NiPic}^{+}\right]$. Also note that the adsorption of picolinate reaches a maximum at about $80 \%$ of the total picolinate present. The $\mathrm{pK}$ for picolinic acid is 5.4 , therefore, as the $\mathrm{pH}$ decreases to below 6 , increased absorption of picolinate is curtailed due to protonation. As a result, the percentage of adsorption for picolinate never goes above $80 \%$.

Three additional adsorption experiments were conducted with the nickel-picolinate system using Milford soil instead of the iron oxide coated sand. The highest and lowest concentrations of picolinate were used for these experiments $\left(10^{-3} \mathrm{M}\right.$ and $\left.10^{-5} \mathrm{M}\right)$. The results of these experiments are shown in Figures 5.5 and 5.6. Results illustrated in Figure 5.6, include two separate experiments conducted under identical conditions; the only difference being the method used for the nickel analysis. In the first case, the nickel and the picolinate were measured using the radioactive tracer technique that was used for most of the experiments conducted for this study. In the second case, the nickel was measured using inductively coupled plasma optical emission spectroscopy (ICP). An attempt was made to measure the picolinate concentrations using an organic carbon analyzer, but the concentrations were too low to provide reliable results. The nickel results obtained using the two methods are fairly consistent. The results and conclusions that can be drawn from these experiments are essentially the same as those determined with the iron oxide coated sand discussed previously. That is, at a concentration of $10^{-3} \mathrm{M}$ picolinate in the 


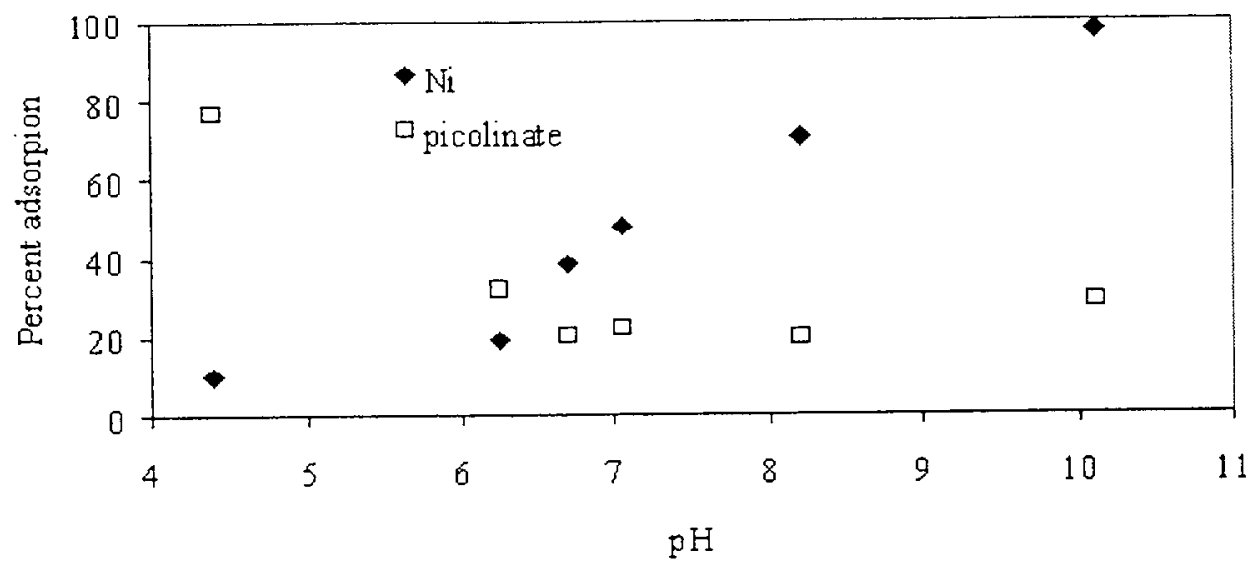

Figure 5.4. Percent Adsorption of $\mathrm{Ni}^{2+}$ and Picolinate on 1.2\% Iron Oxide Coated Sand as a Function of $\mathrm{pH}\left(0.5 \mathrm{~g}\right.$ soil/ $30 \mathrm{ml}, 0.003$ molar $\mathrm{Ca}\left[\mathrm{ClO}_{4}\right]_{2}$ solution, with initial concentrations of $\mathrm{Ni}^{2+}$ and picolinate of $10^{-5} \mathrm{M}$ and $10^{-5} \mathrm{M}$, respectively)

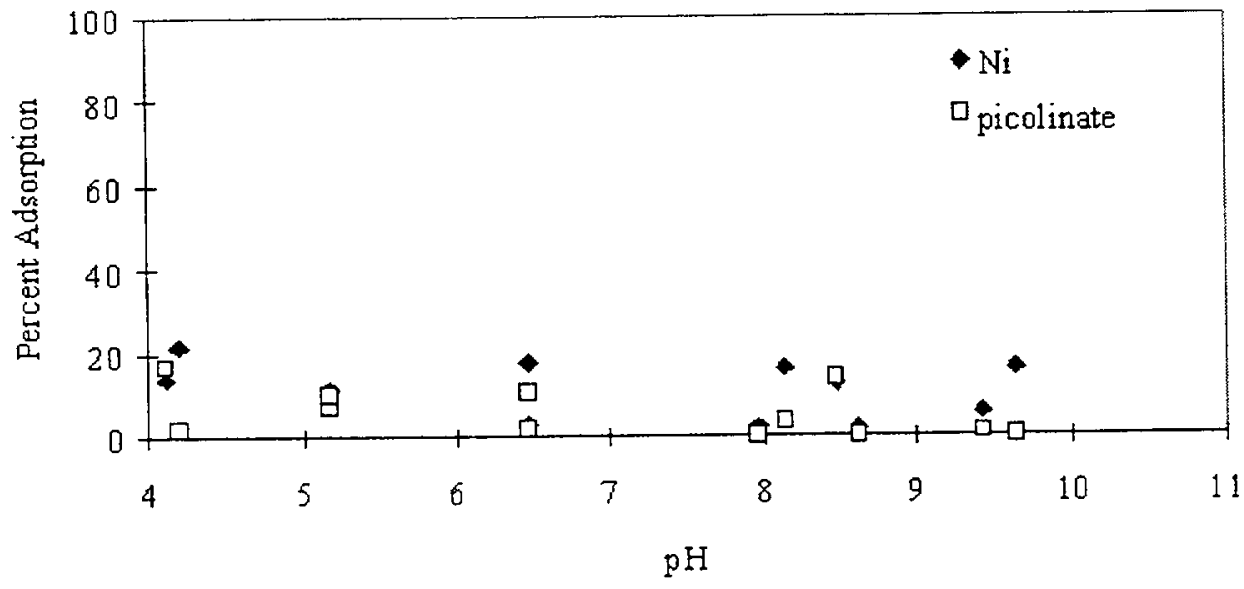

Figure 5.5. Percent Adsorption of $\mathrm{Ni}^{2+}$ and Picolinate on Milford Soil as a Function of $\mathbf{p H}$ $\left(0.5 \mathrm{~g}\right.$ soil $/ 30 \mathrm{ml}, 0.003$ molar $\mathrm{Ca}\left[\mathrm{ClO}_{4}\right]_{2}$ solution, with initial concentrations of $\mathrm{Ni}^{2+}$ and picolinate of $10^{-5} \mathrm{M}$ and $10^{-3} \mathrm{M}$, respectively) 


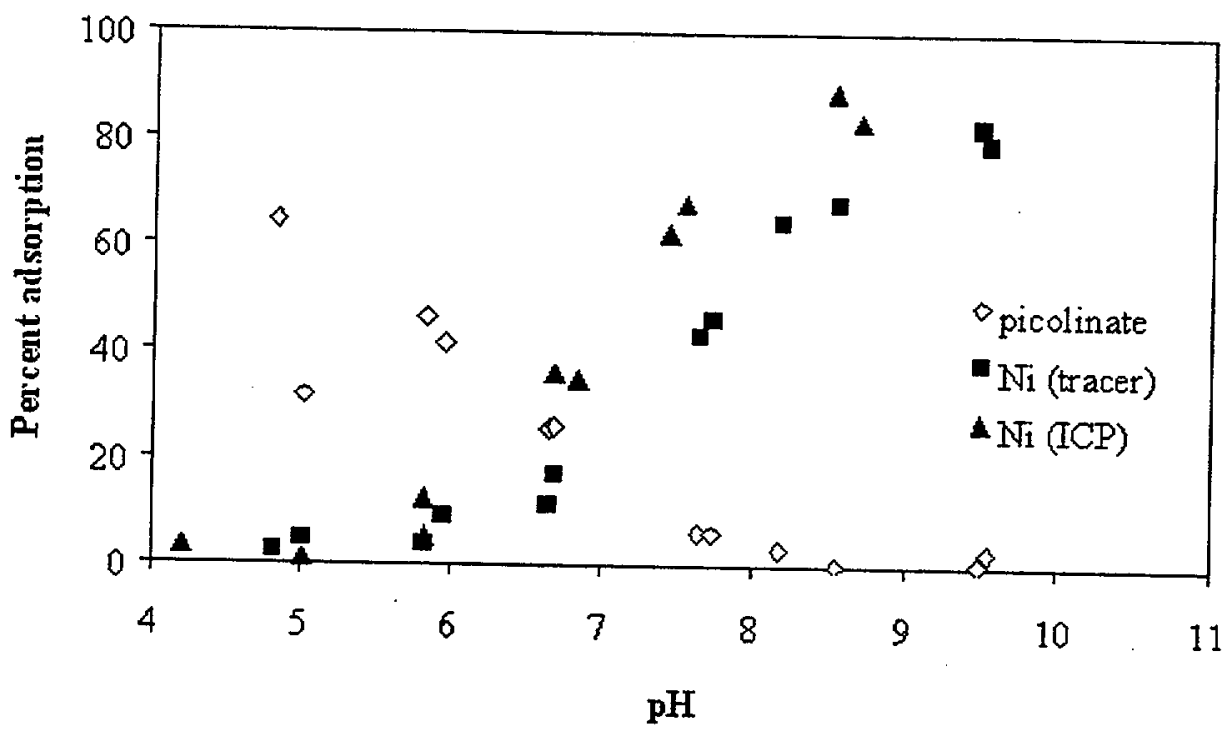

Figure 5.6. Percent Adsorption of $\mathrm{Ni}^{2+}$ (as measured by Ni-63 tracer and ICP methods) and Picolinate on Milford Soil as a Function of $\mathrm{pH}(0.5 \mathrm{~g}$ soil $/ 30 \mathrm{ml}, 0.003 \mathrm{molar}$ $\mathrm{Ca}\left[\mathrm{ClO}_{4}\right]_{2}$ solution, with initial concentrations of $\mathrm{Ni}^{2+}$ and picolinate of $10^{-5} \mathrm{M}$ and $10^{-5} \mathrm{M}$, respectively)

presence of $10^{-5} \mathrm{M}$ nickel, picolinate prevents $\mathrm{Ni}$ adsorption by forming anionic/neutrally charged complexes. The excess free picolinate anion overwhelms any available positively charged surface sites, resulting in relatively little free ligand adsorption. At $10^{-5} \mathrm{M}$ picolinate, nickel complexation is relatively insignificant and both nickel and picolinate adsorption behavior is analogous to their respective free
species.

\subsubsection{Ni-EDTA System}

The adsorption of nickel and EDTA onto iron oxide coated sand as a function of $\mathrm{pH}$ is shown in Figure 5.7. This experiment was conducted with equal initial concentrations of $10^{-5} \mathrm{M}$ for the metal and ligand. Both the nickel and the EDTA exhibit typical anionic adsorption behavior; the adsorption is strongest at low $\mathrm{pH}$ and drops off dramatically with increasing $\mathrm{pH}$. It is readily apparent that the nickel is strongly complexed with EDTA and that these anionic complexes are forming surface complexes on the iron oxide coated sand. These observations and the fact that this behavior occurs at a relatively low EDTA concentration of $10^{-5} \mathrm{M}$, illustrates the fact that EDTA forms much stronger complexes with nickel than does picolinate. Bryce et al. (1994) observed very similar behavior for the Ni-EDTA system.

Nickel and EDTA adsorption results for three different soils (Milford, LK-1, and MNC-7) are illustrated in Figures 5.8, 5.9, and 5.10, respectively. The same experimental conditions used for the iron oxide coated sand experiment discussed above and illustrated in Figure 5.7 were used for these three experiments. In all three cases, the adsorption of nickel is coincident with EDTA, reflecting the formation of 


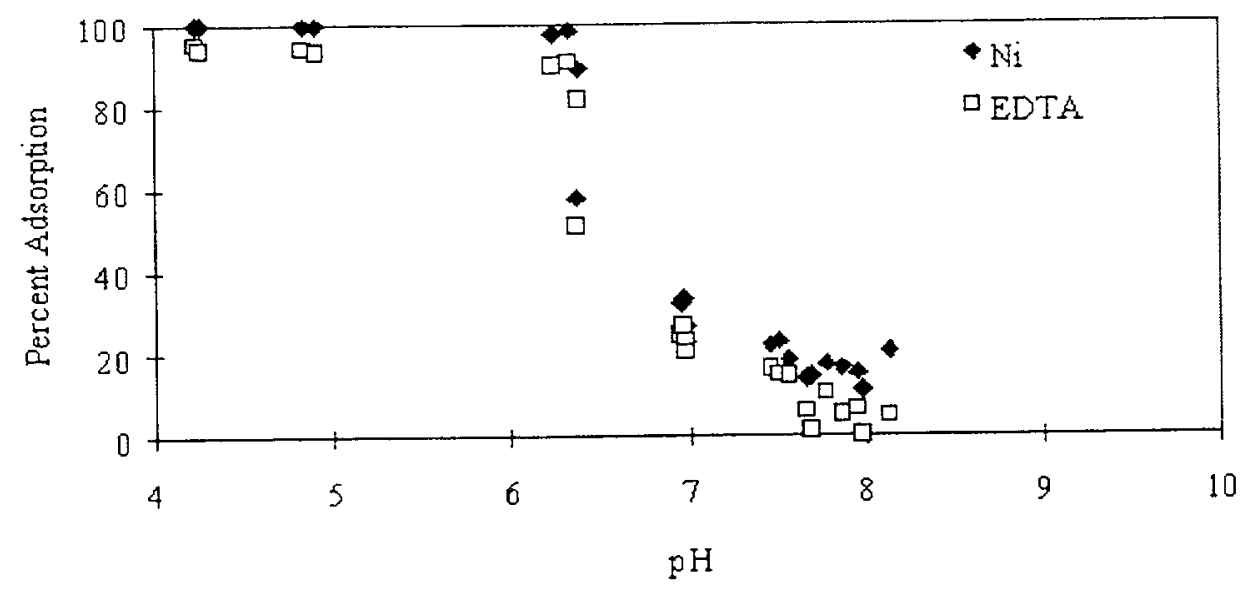

Figure 5.7. Percent Adsorption of $\mathrm{Ni}^{2+}$ and EDTA on $1.2 \%$ Iron Oxide Coated Sand as a Function of $\mathrm{pH}\left(0.5 \mathrm{~g}\right.$ soil $/ 30 \mathrm{ml}, 0.003$ molar $\mathrm{Ca}\left[\mathrm{ClO}_{4}\right]_{2}$ solution, with initial concentrations of $\mathrm{Ni}^{2+}$ and EDTA of $10^{-5} \mathrm{M}$ and $10^{-5} \mathrm{M}$, respectively)

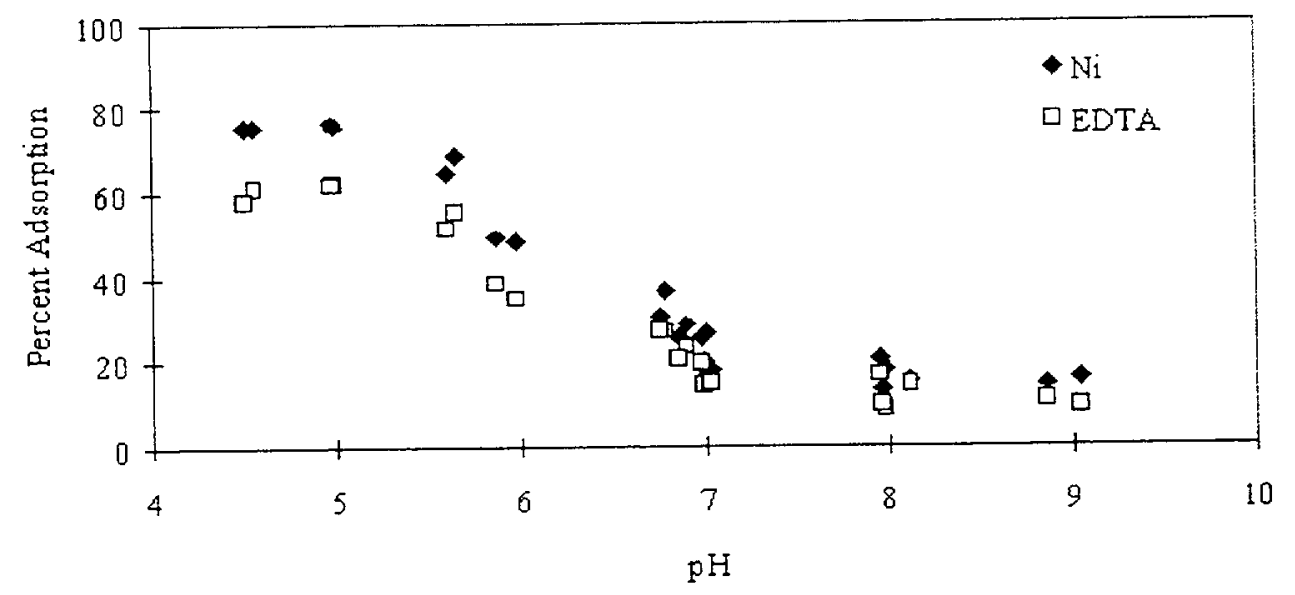

Figure 5.8. Percent Adsorption of $\mathrm{Ni}^{2+}$ and EDTA on Milford Soil as a Function of $\mathrm{pH}$ ( $0.5 \mathrm{~g}$ soil $/ 30 \mathrm{ml}, 0.003 \mathrm{molar} \mathrm{Ca}\left[\mathrm{ClO}_{4}\right]_{2}$ solution, with initial concentrations of $\mathrm{Ni}^{2+}$ and EDTA of $10^{-5} \mathrm{M}$ and $10^{-5} \mathrm{M}$, respectively) 


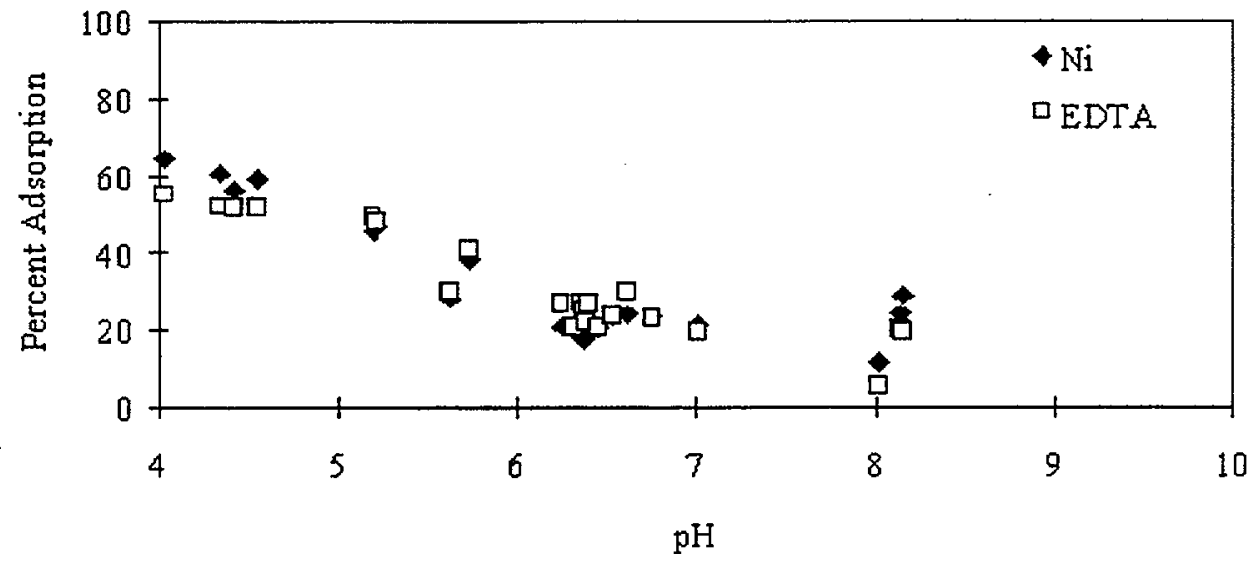

Figure 5.9. Percent Adsorption of $\mathrm{Ni}^{2+}$ and EDTA on $\mathrm{LK}-1$ Soil as a Function of $\mathrm{pH}$ $\left(0.5 \mathrm{~g}\right.$ soil/30 ml, 0.003 molar $\mathrm{Ca}\left[\mathrm{ClO}_{4}\right]_{2}$ solution, with initial concentrations of $\mathrm{Ni}^{2+}$ and EDTA of $10^{-5} \mathrm{M}$ and $10^{-5} \mathrm{M}$, respectively)

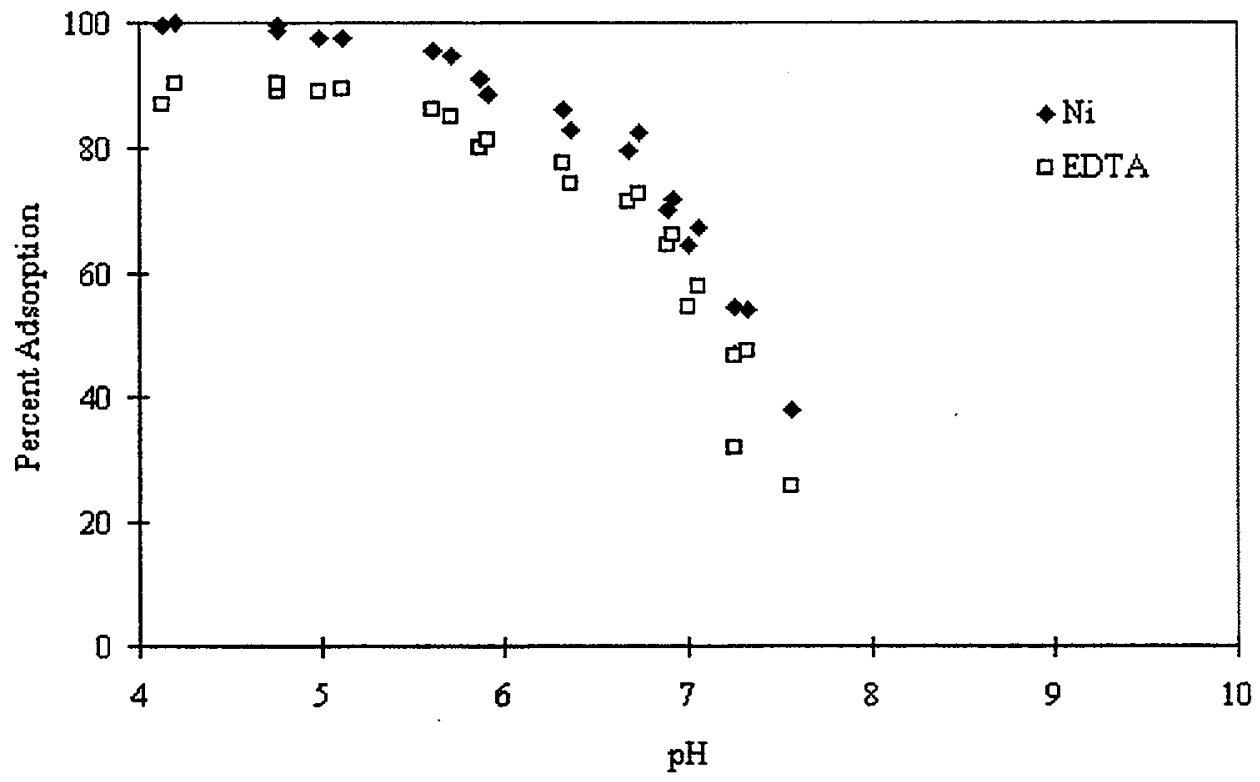

Figure 5.10. Percent Adsorption of $\mathrm{Ni}^{2+}$ and EDTA on MNC-7 Soil as a Function of pH $\left(0.5 \mathrm{~g}\right.$ soil/30 ml, 0.003 molar $\mathrm{Ca}\left[\mathrm{ClO}_{4}\right]_{2}$ solution, with initial concentrations of $\mathrm{Ni}^{2+}$ and EDTA of $10^{-5} \mathrm{M}$ and $10^{-5} \mathrm{M}$, respectively) 
strong anionic nickel-EDTA complexes [likely NiEDTA ${ }^{-2}$ ]. Of these three soils MNC-7 exhibits the highest degree of adsorption for the complex. MNC-7 has the highest total iron concentration (Table 3.3) and tends to adsorb the nickel-EDTA complexes very similarly to that of the iron oxide coated sand. Both the Milford and the LK-1 soil exhibit diminished adsorption relative to the iron oxide coated sand and the MNC-7 soil. The reasons for low adsorption on the Milford soil are readily apparent. Milford soil has the lowest iron oxide content of the three soils and is essentially all sand with very little clay (Table 3.3). The reasons for the low adsorption of the LK-1 soil are less obvious. The LK-1 soil has a moderately high iron oxide content as well as the highest clay content of the three soils (Table 3.3). One possible explanation for relatively low adsorption of the LK-1 soil is that the iron oxides in this soil are more crystalline in nature. For example, Hsi and Langmuir (1985) demonstrated that adsorption of uranyl species is stronger onto HFO and goethite than on synthetic and natural hematite, a more crystalline form of Fe(III) oxide.

This appeared to be directly related to the concentration of adsorption sites of the materials, which is directly related to the surface area of the material. For example, the HFO used by Hsi and Langmuir (1985) had a surface area of $306 \mathrm{~m}^{2} / \mathrm{g}$ and a site density of $20 \mathrm{sites} / \mathrm{nm}^{2}$, whereas their synthetic hematite had a surface area of $3.1 \mathrm{~m}^{2} / \mathrm{g}$ and a site density of 19 sites $/ \mathrm{nm}^{2}$. The LK-1 soil also has a relatively low organic carbon content, but significantly higher than the other two soils. Perhaps the natural organic acids (humic substances) in this soil are acting as effective competitors for adsorption sites with the nickelEDTA complexes.

\subsubsection{Sm-Picolinate System}

The adsorption of $\mathrm{Sm}^{3+}$ an analogue for trivalent actinides, such as $\mathrm{Am}^{+3}, \mathrm{Cm}^{+3}$ and reduced $\mathrm{Pu}^{+3}$, and picolinate onto iron oxide coated sand as a function of $\mathrm{pH}$ is shown in Figure 5.11. This experiment was conducted with equal initial concentrations of $10^{-5} \mathrm{M}$. Sm${ }^{3+}$ shows typical cationic type adsorption; low adsorption at low $\mathrm{pH}$ with increasing adsorption with increasing $\mathrm{pH}$ and nearly complete adsorption at the

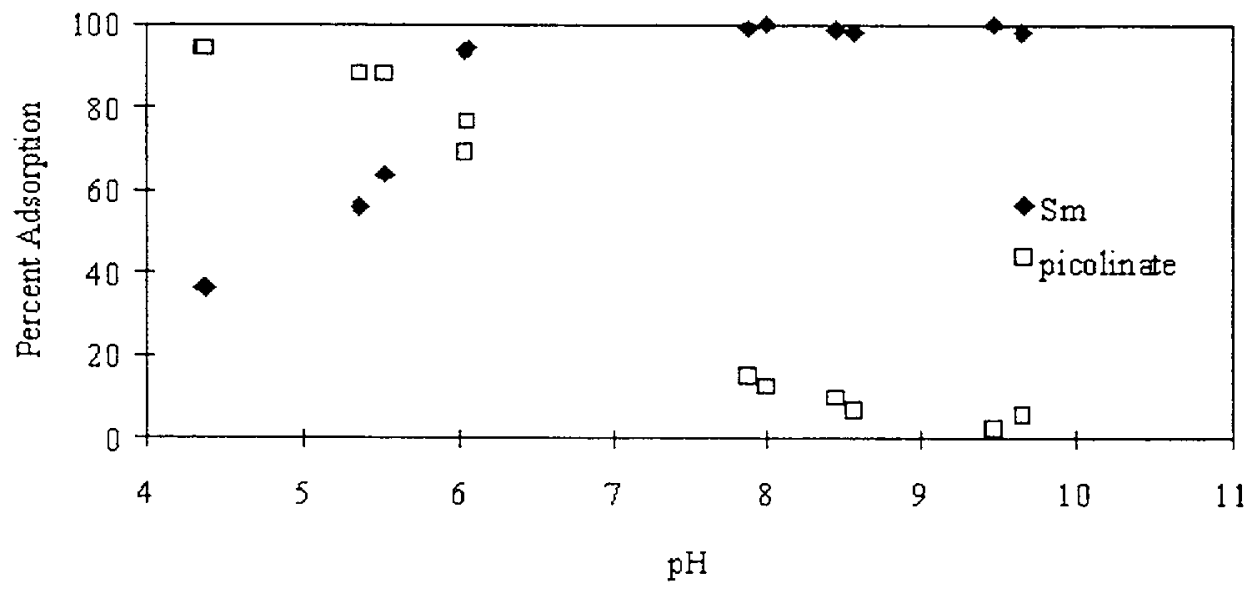

Figure 5.11. Percent Adsorption of $\mathrm{Sm}^{3+}$ and Picolinate on $1.2 \%$ Iron Oxide Coated Sand as a Function of $\mathrm{pH},\left(0.5 \mathrm{~g}\right.$ soil $/ 30 \mathrm{ml}, 0.003$ molar $\mathrm{Ca}\left[\mathrm{ClO}_{4}\right]_{2}$ solution, with initial concentrations of $\mathrm{Sm}^{3+}$ and picolinate of $10^{-5} \mathrm{M}$ and $10^{-5} \mathrm{M}$, respectively) 
highest $\mathrm{pH}$ values. Picolinate is exhibiting typical anionic adsorption behavior; the adsorption is strongest at low $\mathrm{pH}$ and drops off significantly with increasing $\mathrm{pH}$. These results clearly illustrate the lack of significant interaction between picolinate and $\mathrm{Sm}^{3+}$. Both components are acting completely independently and are not affecting the behavior of the other component. Although not shown the adsorption of $\mathrm{Sm}^{+3}$ onto soils without any picolinic acid present is similar to the data shown in Figure 5.11.

The results of two additional adsorption experiments with $\mathrm{Sm}^{3+}$ and picolinate for Milford soil are shown in Figures 5.12 and 5.13. In both cases, the picolinate concentration is $10^{-5} \mathrm{M}$. The $\mathrm{Sm}^{3+}$ concentration for the experiment shown in Figure 5.12 is $10^{-8} \mathrm{M}$, and $10^{-5} \mathrm{M}$ for the experiment shown in Figure 5.13. The results for both of these experiments are essentially the same as that shown in Figure 5.11, with the exception that the picolinate adsorption onto the Milford soil is diminished relative to the iron oxide coated sand. This is not surprising after consideration of the low iron oxide content of the Milford soil (Table 3.3) and the fact that iron oxides tend to be some of the most potent adsorbents in natural soils.

\subsubsection{Th-Picolinate System}

Adsorption results for $\mathrm{Th}^{4+}$ and picolinate at initial concentrations of $10^{-5} \mathrm{M}$ onto iron oxide coated sand are illustrated in Figure 5.14. $\mathrm{Th}^{4+}$ shows the general adsorption trends typical of cations with the exception that the decrease in adsorption with decreasing $\mathrm{pH}$ is much more gradual than for most metal ions. This result is most likely the result of partial precipitation of thorium hydroxide even at low $\mathrm{pH}$ values that is interpreted as adsorption even under acidic conditions in these batch tests. The initial $\mathrm{Th}^{4+}$ concentration used in this experiment appears to have exceeded its solubility limit for $\mathrm{pH}$ values above approximately 4.5 (Felmy et al. 1991).

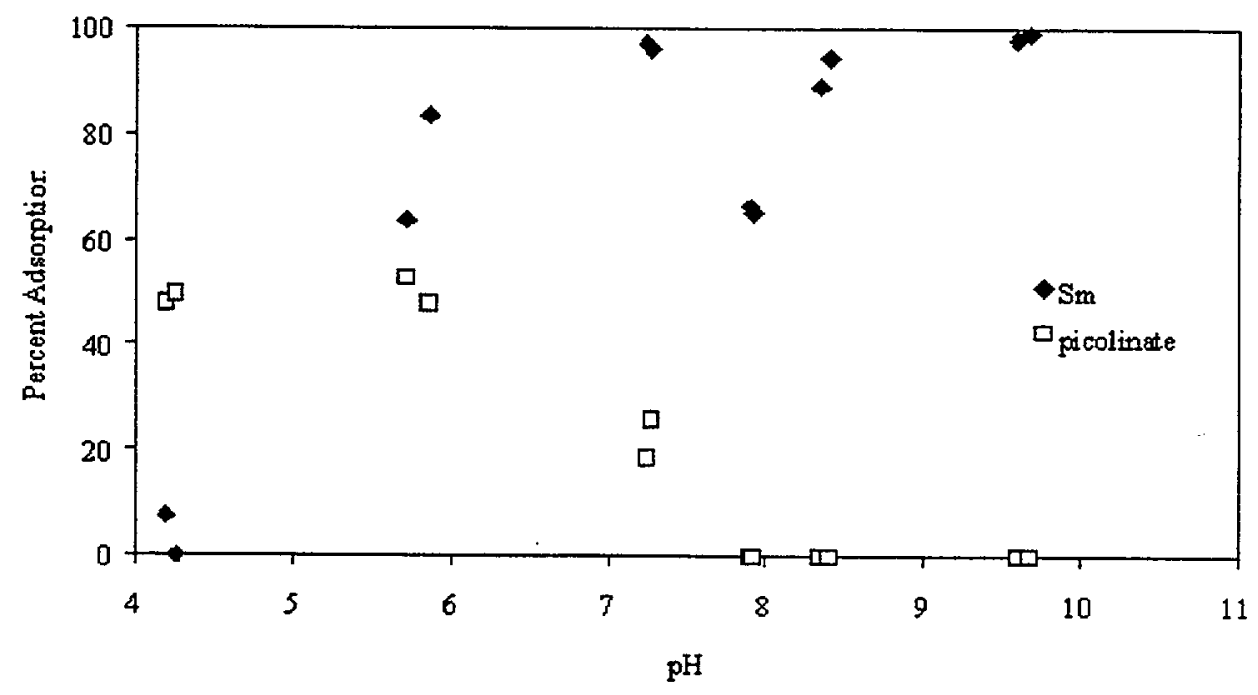

Figure 5.12. Percent Adsorption of $\mathrm{Sm}^{3+}$ and Picolinate on Milford Soil as a Function of $\mathrm{pH}\left(0.5 \mathrm{~g}\right.$ soil $/ 30 \mathrm{ml}, 0.003$ molar $\mathrm{Ca}\left[\mathrm{ClO}_{4}\right]_{2}$ solution, with initial concentrations of $\mathrm{Sm}^{3+}$ and picolinate of $10^{-8} \mathrm{M}$ and $10^{-5} \mathrm{M}$, respectively) 


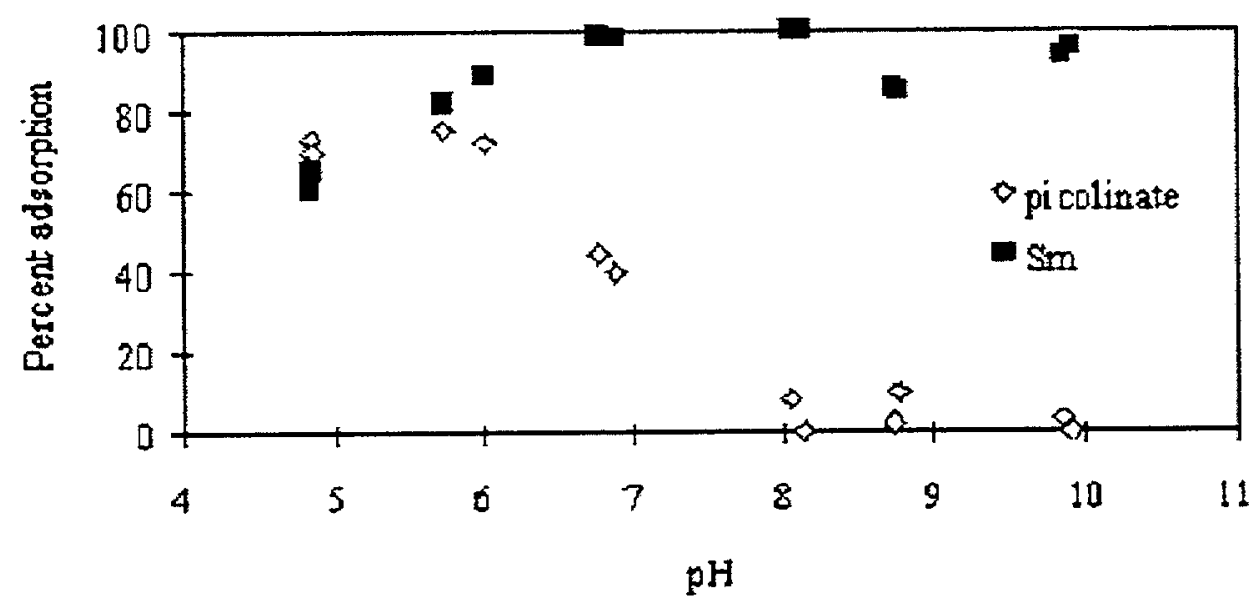

Figure 5.13. Percent Adsorption of $\mathrm{Sm}^{3+}$ and Picolinate on Milford Soil as a Function of $\mathrm{pH}\left(0.5 \mathrm{~g} \mathrm{soil} / 30 \mathrm{ml}, 0.003\right.$ molar $\mathrm{Ca}\left[\mathrm{ClO}_{4}\right]_{2}$ solution, with initial concentrations of $\mathrm{Sm}^{3+}$ and picolinate of $10^{-5} \mathrm{M}$ and $10^{-5} \mathrm{M}$, respectively)

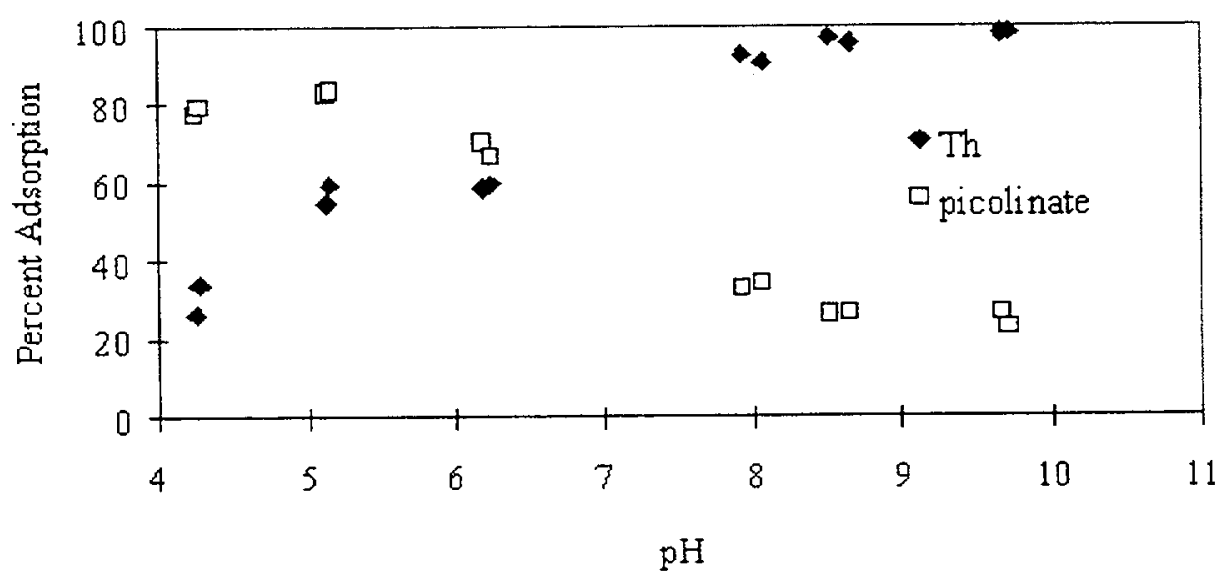

Figure 5.14. Percent Adsorption of $\mathrm{Th}^{4+}$ and Picolinate on 1.2\% Iron Oxide Coated Sand as a Function of $\mathrm{pH}\left(0.5 \mathrm{~g}\right.$ soil/30 ml, 0.003 molar $\mathrm{Ca}\left[\mathrm{ClO}_{4}\right]_{2}$ solution, with initial concentrations of $\mathrm{Th}^{4+}$ and picolinate of $10^{-5} \mathrm{M}$ and $10^{-5} \mathrm{M}$, respectively) 
The picolinate also shows the general features of anionic adsorption typically observed; however, significant adsorption of picolinate remains at alkaline $\mathrm{pH}$ values. This is contrary to what is typically observed for uncomplexed picolinate and may be the result of co-precipitation of picolinate with thorium hydroxide.

Another $\mathrm{Th}^{4+}$ - picolinate adsorption experiment was conducted with Milford soil (Figure 5.15). The results of this experiment are nearly same as that determined for the iron oxide coated sand; both for $\mathrm{Th}^{4+}$ and picolinate. We thus conclude that picolinate is not forming strong complexes with Th and by analog with other quadravalent actinides such as $\mathrm{Np}(\mathrm{IV})$ or $\mathrm{Pu}(\mathrm{IV})$.

\subsubsection{Np-Picolinate System}

The adsorption of $\mathrm{NpO}_{2}^{+}$with no organic ligand present onto iron oxide coated sand as a function of $\mathrm{pH}$ is shown in Figure 5.16. This experiment was conducted at an initial Np concentration of $6.7 \times 10^{-7} \mathrm{M}$. The $\mathrm{NpO}_{2}{ }^{+}$shows typical cationic type adsorption. Figure 5.17 shows results for another adsorption experiment on iron oxide coated sand conducted at the same initial $\mathrm{NpO}_{2}^{+}$concentration and a picolinate concentration of $10^{-5} \mathrm{M}$. Here again the adsorption behavior of $\mathrm{NpO}_{2}{ }^{+}$is cationic in character. In addition, the picolinate is exhibiting typical anionic adsorption behavior. Both components are acting completely independently and are not affected by the behavior of the other component, clearly indicating a lack of significant interaction between picolinate and $\mathrm{NpO}_{2}{ }^{+}$. It is possible that $\mathrm{NpO}_{2}{ }^{+}$is a reasonable analogue for $\mathrm{Pu}(\mathrm{V})$, which would lead to the conclusion that $\mathrm{Pu}(\mathrm{V})$ does not form strong complexes with picolinate at picolinate concentrations less than $1 \times 10^{-4} \mathrm{M}$.

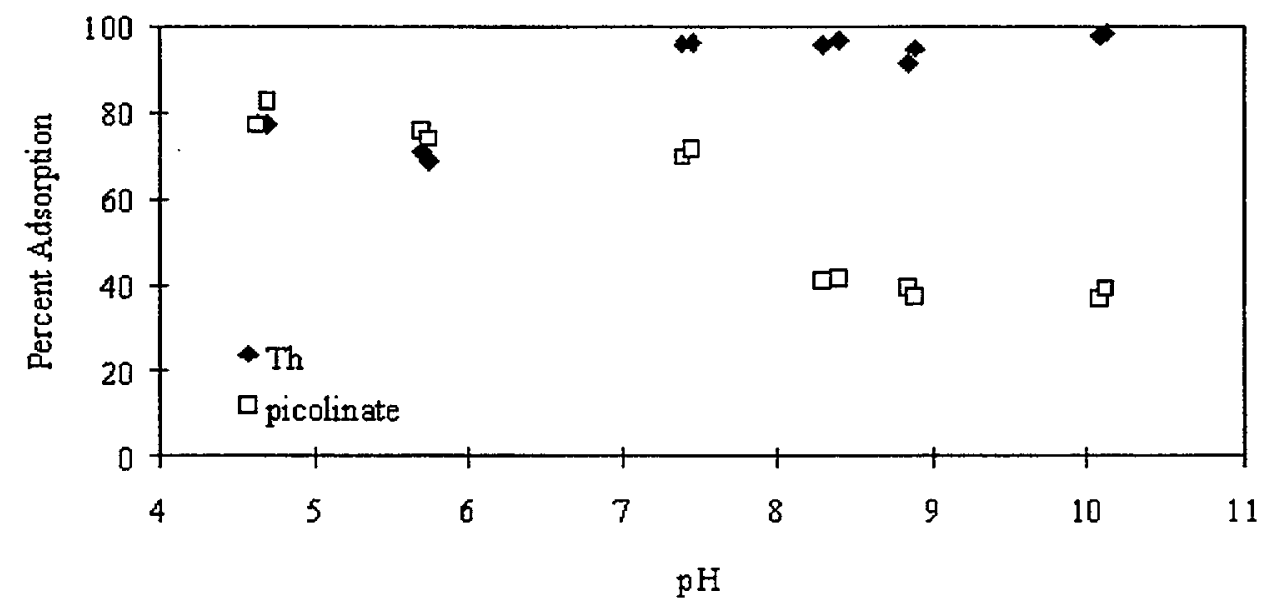

Figure 5.15. Percent Adsorption of $\mathrm{Th}^{4+}$ and Picolinate on Milford Soil as a Function of $\mathrm{pH}$ $\left(0.5 \mathrm{~g}\right.$ soil $/ 30 \mathrm{ml}, 0.003$ molar $\mathrm{Ca}\left[\mathrm{ClO}_{4}\right]_{2}$ solution, with initial concentrations of $\mathrm{Th}^{4+}$ and picolinate of $10^{-5} \mathrm{M}$ and $10^{-5} \mathrm{M}$, respectively) 


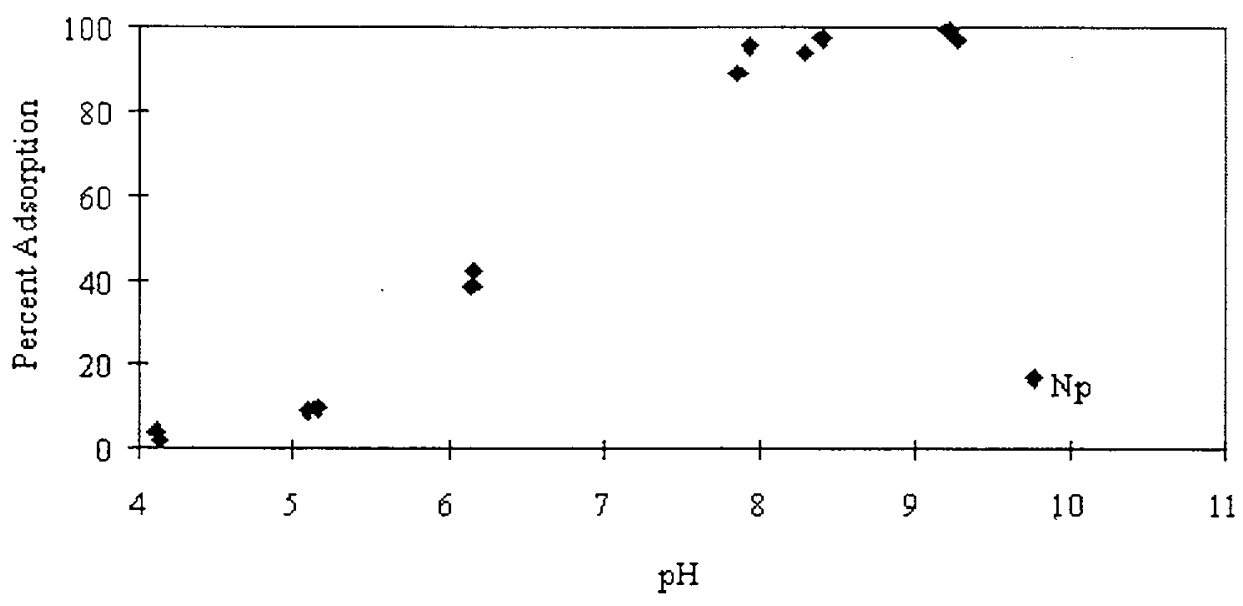

Figure 5.16. Percent Adsorption of $\mathrm{NpO}_{2}{ }^{+}$on $1.2 \%$ Iron Oxide Coated Sand as a Function of $\mathrm{pH}\left(0.5 \mathrm{~g}\right.$ soil $/ 30 \mathrm{ml}, 0.003$ molar $\mathrm{Ca}\left[\mathrm{ClO}_{4}\right]_{2}$ solution, with an initial $\mathrm{NpO}_{2}+$ concentration of $6.7 \times 10^{-7} \mathrm{M}$ )

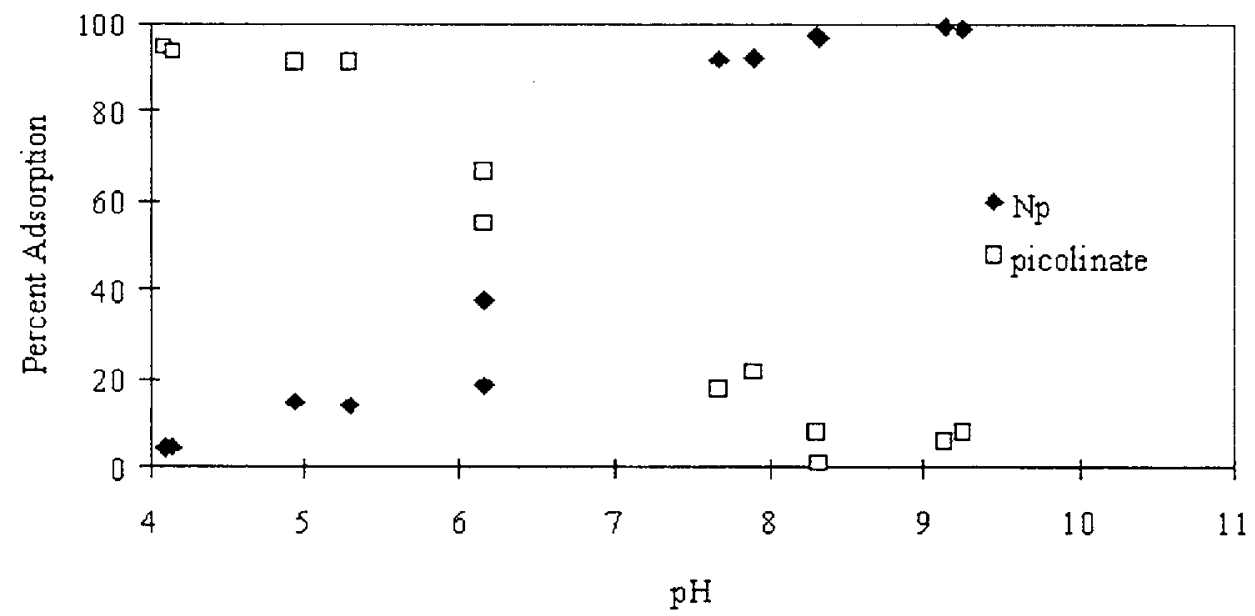

Figure 5.17. Percent Adsorption of $\mathrm{NpO}_{2}{ }^{+}$and Picolinate on $1.2 \%$ Iron Oxide Coated Sand as a Function of $\mathrm{pH}\left(0.5 \mathrm{~g}\right.$ soil $/ 30 \mathrm{ml}, 0.003$ molar $\mathrm{Ca}\left[\mathrm{ClO}_{4}\right]_{2}$ solution, with initial concentrations of $\mathrm{NpO}_{2}^{+}$and picolinate of $6.7 \times 10^{-7} \mathrm{M}$ and $10^{-5} \mathrm{M}$, respectively) 
Two more experiments were conducted with $\mathrm{NpO}_{2}^{+}$using Milford soil as the adsorbent. Figure 5.18 shows the results for adsorption of $\mathrm{NpO}_{2}^{+}$only on Milford soil and Figure 5.19 illustrates results from another experiment with both $\mathrm{NpO}_{2}{ }^{+}$and picolinate on Milford soil. In both cases, the results are practically the same as those observed for the iron oxide coated sand, except that both solutes exhibit slightly lower adsorption, which is again due to the low concentration of strong adsorbents in this soil.

\subsubsection{U-Picolinate System}

The adsorption of $\mathrm{U}(\mathrm{VI})$ added as free $\mathrm{UO}_{2}{ }^{2+}$ in the carbonate-free or carbonate-limited tests and picolinate onto iron oxide coated sand as a function of $\mathrm{pH}$ is shown in Figure 5.20. This experiment was conducted with initial concentrations of $10^{-5} \mathrm{M}$ for $\mathrm{U}(\mathrm{VI})$ and $10^{-3} \mathrm{M}$ for picolinate. The U(VI) shows typical cationic adsorption behavior observed for various iron oxides in the absence of complexing anions (Hsi and Langmuir 1985). As indicated earlier, the high concentration of picolinate $\left(10^{-3} \mathrm{M}\right)$ used in this experiment greatly exceeded the quantity of available adsorption sites, resulting in relatively little or no removal due to adsorption. It is apparent from these results that insignificant interaction occurs between picolinate and U(VI) in solution. Both components are acting completely independently and are not affecting the behavior of each other. If our tests would have been at equilbrium with carbon dioxide the adsorption of $\mathrm{U}(\mathrm{VI})$ at higher $\mathrm{pH}$ values would have dropped because of the formation of strong inorganic complexes between $\mathrm{UO}_{2}{ }^{2+}$ and carbonate. See Davis (2001) for an excellent discourse of U(VI) adsorption in the presence of carbonate solutions.

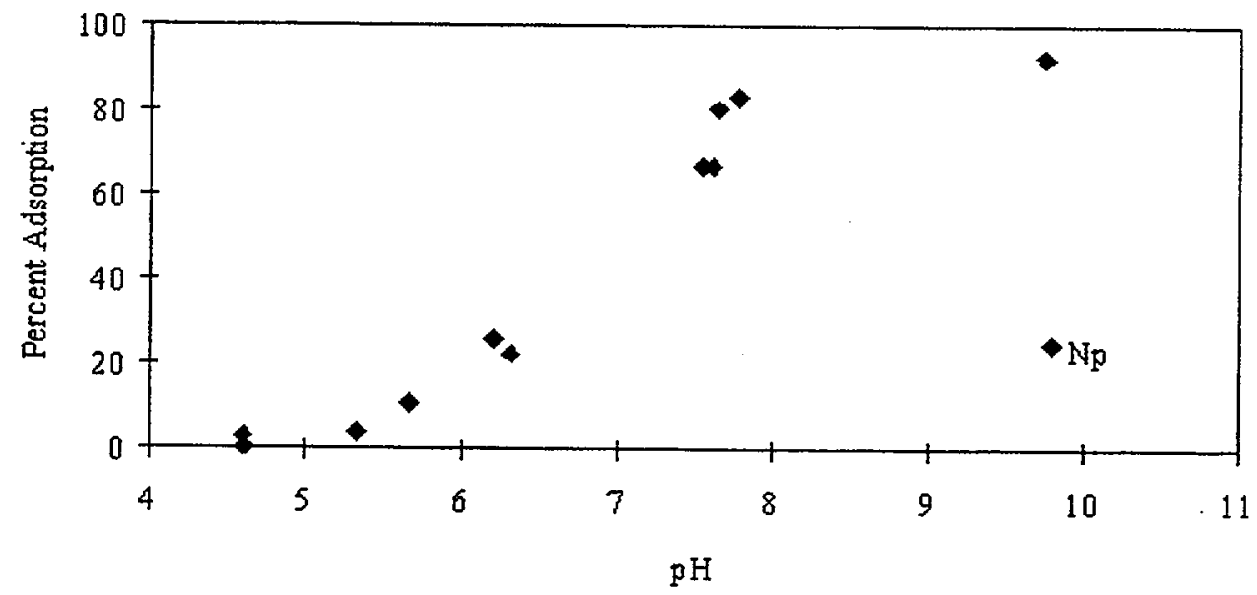

Figure 5.18. Percent Adsorption of $\mathrm{NpO}_{2}{ }^{+}$on Milford Soil as a Function of $\mathrm{pH}(0.5 \mathrm{~g}$ soil/ $30 \mathrm{ml}, 0.003$ molar $\mathrm{Ca}\left[\mathrm{ClO}_{4}\right]_{2}$ solution, with an initial $\mathrm{NpO}_{2}{ }^{+}$concentration of $6.7 \times 10^{-7} \mathrm{M}$ ) 


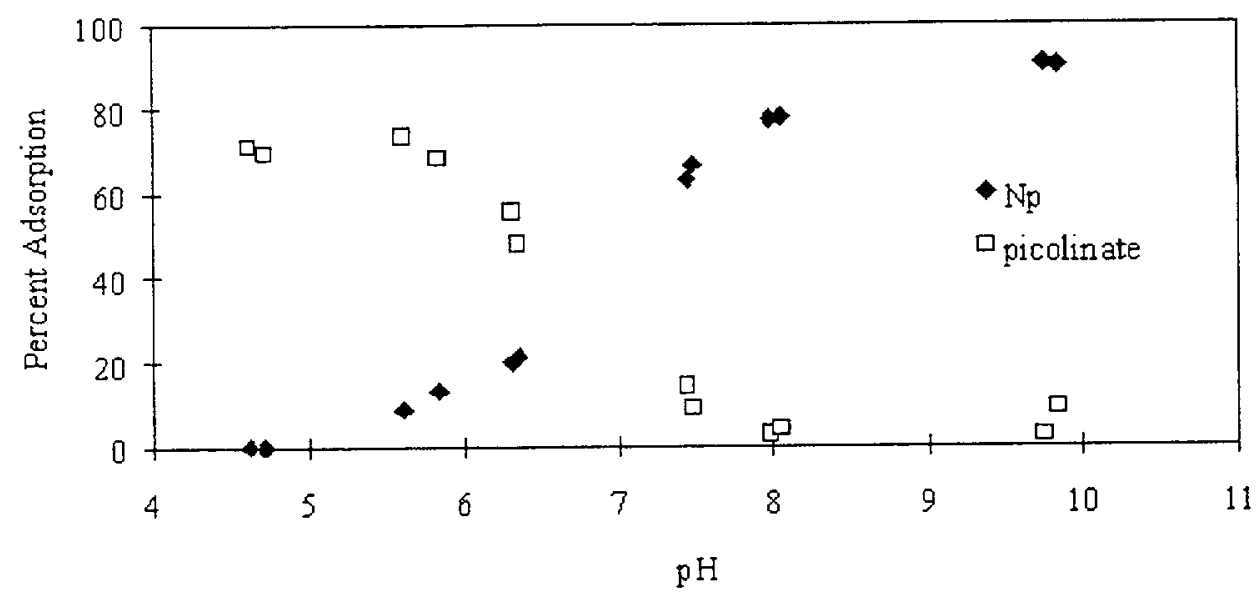

Figure 5.19. Percent Adsorption of $\mathrm{NpO}_{2}{ }^{+}$and Picolinate on Milford Soil as a Function of pH $\left(0.5 \mathrm{~g}\right.$ soil $/ 30 \mathrm{ml}, 0.003$ molar $\mathrm{Ca}\left[\mathrm{ClO}_{4}\right]_{2}$ solution, with initial concentrations of $\mathrm{NpO}_{2}^{+}$and picolinate of $6.7 \times 10^{-7} \mathrm{M}$ and $10^{-5} \mathrm{M}$, respectively)

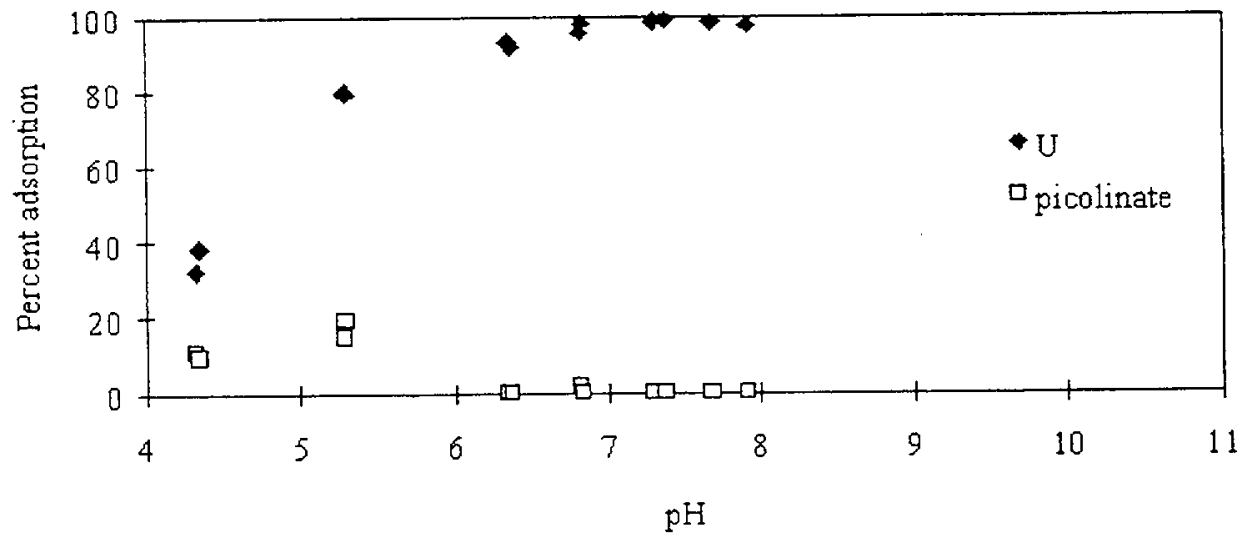

Figure 5.20. Percent Adsorption of $\mathrm{UO}_{2}^{2+}$ and Picolinate on 1.2\% Iron Oxide Coated Sand as a Function of $\mathrm{pH}\left(0.5 \mathrm{~g}\right.$ soil $/ 30 \mathrm{ml}, 0.003$ molar $\mathrm{Ca}\left[\mathrm{ClO}_{4}\right]_{2}$ solution, with initial concentrations of $\mathrm{UO}_{2}{ }^{2+}$ and picolinate of $10^{-5} \mathrm{M}$ and $10^{-3} \mathrm{M}$, respectively) 
Another adsorption experiment conducted using the same conditions used in the previous experiment are shown in Figure 5.21 for adsorption onto Milford soil. Adsorption of both U(VI) and picolinate is very similar to that of the iron oxide coated sand except that the increase in adsorption of U(VI) with pH is more gradual than that observed for the iron oxide coated sand, consistent with the low concentration of strong adsorbents in the Milford soil. The free picolinate anion shows a very low percentage adsorption because its solution concentration is very high relative to the quantity of available positively charged surface sites on the Milford soil.

\subsubsection{U-EDTA System}

The adsorption of $\mathrm{U}(\mathrm{VI})$, added as $\mathrm{UO}_{2}{ }^{2+}$ in these carbonate-free or carbonate-limited tests, and EDTA onto iron oxide coated sand as a function of $\mathrm{pH}$ is shown in Figure 5.22. This experiment was conducted with equal initial concentrations of $10^{-5} \mathrm{M}$. U(VI) is again showing typical cationic adsorption behavior observed for various iron oxides in the absence of complexing anions. The EDTA is again exhibiting typical anionic adsorption behavior; however, less adsorption is observed at lower $\mathrm{pH}$ values than was observed in the nickel experiment (Figure 5.7). Girvin et al. (1993) observed similar behavior during the study of $\mathrm{Co}^{+2}$-EDTA adsorption onto $\delta-\mathrm{Al}_{2} \mathrm{O}_{3}$. Note that adsorption of $\mathrm{Ni}^{2+}$ onto iron oxides is nearly

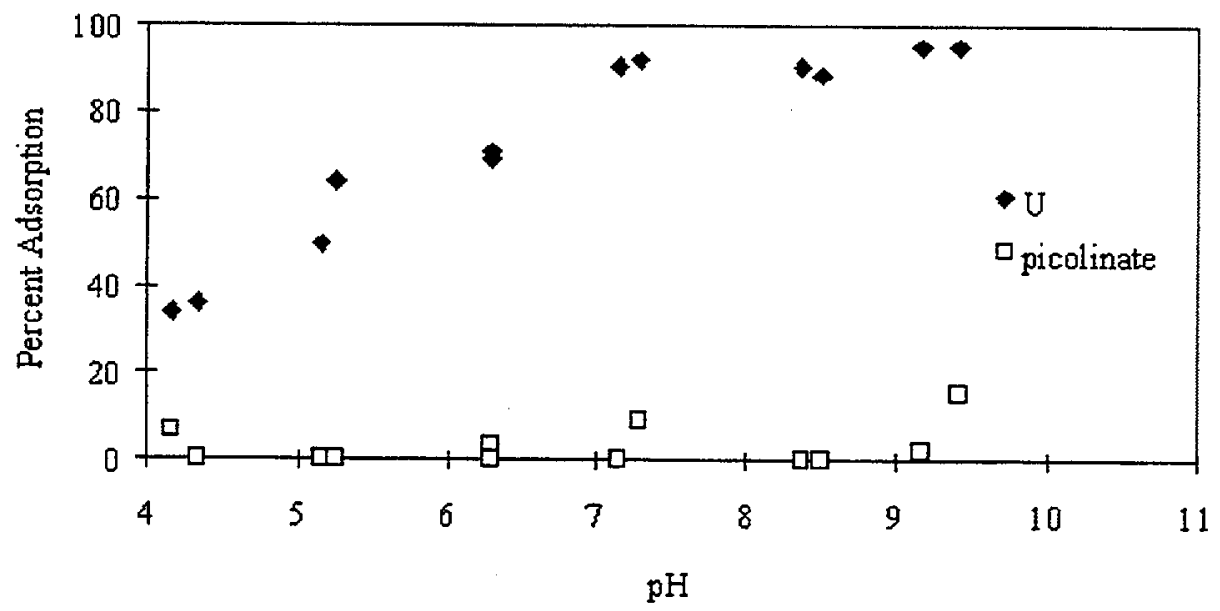

Figure 5.21. Percent Adsorption of $\mathrm{UO}_{2}{ }^{2+}$ and Picolinate on Milford Soil as a Function of $\mathrm{pH}\left(0.5 \mathrm{~g} \text { soil } / 30 \mathrm{ml}, 0.003 \mathrm{molar} \mathrm{Ca}_{[\mathrm{ClO}}\right]_{2}$ solution, with initial concentrations of $\mathrm{UO}_{2}{ }^{2+}$ and picolinate of $10^{-5} \mathrm{M}$ and $10^{-3} \mathrm{M}$, respectively) 


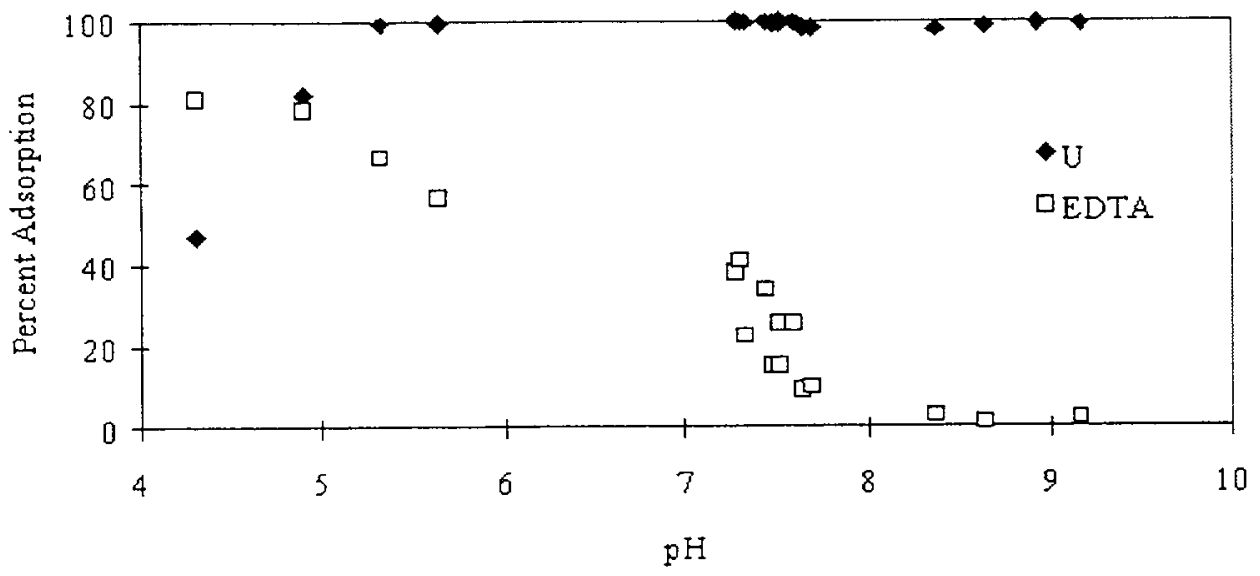

Figure 5.22. Percent Adsorption of $\mathrm{UO}_{2}^{2+}$ and EDTA on 1.2\% Iron Oxide Coated Sand as a Function of $\mathrm{pH}\left(0.5 \mathrm{~g}\right.$ soil/30 ml, 0.003 molar $\mathrm{Ca}\left[\mathrm{ClO}_{4}\right]_{2}$ solution, with initial concentrations of $\mathrm{UO}_{2}{ }^{2+}$ and EDTA of $10^{-5} \mathrm{M}$ and $10^{-5} \mathrm{M}$, respectively)

identical to that of $\mathrm{Co}^{2+}$ (Coughlin and Stone 1995). In the study of Girvin et al. (1993), the adsorption of EDTA was significantly less than when $\mathrm{Co}^{2+}$ was present. It was proposed that the EDTA species that were adsorbed in the absence of $\mathrm{Co}^{2+}$ were Al-EDTA ${ }^{0}$ and Al-HEDTA formed by dissolution of the $\delta$ $\mathrm{Al}_{2} \mathrm{O}_{3}$. When $\mathrm{Co}^{2+}$ and EDTA were present in equal molar concentrations, the dominant EDTA species was Co-EDTA ${ }^{2-}$. It was suggested that the Al-EDTA species (Al-EDTA ${ }^{-}$and Al-HEDTA ${ }^{0}$ ) adsorb as outer sphere complexes and the affinity of the surface hydroxyls is greater for the Co-EDTA ${ }^{2-}$ species than for the Al-EDTA species. In our system, a very similar process appears to be occurring, but with HFO and $\mathrm{Fe}^{3+}$ instead of $\delta-\mathrm{Al}_{2} \mathrm{O}_{3}$ and $\mathrm{Al}^{3+}$. This explains why less adsorption of EDTA occurred in the U(VI) and EDTA system (Figure 5.22) than in the $\mathrm{Ni}^{2+}$ and EDTA system (Figure 5.7). These results and analysis suggest that $\mathrm{U}(\mathrm{VI})$ is not significantly complexed by EDTA under the conditions of this experiment.

$\mathrm{UO}_{2}{ }^{2+}$ and EDTA adsorption results for three different soils (Milford, LK-1, and MNC-7) are illustrated in Figures 5.23, 5.24, and 5.25, respectively. The same experimental conditions used for the iron oxide coated sand experiment discussed above (Figure 5.22) were used for these three experiments. In all three cases, the adsorption of U(VI) is independent of EDTA, reflecting the lack of significant formation of $\mathrm{UO}_{2}{ }^{2+}$-EDTA complexes. Milford soil (Figure 5.23) shows the weakest adsorption for both U(VI) and EDTA, reflecting its sandy character with low iron oxide content (Table 3.3). The LK-1 results (Figure 5.24) indicate weak adsorption for EDTA similar to that of Milford soil. The adsorption of U(VI) onto LK-1 soil; however, is greater than for any of the other soils or the iron oxide coated sand. Apparently, U(VI) has a high affinity for the clay (ion-exchange sites) in this soil. LK-1 has the highest clay content of any of the soils at $46 \%$ (Table 3.3). The adsorption of both U(VI) and EDTA onto MNC-7 soil is very similar to that of the iron oxide coated sand. MNC-7 has the highest iron oxide content of any of the soils (Table 3.3) that explains the similarity in adsorption behavior between this soil and the iron oxide coated sand. 


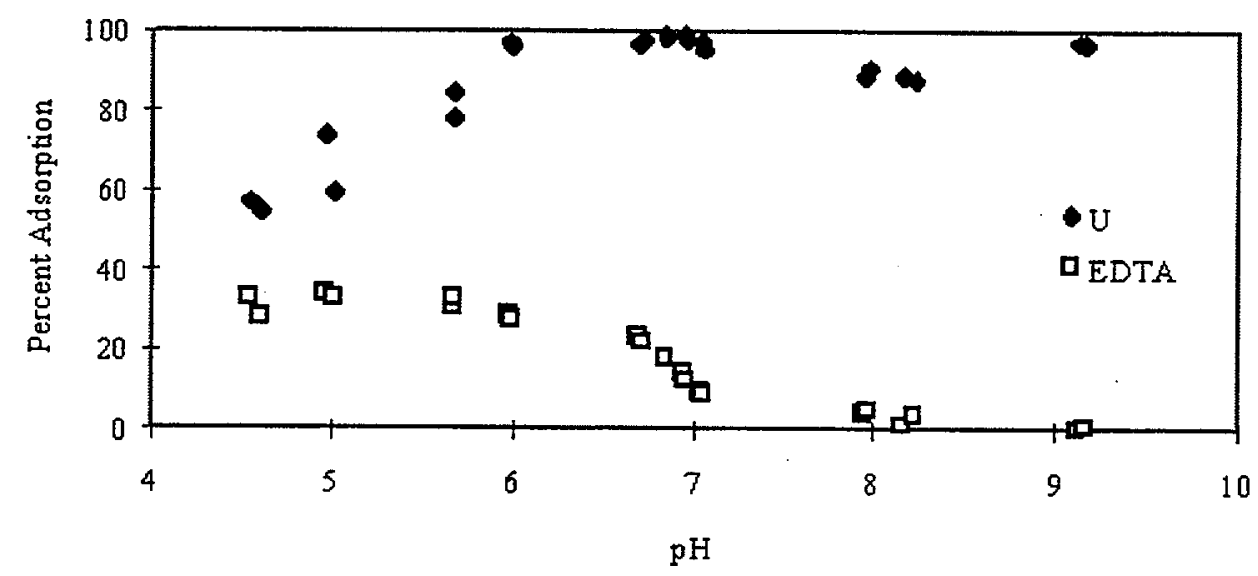

Figure 5.23. Percent Adsorption of $\mathrm{UO}_{2}{ }^{2+}$ and EDTA on Milford Soil as a Function of pH $\left(0.5 \mathrm{~g}\right.$ soil $/ 30 \mathrm{ml}, 0.003$ molar $\mathrm{Ca}\left[\mathrm{ClO}_{4}\right]_{2}$ solution, with initial concentrations of $\mathrm{UO}_{2}{ }^{2+}$ and EDTA of $10^{-5} \mathrm{M}$ and $10^{-5} \mathrm{M}$, respectively)

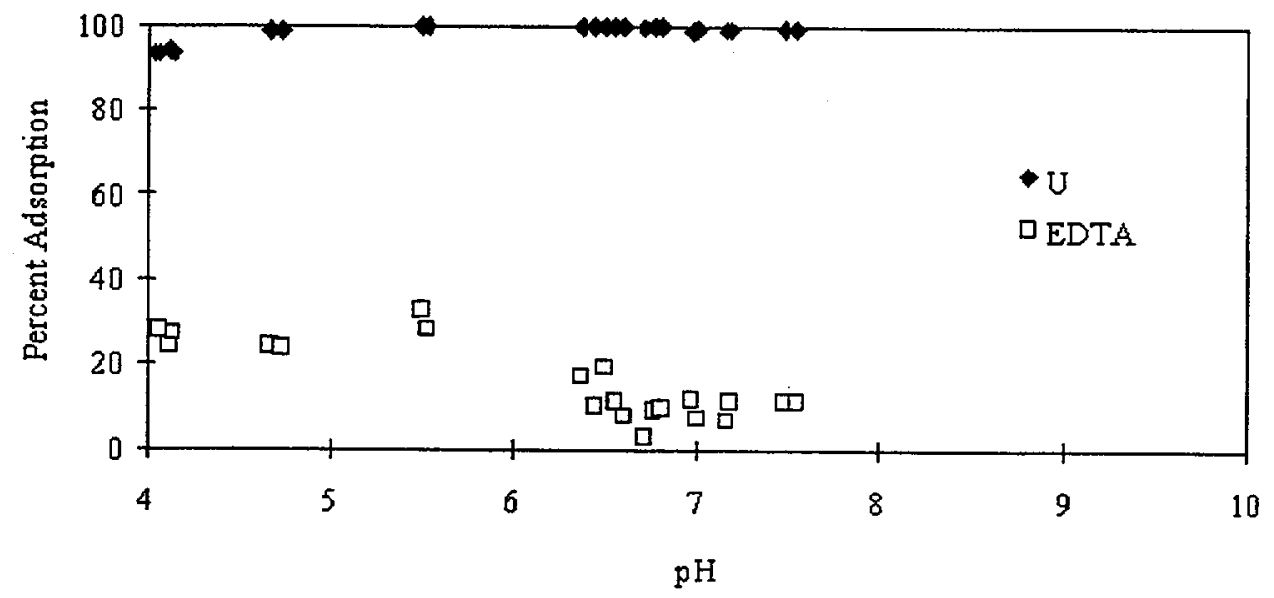

Figure 5.24. Percent Adsorption of $\mathrm{UO}_{2}{ }^{2+}$ and EDTA on LK-1 Soil as a Function of pH $\left(0.5 \mathrm{~g}\right.$ soil $/ 30 \mathrm{ml}, 0.003$ molar $\mathrm{Ca}\left[\mathrm{ClO}_{4}\right]_{2}$ solution, with initial concentrations of $\mathrm{UO}_{2}{ }^{2+}$ and EDTA of $10^{-5} \mathrm{M}$ and $10^{-5} \mathrm{M}$, respectively) 


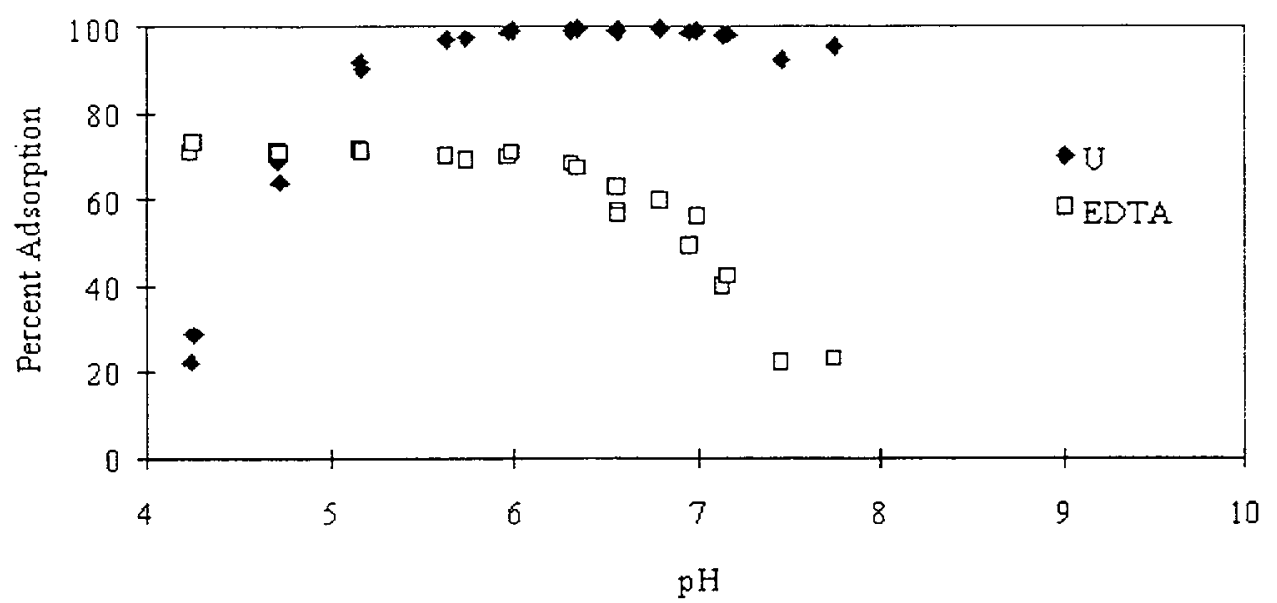

Figure 5.25. Percent Adsorption of $\mathrm{UO}_{2}^{2+}$ and EDTA on MNC-7 Soil as a Function of $\mathrm{pH}$ $\left(0.5 \mathrm{~g} \mathrm{soil} / 30 \mathrm{ml}, 0.003\right.$ molar $\mathrm{Ca}\left[\mathrm{ClO}_{4}\right]_{2}$ solution, with initial concentrations of $\mathrm{UO}_{2}{ }^{2+}$ and EDTA of $10^{-5} \mathrm{M}$ and $10^{-5} \mathrm{M}$, respectively)

\subsubsection{Pu-Picolinate System}

Adsorption of "oxidized" plutonium on Milford soil in the absence of any complexing agent is shown as a function of $\mathrm{pH}$ in Figure 5.26. The initial concentration of $\mathrm{Pu}$ in this experiment was $6.7 \times 10^{-7} \mathrm{M}$. Although the $\mathrm{Pu}$ stock solution was initially in the form of $\mathrm{PuO}_{2}{ }^{2+}$, the oxidation state of the $\mathrm{Pu}$ at the end of the experiment is not certain (Bueppelmann et al. 1988). The adsorption of "oxidized" $\mathrm{Pu}$ on the Milford soil is less than that of the other actinides or actinide analogs used in this study. $\mathrm{Sm}^{3+}, \mathrm{Th}^{4+}$, $\mathrm{NpO}_{2}{ }^{+}$, and $\mathrm{U}(\mathrm{VI})$, all exhibit greater adsorption onto Milford soil than Pu. Because the oxidation state of the $\mathrm{Pu}$ in these experiments is uncertain further discussion regarding the reasons for this behavior would be speculative.

The results of another $\mathrm{Pu}$ adsorption experiment conducted under the same conditions with the exception that $10^{-5} \mathrm{M}$ picolinate was added with the oxidized $\mathrm{Pu}$ to the Milford soil is shown in Figure 5.27. Again the "oxidized" $\mathrm{Pu}$ adsorption is low until $\mathrm{pH}$ values increase to above 8 and then approaches a maximum of $60 \%$ at $\mathrm{pH}$ values just below 10 . At higher $\mathrm{pH}$ values adsorption of picolinate is expected to drop off to zero. The results shown here would suggest that picolinate adsorption remains relatively high at all $\mathrm{pH}$ values. The picolinate concentrations are not reliable because the beta spectra of the ${ }^{14} \mathrm{C}$ used to determine the picolinate concentrations contained interferences resulting from ${ }^{241} \mathrm{Pu}$ impurities in the ${ }^{238} \mathrm{Pu}$ stock solution. However, it is clear that the effect of the picolinate on the adsorption of Pu was insignificant, suggesting no significant amount of complexation.

Figure 5.28 illustrates results for an additional adsorption experiment conducted with "oxidized" Pu and picolinate. In this case, the Pu concentration was reduced to $10^{-8} \mathrm{M}$ but the picolinate was maintained at $10^{-5} \mathrm{M}$. The degree of adsorption of the $\mathrm{Pu}$ is greater in this experiment. The higher degree of adsorption of $\mathrm{Pu}$ at lower concentrations is consistent with an adsorption media that contains a heterogeneous 


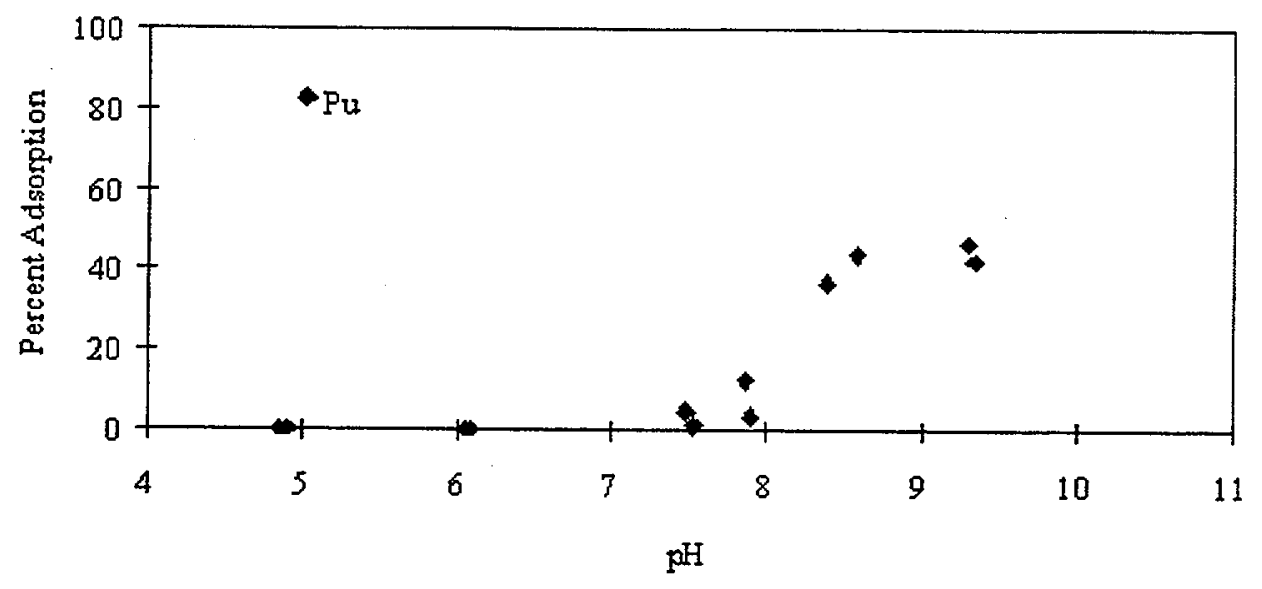

Figure 5.26. Percent Adsorption of Pu on Milford Soil as a Function of $\mathrm{pH}(0.5 \mathrm{~g}$ soil/ $30 \mathrm{ml}, 0.003$ molar $\mathrm{Ca}\left[\mathrm{ClO}_{4}\right]_{2}$ solution, with an initial Pu concentration of $\left.6.7 \times 10^{-7} \mathrm{M}\right)$

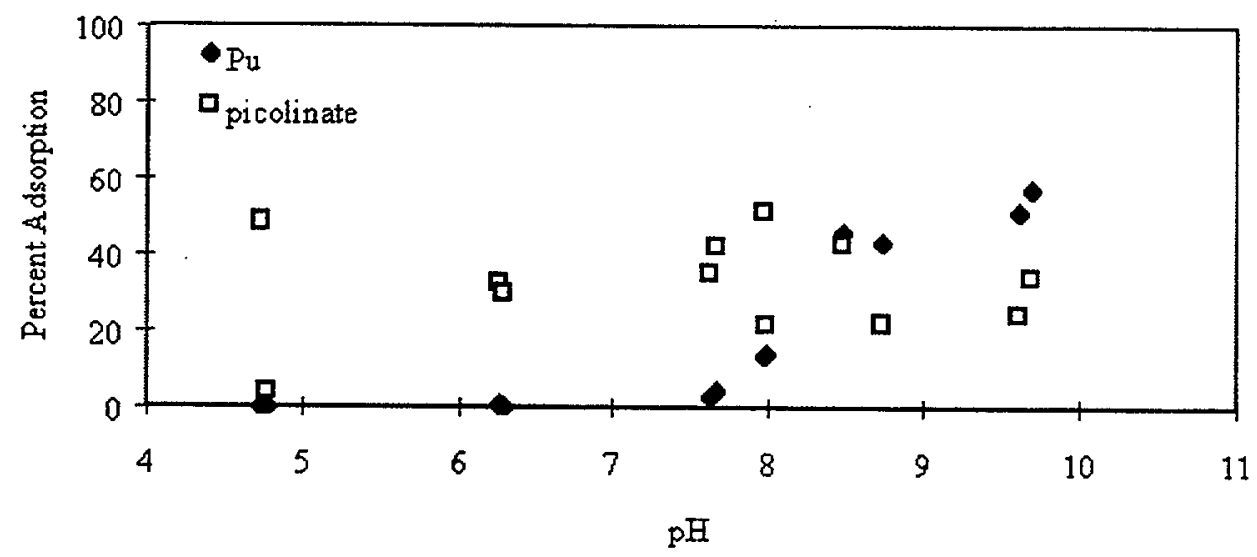

Figure 5.27. Percent Adsorption of Pu and Picolinate on Milford Soil as a Function of $\mathrm{pH}$ $\left(0.5 \mathrm{~g}\right.$ soil $/ 30 \mathrm{ml}, 0.003 \mathrm{molar} \mathrm{Ca}\left[\mathrm{ClO}_{4}\right]_{2}$ solution, with initial concentrations of $\mathrm{Pu}$ and picolinate of $6.7 \times 10^{-7} \mathrm{M}$ and $10^{-5} \mathrm{M}$, respectively) 


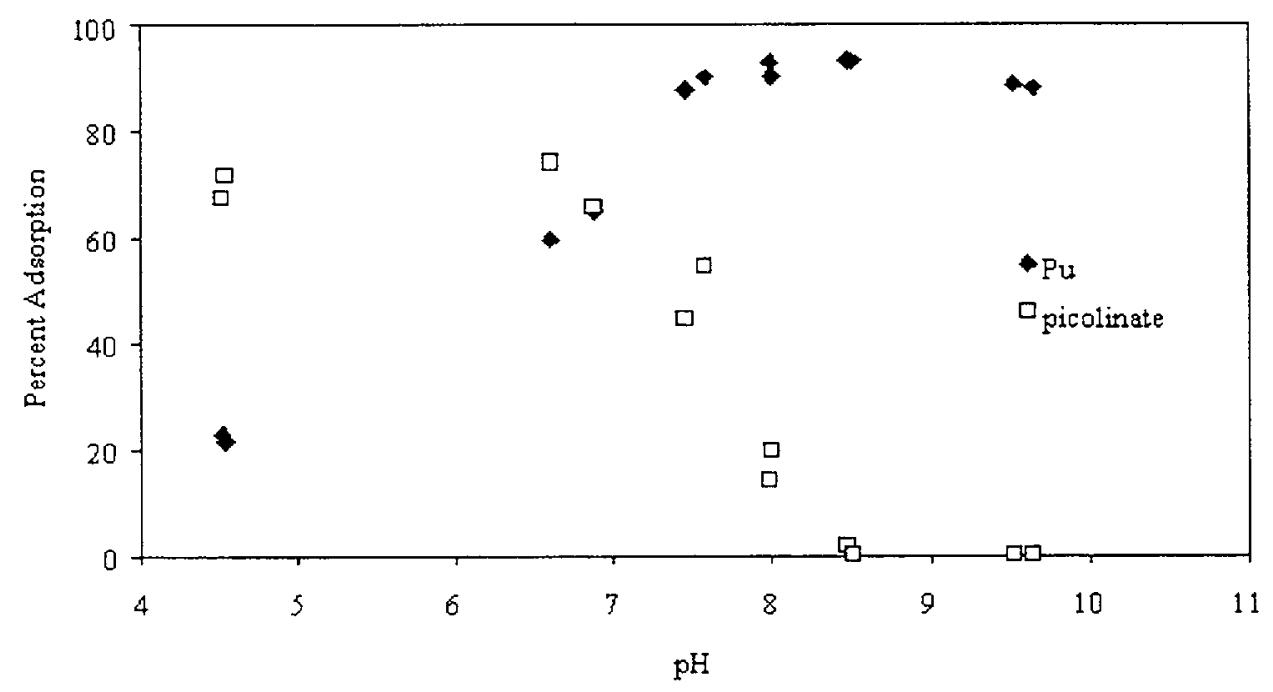

Figure 5.28. Percent Adsorption of Pu and Picolinate on Milford Soil as a Function of pH $\left(0.5 \mathrm{~g}\right.$ soil $/ 30 \mathrm{ml}, 0.003$ molar $\mathrm{Ca}\left[\mathrm{ClO}_{4}\right]_{2}$ solution, with initial concentrations of $\mathrm{Pu}$ and picolinate of $10^{-8} \mathrm{M}$ and $10^{-5} \mathrm{M}$, respectively)

distribution of adsorption sites. In other words, adsorption is taking place at a surface that contains sites with a range of binding energies. Initially, the adsorption will take place at sites with the highest energy and further surface complexation will occur at sites with progressively less energy. As a result of this process, adsorption will be strongest at the lowest concentration of adsorbate and the relative degree (i.e., percentage) of adsorption will decrease with increasing concentration of adsorbate. It seems safe to conclude that the "oxidized" Pu was predominately in valence states (V) and(VI) based on the relatively low adsorption tendencies at least for the tests at $6.7 \times 10^{-7} \mathrm{M}$ Pu starting concentrations. Reduced forms of $\mathrm{Pu}$, valence states (III) and (IV), should have exhibited greater adsorption at the near neutral and alkaline $\mathrm{pH}$ values such as was observed for $\mathrm{Sm}(\mathrm{III})$ and $\mathrm{Th}(\mathrm{IV})$ discussed earlier.

The adsorption of picolinate in the "oxidized" $\mathrm{Pu}$ batch tests is consistent with previous results where complexation to metals was not significant and the ligand was adsorbing as a free anion.

The percent adsorption plots shown in Figures 5.1 through 5.28 can be formulated into $\mathrm{K}_{\mathrm{d}}$ values readily because we also know the volume of solution used and mass of sediment in each test container. For convenience we have included Appendix $\mathrm{B}$ that lists the comparable $\mathrm{Kd}$ values in table form as a function of $\mathrm{pH}$.

\subsection{Flow-Through Column Experiments}

As discussed in Section 3.3, flow through column tests allow one to study the adsorption of complexed metal-organic ligands at soil to solution ratios that are more realistic with actual conditions and under advective flow conditions where species can separate from each other during the various reactions. Further, flow through column tests allow one to study the desorption of adsorbed species more readily than batch adsorption tests. Thus near the end of the project, selected column tests were run to explore 
whether the results of the batch adsorption tests were yielding an accurate picture of the fate of organic ligand-radionuclide complexing agents in soil porewater germane to shallow land burial conditions. The column experiments are discussed in terms of the normalized concentration of the effluent (the observed concentration in aliquots of effluent divided by the constant influent concentration that was pumped into the column at constant flow rate) plotted against the cumulative pore volumes of effluent collected out of the column. As discussed in Section 3.3, a pore volume is the amount of solution necessary to fill the void space [porosity] of the packed column. The breakthrough curve for each column experiment is a plot of the normalized effluent concentration $\left[\mathrm{C}_{\text {eff }} / \mathrm{C}_{\text {inf }}\right]$ plotted on the $y$ axis versus the cumulative pore volumes collected plotted on the $x$ axis. Because the column tests were run at a constant flow rate, the cumulative pore volumes are also linearly related to elapsed time. The number of pore volumes at which the breakthrough curve (normalized effluent concentration as plotted on the y axis) reaches a value of 0.5 is called the retardation factor. The retardation factor is related to the $K_{d}$ as described in several classical transport text books (for example see Freeze and Cherry 1979). The following qualitative discussion describes the results of the six column tests that were run for this project and Figures 5.29 through 5.34 show the breakthrough plots.

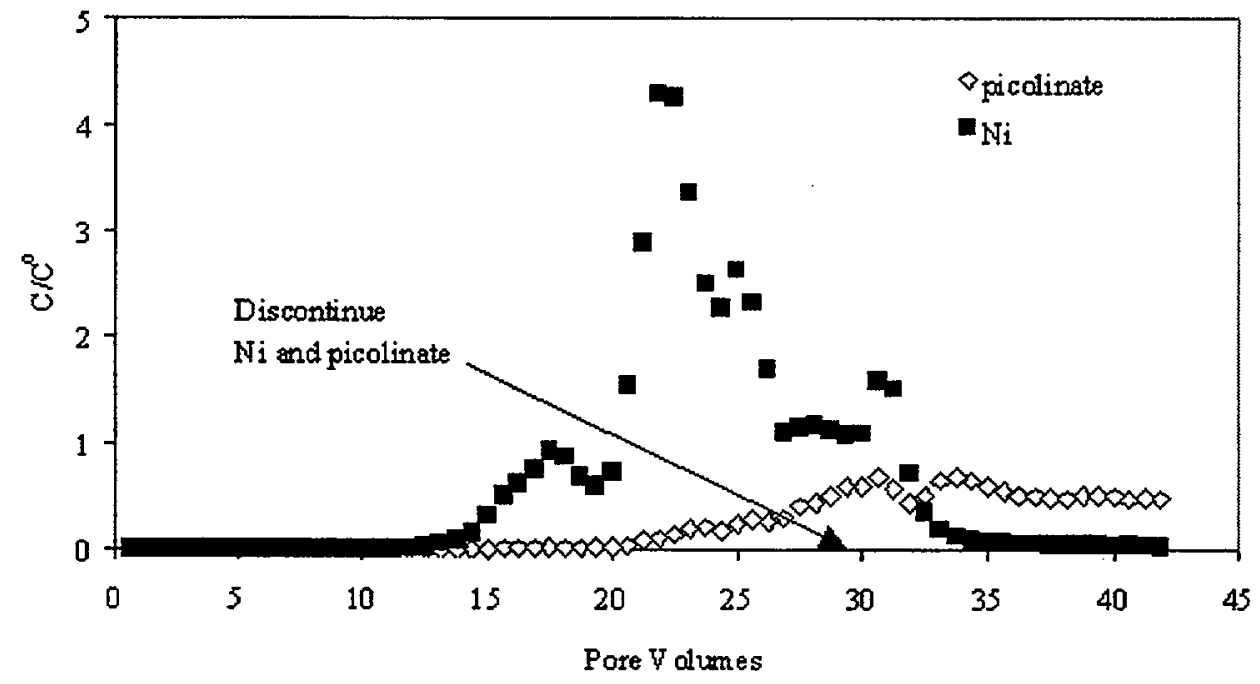

Figure 5.29. Flow Through Column Results for $\mathrm{Ni}^{2+}$ and Picolinate Through $1.2 \%$ Iron Oxide Coated Sand (influent solution 0.003 molar $\mathrm{Ca}\left[\mathrm{ClO}_{4}\right]_{2}$ with initial concentrations of $\mathrm{Ni}^{2+}$ and picolinate of $10^{-6} \mathrm{M}$ and $10^{-4} \mathrm{M}$, respectively) 
$\mathrm{Ni}^{2+}$ and picolinate transport through iron oxide coated sand at initial concentrations of $10^{-6} \mathrm{M}$ and $10^{-4} \mathrm{M}$, respectively, are shown in Figure 5.29. The results indicate fairly complete adsorption of both $\mathrm{Ni}^{2+}$ and picolinate through the first 15 pore volumes of tracer-laden solution. After 15 pore volumes, the nickel begins to breakthrough the column until complete breakthrough is observed at about 17.5 pore volumes. During this time no picolinate is measured in the effluent. After 17.5 pore volumes, the $\mathrm{Ni}^{2+}$ in the effluent begins to decrease and then at about 20 pore volumes a sharp increase in $\mathrm{Ni}^{2+}$ is observed in the effluent. The $\mathrm{Ni}^{2+}$ concentration in the effluent exceeds the influent concentration by a factor of 4 at its peak at about 22 pore volumes. After 22 pore volumes the concentration of $\mathrm{Ni}^{2+}$ in the effluent falls off almost as precipitously (over pore volumes 24 to 34 ) as it increased. The injection of Ni-picolinate was stopped after 29 pore volumes and unspiked background electrolyte was injected for another 15 pore volumes. During the flushing period the Ni concentration in the effluent was somewhat erratic at first but soon dropped to near zero by the $33^{\text {rd }}$ pore volume. Meanwhile the picolinate first broke through in the effluent at about the time the Ni started its dramatic rise (pore volume 20). However the rise in picolinate was slow and gradual. At the time that the tracers were stopped and flushing began, the picolinate break through had reached about $80 \%$. Picolinate breakthrough dropped some after the flushing began but continued until the column was dismantled. The reason for this anomalous $\mathrm{Ni}$ behavior (finding elevated $\mathrm{Ni}$ concentrations of as much as 4 times greater than that in the influent) is not readily apparent. Measurements taken during the course of this experiment indicate that the effluent $\mathrm{pH}$ remained at about 6.7 through the first 20 pore volumes. At 20 pore volumes the $\mathrm{pH}$ increased suddenly to an average of about 7.4 (nearly the same as the influent) until the test was stopped at 42 pore volumes.

Comparison of the conditions of this column experiment with the batch $\mathrm{Ni}^{2+}$-picolinate adsorption experiment conducted at a picolinate concentration of $10^{-4} \mathrm{M}$ (see Figure 5.3 for batch results with similar picolinate but 10 times more $\mathrm{Ni}$ ) indicates that only a small percentage of the $\mathrm{Ni}^{2+}$ and picolinate were adsorbed at $\mathrm{pH} 6.7$ (approximately 5\% for the nickel and 15\% for the picolinate). The adsorption in the batch experiments appears to be relatively low compared to the complete adsorption observed in the column experiment up to approximately 15 pore volumes. This apparent discrepancy between the batch and the column results may be caused by the large difference in the liquid to solid ratios. For example, in the batch experiments the liquid to solid ratio was $60 \mathrm{~L} / \mathrm{kg}$. In the column experiment, 15 pore volumes equates to a liquid to solid ratio of only $3.6 \mathrm{~L} / \mathrm{kg}$. Also the batch data in Figure 5.3 at ten times higher Ni concentration likely underpredicts the percentage adsorption that would occur for a test with 10 times less $\mathrm{Ni}$. Based on the column breakthrough data, the adsorption capacity of the $1.2 \%$ iron oxide coated sand for nickel in the presence of $10^{-4} \mathrm{M}$ picolinate is $3.4 \times 10^{-6} \mathrm{~mol} / \mathrm{kg}$ before substantial breakthrough occurs.

A mass balance of the nickel and picolinate was conducted by accounting for the quantity of material in the effluent and what remained adsorbed on the column material. The material on the column was extracted twice using $1 \mathrm{M}$ nitric acid at a soil to acid ratio of 1 to 5 . For nickel, the mass balance was $102.2 \%$ made up of $96.4 \%$ in the effluent and $5.8 \%$ removed from the soil. For the picolinate $32.1 \%$ was accounted for in the effluent and $49.8 \%$ was extracted from the column for a total of $81.9 \%$. It is uncertain if the $1 \mathrm{M}$ nitric acid is an efficient extractant for removal of picolinate from soil. As a result, 
the mass balance results for the picolinate are less certain. Thus with the excellent mass balance on $\mathrm{Ni}$, we conclude that the unexpected high breakthrough between 20 and 25 pore volumes is not an artifact' error in our measurements.

We speculate that the Ni-picolinate complex and excess free picolinate is at first adsorbed onto the hydrous ferric oxide coatings and then the picolinate starts to interact with the ferric oxide. If the reaction was a simple exchange of metals attached to the picolinate ligand there would have to be strong tendency for the solid adsorbent to adsorb Fe(III)-picolinate complexes because we do not see a massive release of picolinate tracer along with the $\mathrm{Ni}$. However, the picolinic ligand is present at 10 times the $\mathrm{Ni}$ concentration so that percentage changes in picolinic are muted. Further, free Ni adsorption to the ferric oxide coated sand shows that adsorption is quite sensitive to $\mathrm{pH}$ between values of 6.7 to 7.4 as shown in Figure 5.1 where the $\mathrm{Ni}$ percentage adsorbed changes from about 20 to $85 \%$ as $\mathrm{pH}$ increases from 6.7 to 7.4. The adsorption curve in Figure 5.1 would shift to the left (lower $\mathrm{pH}$ adsorption edge) for lower $\mathrm{Ni}$ concentrations and would shift to the right (higher $\mathrm{pH}$ adsorption edge) for larger Ni concentrations. Based on a Ni concentration of $4 \times 10^{-6} \mathrm{M}$ (four times the influent) we would expect at least 20 to $85 \%$ adsorption for the free $\mathrm{Ni}\left[\mathrm{Ni}^{+2}\right]$, if the picolinate was simply exchanging the $\mathrm{Ni}$ for $\mathrm{Fe}$ and allowing the free $\mathrm{Ni}$ ion to interact on its own. We thus can not explain the large percentage release of $\mathrm{Ni}$ between 20 and 25 pore volumes without evoking the partial dissolution of the ferric oxide substrate. This would effectively remove adsorption substrates for both the free cations $\left(\mathrm{Ni}^{2+}\right.$ and $\left.\mathrm{Fe}^{3+}\right)$, free picolinate, and the metal-ligand complexes. Unfortunately, we did not monitor dissolved $\mathrm{Fe}$ in the effluents to determine whether we caused net adsorption site disappearance. A much more quantitative analysis similar to the work of Davis et. al. (2000) for a flow through field test with transition metals and EDTA would be required to fully understand the results of this experiment. This column test does show that predictions that use simple constant $\mathrm{K}_{\mathrm{d}}$ and constant source release constructs may not be exclusively conservative in predicting concentrations of contaminants in water downgradient from disposal sites.

Transport of $\mathrm{Ni}^{2+}$ and picolinate through Milford soil at initial concentrations of $10^{-6} \mathrm{M}$ and $10^{-4} \mathrm{M}$, respectively, are shown in Figure 5.30. The results appear to be consistent with expectations based on the batch adsorption experiments. For example, the batch adsorption results in Figure 5-6 indicate that at $\mathrm{pH} 5.0$ (the average $\mathrm{pH}$ measured in the column effluent), $\mathrm{Ni}^{2+}$ adsorption is relatively low. It can be expected that at the lower $\mathrm{Ni}^{2+}$ concentration used in the column experiment and higher solid to solution ratios, adsorption will be somewhat higher than that observed in the batch experiments (see Figure 5.6). For picolinate at concentrations below $10^{-3} \mathrm{M}$, adsorption at $\mathrm{pH} 5$ is considerably higher than that of $\mathrm{Ni}^{2+}$ (see Figures 5.5 and 5.6). In Figure 5.30, it is apparent that the breakthrough of $\mathrm{Ni}^{2+}$ begins much sooner than that of picolinate. Ten pore volumes equates to only $1.6 \mathrm{~L}$ of leachate $/ \mathrm{kg}$ soil before $\mathrm{Ni}^{2+}$ begins to breakthrough ( $\mathrm{a} \mathrm{Ni}^{2+}$ adsorption capacity of $1.6 \times 10^{-4} \mathrm{~mol} / \mathrm{kg}$ ). It is interesting to note that the breakthrough of both $\mathrm{Ni}^{2+}$ and picolinate in this column test are very gradual and the $\mathrm{C} / \mathrm{C}^{\circ}$ values are considerably less than 1.0. This type of behavior may also be indicative of adsorption site heterogeneity (binding sites with a range of binding energies). Also note that at 25 and 30 pore volumes of effluent there is a sudden decrease in $\mathrm{C} / \mathrm{C}^{\circ}$ for $\mathrm{Ni}^{2+}$. These decreases were due to temporary spikes in $\mathrm{pH}$ that occurred at this time (up to $\mathrm{pH} \mathrm{7.0)}$ ). These $\mathrm{pH}$ spikes resulted in a temporary increase in $\mathrm{Ni}^{2+}$ adsorption, but did not significantly affect the picolinate. We do not know what caused the two sudden changes in effluent $\mathrm{pH}$. 


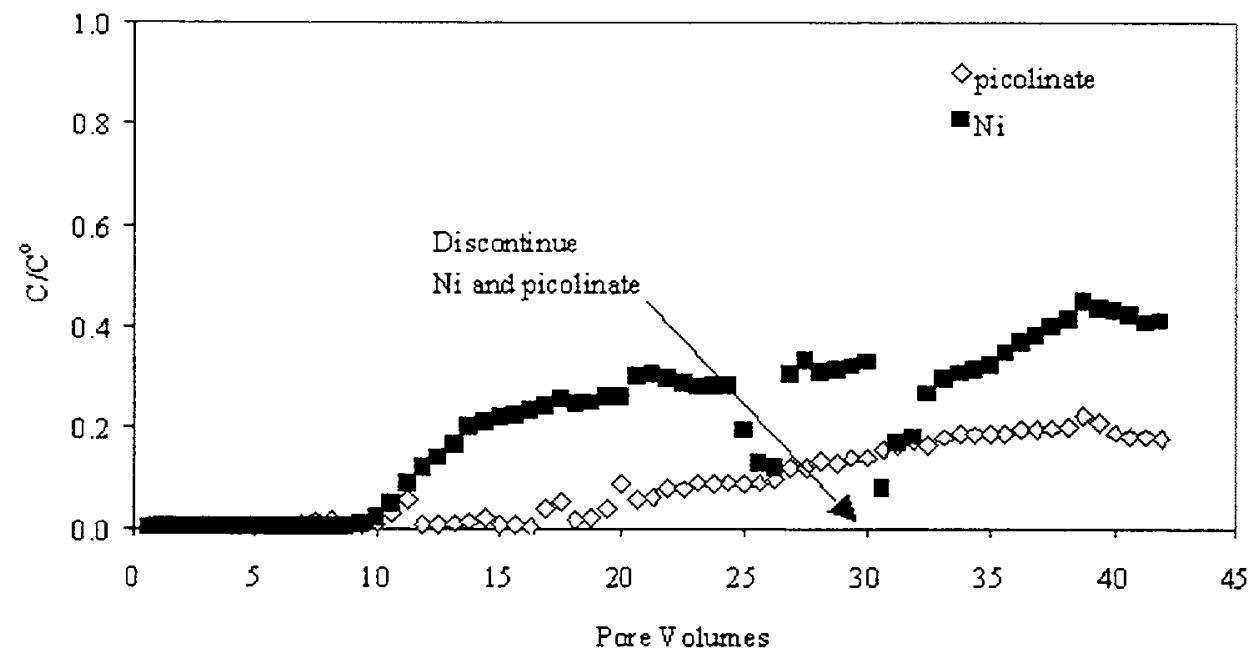

Figure 5.30. Flow Through Column Results for $\mathrm{Ni}^{2+}$ and Picolinate Through Milford Soil (influent solution 0.003 molar $\mathrm{Ca}[\mathrm{ClO} 4])_{2}$ with initial concentrations of $\mathrm{Ni}^{2+}$ and picolinate of $10^{-6} \mathrm{M}$ and $10^{-4} \mathrm{M}$, respectively)

For this test the metal-ligand laden solution was pumped for 30 pore volumes and then the solution without tracers was used to flush for an additional 13 pore volumes. The changing of solutions did not seem to change the breakthrough curves and is not considered related to the $\mathrm{pH}$ excursions. It would thus appear that the adsorption of the metal and ligand are reversible. If the adsorption was not reversible we would have expected the breakthrough curves to drop abruptly a few pore volumes after tracer was no. longer being injected. The mass balance for the data in Figure 5.30 indicated that $29.3 \%$ of the nickel was accounted for in the effluent and $61.8 \%$ was extracted from the soil column for a total of $91.1 \%$ recovered. For the picolinate $11.7 \%$ was in the effluent and $23.1 \%$ was extracted from the soil column for a total of $34.8 \%$ recovered. Based on the shapes of the curves and the mass balances, we did not run the flushing long enough to elute all the reversibly held $\mathrm{Ni}$ and picolinate and that the picolinate, being adsorbed more strongly at the slightly acidic natural $\mathrm{pH}$ of the Milford soil, would require more flushing than would be needed for flushing the $\mathrm{Ni}$.

The break through of another column experiment that was nearly the same as Figure 5.30 but with a picolinate concentration at $10^{-5} \mathrm{M}$ is presented in Figure 5.31. No breakthrough of either $\mathrm{Ni}^{2+}$ or picolinate occurs for the first 30 pore volumes in this experiment. The average $\mathrm{pH}$ of the effluent in this experiment was 5.0, the natural $\mathrm{pH}$ of the Milford soil. No flushing was performed on this column because our intent was to concentrate on tests where relatively early breakthrough for one of the tracers was observed. The fact that the picolinate does not breakthrough is qualitatively consistent with the batch results in Figure 5.6 wherein 50 to $60 \%$ of picolinic acid is expected to adsorb. Given the much higher solid to solution ratio in the column test versus the batch tests breakthrough should be delayed. The lack of any breakthrough for the nickel in this experiment is surprising considering the fact that breakthrough 


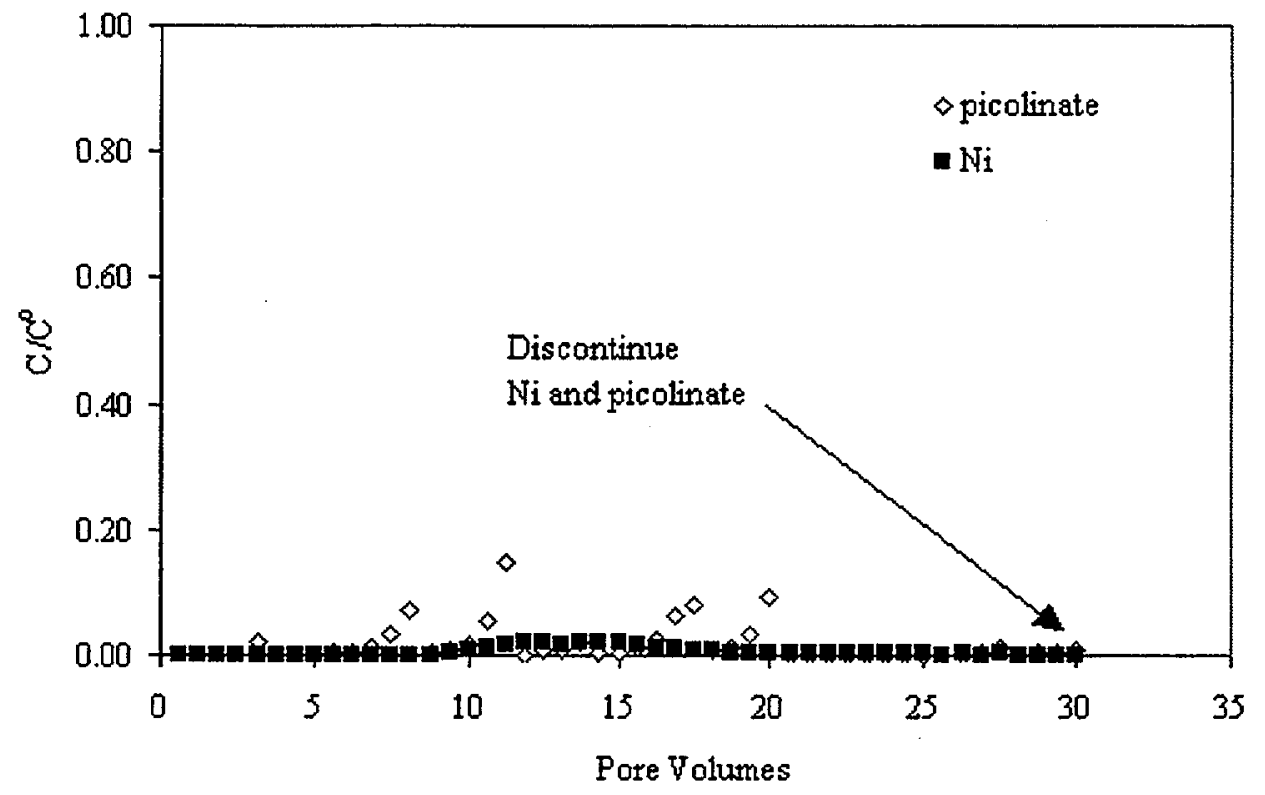

Figure 5.31. Flow Through Column Results for $\mathrm{Ni}^{2+}$ and Picolinate Through Milford Soil (influent solution 0.003 molar $\mathrm{Ca}[\mathrm{ClO} 4]_{2}$ with initial concentrations of $\mathrm{Ni}^{2+}$ and picolinate of $10^{-6} \mathrm{M}$ and $10^{-5} \mathrm{M}$, respectively)

did occur in the previous experiment [Figure 5.30] for the same soil, same $\mathrm{pH}$, and same $\mathrm{Ni}^{2+}$ concentrations and the fact that very little adsorption of $\mathrm{Ni}^{2+}$ occurred at $\mathrm{pH} 5.0$ both in the presence and absence of picolinate in the batch tests shown in Figures 5.5 and 5.6.

The mass balance for this experiment indicated that $0.6 \%$ of the nickel was in the effluent and $64.5 \%$ of the nickel could be extracted from the column material for a total of $65.1 \%$. For the picolinate $1.7 \%$ was in the effluent and $1.0 \%$ extracted from the column material for a total recovery of $2.7 \%$. The poor recovery compared to the other tests especially for the nickel suggests the results may be suspect. The results imply significant irreversible adsorption of both $\mathrm{Ni}$ and picolinate with contact with $1 \mathrm{M}$ nitric acid, an observation that does not seem valid.

Figure 5.32 shows results for the flow-through experiment conducted for $10^{-5} \mathrm{M} \mathrm{Ni}^{2+}$ and $10^{-5} \mathrm{M} \mathrm{EDTA}$ through iron oxide coated sand. Essentially all the $\mathrm{Ni}^{2+}$ and approximately $90 \%$ of the EDTA are completely adsorbed onto the column during the first 32 pore volumes. At this point the concentrations of both $\mathrm{Ni}^{2+}$ and EDTA begin a gradual increase in concentration in the effluent. In this experiment the average effluent $\mathrm{pH}$ was nearly the same as the influent (7.5). Based on the quantity of iron oxide coated sand in the column, EDTA concentration in the influent, an EDTA adsorption maximum of $0.0049 \mathrm{moles} / \mathrm{mole} \mathrm{Fe}$ at pH 4.5 (Szecsody et al. 1994) and an estimated fraction of available sites of 0.18 at pH 7.5 (Dzombak and Morel 1989), it was calculated that the adsorption capacity of this soil column for EDTA should be reached at 75 pore volumes, instead of the $\sim 32$ pore volumes observed. 


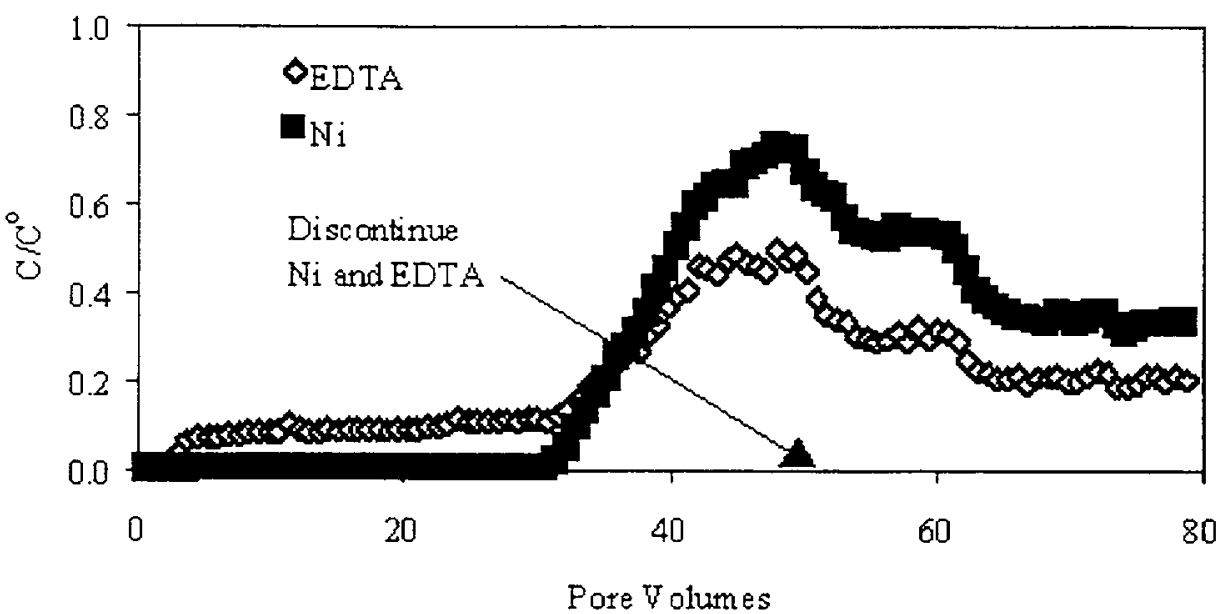

Figure 5.32. Flow Through Column Results for $\mathrm{Ni}^{2+}$ and EDTA Through $1.2 \%$ Iron
Oxide Coated Sand (influent solution 0.003 molar $\mathrm{Ca}\left[\mathrm{ClO}_{4}\right]_{2}$ with initial
concentrations of $\mathrm{Ni}^{2+}$ and EDTA of $10^{-5} \mathrm{M}$ and $10^{-5} \mathrm{M}$, respectively)

The behavior observed in Figure 5.32, [the offset in the breakthrough percentage of Ni and EDTA tracers] can be explained as follows. Initially the Ni-EDTA complex is rapidly adsorbed to the iron oxides on the sand. After adsorption of the complex, dissociation of $\mathrm{Ni}^{2+}$ from some of the Ni-EDTA complex occurs, followed by ligand promoted dissolution (Szecsody et al. 1994; Stumm and Wieland 1990) of some of the iron oxide. This results in liberation of free $\mathrm{Ni}^{2+}$ and $\mathrm{Fe}(\mathrm{III})$-EDTA complexes. At the $\mathrm{pH}$ of this experiment, the free $\mathrm{Ni}^{2+}$ is readily re-adsorbed to the iron oxides. Re-adsorption of the Fe(III)-EDTA complex is slow enough that a low (approximately $10 \%$ of the influent EDTA concentration), but significant amount of EDTA passes through the column until the adsorption capacity of the soil column for $\mathrm{Fe}(\mathrm{III})$-EDTA is reached at approximately 32 pore volumes. After 32 pore volumes, the concentrations of $\mathrm{Ni}^{2+}$ and EDTA in the effluent begin to increase rapidly. It is suggested that after 32 pore volumes the adsorption capacity for all species [free $\mathrm{Ni}, \mathrm{Ni}(\mathrm{II})$-EDTA, Fe(III)-EDTA, and free EDTA] is approaching saturation and all species are beginning to pass through the column with decreased adsorption. After 32 pore volumes the rate of increase in effluent concentration of $\mathrm{Ni}^{2+}$ is faster than that of EDTA. This indicates that exhaustion of the adsorption capacity results in breakthrough behavior that is more complicated than the Ni-EDTA complexes simply passing through the column as one species with diminishing adsorption. The results suggest that in addition to intact Ni-EDTA complexes passing through the column, dissociation of $\mathrm{Ni}^{2+}$ from the adsorbed $\mathrm{Ni}$-EDTA complexes is also occurring. Because the adsorption sites are nearly exhausted, adsorption of the free $\mathrm{Ni}^{2+}$ is inhibited, resulting in an increase in the $\mathrm{Ni}^{2+}$ concentration relative to EDTA in the effluent. Some of the EDTA remains adsorbed as Fe(III)-EDTA complexes.

After 49 pore volumes of $\mathrm{Ni}$-ETDA laden solution was collected, the influent solution was changed to background electrolyte only and the column flushed for an additional 20 pore volumes. The effluent concentrations of both $\mathrm{Ni}$ and EDTA decreased slowly during the flushing but the offset (more $\mathrm{Ni}$ released than EDTA) continued. The mass balance results for this experiment are as follows: $43.1 \%$ of the nickel was in the effluent, $54.2 \%$ was extracted from the soil column for a total recovery of $97.3 \%$. For EDTA, 35.3\% was found in the effluent and $56.3 \%$ was extracted from the column for a total 
recovery of $91.5 \%$. The results are quite good and suggest that with continued flushing, the total mass injected would have shown up in effluent. That is, the adsorption reactions for the various tracers and their interactions with the iron oxide coated sands were reversible.

Figure 5.33 shows results for the flow-through experiment conducted for $10^{-5} \mathrm{M} \mathrm{Ni}^{2+}$ and EDTA through Milford soil that had been pre-equilibrated with caustic to simulate reaction with cement leachate. It is clear that the Ni-EDTA complexes are traveling through the column with very little adsorption. The breakthrough reached $100 \%$ after a few pore volumes. The average $\mathrm{pH}$ measured in the effluent was 9.8 because of our pre-treatment to remove the natural acidity as discussed in Section 3.3. The NiEDTA complex is strong and it remains intact during transport through the soil column.

The lack of adsorption is consistent with the batch results shown in Figure 5.8 that show very little adsorption of the Ni(II)-EDTA complex at $\mathrm{pH}$ values above 9. When injection of the Ni-EDTA laden solution was stopped and background electrolyte flushed through the column, the effluent concentrations of the tracers quickly dropped to zero as one would expect. There is a slight smearing in the trailing edge of this pulsed input compared to the shape of the leading edge. This is commonly found and is attributed to the slower diffusion of some tracer out of smaller pores during the desorption process. See van Genuchten (1981) and van Genuchten and Parker (1984) for discussion on analyzing breakthrough curves and the causes of asymmetry. The mass balance results for this experiment were $99.1 \%$ of the nickel was in the effluent and $0.3 \%$ was extractable from the soil column for a total of $99.4 \%$ recovered. For

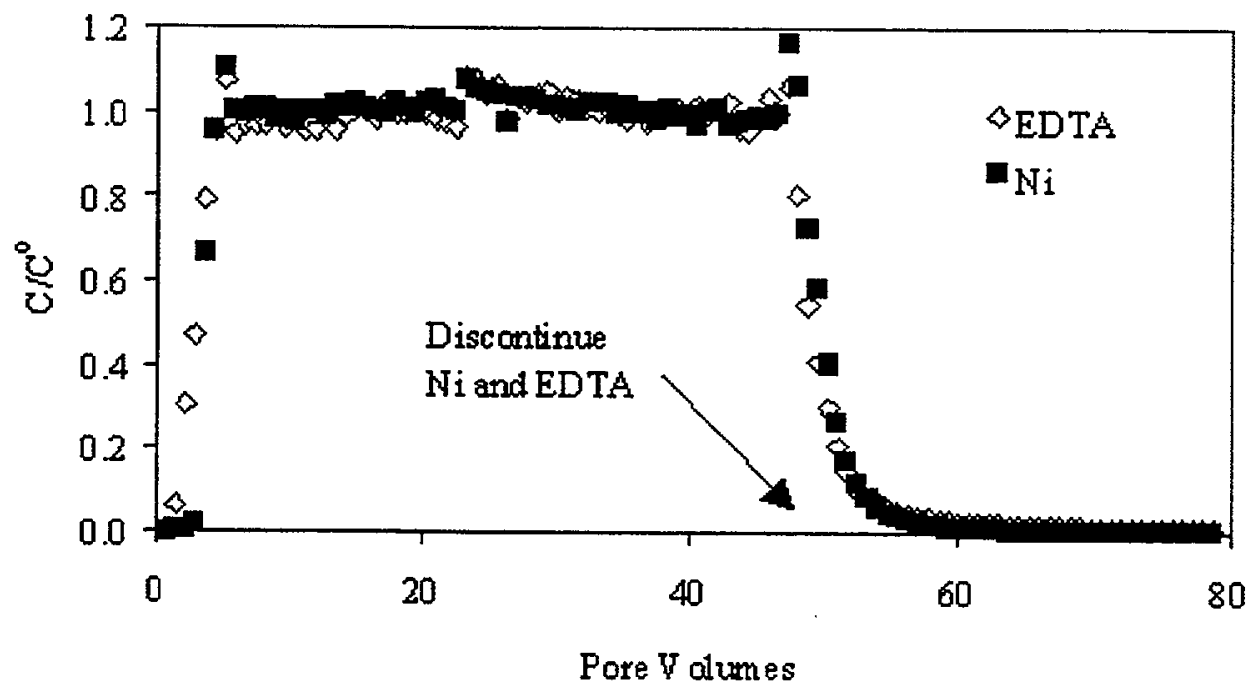

Figure 5.33. Flow Through Column Results for $\mathrm{Ni}^{2+}$ and EDTA Through Milford Soil (influent solution 0.003 molar $\mathrm{Ca}\left[\mathrm{ClO}_{4}\right]_{2}$ with initial concentrations of $\mathrm{Ni}^{2+}$ and EDTA of $10^{-5} \mathrm{M}$ and $10^{-5} \mathrm{M}$, respectively) 
EDTA, $98.1 \%$ was measured in the effluent and $1.7 \%$ was extracted from the soil column for a total of $99.8 \%$ recovered. Within experimental error essentially all of the tracer injected in the first 47 pore volumes was flushed out of the soil by the end of the experiment, suggesting that the small amount of adsorption that occurs in the very beginning of the experiment is completely reversible.

Results of a flow-through column experiment for $\mathrm{Pu}$ and picolinate through a column containing Milford soil that was pre-treated to remove natural acidity [to simulate cement leachate preconditioning] is shown in Figure 5.34. The initial concentrations of $\mathrm{Pu}$ and picolinate were $10^{-7} \mathrm{M}$ and $10^{-4} \mathrm{M}$, respectively. The picolinate is being transported through the column almost completely uninhibited; whereas the $\mathrm{Pu}$ is completely adsorbed. The average effluent $\mathrm{pH}$ was $9.8, \mathrm{a} \mathrm{pH}$ value similar to cement leachate. These results are consistent with the results from the batch adsorption experiment shown in Figure 5.28 where the $\mathrm{Pu}$ and picolinate concentrations were each ten times lower. Both the column and the batch results suggest that oxidized $\mathrm{Pu}$ and picolinate do not form a strong complex and thus are acting independently in their adsorption reactions. At $\mathrm{pH} \mathrm{9.8,} \mathrm{Pu}$ is highly adsorbing and picolinate does not adsorb at all. After 49 pore volumes of $\mathrm{Pu}$ and picolinate injection the solution was changed to background electrolyte alone and flow continued. The effluent concentrations of picolinate dropped rapidly to zero suggesting that any small amount of picolinate adsorbed in the soil was quickly and reversibly desorbed. However, no Pu was flushed out of the column even after an additional 31 pore volumes of flushing. Pu appears to be essentially irreversibly adsorbed to or precipitated in the Milford soil column or at least has a very high desorption $\mathrm{K}_{\mathrm{d}}$ at the high $\mathrm{pH}$ value representative of cement leachate. The mass balance results for this experiment indicate that $0.0 \%$ of the $\mathrm{Pu}$ was found in the effluent, $97.1 \%$ of the Pu was extractable in the $1 \mathrm{M}$ nitric acid from the soil for a total of $97.1 \%$ recovery. For the picolinate $99.1 \%$ was found in the effluent and $0.6 \%$ was extracted from the column for a total of $99.7 \%$.

In summary, some of the column tests showed breakthrough that was qualitatively the same as the batch tests. In all the column tests but the one shown in Figure 5.31 the adsorption of the organic ligand-metal complex, or the free organic ligand and free metal (disassociated species) was reversible. That is, close to the total mass injected was recovered in the flushing stage or would have eventually flushed if enough untraced background solution had been pumped through the column. We do not understand why we had poor recovery in the column test shown in Figure 5.31 and this was the column not flushed at all.

The two tests that used the iron-oxide coated sand show complicated behavior that was interpreted as being caused by the ligand (both EDTA and picolinate) interacting with the ferric oxides. The Ni-organic ligand complex in both cases appears to exchange $\mathrm{Ni}$ for $\mathrm{Fe}$ to some extent such that free $\mathrm{Ni}^{+2}$ is produced and $\mathrm{Fe}$ (III)-organic complexes are formed that adsorb with different strengths to the soil than the $\mathrm{Ni}$-organic complex. Further, we suspect that some of the organic ligand is dissolving the ferric oxide coatings (forming soluble ligand-Fe(III) complexes) and destroying sorption sites. The combination of all these reactions leads to rather complicated breakthrough curves that would require more detailed study. An excellent methodology for studying the transport of ETDA-transition metal complexes has recently been published [Davis et al. 2000]. A more quantitative analyses of our results would be possible using the Davis et al. 2000 approach. 


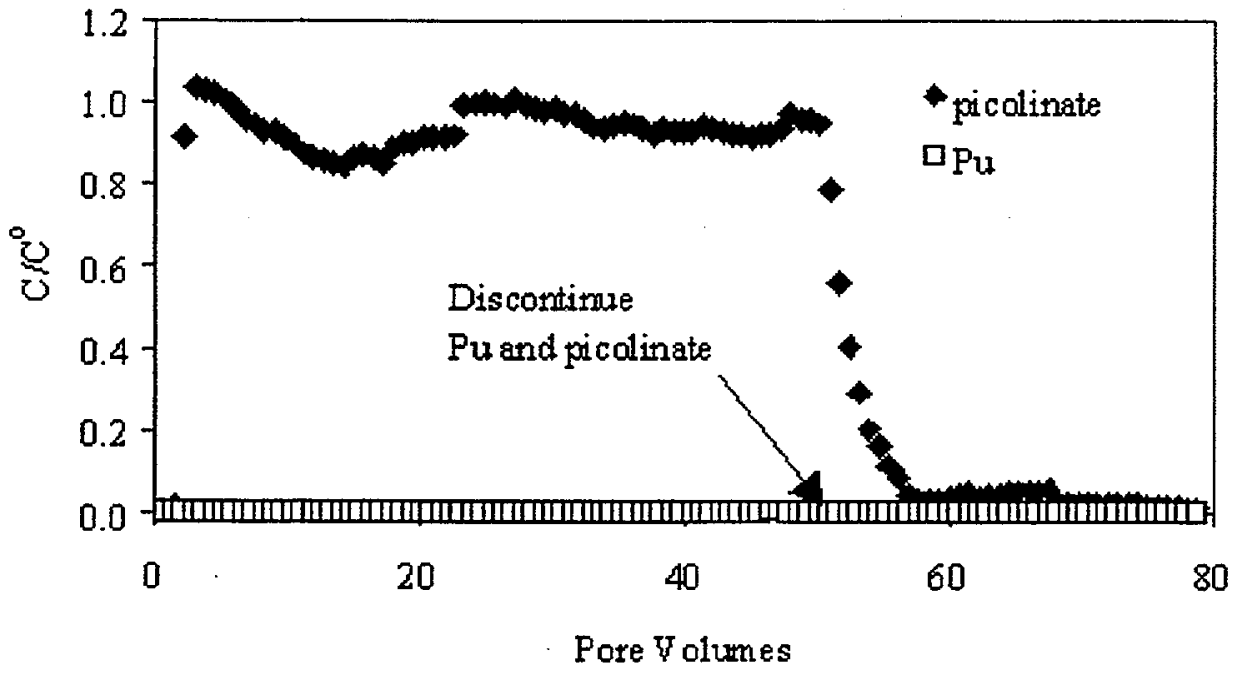
Figure 5.34. Flow Through Column Results for Pu and Picolinate Through Milford Soil (influent solution 0.003 molar $\mathrm{Ca}\left[\mathrm{ClO}_{4}\right]_{2}$ with initial concentrations of $\mathrm{Pu}$ and picolinate of $10^{-7} \mathrm{M}$ and $10^{-4} \mathrm{M}$, respectively)

In two of the column tests the radionuclide-ligand appear to remain as a complex (see Figures 5.31 and 5.33), in three of the tests there is partial disassociation of the metal and ligand such that their breakthrough curves are different (see Figures 5.29, 5.30, and 5.32). For the final column test, the oxidized $\mathrm{Pu}$ and picolinic acid injected into Milford soil that had been pre-treated to remove natural acidity, the complex likely was never formed and the $\mathrm{Pu}$ and picolinate interact with the soil as free ions. 


\subsection{Summary and Recommendations}

The available leach data for cement solidified spent resins from reactor piping decontamination suggests that maximum concentrations of organic ligands range from $2 \times 10^{-3}$ to $10^{-4} \mathrm{M}$ for picolinic acid and $3 \mathrm{x}$ $10^{-4}$ to $10^{-5} \mathrm{M}$ for EDTA. These ranges may in fact be elevated because the cement leachates have high $\mathrm{pH}$ values above 12 . At $\mathrm{pH} 12$, about $0.01 \mathrm{M}$ "free" hydroxide is present in the leachates that will compete for anion exchange sites in the spent resins that contain the sorbed organic ligands and anionic ligand-metal complexes. Because anion exchange resins are regenerated using free hydroxide such as sodium hydroxide, the cement leachate may release higher concentrations of organic ligands and anionic complexes than the leachates of unsolidified spent resins disposed in high integrity containers. Only one datum was available for the concentration of EDTA from leached dewatered spent resins from the CAN-DEREM process. The concentration of total EDTA in the simulated groundwater leachate $(\mathrm{pH}=$ 7.5) was $2.4 \times 10^{-4} \mathrm{M}$. This value is near the high end of the range found in leaching cement solidified resins from separate reactor decontaminations using older CAN-DEREM-like methods. The data base for concentrations of total organic ligands in leachates that could represent conditions in a disposal facility and surrounding sediment pore waters is not robust. For this project we had to conclude that the few data available represent the upper range of concentrations one might find. Obviously, the higher the concentration of organic ligands in leachate the more impact they might have on contaminant mobility because of mass action relationships in forming complexes.

Speciation calculations were conducted to determine the potential significance of organic chelating/ complexing agents in facilitating transport of radionuclides from the cement solidified resin waste forms and dewatered resins and the subsequent solutions formed as leachate interacts with common soil and aquifer materials. This was accomplished using thermodynamic equilibrium calculations to determine the contribution of the organic chelating/complexing agents to the speciation scheme of the important radionuclides and stable metals in the leachates produced from spent resins. Initially the leachate solutions from cementitious waste forms have a high $\mathrm{pH}$, which results from reactions with portland cement. The chemical evolution of these leachates can be expected to follow two pathways. If the leachates are contained within the waste site with an impermeable barrier, the high pH solutions could be neutralized by carbonic acid from the diffusion of $\mathrm{CO}_{2}$ from the atmosphere or soil gas. Impermeable barriers are prone to failure and as a result will eventually leak. If the leachates escape into the soil column, it is expected that the $\mathrm{pH}$ will decrease due to the natural buffering capacity of the soil. To simulate these $\mathrm{pH}$ neutralization processes, speciation calculations were conducted as a function of $\mathrm{pH}$. In these calculations it was assumed that the three principal soil components affecting $\mathrm{pH}$ and the subsequent speciation of important radionuclides and chelating agents are calcite, amorphous ferric hydroxide and gibbsite. The spent resin leachates were allowed to interact with finite amounts of these three representative phases to proxy for all dissolution/precipitation interactions that might occur in sediments. No adsorption reactions were included, however.

The chelate, radionuclide and metal concentrations selected for the speciation calculations were based on a review of decontamination waste leachate data. The most important decontamination processes from a waste disposal perspective are LOMI, CAN-DEREM and CITROX. A total of six cementitious leachates were selected for the modeling analysis to be representative of leachates derived from the LOMI, CAN-DEREM and CITROX spent resins solidified in cement. In general, the concentrations of 
the chelating agents and metals used in the speciation calculations were selected to be the highest measured in any of the INEEL leachates for a given cement waste form. For leachates in contact with cement ( $\mathrm{pH}=12.3$ ), the most significant organic complexation occurred in the CAN-DECON and NS-1 leachates. These two leachates were used as reasonable surrogates for the CAN-DEREM process for which no leach data are available for cement solidified material. EDTA or mixed OH-EDTA complexes dominated the speciation scheme of $\mathrm{Mn}^{2+}, \mathrm{Ni}^{2+}, \mathrm{Sr}^{2+}$, and $\mathrm{Zn}^{2+}$. Significant organic complexation also occurred for $\mathrm{Am}^{3+}, \mathrm{Co}^{2+}$, and $\mathrm{Pu}^{3+}$. In the NS-1 leachates DTPA, EDTA or mixed OH-EDTA complexes dominated the speciation of $\mathrm{Am}^{3+}, \mathrm{Pu}^{3+}$, and $\mathrm{Sr}^{2+}$. Significant organic complexation also occurred for $\mathrm{Co}^{2+}, \mathrm{Mn}^{2+}$, and $\mathrm{Zn}^{2+}$.

Significant organic complexation also occurred in LOMI leachates in contact with cement, but only for leachates containing high concentrations of picolinate. In this case, picolinate complexes dominated the speciation scheme of $\mathrm{CO}^{2+}$ and $\mathrm{Ni}^{2+}$. No comparable leachates are available for LOMI spent resins that are disposed without further treatment aside from dewatering. Assuming that there is no major difference in picolinate concentrations in leachates from cement solidified and dewatered spent resins, the calculations performed in Section 4 for the cement leachates will adequately describe the speciation of all LOMI process leachates.

The calculated speciation results indicate that in cement waste form leachates at high pH, DTPA and EDTA will influence the speciation of a wider range of radionuclides/metals to a greater extent than picolinate. In addition, oxalate at concentrations found in leachates will not significantly influence radionuclide/metal speciation. These findings indicate that the CITROX and LOMI decontamination processes may be preferred over the CAN-DEREM from a radionuclide mobility standpoint, because the two former processes do not use EDTA or DTPA.

As the $\mathrm{pH}$ of the leachate solution decreases, the effect of organic complexation increases. As $\mathrm{pH}$ decreases, the importance of hydrolysis of metals/radionuclides decreases, allowing more complexation with the leached organic ligands. For the LOMI leachates, the picolinate complexes dominated the speciation of $\mathrm{Co}^{2+}, \mathrm{Ni}^{2+}, \mathrm{Zn}^{2+}$ and was significant for $\mathrm{Mn}^{2+}$ and trivalent actinides, especially for the FitzPatrick leachate with its higher picolinate concentration. For the CAN-DECON leachate nearly all the metals and radionuclides are predicted to be complexed with EDTA until the pH drops below 6 . Two exceptions are $\mathrm{Pu}^{4+}$ and $\mathrm{Cs}^{+}$which appear to remain unaffected by the organic ligands. In the CITROX leachates, oxalate and citrate complexes are predicted to dominate the speciation of trivalent actinides and nickel at common groundwater $\mathrm{pH}$ values (5-8.5).

Only one leach data set was available to address the leaching of un-solidified dewatered spent resins. This recent data set is for spent resins from the CAN-DEREM decontamination process. The leachate contained $2.4 \times 10^{-4} \mathrm{M}$ of total EDTA, which is near the high end of the range found in leachates from the cement solidified spent resins from the CAN-DECON and NS-1 processes. In addition, much higher concentrations of $\mathrm{Ni}^{2+}, \mathrm{Cr}^{3+}$, and $\mathrm{Mn}^{2+}$, occurred in the leachates from the dewatered spent resins relative to the cement solidified waste leachates. These higher concentrations of transition metals in the leachates, significantly affects the speciation schemes of the system. The general speciation results for the non-solidified spent resin leachate that has not been in contact with the soil components $(\mathrm{pH} 7.49)$ are as follows. EDTA was found to dominate the speciation scheme of $\mathrm{Am}^{3+}, \mathrm{Co}^{2+}, \mathrm{Fe}^{3+}, \mathrm{Ni}^{2+}, \mathrm{Pu}^{3+}$, and $\mathrm{Cr}^{3+}$. EDTA accounted for fractional speciation of $\mathrm{Mn}^{2+}$ and $\mathrm{Zn}^{2+}$ (7\% and $23 \%$, respectively). $\mathrm{Cs}^{+}, \mathrm{Pu}^{4+}$, and $\mathrm{Sr}^{2+}$ were essentially uncomplexed by EDTA. It was apparent that an excess of metals relative to EDTA 
occurred in the leachate solution. As a result, complexation by EDTA preferentially occurred with the metals that had the largest equilibrium stability constants. This had the general effect of reducing the degree of complexation by EDTA for a number of radionuclides and metals. When the leachate solution was equilibrated with calcite, amorphous ferric hydroxide and gibbsite and the $\mathrm{pH}$ was adjust between 6 and 10, the major speciation changes that occurred were the result of $\mathrm{Cr}(\mathrm{OH})_{3}(\mathrm{am})$ precipitation above $\mathrm{pH}$ 7.5. As the $\mathrm{Cr}(\mathrm{OH})_{3}(\mathrm{am})$ precipitated, EDTA was freed for complexation with other metals. The majority of the freed EDTA combined with the excess available $\mathrm{Mn}^{2+}$.

It is important to recognize that these speciation calculations ignore the potential influence of soil adsorption reactions between the surface sites on soils and the free radionuclide/metals, free ligands and radionuclide/ligand complexes themselves.

The results of these speciation calculations can be condensed to the following conclusions. The organic chelating agents in decontamination waste leachates with the highest potential for mobilizing metals and radionuclides are EDTA and picolinate assuming that new decontamination schemes that use other chelates are not developed. The potential for EDTA to mobilize metals is highest for divalent transition metals, with a moderate potential for trivalent actinides. Picolinate appears to have significant potential to mobilize only $\mathrm{Ni}^{2+}$ and $\mathrm{Co}^{2+}$.

In the batch adsorption studies we found that picolinate concentrations have to be $10^{-4} \mathrm{M}$ or larger to significantly lower the adsorption tendencies of divalent transition metals such as $\mathrm{Ni}$ and $\mathrm{Co}$. For other metals including $\mathrm{Sm}^{3+}$ [an analog for all trivalent actinides], $\mathrm{Th}^{4+}$ [an analog for all quadrivalent actinides], $\mathrm{NpO}^{2+}$ [a likely analog for $\left.\mathrm{Pu}(\mathrm{V})\right], \mathrm{UO}_{2}{ }^{2+}$, and oxidized $\mathrm{Pu}$, the picolinic acid concentration must reach concentrations greater than $10^{-3} \mathrm{M}$ before any adsorption lowering impacts are expected for radionuclides and metals. Flow through column tests show that the type of soil and porewater $\mathrm{pH}$ are important variables that combine with organic ligand concentration to affect cationic metal/radionuclide adsorption. Even at picolinate concentrations of $10^{-4} \mathrm{M}$, soils with moderate hydrous oxide content and/or high cation exchange clay mineral content can retard the breakthrough of $\mathrm{Ni}$ for up to 10 pore volumes. We estimate that complete loss of adsorption tendencies would require picolinate concentrations in the neighborhood of $10^{-3} \mathrm{M}$.

EDTA forms stronger complexes with divalent transition metals and both batch and column tests with $\mathrm{Ni}$ have shown that metal adsorption can be blocked when EDTA solution concentrations are $10^{-5} \mathrm{M}$ or higher. In a similar fashion EDTA complexes with oxycations such as $\mathrm{NpO}_{2}{ }^{+}, \mathrm{UO}_{2}{ }^{2+}$, and oxidized $\mathrm{Pu}$ are much weaker. Batch adsorption tests suggest that EDTA concentrations would have to be greater than $10^{-3} \mathrm{M}$ to have adverse effects on (other than divalent transition metals) cationic metal/radionuclide adsorption onto most soils in contact with pore fluids at environmentally common pH's. Column tests also suggest that the adsorption of the ligands and ligand-metal/radionuclide complexes is reversible as evidenced from the flushing stages of the column tests.

Aside from the strong EDTA-divalent transition metal complex, most other picolinate and ETDA-cationic metal complexes appear to be labile (readily dissociated) during interactions with soils. As these organic ligand-cationic metal complexes migrate from the disposal facility, dilution and interaction with competing cations in the pore fluids and adsorption reactions will result in dissociation of all but the strongest or most kinetically recalcitrant complexes. It appears that the enhanced migration of cationic metals/radionuclides via organic ligand complexation may be limited to unique conditions. Conditions that promote enhanced 
migration over long distances include high concentrations of organic ligands, low concentrations of competing cations, alkaline $\mathrm{pH}$ values, organic ligands with slow biodegradation rates, and kinetically inert complexes. The column tests also showed evidence that picolinate and EDTA can react with iron hydrous oxides present as amorphous phases or coatings on sediments to exchange Fe(III) species for the divalent transition metals with the formation of Fe(III)-ligand aqueous species that can also adsorb to surface sorption sites. It also appears that these two organic ligands can partially dissolve ferric oxyhydroxides and destroy some of their sorption sites. The loss of sorption sites through dissolution is a likely cause of the "snow plow" effect shown in Figure 5.29 where Ni concentrations exited the column at four times higher concentrations than were present in the influent.

At high $\mathrm{pH}$ values such as that created by cementitious wastes, mobilization of $\mathrm{Ni}^{2+}$ by EDTA becomes very significant. Under these conditions, adsorption of $\mathrm{Ni}^{2+}$ by soils and sediments is essentially zero. As a result, mixtures of metal/radionuclides and chelating agents (particularly EDTA) should not be co-disposed with high $\mathrm{pH}$ materials such as cement. This also indicates that cementitious waste forms are not a preferred disposal option for mixtures of transition metal/radionuclides and strongly binding chelating agents such as EDTA. For weaker binding organic complexants such as picolinate, citrate and oxalate, co-disposal of decontamination wastes and concrete should be acceptable.

The data present in Section 5 and Appendix $B$ show that the $\mathrm{K}_{d}$ for metals/radionuclides, organic ligands, and their complexes are highly variable and a strong function of $\mathrm{pH}$, ligand concentration and metal/ radionuclide concentration. These complicated relationships can be "systematized" using an adsorption construct called surface complexation modeling that is described below.

As we close out this project we offer the following recommendations. The available data base for leaching of spent resins from decontamination efforts is quite sparse. If possible, more data should be collected on the compositions of corrosion product/radionuclide laden fluids that are treated with the various ion exchange resins. The important data are the concentrations of the major metals, total organic ligand content, $\mathrm{pH}$, and other common cations and inorganic anions. Knowledge of the radionuclide content is of lesser importance to perform thermodynamic speciation calculations and soil adsorption tests. This type of data also would be of interest to understand the ion exchange efficacy of the resins. It is possible that vendors would consider this information as proprietary as it could be used to understand the specifics of competitors methods.

Of direct interest is more leach tests on spent resins after dewatering and prior to packaging for disposal. As mentioned only one data set is available for one resin used to treat the spent fluids from one CANDEREM with AP reduction decontamination. More co-operation between researchers and vendors should be fostered to improve the database and general state of knowledge of the composition of spent resins and their leachates.

The other area that warrants more work is the quantitative determination of the adsorption properties of sediments and soils for picolinate-metal complexes using the "generalized surface complexation modeling approach" that is explained in Davis (2001), and Davis et al. (2000). Using this adsorption construct one would develop adsorption constants for particular soils that are akin to thermodynamic stability constants. Essentially the adsorption surface site is treated as if it were another ligand. Using batch adsorption tests, similar to those described in Section 5.1, wherein the concentrations of the metal and the organic ligand are varied systematically across a wide $\mathrm{pH}$ range, one can determine the adsorption stability constants. 
In addition one has to determine number of sorption sites per gram or per surface area for each soil. Specific surface areas are determined with traditional techniques such as tritium exchange and BET measurements (see Dzomback and Morell [1989] for details.

After such systematic studies have been performed on a few representative soils, all the parameters would be available to build a coupled chemical reaction transport model that can predict the migration of picolinate-metal/radionuclide wastes through aquifer sediments much like Davis et al. (2000) have performed for EDTA-transition metal complexes at a field site at Cape Cod, Maine. 


\subsection{References}

Akers, D. W., J. W. McConnell, and N. Morcos. 1993b. Characteristics of Low-Level Radioactive Decontamination Waste. NUREG/CR-5672, EGG-2635, Vol. 3, U.S. Nuclear Regulatory Commission, Washington, D.C.

Akers, D. W., C. V. McIsaac, J. W. McConnell, N. Morcos, and R. M. Neilson, Jr. 1993a. Radionuclide Releases from Cement-Solidified Decontamination Ion-Exchange Resins Leached in Simulated Groundwaters. EGG-M-93056, EG\&G Idaho, Inc., Idaho Falls, Idaho.

Akers, D. W., N. C. Kraft, and J. W. Mandler. 1994a. Release of Radionuclides and Chelating Agents from Cement Solidified Decontamination Low-Level Radioactive Waste Collected from the Peach Bottom Atomic Power Station Unit 3. NUREG/CR-6164, EGG-2722, U.S. Nuclear Regulatory Commission, Washington, D.C.

Akers, D. W., N. C. Kraft, and J. W. Mandler. 1994b. Compression and Immersion Tests and Leaching of Radionuclides, Stable Metals, and Chelating Agents from Cement-Solidified Decontamination Waste Collected from Nuclear Power Stations. NUREG/CR-6201, EGG-2736, U.S. Nuclear Regulatory Commission, Washington, D.C.

ANS. 1986. Measurement of the Leachbility of Solidified Low-Level Radioactive Wastes by a Short-term Test Procedure. ANSU/ANS 16.1, American Nuclear Society, La Grange Park, Illinois.

Bryce, A. L., W. A. Kornicker, and A. W. Elzerman. 1994. "Nickel Adsorption to Hydrous Ferric Oxide in the Presence of EDTA: Effects of Component Addition Sequence." Environ. Sci. Technol. 28:2353-2359.

Bueppelmann, K., J. I. Kim, and C. Lierse. 1988. "The Redox-Behavior of Plutonium in Saline Solutions Under Radiolysis Effects." Radiochim. Acta 44-45 (Pt. 1):65-70.

Coughlin, B. R., and A. T. Stone. 1995. "Nonreversible Adsorption of Divalent Metal Ions ( $\mathrm{Mn}^{\mathrm{II}}, \mathrm{Co}^{\mathrm{II}}$, $\mathrm{Ni}^{\mathrm{II}}, \mathrm{Cu}^{\mathrm{II}}$, and $\left.\mathrm{Pb}^{\mathrm{II}}\right)$ onto Goethite: Effects of Acidification, $\mathrm{Fe}^{\mathrm{II}}$ Addition, and Picolinic Acid Addition." Environ. Sci. Technol. 29:2445-2455.

Criscenti, L. J., and R. J. Serne. 1990. "Thermodynamic Modeling of Cement/Groundwater Interactions as a Tool for Long-Term Performance Assessment." In Scientific Basis for Nuclear Waste Management XIII. Editors V. M. Oversby and P. W. Brown, Materials Research Society, Pittsburg, Pennsylvania. Vol. 176:81-90. 
Criscenti, L. J., R. J. Serne, K. M. Krupka, and M. I. Wood. 1996. Predictive Calculations to Assess the Long-Term Effect of Cementitious Materials on the pH and Solubility of Uranium (VI) in a Shallow Land Disposal Environment. PNNL-11182, Pacific Northwest National Laboratory, Richland, Washington.

Davis, J. A., D. B. Kent, J. A. Coston, K. M. Hess, and J. L. Joye. 2000. "Multispecies Reactive Tracer Test in an Aquifer with Spatially Variable Chemical Conditions." Water Resources Research 36:119-134.

Davis, J. A. 2001. Surface Complexation Modeling of Uranium (IV) Adsorption on Natural Mineral Assemblages. NUREG/CR-6708, U.S. Nuclear Regulatory Commission, Washington, D.C.

Dayal, R., R. F. Pietrzak, and J. H. Clinton. 1986. "Oxidation-Induced Geochemical Changes in Trench Leachates from Maxey Flats Low-level Radioactive Waste Disposal Site." Nucl. Tech. 72:184-193.

Dzombak, D. A., and F.M.M. Morel. 1989. Surface Complexation Modeling. John Wiley and Sons, New York.

Felmy, A. R., D. Rai, and M. J. Mason. 1991. "The Solubility of Hydrous Thorium(IV) Oxide in Chloride Media: Development of an Aqueous Ion-Interaction Model." Radiochim. Acta 55:177-185.

Freeze, R. A., and J. A. Cherry. 1979. Groundwater. Prentice-Hall, Inc., Englewood Cliffs, New Jersey.

Girvin, D. C., P. L. Gassman, and H. Bolton, Jr. 1993. "Adsorption of Aqueous Cobalt Ethylenediaminetetraacetate by $\delta-\mathrm{Al}_{2} \mathrm{O}_{3}$." Soil Sci. Soc. Am. J. 57:47-57.

Hsi, C. D., and D. Langmuir. 1985. "Adsorption of Uranyl onto Ferric Oxyhydroxides: Application of the Surface Complexation Site-Binding Model." Geochem. Cosmochim. Acta 49: 1931-1941.

Krupka, K. M., and R. J. Serne. 1998. Effects on Radionuclide Concentrations by Cement/ Ground-Water Interaction in Support of Performance Assessment of Low-Level Radioactive Waste Disposal Facilities. NUREG/CR-6377 (PNNL-11408), Pacific Northwest National Laboratory, Richland, Washington.

Martell, A. E., and R. M. Smith. 1989. Critical Stability Constants, Vol. 5: First Supplement. Plenum Press, New York.

McIsaac, E. V. 1993. "Leachability of Chelated Ion-Exchange Resins Solidified in Cement or Cement and Fly Ash." Waste Management 13:41-54.

McIsaac, C. V., D. W. Akers, J. W. McConnell, and N. Marcos. 1992. Leach Studies of CementSolidified Ion Exchange Resins from Decontamination Processes at Operating Nuclear Power Stations. EGG-M-92090, Idaho National Engineering Laboratory, Idaho Falls, Idaho. 
McIsaac, E. V., D. W. Akers, and J. W. McConnell. 1991. Effect of $p H$ on the Release of Radionuclides and Chelating Agents from Cement-Solidified Decontamination Ion-Exchange Resins Collected from Operating Nuclear Power Stations. NUREG/CR-5601, U.S. Nuclear Regulatory Commission, Washington, D.C.

McIsaac, C. V., and D. W. Akers. 1991. Characteristics of Low-Level Radioactive Waste. 1990 Annual Report, NUREG/CR-5672, Vol. 1, U.S. Nuclear Regulatory Commission, Washington, D.C.

Mclsaac, E. V., and J. W. Mandler. 1989. The Leachability of Decontamination Ion-Exchange Resins Solidified in Cement at Operating Nuclear Power Plants. NUREG/CR-5224, U.S. Nuclear Regulatory Commission, Washington, D.C.

Means, J. L., and C. A. Alexander. 1981. "The Environmental Biogeochemistry of Chelating Agents and Recommendations for the Disposal of Chelated Radioactive Wastes." Nuclear and Chemical Waste Management 2:183-196.

Means, J. L., D. A. Crerar, and J. 0. Duguid. 1978. "Migration of Radioactive Wastes: Radionuclide Mobilization by Complexing Agents." Science 200:1477-1482.

Morcos, N., J. W. McConnell, and D. W. Akers. 1992. Characteristics of Low-Level Radioactive Waste. NUREG/CR5672, EGG-2635, Vol. 2, U.S. Nuclear Regulatory Commission, Washington, D.C.

O'Donnell, E. 1983. "Insights Gained from NRC Research Investigations at the Maxey Flats LLW SLB Facility." In Proceedings of the Fifth Annual Participants' Information Meeting DOE Low-Level Waste Management Program, pp. 254-268. CONF-8308106, National Technical Information Service, Springfield, Virginia.

Papelis, C., K. F. Hayes, and J. 0. Leckie. 1988. HYDRAQL: A Program for the Computation of Aqueous Batch Systems Including Surface-Complexation Modeling of Ion Adsorption at the Oxide/Solution Interface. Technical Report No. 306, Environmental Engineering and Science, Department of Civil Engineering, Stanford University, Stanford, California.

Polzer, W. L., E. B. Fowler, and E. H. Essington. 1982. "Radioecology Studies at Maxey Flats, Kentucky: Radionuclides in Vegetal Samples." In Radionuclide Distributions and Migration Mechanisms at Shallow Land Burial Sites, pp. V-1-24. NUREG/CR-2383, U.S. Nuclear Regulatory Commission, Washington, D.C.

Schecher, W. E., and D. C. McAvoy. 1998. MINEQL+ A Chemical Equilibrium Modeling System, Version 4.0 for Windows, User's Manual. Environmental Research Software, Hallowell, Maine.

Serne, R. J., A. R. Felmy, K. J. Cantrell, K. M. Krupka, J. A. Campbell, H. Bolton, Jr., and J. K. Fredrickson. 1996. Characterization of Radionuclides-Chelating Agent Complexes Found in Low-Level Radioactive Decontamination Waste. NUREG/CR-6124, U.S. Nuclear Regulatory Commission, Washington, D.C. 
Shaw, R. A., and C. J. Wood. 1985. "Chemical Decontamination: An Overview." Nuclear News 6:107-111.

Smee, J. L., D. Bradbury, and J. E. LeSurf. 1986. "Recent Experience with Dilute Chemical Decontamination." In Proceedings of the Symposium on Advanced Nuclear Services, pp. 1-18. Toronto Nuclear Association, Toronto, Ontario, Canada.

Speranzini, B. A., R. Voit, and M. Helms. 1990. "CAN-DECON Makes a Strong Comeback as CAN-DEREM." Nuclear Engineering International 9:52-55.

Stumm, W., and E. Wieland. 1990. "Dissolution of Oxide and Silicate Minerals: Rate Depend on Surface Speciation." In Aquatic Chemical Kinetics, ed. W. Stumm, pp. 367-400. Wiley-Interscience, New York.

Swan, T., M. G. Segal, W. J. Williams, and M. E. Pick. 1987. LOMI Decontamination Reagents and Related Preoxidation Processes. EPRI NP-5522M, Electric Power Research Institute, Palo Alto, California.

Szecsody, J. E., J. M. Zachara, and P. L. Bruckhart. 1994. "Adsorption-Dissolution Reactions Affecting the Distribution and Stability of Co"EDTA in Iron Oxide-Coated Sand." Environ. Sci. Technol. 28:1706-1716.

Van Genuchten, M. Th. 1981. Non-Equilibrium Transport Parameters from Miscible Displacement Experiments. Research Report 119, U.S. Salinity Laboratory, U.S. Department of Agriculture, Washington, D.C.

Van Genuchten, M. Th., and J.C. Parker. 1981. Determining Transport Parameters from Laboratory and Field Tracer Experiments. Bulletin 84-3, Virginia Agricultural Experiment Station, Blacksburg, Virginia.

Zachara, J. M, D. C. Girvin, R. L. Schmidt, and C. T. Resch. 1987. "Chromate Adsorption on Amorphous Iron Oxyhydroxide in the Presence of Major Groundwater Ions." Environ. Sci. Technol. 21: 589-594. 


\section{Appendix A}

\section{Thermodynamic Data}

The thermodynamic data tabulated in Appendix A are arranged in 12 columns. The first column is the species identification number. The second column is the log of the formation constant of the species, at zero ionic strength and $25^{\circ} \mathrm{C}$. Columns 3 through 10 contain a series of up to 4 component $\mathrm{ID}$ numbers and stoichiometric coefficients (respectively) of components that make up the species of interest. Column eleven contains the standard enthalpy of formation of the species at $25^{\circ} \mathrm{C}(\mathrm{kcal} / \mathrm{mol})$. The last column may contain information regarding the name or chemical symbol of the species or the source of the data.

For this report the second column (log $\mathrm{K}$ ) and columns 3-10 are of most interest as they define the formation stoichiometry and identify the logarithm of the stability constant for the reaction. For example, the first line defines the reaction that forms the radionuclide-ligand complex AmEDTA- (given ID number 600 ). The reaction is one mole of $\mathrm{Am}^{3+}$ (D number 40) and one mole of $\mathrm{EDTA}^{4}$ (ID number 128) forming one mole of complex.

$$
\begin{gathered}
\mathrm{Am}^{3+}+\mathrm{EDTA}^{4-}=\mathrm{AmEDTA}^{-} \\
\log \mathrm{k}=\log \frac{\left[\mathrm{AmEDTA}^{-}\right]}{\left[\mathrm{Am}^{3+}\right]\left[\mathrm{EDTA}^{4-}\right]}=20.64
\end{gathered}
$$

As discussed in the text, the original sources for many of the thermodynamic constants in the database were not identified. In addition, when necessary the original database was supplemented with data that were not critically evaluated or in some cases estimates were used for complexes suspected of being important. 
THERMO.DAT

Page 1 of 17

Thursday, July 13, 1995

23

56

7

$8 \quad 9 \quad 10$

11

573 List of TYPE II species; Revised from W2THRM.sav, 4/89(gap)

\begin{tabular}{|c|c|c|c|c|c|c|c|c|c|c|c|}
\hline 600 & 20.64 & 40 & 1 & 128 & 1 & 0 & 0 & 0 & 0 & 0.0 & AmEDTA(I-) KC \\
\hline 610 & 26.2 & 40 & 1 & 170 & 1 & 0 & 0 & 0 & 0 & 0.0 & AmDTPA(2-)KC \\
\hline 611 & 28.18 & 40 & 1 & 170 & 1 & 50 & 1 & 0 & 0 & 0.0 & AmHDTPA(1-) KC \\
\hline 620 & 9.72 & 40 & 1 & 117 & 1 & 0 & 0 & 0 & 0 & 0.0 & AmCit KC \\
\hline 621 & 12.9 & 40 & 1 & 117 & 2 & 0 & 0 & 0 & 0 & 0.0 & $\mathrm{Am}(\mathrm{Cit}) 2(3-) \mathrm{KC}$ \\
\hline 622 & 12.61 & 40 & 1 & 117 & 1 & 50 & 1 & 0 & 0 & 0.0 & $\mathrm{AmHCit}(\mathrm{l}+) \mathrm{KC}$ \\
\hline 630 & 7.02 & 40 & 1 & 118 & 1 & 0 & 0 & 0 & 0 & 0.0 & $\mathrm{AmOx}(1+) \mathrm{KC}$ \\
\hline 631 & 12.3 & 40 & 1 & 118 & 2 & 0 & 0 & 0 & 0 & 0.0 & $\mathrm{Am}(\mathrm{Ox}) 2(1-) \mathrm{KC}$ \\
\hline 640 & 4.49 & 40 & 1 & 126 & 1 & 0 & 0 & 0 & 0 & 0.0 & $\operatorname{AmPic}(2+) \mathrm{KC}$ \\
\hline 641 & 8.23 & 40 & 1 & 126 & 2 & 0 & 0 & 0 & 0 & 0.0 & $\mathrm{Am}(\mathrm{Pic}) 2(1+) \mathrm{KC}$ \\
\hline 642 & 11.10 & 40 & 1 & 126 & 3 & 0 & 0 & 0 & 0 & 0.0 & $\mathrm{Am}(\mathrm{Pic}) 3 \mathrm{KC}$ \\
\hline 650 & 7.7 & 40 & 1 & 101 & 1 & 0 & 0 & 0 & 0 & 0.0 & AmCO3(1+) Cantrell, 1988 \\
\hline 651 & 12.8 & 40 & 1 & 101 & 2 & 0 & 0 & 0 & 0 & 0.0 & Arn(CO3)2(1-) Cantrell, 1988 \\
\hline 660 & 3.65 & 40 & 1 & 102 & 1 & 0 & 0 & 0 & 0 & 0.0 & $\mathrm{AmSO} 4(1+) \mathrm{KC}$ \\
\hline 670 & -8.2 & 40 & 1 & 50 & -1 & 0 & 0 & 0 & 0 & 0.0 & $\operatorname{AmOH}(2+)$ Rai et al., 1983 \\
\hline 671 & -17.1 & 40 & 1 & 50 & -2 & 0 & 0 & 0 & 0 & 0.0 & $\operatorname{Arn}(\mathrm{OH}) 2(1+)$ Rai et al., 1983 \\
\hline 672 & -28.6 & 40 & 1 & 50 & -3 & 0 & 0 & 0 & 0 & 0.0 & Am(OH)3 Felmy et al., 1990 \\
\hline 700 & 20.9 & 41 & 1 & 128 & 1 & 0 & 0 & 0 & 0 & 0.0 & PUEDTA(O) KC \\
\hline 710 & 10.98 & 41 & 1 & 118 & 1 & 0 & 0 & 0 & 0 & 0.0 & $\mathrm{PuOx}(2+) \mathrm{KC}$ \\
\hline 711 & 20.27 & 41 & 1 & 118 & 2 & 0 & 0 & 0 & 0 & 0.0 & $\mathrm{Pu}(\mathrm{Ox}) 2(0) \mathrm{KC}$ \\
\hline 712 & 26.75 & 41 & 1 & 118 & 3 & 0 & 0 & 0 & 0 & 0.0 & $\mathrm{Pu}(\mathrm{Ox}) 3(2-) \mathrm{KC}$ \\
\hline 713 & 29.74 & 41 & 1 & 118 & 4 & 0 & 0 & 0 & 0 & 0.0 & $\mathrm{Pu}(\mathrm{Ox}) 4(4-) \mathrm{KC}$ \\
\hline 720 & 19.1 & 41 & 1 & 117 & 1 & 0 & 0 & 0 & 0 & 0.0 & PuCit(t) KC \\
\hline 721 & 34.3 & 41 & 1 & 117 & 2 & 0 & 0 & 0 & 0 & 0.0 & $\mathrm{Pu}(\mathrm{Cit}) 2(2-) \mathrm{KC}$ \\
\hline 725 & 5.80 & 41 & 1 & 126 & 1 & 0 & 0 & 0 & 0 & 0.0 & PuPic $(3+) \mathrm{KC}$ \\
\hline 730 & -0.505 & 41 & 1 & 50 & -1 & 0 & 0 & 0 & 0 & 0.0 & $\begin{array}{l}\text { PuOH }(3+) \text { Lemire and } \\
\text { Tremaine, } 1980\end{array}$ \\
\hline 731 & -2.32 & 41 & 1 & 50 & -2 & 0 & 0 & 0 & 0 & 0.0 & $\begin{array}{l}\mathrm{Pu}(\mathrm{OH}) 2(2+) \text { Lemire and } \\
\text { Tremaine, } 1980\end{array}$ \\
\hline 732 & -5.28 & 41 & 1 & 50 & -3 & 0 & 0 & 0 & 0 & 0.0 & $\begin{array}{l}\mathrm{Pu}(\mathrm{OH}) 3(+) \text { Lemire and } \\
\text { Tremaine, } 1980\end{array}$ \\
\hline 733 & -9.52 & 41 & 1 & 50 & -4 & 0 & 0 & 0 & 0 & 0.0 & $\begin{array}{l}\text { Pu(OH)4(0) Lemire and } \\
\text { Tremaine, } 1980\end{array}$ \\
\hline 740 & 19.14 & 41 & 1 & 101 & 1 & 0 & 0 & 0 & 0 & 0.0 & PuCO3(2+) Falck, 1992 \\
\hline 741 & 33.12 & 41 & 1 & 101 & 2 & 0 & 0 & 0 & 0 & 0.0 & Pu(CO3)2(0) Falck, 1992 \\
\hline 742 & 42.32 & 41 & 1 & 101 & 3 & 0 & 0 & 0 & 0 & 0.0 & Pu(CO3)3(2-) Falck, 1992 \\
\hline 743 & 46.65 & 41 & 1 & 101 & 4 & 0 & 0 & 0 & 0 & 0.0 & Pu(CO3)4(4-) Falck, 1992 \\
\hline 744 & 44.50 & 41 & 1 & 101 & 5 & 0 & 0 & 0 & 0 & 0.0 & Pu(CO3)5(6-) Falck, 1992 \\
\hline 750 & 0.01 & 41 & 1 & 50 & -3 & 101 & 1 & 0 & 0 & 0.0 & $\mathrm{Pu}(\mathrm{OH}) 3 \mathrm{CO} 3(-)$ Falck, 1992 \\
\hline 760 & 5.77 & 41 & 1 & 102 & 1 & 0 & 0 & 0 & 0 & 0.0 & $\begin{array}{l}\text { PuSO } 4(2+) \text { Lemire and } \\
\text { Tremaine, } 1980\end{array}$ \\
\hline 761 & 10.25 & 41 & 1 & 102 & 2 & 0 & 0 & 0 & 0 & 0.0 & $\mathrm{Pu}(\mathrm{SO} 4) 2(0)$ Read, 1991 \\
\hline 770 & 0.14 & 41 & 1 & 103 & 1 & 0 & 0 & 0 & 0 & 0.0 & $\begin{array}{l}\text { PuCl(3+) Schwab and Felmy, } \\
1982\end{array}$ \\
\hline 1000 & 3.22 & 1 & 1 & 101 & 1 & 0 & 0 & 0 & 0 & 3.5460 & $\mathrm{CaCO} 3(\mathrm{aq}), \mathrm{PB} 82$ \\
\hline 1010 & 11.43 & 1 & 1 & 50 & 1 & 101 & 1 & 0 & 0 & -0.8710 & $\mathrm{CaHCO} 3, \mathrm{~PB} 82$ \\
\hline 1020 & 2.31 & 1 & 1 & 102 & 1 & 0 & 0 & 0 & 0 & 1.6000 & CaSO4 S/M,W2 \\
\hline 1030 & 0.94 & 1 & 1 & 104 & 1 & 0 & 0 & 0 & 0 & 3.7980 & $? ?$ \\
\hline 1060 & 20.96 & 1 & 1 & 50 & 2 & 109 & 1 & 0 & 0 & 0.0000 & VT84,Chris,\#4 \\
\hline 1070 & 6.46 & 1 & 1 & 109 & 1 & 0 & 0 & 0 & 0 & 0.0000 & VT84,Chris,\#l \\
\hline 1080 & 15.08 & 1 & 1 & 50 & 1 & 109 & 1 & 0 & 0 & 0.0000 & VT84,Chris,\#2 \\
\hline 1100 & 11.00 & 1 & 1 & 128 & 1 & 0 & 0 & 0 & 0 & 0.0000 & CaEDTA S/M \\
\hline 1101 & 16.0 & 1 & 1 & 128 & 1 & 50 & 1 & 0 & 0 & 0.0 & CaHEDTA(-) Morel \\
\hline
\end{tabular}


THERMO.DAT Page 2 of 17

Thursday, July 13, $1995 \quad$ 9:43:58 AM

\begin{tabular}{|c|c|c|c|c|c|c|c|c|c|c|c|}
\hline 1200 & 2.2 & 1 & 1 & 126 & 1 & 0 & 0 & 0 & 0 & 0.0 & CaPIC $(1+)$ Morel \\
\hline 1201 & 3.8 & 1 & 1 & 126 & 2 & 0 & 0 & 0 & 0 & 0.0 & $\mathrm{Ca}(\mathrm{PIC}) 2$ Morel \\
\hline 1210 & 4.7 & 1 & 1 & 117 & 1 & 0 & 0 & 0 & 0 & 0.0 & CaCit(1-) Morel \\
\hline 1211 & 9.5 & 1 & 1 & 117 & 1 & 50 & 1 & 0 & 0 & 0.0 & CaHCit Morel \\
\hline 1213 & 12.3 & 1 & 1 & 117 & 1 & 50 & 2 & 0 & 0 & 0.0 & $\mathrm{CaH} 2 \mathrm{Cit}(\mathrm{l}+)$ Morel \\
\hline 1220 & 3.0 & 1 & 1 & 118 & 1 & 0 & 0 & 0 & 0 & 0.0 & $\mathrm{CaO} \times \mathrm{KC}$ \\
\hline 1221 & 1.84 & 1 & 1 & 118 & 1 & 50 & 1 & 0 & 0 & 0.0 & $\mathrm{CaHOx}(1+) \mathrm{KC}$ \\
\hline 1230 & 12.88 & 1 & 1 & 170 & 1 & 0 & 0 & 0 & 0 & 0.0 & CaDTPA(3-)Lindsay 1231 \\
\hline 19.65 & 1 & 1 & 170 & 1 & 50 & 1 & 0 & 0 & 0.0 & CaHDTP & $A(2-)$ Lindsay \\
\hline 1350 & -12.85 & 1 & 1 & 50 & -1 & 0 & 0 & 0 & 0 & 15.8380 & $\mathrm{CaOH}+, \mathrm{B} / \mathrm{M}$ \\
\hline 1360 & 2.98 & 2 & 1 & 101 & 1 & 0 & 0 & 0 & 0 & 2.0200 & $\mathrm{MgCO} 3(\mathrm{aq}), \mathrm{W} 2 ? ?$ \\
\hline 1370 & 11.51 & 2 & 1 & 50 & 1 & 101 & 1 & 0 & 0 & -2.4270 & $\mathrm{MgHCO} 3, \mathrm{w} 2$ \\
\hline 1380 & 2.25 & 2 & 1 & 102 & 1 & 0 & 0 & 0 & 0 & 1.4000 & $\mathrm{MgSO} 4(\mathrm{aq}), \mathrm{W} 2$ \\
\hline 1385 & -1.00 & 2 & 1. & 103 & 1 & 0 & 0 & 0 & 0 & 0.0000 & $? ? \mathrm{MgCl}+, \mathrm{S} / \mathrm{M}$ \\
\hline 1390 & 1.82 & 2 & 1 & 104 & 1 & 0 & 0 & 0 & 0 & 4.6740 & $\mathrm{MgF}+, \mathrm{phr}$ \\
\hline 1420 & 6.59 & 2 & 1 & 109 & 1 & 0 & 0 & 0 & 0 & 0.0000 & MgPO4-,VT 84,phr \\
\hline 1425 & 21.07 & 2 & 1 & 109 & 1 & 50 & 2 & 0 & 0 & 0.0000 & $\mathrm{MgH} 2 \mathrm{PO} 4+, \mathrm{VT} 84, \mathrm{phr}$ \\
\hline 1430 & 15.22 & 2 & 1 & 50 & 1 & 109 & 1 & 0 & 0 & 0.0000 & MgHPO4,VT84,phr \\
\hline 1435 & 8.95 & 2 & 1 & 128 & 1 & 0 & 0 & 0 & 0 & 0.0000 & MgEDTA Davis \\
\hline 1436 & 15.1 & 2 & 1 & 128 & 1 & 50 & 1 & 0 & 0 & 0.0 & MgHEDTA Morel \\
\hline 1500 & 2.6 & 2 & 1 & 126 & 1 & 0 & 0 & 0 & 0 & 0.0 & MgPic(1+) Morel \\
\hline 1501 & 4.0 & 2 & 1 & 126 & 2 & 0 & 0 & 0 & 0 & 0.0 & $\mathrm{Mg}(\mathrm{Pic}) 2$ Morel \\
\hline 1510 & 4.7 & 2 & 1 & 117 & 1 & 0 & 0 & 0 & 0 & 0.0 & Mgcit(1-) Morel \\
\hline 1511 & 9.2 & 2 & 1 & 117 & 1 & 50 & 1 & 0 & 0 & 0.0 & MgHCit Morel \\
\hline 1520 & 3.42 & 2 & 1 & 118 & 1 & 0 & 0 & 0 & 0 & 0.0 & MgOx KC \\
\hline 1521 & 4.38 & 2 & 1 & 118 & 2 & 0 & 0 & 0 & 0 & 0.0 & $\mathrm{Mg}(\mathrm{Ox}) 2(2-) \mathrm{KC}$ \\
\hline 1530 & 11.47 & 2 & 1 & 170 & 1 & 0 & 0 & 0 & 0 & 0.0 & MgDTPA Lindsay \\
\hline 1531 & 18.98 & 2 & 1 & 170 & 1 & 50 & 1 & 0 & 0 & 0.0 & MgHDTPA Lindsay \\
\hline 1730 & -11.44 & 2 & 1 & 50 & -1 & 0 & 0 & 0 & 0 & 15.4190 & $\mathrm{MgOH}-, \mathrm{B} / \mathrm{M}$ \\
\hline 1750 & 11.50 & 3 & 1 & 50 & 1 & 101 & 1 & 0 & 0 & 0.0000 & $\mathrm{SrHCO} 3(\mathrm{aq}), \mathrm{P} / \mathrm{B}$ \\
\hline 1760 & 2.76 & 3 & 1 & 101 & 1 & 0 & 0 & 0 & 0 & 0.0000 & $\mathrm{SrCO} 3(\mathrm{aq}), \mathrm{P} / \mathrm{B}$ \\
\hline 1766 & 2.55 & 3 & 1 & 102 & 1 & 0 & 0 & 0 & 0 & 0.0000 & $\mathrm{SrSO} 4(\mathrm{aq}), \mathrm{S} / \mathrm{M}$ \\
\hline 1770 & -13.29 & 3 & 1 & 50 & -1 & 0 & 0 & 0 & 0 & 0.0000 & $\mathrm{SrOH}(\mathrm{aq}), \mathrm{B} / \mathrm{M}$ \\
\hline 1780 & 1.8 & 3 & 1 & 126 & 1 & 0 & 0 & 0 & 0 & 0.0 & StPic(l+) Morel \\
\hline 1781 & 3.0 & 3 & 1 & 126 & 2 & 0 & 0 & 0 & 0 & 0.0 & $\mathrm{St}(\mathrm{Pic}) 2$ Morel \\
\hline 1790 & 4.1 & 3 & 1 & 117 & 1 & 0 & 0 & 0 & 0 & 0.0 & SrCit(1-) Morel \\
\hline 1800 & 2.54 & 3 & 1 & 118 & 1 & 0 & 0 & 0 & 0 & 0.0 & SrOx KC \\
\hline 1810 & 10.5 & 3 & 1 & 128 & 1 & 0 & 0 & 0 & 0 & 0.0 & StEDTA(2-) Morel \\
\hline 1811 & 14.9 & 3 & 1 & 128 & 1 & 50 & 0 & 0 & 0 & 0.0 & SrHEDTA(-) Morel \\
\hline 1820 & 11.86 & 3 & 1 & 170 & 1 & 0 & 0 & 0 & 0 & 0.0 & StDTPA KC \\
\hline 1821 & 18.07 & 3 & 1 & 170 & 1 & 50 & 0 & 0 & 0 & 0.0 & SrHDTPA KC \\
\hline 1960 & 0.85 & 4 & 1 & 102 & 1 & 0 & 0 & 0 & 0 & 2.2500 & KSo4-. W2 \\
\hline 1962 & -0.70 & 4 & 1 & 103 & 1 & 0 & 0 & 0 & 0 & 0.0000 & ?? $\mathrm{KCl}(0), \mathrm{S} / \mathrm{M}$ ?? \\
\hline 1965 & 13.43 & 4 & 1 & 109 & 1 & 50 & 1 & 0 & 0 & -3.5300 & KHPO4-, VT84 \\
\hline 1970 & 1.3 & 4 & 1 & 117 & 1 & 0 & 0 & 0 & 0 & 0.0 & KCit(2-) Morel \\
\hline 1980 & 1.7 & 4 & 1 & 128 & 1 & 0 & 0 & 0 & 0 & 0.0 & KEDTA(3-) Morel \\
\hline 2000 & 1.27 & 5 & 1 & 101 & 1 & 0 & 0 & 0 & 0 & 8.9110 & $\mathrm{NaCO} 3-, \mathrm{phr}$ \\
\hline 2005 & 10.08 & 5 & 1 & 101 & 1 & 50 & 1 & 0 & 0 & -3.6040 & $\mathrm{NaHCO} 3, \mathrm{phr}$ \\
\hline 2010 & 0.70 & 5 & 1 & 102 & 1 & 0 & 0 & 0 & 0 & 1.1200 & NaSO4-, W2, \\
\hline 2015 & 12.64 & 5 & 1 & 109 & 1 & 50 & 1 & 0 & 0 & -3.5300 & NaHPO4-, phr \\
\hline 2020 & 1.4 & 5 & 1 & 117 & 1 & 0 & 0 & 0 & 0 & 0.0 & NaCit(2-) Morel \\
\hline 2030 & 2.5 & 5 & 1 & 128 & 1 & 0 & 0 & 0 & 0 & 0.0 & NaEDTA(3-) Morel \\
\hline 2070 & 3.92 & 6 & 1 & 102 & 1 & 0 & 0 & 0 & 0 & 3.9100 & $\mathrm{FeSO} 4(+), \mathrm{w} 2$ \\
\hline 2080 & 5.42 & 6 & 1 & 102 & 2 & 0 & 0 & 0 & 0 & 4.6000 & $\mathrm{Fe}(\mathrm{SO} 4) 2-, \mathrm{W} 2$ \\
\hline 2090 & 1.48 & 6 & 1 & 103 & 1 & 0 & 0 & 0 & 0 & 5.6000 & $\mathrm{FeC} 12+$ \\
\hline
\end{tabular}


THERMO.DAT Page 3 of 17

Thursday, July 13, $1995 \quad$ 9:43:58 AM

\begin{tabular}{|c|c|c|c|c|c|c|c|c|c|c|c|}
\hline 2100 & 2.13 & 6 & 1 & 103 & 2 & 0 & 0 & 0 & 0 & 0.0000 & \\
\hline 2110 & 1.13 & 6 & 1 & 103 & 3 & 0 & 0 & 0 & 0 & 0.0000 & \\
\hline 2120 & 6.20 & 6 & 1 & 104 & 1 & 0 & 0 & 0 & 0 & 2.7000 & $\mathrm{FeF} 2+\mathrm{W} 2$ \\
\hline 2130 & 10.80 & 6 & 1 & 104 & 2 & 0 & 0 & 0 & 0 & 4.8000 & \\
\hline 2140 & 14.00 & 6 & 1 & 104 & 3 & 0 & 0 & 0 & 0 & 5.4000 & \\
\hline 2150 & 0.70 & 6 & 1 & 105 & 1 & 0 & 0 & 0 & 0 & 6.0000 & $\mathrm{FeBr} 2+\mathrm{S} / \mathrm{M}$ \\
\hline 2160 & 2.10 & 6 & 1 & 106 & 1 & 0 & 0 & 0 & 0 & 0.0000 & FeI2+ \\
\hline 2170 & 17.77 & 6 & 1 & 50 & 1 & 109 & 1 & 0 & 0 & 2.2300 & FeHPO4, W2 \\
\hline 2180 & 24.98 & 6 & 1 & 50 & 2 & 109 & 1 & 0 & 0 & -4.5200 & $\mathrm{FeH} 2 \mathrm{PO} 4, \mathrm{~W} 2$ \\
\hline 2190 & 23.50 & 6 & 1 & 50 & 1 & 112 & 1 & 0 & 0 & 0.0000 & \\
\hline 2200 & 13.9 & 6 & 1 & 126 & 2 & 0 & 0 & 0 & 0 & 0.0 & $\mathrm{Fe}(\mathrm{Pic}) 2(1+)$ Morel \\
\hline 2201 & 10.9 & 6 & 1 & 126 & 2 & 50 & -1 & 0 & 0 & 0.0 & FeOH(Pic) Morel \\
\hline 2300 & 13.5 & 6 & 1 & 117 & 1 & 0 & 0 & 0 & 0 & 0.0 & FeCit Morel \\
\hline 2301 & 24.7 & 6 & 2 & 117 & 2 & 50 & -2 & 0 & 0 & 0.0 & $\mathrm{Fe} 2(\mathrm{OH}) 2(\mathrm{Cit}) 2$ Morel \\
\hline 2302 & 14.4 & 6 & 1 & 117 & 1 & 50 & 1 & 0 & 0 & 0.0 & FeHCit(1+) KC \\
\hline 2303 & 10.2 & 6 & 1 & 117 & 1 & 50 & -1 & 0 & 0 & 0.0 & $\mathrm{Fe}(\mathrm{OH}) \mathrm{Cit}(\mathrm{l}-) \mathrm{KC}$ \\
\hline 2400 & 27.7 & 6 & 1 & 128 & 1 & 0 & 0 & 0 & 0 & 0.0 & FeEDTA(-) Morel \\
\hline 2401 & 29.2 & 6 & 1 & 128 & 1 & 50 & 1 & 0 & 0 & 0.0 & FeHEDTA Morel \\
\hline 2402 & 19.8 & 6 & 1 & 128 & 1 & 50 & -1 & 0 & 0 & 0.0 & Fe(OH)EDTA(-) Morel \\
\hline 2403 & 9.7 & 6 & 1 & 128 & 1 & 50 & -2 & 0 & 0 & 0.0 & Fe(OH)2EDTA(2-) Morel \\
\hline 2500 & 30.53 & 6 & 1 & 170 & 1 & 0 & 0 & 0 & 0 & 0.0 & FeDTPA Lindsay \\
\hline 2501 & 34.53 & 6 & 1 & 170 & 1 & 50 & 0 & 0 & 0 & 0.0 & FeHDTPA Lindsay \\
\hline 2502 & 19.43 & 6 & 1 & 170 & 1 & 50 & -1 & 0 & 0 & 0.0 & $\mathrm{Fe}(\mathrm{OH}) \mathrm{DTPA}$ Lindsay \\
\hline 2670 & -2.19 & 6 & 1 & 50 & -1 & 0 & 0 & 0 & 0 & 10.4000 & $\mathrm{FeOH} 2+$,gap, $7 / 81$ \\
\hline 2680 & -5.67 & 6 & 1 & 50 & -2 & 0 & 0 & 0 & 0 & 12.0000 & $\mathrm{Fe}(\mathrm{OH}) 2+$, gap \\
\hline 2690 & -13.60 & 6 & 1 & 50 & -3 & 0 & 0 & 0 & 0 & 28.0000 & $\mathrm{Fe}(\mathrm{OH}) 3(0)$, gap \\
\hline 2700 & -21.60 & 6 & 1 & 50 & -4 & 0 & 0 & 0 & 0 & 44.0000 & $\mathrm{Fe}(\mathrm{OH}) 4-$, gap \\
\hline 2710 & -2.95 & 6 & 2 & 50 & -2 & 0 & 0 & 0 & 0 & 10.0000 & ?? $\mathrm{Fe} 2(\mathrm{OH}) 2$, gap \\
\hline 2715 & -6.31 & 6 & 3 & 50 & -4 & 0 & 0 & 0 & 0 & 14.3000 & $\mathrm{Fe} 3(\mathrm{OH}) 4$, gap \\
\hline 2720 & 2.20 & 7 & 1 & 102 & 1 & 0 & 0 & 0 & 0 & 1.6000 & \\
\hline 2725 & 1.10 & 7 & 1 & 101 & 1 & 50 & 1 & 0 & 0 & 0.0000 & FeHCO3, SM5 \\
\hline 2730 & 0.90 & 7 & 1 & 103 & 1 & 0 & 0 & 0 & 0 & 0.0000 & $? ? \mathrm{FeCl}+$ \\
\hline 2740 & 1.30 & 7 & 1 & 107 & 1 & 0 & 0 & 0 & 0 & 0.0000 & $? ?$ \\
\hline 2750 & 2.10 & 7 & 1 & 107 & 2 & 0 & 0 & 0 & 0 & 0.0000 & $? ?$ \\
\hline 2760 & 3.60 & 7 & 1 & 107 & 4 & 0 & 0 & 0 & 0 & 0.0000 & $? ?$ \\
\hline 2770 & 35.40 & 7 & 1 & 114 & 6 & 0 & 0 & 0 & 0 & 0.0000 & $? ?$ \\
\hline 2780 & 3.70 & 7 & 1 & 115 & 1 & 0 & 0 & 0 & 0 & 0.0000 & $? ?$ \\
\hline 2790 & -9.50 & 7 & 1 & 50 & -1 & 0 & 0 & 0 & 0 & 13.2000 & $\mathrm{FeOH}+, \mathrm{B} / \mathrm{M}$ \\
\hline 2791 & -20.57 & 7 & 1 & 50 & -2 & 0 & 0 & 0 & 0 & 28.5600 & $\mathrm{Fe}(\mathrm{OH}) 2(0), \mathrm{B} / \mathrm{M}$ \\
\hline 2792 & -31.00 & 7 & 1 & 50 & -3 & 0 & 0 & 0 & 0 & 30.3000 & $\mathrm{Fe}(\mathrm{OH}) 3-, \mathrm{B} / \mathrm{M}$ \\
\hline 2793 & -46.00 & 7 & 1 & 50 & -4 & 0 & 0 & 0 & 0 & 0.0000 & $? ? \mathrm{Fe}(\mathrm{OH}) 4(2-)$ \\
\hline 3290 & 11.59 & 8 & 1 & 50 & 1 & 101 & 1 & 0 & 0 & 0.0000 & $\mathrm{MnHCO} 3(\mathrm{aq}), \mathrm{PB} 82$ \\
\hline 3300 & 2.60 & 8 & 1 & 102 & 1 & 0 & 0 & 0 & 0 & 2.1000 & $? ?$ \\
\hline 3310 & 1.10 & 8 & 1 & 103 & 1 & 0 & 0 & 0 & 0 & 0.0000 & $? ?$ \\
\hline 3320 & 1.10 & 8 & 1 & 103 & 2 & 0 & 0 & 0 & 0 & 0.0000 & $? ?$ \\
\hline 3330 & 0.60 & 8 & 1 & 103 & 3 & 0 & 0 & 0 & 0 & 0.0000 & $? ?$ \\
\hline 3340 & 0.70 & 8 & 1 & 107 & 1 & 0 & 0 & 0 & 0 & 0.0000 & $? ?$ \\
\hline 3350 & 1.20 & 8 & 1 & 107 & 2 & 0 & 0 & 0 & 0 & 0.0000 & $? ?$ \\
\hline 3360 & 16.20 & 8 & 1 & 50 & 1 & 109 & 1 & 0 & 0 & 0.0000 & $? ?$ \\
\hline 3400 & 4.0 & 8 & 1 & 126 & 1 & 0 & 0 & 0 & 0 & 0.0 & MnPic(l+) Morel \\
\hline 3401 & 7.1 & 8 & 1 & 126 & 2 & 0 & 0 & 0 & 0 & 0.0 & Mn(Pic)2 Morel \\
\hline 3402 & 8.8 & 8 & 1 & 126 & 3 & 0 & 0 & 0 & 0 & 0.0 & Mn(Pic)3(1-) Morel \\
\hline 3500 & 5.5 & 8 & 1 & 117 & 1 & 0 & 0 & 0 & 0 & 0.0 & MnCit(l-) Morel \\
\hline 3501 & 9.4 & 8 & 1 & 117 & 1 & 50 & 1 & 0 & 0 & 0.0 & MnHCit Morel \\
\hline 3600 & 3.9 & 8 & 1 & 118 & 1 & 0 & $\hat{0}$ & 0 & 0 & 0.0 & $\mathrm{MnOx} \mathrm{KC}$ \\
\hline 3601 & 5.25 & 8 & 1 & 118 & 2 & 0 & 0 & 0 & 0 & 0.0 & $\mathrm{Mn}(\mathrm{Ox}) 2(2-) \mathrm{KC}$ \\
\hline
\end{tabular}


THERMO.DAT Page 4 of 17

Thursday, July 13, 1995

9:43:58 AM

\begin{tabular}{|c|c|c|c|c|c|c|c|c|c|c|c|}
\hline 3700 & 15.6 & 8 & 1 & 128 & 1 & 0 & 0 & 0 & 0 & 0.0 & MnEDTA(2-) Morel \\
\hline 3701 & 19.1 & 8 & 1 & 128 & 1 & 50 & 1 & 0 & 0 & 0.0 & MnHEDTA(-) Morel \\
\hline 3800 & 17.64 & 8 & 1 & 170 & 1 & 0 & 0 & 0 & 0 & 0.0 & MnDTPA(3-) Lindsay \\
\hline 3801 & 22.70 & 8 & 1 & 170 & 1 & 50 & 1 & 0 & 0 & 0.0 & MnHDTPA(2-) Lindsay \\
\hline 3900 & -10.59 & 8 & 1 & 50 & -1 & 0 & 0 & 0 & 0 & 0.0000 & $\mathrm{MnOH}+, \mathrm{B} / \mathrm{M}$ \\
\hline 3901 & -22.2 & 8 & 1 & 50 & -2 & 0 & 0 & 0 & 0 & 0.0000 & $\mathrm{Mn}(\mathrm{OH}) 2(\mathrm{aq}), \mathrm{B} / \mathrm{M}$ \\
\hline 3910 & -34.80 & 8 & 1 & 50 & -3 & 0 & 0 & 0 & 0 & 0.0000 & $\mathrm{Mn}(\mathrm{OH}) 3(\mathrm{aq}), \mathrm{B} / \mathrm{M}$ \\
\hline 3911 & -48.3 & 8 & 1 & 50 & -4 & 0 & 0 & 0 & 0 & 0.0000 & $\mathrm{Mn}(\mathrm{OH}) 4(\mathrm{aq}), \mathrm{B} / \mathrm{M}$ \\
\hline 3912 & -10.56 & 8 & 2 & 50 & -1 & 0 & 0 & 0 & 0 & 0.0000 & $\mathrm{Mn} 2 \mathrm{OH}(\mathrm{aq}), \mathrm{B} / \mathrm{M}$ \\
\hline 3913 & -23.90 & 8 & 2 & 50 & -3 & 0 & 0 & 0 & 0 & 0.0000 & $\mathrm{Mn} 2(\mathrm{OH}) 3(\mathrm{aq}), \mathrm{B} / \mathrm{M}$ \\
\hline 3915 & 0.2 & 8 & 1 & 157 & 1 & 0 & 0 & 0 & 0 & 0.0000 & MnNO3 S/M \\
\hline 3916 & 0.6 & 8 & 1 & 157 & 2 & 0 & 0 & 0 & 0 & 0.0000 & $\mathrm{Mn}(\mathrm{NO} 3) 2 \mathrm{~S} / \mathrm{M}$ \\
\hline 3920 & 6.75 & 9 & 1 & 101 & 1 & 0 & 0 & 0 & 0 & 0.0000 & B/M gap \\
\hline 3930 & 9.92 & 9 & 1 & 101 & 2 & 0 & 0 & 0 & 0 & 0.0000 & $\mathrm{~B} / \mathrm{M}$ gap \\
\hline 3940 & 2.30 & 9 & 1 & 102 & 1 & 0 & 0 & 0 & 0 & 0.0000 & $? ?$ \\
\hline 3950 & 0.60 & 9 & 1 & 103 & 1 & 0 & 0 & 0 & 0 & 0.0000 & $? ?$ \\
\hline 3960 & 0.40 & 9 & 1 & 103 & 2 & 0 & 0 & 0 & 0 & 0.0000 & $? ?$ \\
\hline 3970 & 1.30 & 9 & 1 & 104 & 1 & 0 & 0 & 0 & 0 & 0.0000 & $? ?$ \\
\hline 3980 & 1.10 & 9 & 1 & 105 & 1 & 0 & 0 & 0 & 0 & 0.0000 & $? ?$ \\
\hline 3990 & 5.80 & 9 & 1 & 107 & 1 & 0 & 0 & 0 & 0 & 0.0000 & $? ?$ \\
\hline 4000 & 10.70 & 9 & 1 & 107 & 2 & 0 & 0 & 0 & 0 & 0.0000 & $? ?$ \\
\hline 4010 & 16.60 & 9 & 1 & 50 & 1 & 109 & 1 & 0 & 0 & 0.0000 & $? ?$ \\
\hline 4840 & -8.00 & 9 & 1 & 50 & -1 & 0 & 0 & 0 & 0 & 0.0000 & $\mathrm{~B} / \mathrm{M}$ gap $<$ \\
\hline 4841 & -17.30 & 9 & 1 & 50 & -2 & 0 & 0 & 0 & 0 & 0.0000 & $\mathrm{~B} / \mathrm{M}$ gap $<$ \\
\hline 4842 & -27.80 & 9 & 1 & 50 & -3 & 0 & 0 & 0 & 0 & 0.0000 & $\mathrm{~B} / \mathrm{M}$ gap $<$ \\
\hline 4843 & -39.60 & 9 & 1 & 50 & -4 & 0 & 0 & 0 & 0 & 0.0000 & B/M gap \\
\hline 4850 & -10.36 & 9 & 2 & 50 & -2 & 0 & 0 & 0 & 0 & 0.0000 & B/M gap \\
\hline 5000 & 2.7 & 10 & 1 & 102 & 1 & 0 & 0 & 0 & 0 & 1.6000 & $\mathrm{~K}-\mathrm{S} / \mathrm{M}, \mathrm{dH}-? ?$ \\
\hline 5006 & 2.78 & 10 & 1 & 101 & 1 & 0 & 0 & 0 & 0 & 0.0000 & $\mathrm{~S} / \mathrm{M}$ \\
\hline 5060 & -12.80 & 10 & 1 & 50 & -1 & 0 & 0 & 0 & 0 & 0.0000 & $? ?$ \\
\hline 5070 & 2.90 & 11 & 1 & 101 & 1 & 0 & 0 & 0 & 0 & 0.0000 & Stipp \\
\hline 5071 & 6.4 & 11 & 1 & 101 & 2 & 0 & 0 & 0 & 0 & 0.0000 & Stipp \\
\hline 5072 & 1.5 & 11 & 1 & 101 & 1 & 50 & 1 & 0 & 0 & 0.0000 & Stipp \\
\hline 5080 & 2.30 & 11 & 1 & 102 & 1 & 0 & 0 & 0 & 0 & 0.0000 & $? ?$ \\
\hline 5090 & 1.98 & 11 & 1 & 103 & 1 & 0 & 0 & 0 & 0 & 0.3000 & $\mathrm{CdCl}+, \mathrm{S} / \mathrm{M}$ \\
\hline 5100 & 2.60 & 11 & 1 & 103 & 2 & 0 & 0 & 0 & 0 & 0.9000 & $\mathrm{CdC12}(0), \mathrm{S} / \mathrm{M}$ \\
\hline 5110 & 2.40 & 11 & 1 & 103 & 3 & 0 & 0 & 0 & 0 & 2.4000 & $\mathrm{CdC13-,} \mathrm{S/M}$ \\
\hline 5120 & 1.10 & 11 & 1 & 104 & 1 & 0 & 0 & 0 & 0 & 0.0000 & $? ?$ \\
\hline 5130 & 2.10 & 11 & 1 & 105 & 1 & 0 & 0 & $\mathbf{0}$ & 0 & 0.0000 & $? ?$ \\
\hline 5140 & 2.90 & 11 & 1 & 105 & 1 & 0 & 0 & 0 & 0 & 0.0000 & $? ?$ \\
\hline 5150 & 3.00 & 11 & 1 & 105 & 3 & 0 & 0 & 0 & 0 & 0.0000 & $? ?$ \\
\hline 5160 & 3.10 & 11 & 1 & 105 & 4 & 0 & 0 & 0 & 0 & 0.0000 & $? ?$ \\
\hline 5170 & 2.90 & 11 & 1 & 106 & 1 & 0 & 0 & 0 & 0 & 0.0000 & $? ?$ \\
\hline 5180 & 4.20 & 11 & 1 & 106 & 2 & 0 & 0 & 0 & 0 & 0.0000 & $? ?$ \\
\hline 5190 & 5.90 & 11 & 1 & 106 & 3 & 0 & 0 & 0 & 0 & 0.0000 & $? ?$ \\
\hline 5200 & 6.60 & 11 & 1 & 106 & 4 & 0 & 0 & 0 & 0 & 0.0000 & $? ?$ \\
\hline 5210 & 2.50 & 11 & 1 & 107 & 1 & 0 & 0 & 0 & 0 & 0.0000 & $? ?$ \\
\hline 5220 & 4.50 & 11 & 1 & 107 & 2 & 0 & 0 & 0 & 0 & 0.0000 & $?$ \\
\hline 5230 & 6.00 & 11 & 1 & 107 & 3 & 0 & 0 & 0 & 0 & 0.0000 & $? ?$ \\
\hline 5240 & 6.80 & 11 & 1 & 107 & 4 & 0 & 0 & 0 & 0 & 0.0000 & $?$ \\
\hline 5250 & 6.50 & 11 & 1 & 107 & 5 & 0 & 0 & 0 & 0 & 0.0000 & $?$ \\
\hline 5260 & 4.80 & 11 & 1 & 107 & 6 & 0 & 0 & 0 & 0 & 0.0000 & $? ?$ \\
\hline 5270 & 3.90 & 11 & 1 & 109 & 1 & 0 & 0 & 0 & 0 & 0.0000 & $? ?$ \\
\hline 5280 & 16.90 & 11 & 1 & 128 & 1 & 0 & 0 & 0 & 0 & 0.0000 & CdEDTA Davis \\
\hline 5281 & 21.5 & 11 & 1 & 128 & 1 & 50 & 1 & 0 & 0 & 0.0 & CdHEDTA Morel \\
\hline 5930 & -10.08 & 11 & 1 & 50 & -1 & 0 & 0 & 0 & 0 & 13.1000 & $\mathrm{CdOH}+, \mathrm{B} / \mathrm{M}$ \\
\hline
\end{tabular}


THERMO.DAT Page 5 of 17

Thursday, July 13, $1995 \quad$ 9:43:58 AM

\begin{tabular}{|c|c|c|c|c|c|c|c|c|c|c|c|}
\hline 5940 & -20.35 & 11 & 1 & 50 & -2 & 0 & 0 & 0 & 0 & 0.0000 & ?? $\mathrm{Cd}(\mathrm{OH}) 2(0)$ \\
\hline 5950 & -33.30 & 11 & 1 & 50 & -3 & 0 & 0 & 0 & 0 & 0.0000 & ?? $\mathrm{Cd}(\mathrm{OH}) 3-$ \\
\hline 5951 & -47.35 & 11 & 1 & 50 & -4 & 0 & 0 & 0 & 0 & 0.0000 & ?? $\mathrm{Cd}(\mathrm{OH}) 4(2-)$ \\
\hline 5952 & -9.39 & 11 & 2 & 50 & -1 & 0 & 0 & 0 & 0 & 10.9000 & $\mathrm{Cd} 2(\mathrm{OH}) 1(2+)$ \\
\hline 5955 & 5.30 & 12 & 1 & 101 & 1 & 0 & 0 & 0 & 0 & 0.0000 & ?? $\mathrm{ZnCO} 3(0), \mathrm{W} 2$ \\
\hline 5956 & 9.63 & 12 & 1 & 101 & 2 & 0 & 0 & 0 & 0 & 0.0000 & ?? $\mathrm{Zn}(\mathrm{CO} 3) 2(2-)$ \\
\hline 5957 & 12.43 & 12 & 1 & 50 & 1 & 101 & 1 & 0 & 0 & 0.0000 & ?? $\mathrm{ZnHCO} 3+, \mathrm{W} 2$ \\
\hline 5960 & 2.38 & 12 & 1 & 102 & 1 & 0 & 0 & 0 & 0 & 1.5000 & $\mathrm{ZnSO} 4(0), \mathrm{W} 2$ \\
\hline 5965 & 3.28 & 12 & $i$ & 102 & 2 & 0 & 0 & 0 & 0 & 0.0000 & $? ? \mathrm{Zn}(\mathrm{SO} 4) 2(2-)$ \\
\hline 5970 & 0.43 & 12 & 1 & 103 & 1 & 0 & 0 & 0 & 0 & 0.0000 & $\mathrm{ZnCl}+$ Marcus \\
\hline 5980 & 0.61 & 12 & 1 & 103 & 2 & 0 & 0 & 0 & 0 & 0.0000 & ZnC12 Marcus \\
\hline 5990 & 0.53 & 12 & 1 & 103 & 3 & 0 & 0 & 0 & 0 & 0.0000 & ZnC13 Marcus \\
\hline 5995 & 0.20 & 12 & 1 & 103 & 4 & 0 & 0 & 0 & 0 & 0.0000 & $\mathrm{ZnC14}$ Marcus \\
\hline 5997 & -7.48 & 12 & 1 & 50 & -1 & 103 & 1 & 0 & 0 & 0.0000 & ?? $\mathrm{ZnOHCl}(\mathrm{aq}), \mathrm{w} 2$ \\
\hline 6000 & 1.15 & 12 & 1 & 104 & 1 & 0 & 0 & 0 & 0 & 0.0000 & $? ? \mathrm{ZnF}+, \mathrm{W} 2$ \\
\hline 6010 & 0.10 & 12 & 1 & 105 & 1 & 0 & 0 & 0 & 0 & 0.0000 & $? ?$ \\
\hline 6020 & 2.20 & 12 & 1 & 107 & 1 & 0 & 0 & 0 & 0 & 0.0000 & $? ?$ \\
\hline 6030 & 4.50 & 12 & 1 & 107 & 2 & 0 & 0 & 0 & 0 & 0.0000 & $? ?$ \\
\hline 6040 & 7.00 & 12 & 1 & 107 & 3 & 0 & 0 & 0 & 0 & 0.0000 & $? ?$ \\
\hline 6050 & 9.00 & 12 & 1 & 107 & 4 & 0 & 0 & 0 & 0 & 0.0000 & $? ?$ \\
\hline 6060 & 15.70 & 12 & 1 & 50 & 1 & 109 & 1 & 0 & 0 & 0.0000 & $? ?$ \\
\hline 6100 & 5.7 & 12 & 1 & 126 & 1 & 0 & 0 & 0 & 0 & 0.0 & ZnPic $(1+)$ Morel \\
\hline 6101 & 10.3 & 12 & 1 & 126 & 2 & 0 & 0 & 0 & 0 & 0.0 & $\mathrm{Zn}(\mathrm{Pic}) 2$ Morel \\
\hline 6102 & 13.6 & 12 & 1 & 126 & 3 & 0 & 0 & 0 & 0 & 0.0 & $\mathrm{Zn}(\mathrm{Pic}) 3(1-)$ Morel \\
\hline 6200 & 6.3 & 12 & 1 & 117 & 1 & 0 & 0 & 0 & 0 & 0.0 & $\mathrm{ZnCit}(1-)$ Morel \\
\hline 6201 & 8.6 & 12 & 1 & 117 & 2 & 0 & 0 & 0 & 0 & 0.0 & $\mathrm{Zn}(\mathrm{Cit}) 2(4-)$ Morel \\
\hline 6202 & 13.5 & 12 & 1 & 117 & 1 & 50 & 1 & 0 & 0 & 0.0 & ZnHCit Morel \\
\hline 6203 & 12.9 & 12 & 1 & 117 & 1 & 50 & 2 & 0 & 0 & 0.0 & $\mathrm{ZnH} 2 \mathrm{Cit}(\mathrm{l}+)$ Morel \\
\hline 6300 & 4.9 & 12 & 1 & 118 & 1 & 0 & 0 & 0 & 0 & 0.0 & $\mathrm{ZnOx} \mathrm{KC}$ \\
\hline 6301 & 7.6 & 12 & 1 & 118 & 2 & 0 & 0 & 0 & 0 & 0.0 & $\mathrm{Zn}(\mathrm{Ox}) 2(2-) \mathrm{KC}$ \\
\hline 6400 & 18.3 & 12 & 1 & 128 & 1 & 0 & 0 & 0 & 0 & 0.0 & ZnEDTA(2-) Morel \\
\hline 6401 & 21.7 & 12 & 1 & 128 & 1 & 50 & 1 & 0 & 0 & 0.0 & ZnHEDTA(-) Morel \\
\hline 6402 & 9.4 & 12 & 1 & 128 & 1 & 50 & -1 & 0 & 0 & 0.0 & $\mathrm{Zn}(\mathrm{OH}) \mathrm{EDTA}(3-) \mathrm{Mor}$ \\
\hline 6500 & 20.42 & 12 & 1 & 170 & 1 & 0 & 0 & 0 & 0 & 0.0 & ZnDTPA(3-) Lindsay \\
\hline 6501 & 26.68 & 12 & 1 & 170 & 1 & 50 & 1 & 0 & 0 & 0.0 & ZnHDTPA(2-) Lindsay \\
\hline 6740 & -8.96 & 12 & 1 & 50 & -1 & 0 & 0 & 0 & 0 & 0.0000 & $? ? \mathrm{ZnOH}+, \mathrm{W} 2$ \\
\hline 6750 & -16.90 & 12 & 1 & 50 & -2 & 0 & 0 & 0 & 0 & 0.0000 & ?? \\
\hline 6760 & -28.40 & 12 & 1 & 50 & -3 & 0 & 0 & 0 & 0 & 0.0000 & $? ?$ \\
\hline 6765 & -41.20 & 12 & 1 & 50 & -4 & 0 & 0 & 0 & 0 & 0.0000 & $? ?$ \\
\hline 6770 & -9.00 & 12 & 2 & 50 & -1 & 0 & 0 & 0 & 0 & 0.0000 & ?? $\mathrm{Zn} 2 \mathrm{OH}(3+), \mathrm{B} / \mathrm{M}$ \\
\hline 6775 & -57.80 & 12 & 2 & 50 & -6 & 0 & 0 & 0 & 0 & 0.0000 & ?? $\mathrm{B} / \mathrm{M}$ \\
\hline 6775 & 2.30 & 13 & 1 & 102 & 1 & 0 & 0 & 0 & 0 & 0.0000 & $? ?$ \\
\hline 6780 & 0.50 & 13 & 1 & 103 & 1 & 0 & 0 & 0 & 0 & 0.0000 & $? ?$ \\
\hline 6785 & 22.30 & 13 & 1 & 170 & 1 & 0 & 0 & 0 & 0 & 0.0 & NiDTPA(3-) Lindsay \\
\hline 6786 & 28.63 & 13 & 1 & 170 & 1 & 50 & 1 & 0 & 0 & 0.0 & NiHDTPA(2-) Lindsay \\
\hline 6790 & 1.10 & 13 & 1 & 104 & 1 & 0 & 0 & 0 & 0 & 0.0000 & ?? \\
\hline 6800 & 0.60 & 13 & 1 & 105 & 1 & 0 & 0 & 0 & 0 & 0.0000 & $? ?$ \\
\hline 6810 & 2.70 & 13 & 1 & 107 & 1 & 0 & 0 & 0 & 0 & 0.0000 & $? ?$ \\
\hline 6820 & 4.80 & 13 & 1 & 107 & 2 & 0 & 0 & 0 & 0 & 0.0000 & $? ?$ \\
\hline 6830 & 6.50 & 13 & 1 & 107 & 3 & 0 & 0 & 0 & 0 & 0.0000 & $? ?$ \\
\hline 6840 & 7.70 & 13 & 1 & 107 & 4 & 0 & 0 & 0 & 0 & 0.0000 & $? ?$ \\
\hline 6841 & 7.2 & 13 & 1 & 126 & 1 & 0 & 0 & 0 & 0 & 0.0 & NiPic(l+) Morel \\
\hline 6842 & 13.2 & 13 & 1 & 126 & 2 & 0 & 0 & 0 & 0 & 0.0 & $\mathrm{Ni}(\mathrm{Pic}) 2 \mathrm{Morel}$ \\
\hline 6843 & 17.9 & 13 & 1 & 126 & 3 & 0 & 0 & 0 & 0 & 0.0 & Ni(Pic) $3(1-)$ Morel \\
\hline 6844 & 6.7 & 13 & 1 & 117 & 1 & 0 & 0 & 0 & 0 & 0.0 & NiCit(1-) Morel \\
\hline 6845 & 10.6 & 13 & 1 & 117 & 1 & 50 & 1 & 0 & 0 & 0.0 & NiHCit Morel \\
\hline
\end{tabular}




\begin{tabular}{|c|c|c|c|c|c|c|c|c|c|c|c|}
\hline \multicolumn{12}{|c|}{ THERMO.DAT Page 6 of 17} \\
\hline \multicolumn{4}{|c|}{ Thursday, July 13, 1995} & \multicolumn{8}{|c|}{ 9:43:58 AM } \\
\hline 6846 & 13.4 & 13 & 1 & 117 & 1 & 50 & 2 & 0 & 0 & 0.0 & NiH2Cit(l+) Morel \\
\hline 6847 & 5.2 & 13 & 1 & 118 & $i$ & 0 & $\overline{0}$ & 0 & 0 & 0.0 & $\mathrm{NiOx} \mathrm{KC}$ \\
\hline 6848 & 6.5 & 13 & 1 & 118 & 2 & 0 & 0 & 0 & 0 & 0.0 & $\mathrm{Ni}(\mathrm{Ox}) 2(2-) \mathrm{KC}$ \\
\hline 6850 & -30.00 & 13 & 1 & 50 & -3 & 0 & 0 & 0 & 0 & 0.0000 & $\mathrm{Ni}(\mathrm{OH}) 3-\mathrm{B} / \mathrm{M}$ \\
\hline 6860 & -19.00 & 13 & 1 & 50 & -2 & 0 & 0 & 0 & 0 & 0.0000 & $\mathrm{Ni}(\mathrm{OH}) 2(0) \mathrm{B} / \mathrm{M}$ \\
\hline 7590 & -9.86 & 13 & 1 & 50 & -1 & 0 & 0 & 0 & 0 & 0.0000 & $\mathrm{NiOH}(+) \mathrm{B} / \mathrm{M}$ \\
\hline 7591 & 20.4 & 13 & 1 & 128 & 1 & 0 & 0 & 0 & 0 & 0.0 & NiEDTA(2-) Morel \\
\hline 7592 & 24.0 & 13 & 1 & 128 & 1 & 50 & 1 & 0 & 0 & 0.0 & NiHEDTA(-) Morel \\
\hline 7593 & 7.8 & 13 & 1 & 128 & 1 & 50 & -1 & 0 & 0 & 0.0 & Ni(OH)EDtÁ(3-) Morel \\
\hline 7595 & 30.70 & 14 & 2 & 99 & 2 & 0 & 0 & 0 & 0 & 0.0000 & ?? \\
\hline 7600 & 2.40 & 14 & 1 & 102 & 1 & 0 & 0 & 0 & 0 & 0.0000 & $\ddot{?}$ \\
\hline 7610 & 3.50 & 14 & 1 & 102 & 2 & 0 & 0 & 0 & 0 & 0.0000 & $? ?$ \\
\hline 7620 & 7.27 & 14 & 1 & 103 & 1 & 0 & 0 & 0 & 0 & 0.0000 & $? ?$ \\
\hline 7630 & 14.00 & 14 & 1 & 103 & 2 & 0 & 0 & 0 & 0 & 0.0000 & $? ?$ \\
\hline 7640 & 14.88 & 14 & 1 & 103 & 3 & 0 & 0 & 0 & 0 & 0.0000 & $? ?$ \\
\hline 7650 & 15.60 & 14 & 1 & 103 & 4 & 0 & 0 & 0 & 0 & 0.0000 & $? ?$ \\
\hline 7660 & 1.60 & 14 & 1 & 104 & 1 & 0 & 0 & 0 & 0 & 0.0000 & $? ?$ \\
\hline 7670 & 9.60 & 14 & 1 & 105 & 1 & 0 & 0 & 0 & 0 & 0.0000 & $? ?$ \\
\hline 7680 & 18.10 & 14 & 1 & 105 & 2 & 0 & 0 & 0 & 0 & 0.0000 & $? ?$ \\
\hline 7690 & 20.50 & 14 & 1 & 105 & 3 & 0 & 0 & 0 & 0 & 0.0000 & $? ?$ \\
\hline 7700 & 21.60 & 14 & 1 & 105 & 4 & 0 & 0 & 0 & 0 & 0.0000 & $? ?$ \\
\hline 7710 & 13.40 & 14 & 1 & 106 & 1 & 0 & 0 & 0 & 0 & 0.0000 & $? ?$ \\
\hline 7720 & 24.60 & 14 & 1 & 106 & 2 & 0 & 0 & 0 & 0 & 0.0000 & $? ?$ \\
\hline 7730 & 28.40 & 14 & 1 & 106 & 3 & 0 & 0 & 0 & 0 & 0.0000 & $? ?$ \\
\hline 7740 & 30.30 & 14 & 1 & 106 & 4 & 0 & 0 & 0 & 0 & 0.0000 & $? ?$ \\
\hline 7750 & 8.70 & 14 & 1 & 107 & 1 & 0 & 0 & 0 & 0 & 0.0000 & $? ?$ \\
\hline 7760 & 17.50 & 14 & 1 & 107 & 2 & 0 & 0 & 0 & 0 & 0.0000 & $? ?$ \\
\hline 7770 & 18.50 & 14 & 1 & 107 & 3 & 0 & 0 & 0 & 0 & 0.0000 & $? ?$ \\
\hline 7780 & 19.30 & 14 & 1 & 107 & 4 & 0 & 0 & 0 & 0 & 0.0000 & $? ?$ \\
\hline 7790 & 68.00 & 14 & 1 & 50 & 2 & 108 & 2 & 0 & 0 & 0.0000 & $? ?$ \\
\hline 7800 & 54.20 & 14 & 1 & 108 & 2 & 0 & 0 & 0 & 0 & 0.0000 & $? ?$ \\
\hline 8040 & -3.16 & 14 & 1 & 50 & -1 & 0 & 0 & 0 & 0 & 0.0000 & ?? \\
\hline 8050 & -5.48 & 14 & 1 & 50 & -2 & 0 & 0 & 0 & 0 & 0.0000 & $? ?$ \\
\hline 8052 & -20.26 & 14 & 1 & 50 & -3 & 0 & 0 & 0 & 0 & 0.0000 & $? ?$ \\
\hline 8054 & 4.75 & 14 & 1 & 50 & -1 & 103 & 1 & 0 & 0 & 0.0000 & $? ?$ \\
\hline 8060 & 6.60 & 15 & 1 & 101 & 1 & 0 & 0 & 0 & 0 & 0.0 & Bilinski $8 / 88$ \\
\hline 8070 & 10.06 & 15 & 1 & 101 & 2 & 0 & 0 & 0 & 0 & 0.0 & Bilinski $8 / 88$ \\
\hline 8080 & 2.70 & 15 & 1 & 102 & 1 & 0 & 0 & 0 & 0 & 0.0000 & $? ?$ \\
\hline 8090 & 1.59 & 15 & 1 & 103 & 1 & 0 & 0 & 0 & 0 & 0.0000 & PbCl Smith/Martel \\
\hline 8100 & 1.80 & 15 & 1 & 103 & 2 & 0 & 0 & 0 & 0 & 0.0000 & $\mathrm{PbC12} \mathrm{Sm} / \mathrm{Ma}$ \\
\hline 8110 & 1.70 & 15 & 1 & 103 & 3 & 0 & 0 & 0 & 0 & 0.0000 & $\mathrm{PbCl} 3 \mathrm{Sm} / \mathrm{Ma}$ \\
\hline 8120 & 1.40 & 15 & 1 & 103 & 1 & 0 & 0 & 0 & 0 & 0.0000 & $\mathrm{PbC1} 4 \mathrm{Sm} / \mathrm{Ma}$ \\
\hline 8130 & 2.20 & 15 & 1 & 105 & 2 & 0 & 0 & 0 & 0 & 0.0000 & $? ?$ \\
\hline 8140 & 3.00 & 15 & 1 & 105 & 3 & 0 & 0 & 0 & 0 & 0.0000 & $? ?$ \\
\hline 8150 & 1.80 & 15 & 1 & 106 & 1 & 0 & 0 & 0 & 0 & 0.0000 & $? ?$ \\
\hline 8160 & 3.60 & 15 & 1 & 106 & 2 & 0 & 0 & 0 & 0 & 0.0000 & $? ?$ \\
\hline 8170 & 4.20 & 15 & 1 & 106 & 3 & 0 & 0 & 0 & 0 & 0.0000 & $? ?$ \\
\hline 8180 & 4.40 & 15 & 1 & 106 & 4 & 0 & 0 & 0 & 0 & 0.0000 & $? ?$ \\
\hline 8190 & 1.17 & 15 & 1 & 157 & 1 & 0 & 0 & 0 & 0 & 0.0000 & S/M gap $8 / 88$ \\
\hline 8191 & 1.4 & 15 & 1 & 157 & 2 & 0 & 0 & 0 & 0 & 0.0000 & S/M gap $8 / 88$ \\
\hline 8520 & -7.71 & 15 & 1 & 50 & -1 & 0 & 0 & 0 & 0 & 0.0000 & $\mathrm{~B} / \mathrm{M}$ gap $8 / 88$ \\
\hline 8530 & -17.12 & 15 & 1 & 50 & -2 & 0 & 0 & 0 & 0 & 0.0000 & $\mathrm{~B} / \mathrm{M}$ gap $8 / 88$ \\
\hline 8540 & -28.06 & 15 & 1 & 50 & -3 & 0 & 0 & 0 & 0 & 0.0000 & $\mathrm{~B} / \mathrm{M}$ gap $8 / 88$ \\
\hline 8545 & -6.36 & 15 & 2 & 50 & -1 & 0 & 0 & 0 & 0 & 0.0000 & $\mathrm{~B} / \mathrm{M}$ gap $8 / 88$ \\
\hline 8546 & -23.88 & 15 & 3 & 50 & -4 & 0 & 0 & 0 & 0 & 0.0000 & $\mathrm{~B} / \mathrm{M}$ gap $8 / 88$ \\
\hline 8547 & -20.88 & 15 & 4 & 50 & -4 & 0 & 0 & 0 & 0 & 0.0000 & B/M gap $8 / 88$ \\
\hline
\end{tabular}


THERMO.DAT Page 7 of 17 Thursday, July 13, $1995 \quad$ 9:43:58 AM

\begin{tabular}{|c|c|c|c|c|c|c|c|c|c|c|c|}
\hline 8548 & -43.61 & 15 & 6 & 50 & -8 & 0 & 0 & 0 & 0 & 0.0000 & B/M gap 8/88 \\
\hline 8555 & 5.95 & 16 & 1 & 101 & 1 & 0 & 0 & 0 & 0 & 0.0000 & Oxalate correl'n \\
\hline 8556 & 12.44 & 16 & 1 & 101 & 1 & 50 & 1 & 0 & 0 & 0.0000 & Oxalate correl'n \\
\hline 8557 & 10.00 & 16 & 1 & 101 & 2 & 0 & 0 & 0 & 0 & 0.0000 & Oxalate guess \\
\hline 8560 & 2.50 & 16 & $i$ & 102 & 1 & 0 & 0 & 0 & 0 & 0.0000 & $? ?$ \\
\hline 8570 & 0.56 & 16 & 1 & 103 & 1 & 0 & 0 & 0 & 0 & 0.0000 & S/M,gap 860812 \\
\hline 8580 & 0.60 & 16 & 1 & 105 & 1 & 0 & 0 & 0 & 0 & 0.0000 & $? ?$ \\
\hline 8590 & 2.00 & 16 & 1 & 107 & 1 & 0 & 0 & 0 & 0 & 0.0000 & $? ?$ \\
\hline 8600 & 3.50 & 16 & 1 & 107 & 2 & 0 & 0 & 0 & 0 & 0.0000 & $? ?$ \\
\hline 8610 & 4.50 & 16 & 1 & 107 & 3 & 0 & 0 & 0 & 0 & 0.0000 & $? ?$ \\
\hline 8620 & 5.20 & 16 & 1 & 107 & 4 & 0 & 0 & 0 & 0 & 0.0000 & $? ?$ \\
\hline 8630 & 5.30 & 16 & 1 & 107 & 5 & 0 & 0 & 0 & 0 & 0.0000 & $? ?$ \\
\hline 8640 & 6.50 & 16 & 1 & 107 & 6 & 0 & 0 & 0 & 0 & 0.0000 & $? ?$ \\
\hline 8650 & 6.4 & 16 & 1 & 126 & 1 & 0 & 0 & 0 & 0 & 0.0 & CoPic(l+) Morel \\
\hline 8651 & 11.3 & 16 & 1 & 126 & 2 & 0 & 0 & 0 & 0 & 0.0 & $\mathrm{Co}(\mathrm{Pic}) 2 \mathrm{Morel}$ \\
\hline 8652 & 15.8 & 16 & 1 & 126 & 3 & 0 & 0 & 0 & 0 & 0.0 & $\mathrm{Co}(\mathrm{Pic}) 3(1-)$ Morel \\
\hline 8660 & 6.3 & 16 & 1 & 117 & 1 & 0 & 0 & 0 & 0 & 0.0 & CoCit(1-) Morel \\
\hline 8661 & 10.3 & 16 & 1 & 117 & 1 & 50 & 1 & 0 & 0 & 0.0 & CoHCit Morel \\
\hline 8662 & 12.9 & 16 & 1 & 117 & 1 & 50 & 2 & 0 & 0 & 0.0 & $\mathrm{CoH} 2 \mathrm{Cit}(1+)$ Morel \\
\hline 8670 & 4.7 & 16 & 1 & 118 & 1 & 0 & 0 & 0 & 0 & 0.0 & $\mathrm{CoO} \times \mathrm{KC}$ \\
\hline 8671 & 7.0 & 16 & 1 & 118 & 2 & 0 & 0 & 0 & 0 & 0.0 & $\mathrm{Co}(\mathrm{Ox}) 2(2-) \mathrm{KC}$ \\
\hline 8680 & 18.1 & 16 & 1 & 128 & 1 & 0 & 0 & 0 & 0 & 0.0 & CoEDTA(2-) Morel \\
\hline 8681 & 21.5 & 16 & 1 & 128 & 1 & 50 & 1 & 0 & 0 & 0.0 & CoHEDTA(-) Morel \\
\hline 8690 & 21.28 & 16 & 1 & 170 & 1 & 0 & 0 & 0 & 0 & 0.0 & CoDTPA(3-) Lindsay \\
\hline 8691 & 26.88 & 16 & 1 & 170 & 1 & 50 & 1 & 0 & 0 & 0.0 & CoHDTPA(2-) Lindsay \\
\hline 8700 & 0.20 & 16 & 1 & 157 & 1 & 0 & 0 & 0 & 0 & 0.0000 & S/M,gap \\
\hline 8702 & 0.66 & 16 & 1 & 157 & 2 & 0 & 0 & 0 & 0 & 0.0000 & S/M,gap \\
\hline 9300 & -9.65 & 16 & 1 & 50 & -1 & 0 & 0 & 0 & 0 & 0.0000 & B/M,gap \\
\hline 9302 & -18.80 & 16 & 1 & 50 & -2 & 0 & 0 & 0 & 0 & 0.0000 & $\mathrm{~B} / \mathrm{M}$,gap \\
\hline 9304 & -31.50 & 16 & 1 & 50 & -3 & 0 & 0 & 0 & 0 & 0.0000 & B/M,gap \\
\hline 9306 & -46.30 & 16 & 1 & 50 & -4 & 0 & 0 & 0 & 0 & 0.0000 & $\mathrm{~B} / \mathrm{M}$,gap \\
\hline 9308 & -11.20 & 16 & 2 & 50 & -1 & 0 & 0 & 0 & 0 & 0.0000 & $\mathrm{~B} / \mathrm{M}$,gap \\
\hline 9310 & -30.53 & 16 & 4 & 50 & -4 & 0 & 0 & 0 & 0 & 0.0000 & $\mathrm{~B} / \mathrm{M}$,gap \\
\hline 9330 & 5.20 & 17 & 1 & 104 & 1 & 0 & 0 & 0 & 0 & 0.0000 & $? ?$ \\
\hline 9340 & 9.10 & 17 & 1 & 104 & 2 & 0 & 0 & 0 & 0 & 0.0000 & $? ?$ \\
\hline 9350 & 12.00 & 17 & 1 & 104 & 3 & 0 & 0 & 0 & 0 & 0.0000 & $? ?$ \\
\hline 9360 & 7.10 & 17 & 1 & 107 & 1 & 0 & 0 & 0 & 0 & 0.0000 & $? ?$ \\
\hline 9370 & 13.90 & 17 & 1 & 107 & 2 & 0 & 0 & 0 & 0 & 0.0000 & $? ?$ \\
\hline 9380 & 19.90 & 17 & 1 & 107 & 3 & 0 & 0 & 0 & 0 & 0.0000 & $? ?$ \\
\hline 9390 & 25.50 & 17 & 1 & 107 & 4 & 0 & 0 & 0 & 0 & 0.0000 & $? ?$ \\
\hline 9400 & 30.60 & 17 & 1 & 107 & 5 & 0 & 0 & 0 & 0 & 0.0000 & $? ?$ \\
\hline 9410 & 35.00 & 17 & 1 & 107 & 6 & 0 & 0 & 0 & 0 & 0.0000 & $? ?$ \\
\hline 9920 & 26.04 & 19 & 1 & 128 & 1 & 0 & 0 & 0 & 0 & 0.0 & $\ddot{\mathrm{CrEDTA}}(-) \mathrm{KC}$ \\
\hline 9921 & 28.25 & 19 & 1 & 128 & 1 & 50 & 1 & 0 & 0 & 0.0 & CrHEDTA KC \\
\hline 9922 & 18.65 & 19 & 1 & 128 & 1 & 50 & -1 & 0 & 0 & 0.0 & $\mathrm{Cr}(\mathrm{OH}) \mathrm{EDTA}(2-) \mathrm{KC}$ \\
\hline 9930 & 9.40 & 19 & 1 & 117 & 1 & 0 & 0 & 0 & 0 & 0.0 & CrCit KC \\
\hline 9940 & 6.66 & 19 & 1 & 118 & 1 & 0 & 0 & 0 & 0 & 0.0 & $\mathrm{CrOx}(+) \mathrm{KC}$ \\
\hline 9941 & 12.27 & 19 & I & 118 & 2 & 0 & 0 & 0 & 0 & 0.0 & $\mathrm{Cr}(\mathrm{Ox}) 2(-) \mathrm{KC}$ \\
\hline 9942 & 16.76 & 19 & 1 & 118 & 3 & 0 & 0 & 0 & 0 & 0.0 & $\mathrm{Cr}(\mathrm{Ox}) 3(3-) \mathrm{KC}$ \\
\hline 9943 & 4.49 & 19 & 1 & 118 & 2 & 50 & -1 & 0 & 0 & 0.0 & $\mathrm{CrOH}(\mathrm{Ox}) 2(2-) \mathrm{KC}$ \\
\hline 9944 & -5.72 & 19 & 1 & 118 & 2 & 50 & -2 & 0 & 0 & 0.0 & $\mathrm{Cr}(\mathrm{OH}) 2(\mathrm{Ox}) 2(3-) \mathrm{KC}$ \\
\hline 9950 & 11.72 & 19 & 1 & 126 & 2 & 0 & 0 & 0 & 0 & 0.0 & $\mathrm{Cr}(\mathrm{Pic}) 2(+) \mathrm{KC}$ \\
\hline 9450 & 1.30 & 18 & 1 & 102 & 1 & 0 & 0 & 0 & 0 & 0.0000 & $? ?$ \\
\hline 9460 & 3.30 & 18 & 1 & 103 & 1 & 0 & 0 & 0 & 0 & 0.000 & Butler uncorr \\
\hline 9470 & 5.30 & 18 & 1 & 103 & 2 & 0 & 0 & 0 & 0 & 0.000 & $"$ \\
\hline 9480 & 5.30 & 18 & 1 & 103 & 3 & 0 & 0 & 0 & 0 & 0.000 & $"$ \\
\hline
\end{tabular}


THERMO.DAT Page 8 of 17

Thursday, July 13, 1995

9:43:58 AM

\begin{tabular}{|c|c|c|c|c|c|c|c|c|c|c|c|}
\hline 9490 & 6.10 & 18 & 1 & 103 & 4 & 0 & 0 & 0 & 0 & 0.000 & $"$ \\
\hline 9500 & 4.30 & 18 & 1 & 105 & 1 & 0 & 0 & 0 & 0 & 0.0000 & $? ?$ \\
\hline 9510 & 7.30 & 18 & 1 & 105 & 2 & 0 & 0 & 0 & 0 & 0.0000 & $? ?$ \\
\hline 9520 & 7.70 & 18 & 1 & 105 & 3 & 0 & 0 & 0 & 0 & 0.0000 & $? ?$ \\
\hline 9530 & 8.10 & 18 & 1 & 105 & 4 & 0 & 0 & 0 & 0 & 0.0000 & $? ?$ \\
\hline 9540 & 14.00 & 18 & 1 & 106 & 1 & 0 & 0 & 0 & 0 & 0.0000 & $? ?$ \\
\hline 9550 & 13.90 & 18 & 1 & 106 & 2 & 0 & 0 & 0 & 0 & 0.0000 & $? ?$ \\
\hline 9560 & 3.20 & 18 & 1 & 107 & 1 & 0 & 0 & 0 & 0 & 0.0000 & ?? \\
\hline 9570 & 7.20 & 18 & 1 & 107 & 2 & 0 & 0 & 0 & 0 & 0.0000 & $? ?$ \\
\hline 9580 & 14.00 & 18 & 1 & 50 & 1 & 108 & 1 & 0 & 0 & 0.0000 & $? ?$ \\
\hline 9590 & 19.00 & 18 & 1 & 50 & 2 & 108 & 2 & 0 & 0 & 0.0000 & $? ?$ \\
\hline 9600 & 17.30 & 18 & 1 & 108 & 1 & 0 & 0 & 0 & 0 & 0.0000 & $? ?$ \\
\hline 9880 & -11.90 & 18 & 1 & 50 & -1 & 0 & 0 & 0 & 0 & 0.0000 & $? ?$ \\
\hline 9881 & -24.00 & 18 & 1 & 50 & -2 & 0 & 0 & 0 & 0 & 0.0000 & $? ?$ \\
\hline 9890 & 4.90 & 19 & 1 & 102 & 1 & 0 & 0 & 0 & 0 & 0.0000 & $? ?$ \\
\hline 9900 & 5.20 & 19 & 1 & 104 & 1 & 0 & 0 & 0 & 0 & 0.0000 & $? ?$ \\
\hline 9910 & 9.10 & 19 & 1 & 104 & 2 & 0 & 0 & 0 & 0 & 0.0000 & $? ?$ \\
\hline 10000 & -3.30 & 19 & 1 & 50 & -1 & 0 & 0 & 0 & 0 & 0.0000 & $? ?$ \\
\hline 10010 & -8.80 & 19 & 1 & 50 & -2 & 0 & 0 & 0 & 0 & 0.0000 & $? ?$ \\
\hline 10020 & -23.80 & 19 & 1 & 50 & -4 & 0 & 0 & 0 & 0 & 0.0000 & ?? \\
\hline 10022 & -135.20 & 19 & 2 & 50 & -14 & 99 & -6 & 0 & 0 & 0.0000 & $? ?$ \\
\hline 10024 & -68.40 & 19 & 1 & 50 & -7 & 99 & -3 & 0 & 0 & 0.0000 & $? ?$ \\
\hline 10026 & -74.90 & 19 & 1 & 50 & -8 & 99 & -3 & 0 & 0 & 0.0000 & $? ?$ \\
\hline 10030 & 3.02 & 20 & 1 & 102 & 1 & 0 & 0 & 0 & 0 & 2.15 & AlSo4n DKN,1984 \\
\hline 10040 & 4.92 & 20 & 1 & 102 & 2 & 0 & 0 & 0 & 0 & 2.84 & DKN \\
\hline 10050 & 6.98 & 20 & 1 & 104 & 1 & 0 & 0 & 0 & 0 & 1.06 & AlFn DKN \\
\hline 10060 & 12.60 & 20 & 1 & 104 & 2 & 0 & 0 & 0 & 0 & 1.98 & DKN \\
\hline 10070 & 16.65 & 20 & 1 & 104 & 3 & 0 & 0 & 0 & 0 & 2.16 & DKN \\
\hline 10080 & 19.03 & 20 & 1 & 104 & 4 & 0 & 0 & 0 & 0 & 2.20 & DKN \\
\hline 10090 & 20.91 & 20 & 1 & 104 & 5 & 0 & 0 & 0 & 0 & 1.84 & DKN \\
\hline 10100 & 20.86 & 20 & 1 & 104 & 6 & 0 & 0 & 0 & 0 & 0.10 & DKN \\
\hline 10200 & 18.9 & 20 & 1 & 128 & 1 & 0 & 0 & 0 & 0 & 0.0 & AlEDTA $(-)$ Morel \\
\hline 10201 & 21.6 & 20 & 1 & 128 & 1 & 50 & 1 & 0 & 0 & 0.0 & AlHEDTA Morel \\
\hline 10202 & 12.6 & 20 & 1 & 128 & 1 & 50 & -1 & 0 & 0 & 0.0 & $\mathrm{Al}(\mathrm{OH}) \mathrm{EDTA}(2-)$ Morel \\
\hline 10203 & 2.0 & 20 & 1 & 128 & 1 & 50 & -2 & 0 & 0 & 0.0 & Al(OH)2EDTA(3-) Morel \\
\hline 10210 & 26.67 & 20 & 1 & 170 & 1 & 50 & 1 & 0 & 0 & 0.0 & AlHDTPA(-) Lindsay \\
\hline 10211 & 13.87 & 20 & 1 & 170 & 1 & 50 & -1 & 0 & 0 & 0.0 & $\mathrm{Al}(\mathrm{OH}) \mathrm{DTPA}(3-)$ Lindsay \\
\hline 10220 & 9.96 & 20 & 1 & 117 & 1 & 0 & $\mathbf{0}$ & 0 & 0 & 0.0 & AlCit KC \\
\hline 10221 & 12.93 & 20 & 1 & 117 & 1 & 50 & 1 & 0 & 0 & 0.0 & AlHCit(+) KC \\
\hline 10230 & 7.77 & 20 & 1 & 118 & 1 & 0 & 0 & 0 & 0 & 0.0 & $\mathrm{AlOx}(+) \mathrm{KC}$ \\
\hline 10231 & 13.33 & 20 & 1 & 118 & 2 & 0 & 0 & 0 & 0 & 0.0 & $\mathrm{Al}(\mathrm{Ox}) 2(-) \mathrm{KC}$ \\
\hline 10232 & 16.92 & 20 & 1 & 118 & 3 & 0 & 0 & 0 & 0 & 0.0 & $\mathrm{Al}(\mathrm{Ox}) 3(3-) \mathrm{KC}$ \\
\hline 10340 & -4.99 & 20 & 1 & 50 & -1 & 0 & 0 & 0 & 0 & 11.90 & AlOHn DKN \\
\hline 10345 & -10.13 & 20 & 1 & 50 & -2 & 0 & 0 & 0 & 0 & 22.00 & DKN \\
\hline 10350 & -23.30 & 20 & 1 & 50 & -4 & 0 & 0 & 0 & 0 & 44.00 & K Robie,H NBS \\
\hline 10355 & -16.76 & 20 & 1 & 50 & -3 & 0 & 0 & 0 & 0 & 33.00 & DKN, 1984 \\
\hline 10360 & -0.10 & 21 & 1 & 103 & 1 & 0 & 0 & 0 & 0 & 0.0000 & $? ?$ \\
\hline 10370 & 0.00 & 21 & 1 & 104 & 1 & 0 & 0 & 0 & 0 & 0.0000 & $? ?$ \\
\hline 10420 & 0.60 & 22 & 1 & 102 & 1 & 0 & 0 & 0 & 0 & 0.0000 & $? ?$ \\
\hline 10480 & -13.40 & 22 & 1 & 50 & -1 & 0 & 0 & 0 & 0 & 0.0000 & $? ?$ \\
\hline 10490 & 1.90 & 23 & 1 & 102 & 1 & 0 & 0 & 0 & 0 & 0.0000 & $? ?$ \\
\hline 10500 & 3.00 & 23 & 1 & 102 & 2 & 0 & 0 & 0 & 0 & 0.0000 & $? ?$ \\
\hline 10510 & 2.00 & 23 & 1 & 102 & 3 & 0 & 0 & 0 & 0 & 0.0000 & $? ?$ \\
\hline 10520 & 1.60 & 23 & 1 & 103 & 1 & 0 & 0 & 0 & 0 & 0.0000 & $? ?$ \\
\hline 10530 & 5.60 & 23 & 1 & 104 & 1 & 0 & 0 & 0 & 0 & 0.0000 & $? ?$ \\
\hline 10540 & 9.70 & 23 & 1 & 104 & 2 & 0 & 0 & 0 & 0 & 0.0000 & $? ?$ \\
\hline
\end{tabular}


THERMO.DAT Page 9 of 17

Thursday, July 13, $1995 \quad$ 9:43:58 AM

\begin{tabular}{|c|c|c|c|c|c|c|c|c|c|c|c|}
\hline 10550 & 12.70 & 23 & 1 & 104 & 3 & 0 & 0 & 0 & 0 & 0.0000 & $? ?$ \\
\hline 10770 & -6.30 & 23 & 1 & 50 & -1 & 0 & 0 & 0 & 0 & 0.0000 & $? ?$ \\
\hline 10901 & -2.30 & 25 & 1 & 50 & -1 & 0 & 0 & 0 & 0 & 0.0000 & $\mathrm{TiOOH}(+), \mathrm{B} / \mathrm{M}$ \\
\hline 10902 & -4.80 & 25 & 1 & 50 & -2 & 0 & 0 & 0 & 0 & 0.0000 & $\mathrm{TiO}(\mathrm{OH}) 2(0), \mathrm{B} / \mathrm{M}$ \\
\hline 10906 & -1.68 & 25 & 8 & 50 & -12 & 0 & 0 & 0 & 0 & 0.0000 & Einaga81 \\
\hline 11010 & 26.36 & 25 & 1 & 50 & 1 & 109 & 1 & 0 & 0 & 0.0000 & TiHPo4(aq),Einaga \\
\hline 11012 & 6.65 & 25 & 1 & 104 & 1 & 0 & 0 & 0 & 0 & 0.0 & TiOF $(+)$ Bond \\
\hline 11013 & 11.74 & 25 & 1 & 104 & 2 & 0 & 0 & 0 & 0 & 0.0 & TiOF2(aq) Bond \\
\hline 11014 & 16.32 & 25 & 1 & 104 & 3 & 0 & 0 & 0 & 0 & 0.0 & TiOF3(-) Bond \\
\hline 11015 & 20.38 & 25 & 1 & 104 & 4 & 0 & 0 & 0 & 0 & 0.0 & TiOF4(2-) Bond \\
\hline 11020 & 9.70 & 26 & 1 & 104 & 2 & 0 & 0 & 0 & 0 & 0.0000 & $? ?$ \\
\hline 11030 & 10.20 & 26 & 1 & 104 & 3 & 0 & 0 & 0 & 0 & 0.0000 & $? ?$ \\
\hline 11040 & 1.10 & 26 & 1 & 105 & 1 & 0 & 0 & 0 & 0 & 0.0000 & $? ?$ \\
\hline 11050 & 1.70 & 26 & 1 & 105 & 2 & 0 & 0 & 0 & 0 & 0.0000 & $? ?$ \\
\hline 11060 & 1.40 & 26 & 1 & 105 & 3 & 0 & 0 & 0 & 0 & 0.0000 & $? ?$ \\
\hline 11110 & -3.20 & 26 & 1 & 50 & -1 & 0 & 0 & 0 & 0 & 0.0000 & $? ?$ \\
\hline 11480 & 3.70 & 29 & 1 & 102 & 1 & 0 & 0 & 0 & 0 & 0.0000 & $? ?$ \\
\hline 11490 & 0.80 & 29 & 1 & 103 & 1 & 0 & 0 & 0 & 0 & 0.0000 & $? ?$ \\
\hline 11500 & 4.10 & 29 & 1 & 104 & 1 & 0 & 0 & 0 & 0 & 0.0000 & $? ?$ \\
\hline 11510 & 7.50 & 29 & 1 & 104 & 2 & 0 & 0 & 0 & 0 & 0.0000 & $? ?$ \\
\hline 11520 & 0.70 & 29 & 1 & 105 & 1 & 0 & 0 & 0 & 0 & 0.0000 & $? ?$ \\
\hline 11530 & 19.30 & 29 & 1 & 109 & 1 & 0 & 0 & 0 & 0 & 0.0000 & $? ?$ \\
\hline 11840 & -7.90 & 29 & 1 & 50 & -1 & 0 & 0 & 0 & 0 & 0.0000 & ?? \\
\hline 11850 & 26.90 & 30 & 1 & 107 & 2 & 0 & 0 & 0 & 0 & 0.0000 & $? ?$ \\
\hline 11870 & 5.80 & 31 & 1 & 102 & 1 & 0 & 0 & 0 & 0 & 0.0000 & $? ?$ \\
\hline 11880 & 9.40 & 31 & 1 & 102 & 2 & 0 & 0 & 0 & 0 & 0.0000 & $? ?$ \\
\hline 11890 & 1.40 & 31 & 1 & 103 & 1 & 0 & 0 & 0 & 0 & 0.0000 & $? ?$ \\
\hline 11900 & 8.80 & 31 & 1 & 104 & 1 & 0 & 0 & 0 & 0 & 0.0000 & $? ?$ \\
\hline 11910 & 15.70 & 31 & 1 & 104 & 2 & 0 & 0 & 0 & 0 & 0.0000 & $? ?$ \\
\hline 11920 & 20.80 & 31 & 1 & 104 & 3 & 0 & 0 & 0 & 0 & 0.0000 & $? ?$ \\
\hline 12090 & -2.10 & 31 & 1 & 50 & -1 & 0 & 0 & 0 & 0 & 0.0000 & $? ?$ \\
\hline 12100 & -5.20 & 32 & 1 & 50 & -1 & 0 & 0 & 0 & 0 & 0.0000 & ?? UO2OH(t),NEAj \\
\hline 12110 & -11.90 & 32 & 1 & 50 & -2 & 0 & 0 & 0 & 0 & 0.0000 & ?? after NEA \\
\hline 12112 & -19.20 & 32 & 1 & 50 & -3 & 0 & 0 & 0 & 0 & 0.0000 & ?? NEA \\
\hline 12114 & -33.00 & 32 & 1 & 50 & -4 & 0 & 0 & 0 & 0 & 0.0000 & ?? NEA \\
\hline 12120 & -5.62 & 32 & 2 & 50 & -2 & 0 & 0 & 0 & 0 & 0.0000 & ?? NEA \\
\hline 12122 & -2.70 & 32 & 2 & 50 & -1 & 0 & 0 & 0 & 0 & 0.0000 & ?? NEA \\
\hline 12123 & -11.90 & 32 & 3 & 50 & -4 & 0 & 0 & 0 & 0 & 0.0000 & ?? NEA \\
\hline 12125 & -15.55 & 32 & 3 & 50 & -5 & 0 & 0 & 0 & 0 & 0.0000 & ?? NEA \\
\hline 12127 & -21.90 & 32 & 4 & 50 & -7 & 0 & 0 & 0 & 0 & 0.0000 & ?? NEA \\
\hline 12128 & -31.00 & 32 & 3 & 50 & -7 & 0 & 0 & 0 & 0 & 0.000 & NEA \\
\hline 12130 & 9.63 & 32 & 1 & 101 & 1 & 0 & 0 & 0 & 0 & 0.0000 & ?? CO3 cpxs NEA \\
\hline 12135 & 17.00 & 32 & 1 & 101 & 2 & 0 & 0 & 0 & 0 & 0.0000 & ?? NEA \\
\hline 12140 & 21.63 & 32 & 1 & 101 & 3 & 0 & 0 & 0 & 0 & 0.0000 & ?? NEA \\
\hline 12141 & -1.18 & 32 & 2 & 101 & 1 & 50 & -3 & 0 & 0 & 0.0000 & $? ? \mathrm{vj}$ \\
\hline 12145 & 5.08 & 32 & 1 & 104 & 1 & 0 & 0 & 0 & 0 & 0.0000 & $? ? \mathrm{vj}$ \\
\hline 12150 & 8.84 & 32 & 1 & 104 & 2 & 0 & 0 & 0 & 0 & 0.0000 & $? ? \mathrm{vj}$ \\
\hline 12155 & 11.27 & 32 & 1 & 104 & 3 & 0 & 0 & 0 & 0 & 0.0000 & $? ? \mathrm{vj}$ \\
\hline 12160 & 12.43 & 32 & 1 & 104 & 4 & 0 & 0 & 0 & 0 & 0.0000 & $? ? \mathrm{vj}$ \\
\hline 12165 & 0.21 & 32 & 1 & 103 & 1 & 0 & 0 & 0 & 0 & 0.0000 & ?? S/M \\
\hline 12170 & 2.95 & 32 & 1 & 102 & 1 & 0 & 0 & 0 & 0 & 0.0000 & ?? S/M \\
\hline 12175 & 4.00 & 32 & 1 & 102 & 2 & 0 & 0 & 0 & 0 & 0.0000 & ?? S/M \\
\hline 12180 & 23.20 & 32 & 1 & 109 & 1 & 50 & 2 & 0 & 0 & 0.0000 & ?? vj thesis \\
\hline 12185 & 22.90 & 32 & 1 & 109 & 1 & 50 & 3 & 0 & 0 & 0.0000 & ?? vj thesis \\
\hline 12200 & 45.24 & 32 & 1 & 109 & 2 & 50 & 4 & 0 & 0 & 0.0000 & ?? vj thesis \\
\hline 12205 & 46.00 & 32 & 1 & 109 & 2 & 50 & 5 & 0 & 0 & 0.0000 & ?? vj thesis \\
\hline
\end{tabular}


THERMO.DAT Page 10 of 17

Thursday, July 13, 1995

\section{9:43:58 AM}

\begin{tabular}{|c|c|c|c|c|c|c|c|c|c|c|c|}
\hline 12210 & 20.53 & 32 & 1 & 112 & 1 & 50 & 1 & 0 & 0 & 0.0000 & $? ? ? ?$ \\
\hline 12211 & 6.36 & 32 & 1 & 118 & 1 & 0 & 0 & 0 & 0 & 0.0000 & ?? S/M I=0.1 \\
\hline 12212 & 10.59 & 32 & 1 & 118 & 2 & 0 & 0 & 0 & 0 & 0.0000 & ?? $\mathrm{S} / \mathrm{M} \mathrm{I}=0.1$ \\
\hline 12212 & 11.00 & 32 & 1 & 118 & 3 & 0 & 0 & 0 & 0 & 0.0000 & $? ? \mathrm{~S} / \mathrm{M} \mathrm{I}=1.0$ \\
\hline 12225 & -0.65 & 36 & 1 & 50 & -1 & 0 & 0 & 0 & 0 & 0.0000 & $? ?$ \\
\hline 12230 & -2.26 & 36 & 1 & 50 & -2 & 0 & 0 & 0 & 0 & 0.0000 & $? ?$ \\
\hline 12235 & -4.89 & 36 & 1 & 50 & -3 & 0 & 0 & 0 & 0 & 0.0000 & ?? \\
\hline 12240 & -8.55 & 36 & 1 & 50 & -4 & 0 & 0 & 0 & 0 & 0.0000 & $? ?$ \\
\hline 12245 & -13.16 & 36 & 1 & 50 & -5 & 0 & 0 & 0 & 0 & 0.0000 & $? ?$ \\
\hline 12250 & -5.75 & 36 & 2 & 50 & -5 & 0 & 0 & 0 & 0 & 0.0000 & $? ?$ \\
\hline 12255 & 3.69 & 36 & 1 & 102 & 1 & 0 & 0 & 0 & 0 & 0.0000 & ?? \\
\hline 12260 & 6.05 & 36 & 1 & 102 & 2 & 0 & 0 & 0 & 0 & 0.0000 & $? ?$ \\
\hline 12265 & -0.86 & 36 & 1 & 103 & 1 & 0 & 0 & 0 & 0 & 0.0000 & $? ?$ \\
\hline 12270 & 8.60 & 36 & 1 & 104 & 1 & 0 & 0 & 0 & 0 & 0.0000 & ?? \\
\hline 12275 & 14.40 & 36 & 1 & 104 & 2 & 0 & 0 & 0 & 0 & 0.0000 & ?? \\
\hline 12280 & 19.10 & 36 & 1 & 104 & 3 & 0 & 0 & 0 & 0 & 0.0000 & ?? \\
\hline 12285 & 23.60 & 36 & 1 & 104 & 4 & 0 & 0 & 0 & 0 & 0.0000 & ?? \\
\hline 12290 & 25.22 & 36 & 1 & 104 & 5 & 0 & 0 & 0 & 0 & 0.0000 & ?? \\
\hline 12295 & 27.68 & 36 & 1 & 104 & 6 & 0 & 0 & 0 & 0 & 0.0000 & $? ?$ \\
\hline 12300 & 24.34 & 36 & 1 & 109 & 1 & 50 & 1 & 0 & 0 & 0.0000 & ?? \\
\hline 12305 & 46.70 & 36 & 1 & 109 & 2 & 50 & 2 & 0 & 0 & 0.0000 & ?? \\
\hline 12310 & 67.67 & 36 & 1 & 109 & 3 & 50 & 3 & 0 & 0 & 0.0000 & ?? \\
\hline 12315 & 88.05 & 36 & 1 & 109 & 4 & 50 & 4 & 0 & 0 & 0.0000 & $? ?$ \\
\hline 12530 & 10.32 & 50 & 1 & 101 & 1 & 0 & 0 & 0 & 0 & -3.5610 & HCO3-, pb82 \\
\hline 12540 & 16.67 & 50 & 2 & 101 & 1 & 0 & 0 & 0 & 0 & -5.7380 & $\mathrm{H} 2 \mathrm{CO} 3, \mathrm{pb} 82$ \\
\hline 12550 & 1.99 & 50 & 1 & 102 & 1 & 0 & 0 & 0 & 0 & 4.9100 & HSO4-, W2 \\
\hline 12555 & 0.20 & 50 & 1 & 103 & 1 & 0 & 0 & 0 & 0 & 0.0000 & $\mathrm{HCl}$, Henly \\
\hline 12560 & 3.17 & 50 & 1 & 104 & 1 & 0 & 0 & 0 & 0 & 3.4600 & $\mathrm{HF}, \mathrm{W} 2$ \\
\hline 12565 & 3.75 & 50 & 1 & 104 & 2 & 0 & 0 & 0 & 0 & 4.5500 & HF2-, W2 \\
\hline 12570 & 9.24 & 50 & 1 & 107 & 1 & 0 & 0 & 0 & 0 & 0.0 & NH4OH, Butler \\
\hline 12580 & 12.92 & 50 & 1 & 108 & 1 & 0 & 0 & 0 & 0 & -12.1000 & $\mathrm{HS}-, \mathrm{S} / \mathrm{M}$ \\
\hline 12590 & 19.91 & 50 & 2 & 108 & 1 & 0 & 0 & 0 & 0 & -5.3000 & $\mathrm{H} 2 \mathrm{~S}, \mathrm{~S} / \mathrm{M}$ \\
\hline 12600 & 12.35 & 50 & 1 & 109 & 1 & 0 & 0 & 0 & 0 & -3.5300 & phr \\
\hline 12610 & 19.55 & 50 & 2 & 109 & 1 & 0 & 0 & 0 & 0 & -4.5200 & phr \\
\hline 12620 & 21.70 & 50 & 3 & 109 & 1 & 0 & 0 & 0 & 0 & -3.6200 & phr \\
\hline 12650 & 9.32 & 50 & 1 & 114 & 1 & 0 & 0 & 0 & 0 & 0.0000 & $? ?$ \\
\hline 12651 & 6.40 & 50 & 1 & 117 & 1 & 0 & 0 & 0 & 0 & 0.0 & HCit(2-) Morel \\
\hline 12652 & 11.16 & 50 & 2 & 117 & 1 & 0 & 0 & 0 & 0 & 0.0 & H2Cit(1-) Morel \\
\hline 12653 & 14.29 & 50 & 3 & 117 & 1 & 0 & 0 & 0 & 0 & 0.0 & H3Cit Morel \\
\hline 12655 & 1.25 & 50 & 2 & 118 & 1 & 0 & 0 & 0 & 0 & 0.0000 & ?? S/M \\
\hline 12656 & 4.27 & 50 & 1 & 118 & 1 & 0 & 0 & 0 & 0 & 0.0000 & $? ? \mathrm{~S} / \mathrm{M}$ \\
\hline 12658 & 5.39 & 50 & 1 & 126 & 1 & 0 & 0 & 0 & 0 & 0.0 & HPiC Morel \\
\hline 12659 & 6.40 & 50 & 2 & 126 & 1 & 0 & 0 & 0 & 0 & 0.0 & H2Pic(l+) Morel \\
\hline 12660 & 11.00 & 50 & 1 & 128 & 1 & 0 & 0 & 0 & 0 & 0.0 & HEDTA(3-) S/M \\
\hline 12661 & 17.3 & 50 & 2 & 128 & 1 & 0 & 0 & 0 & 0 & 0.0 & H2EDTA(2-) SIM/ \\
\hline 12661 & 19.6 & 50 & 3 & 128 & 1 & 0 & 0 & 0 & 0 & 0.0 & H3EDTA(1-) S/M \\
\hline 12661 & 21.8 & 50 & 4 & 128 & 1 & 0 & 0 & 0 & 0 & 0.0 & H4EDTA S/M \\
\hline 12670 & 11.48 & 50 & 1 & 170 & 1 & 0 & 0 & 0 & 0 & 0.0 & HDTPA(4-) Lindsay \\
\hline 12671 & 20.89 & 50 & 2 & 170 & 1 & 0 & 0 & 0 & 0 & 0.0 & H2DTPA (3-) Lindsay \\
\hline 12672 & 25.83 & 50 & 3 & 170 & 1 & 0 & 0 & 0 & 0 & 0.0 & H3DTPA(2-) Lindsay \\
\hline 12673 & 28.92 & 50 & 4 & 170 & 1 & 0 & 0 & 0 & 0 & 0.0 & H4DTPA(-) Lindsay \\
\hline 12674 & 30.96 & 50 & 5 & 170 & 1 & 0 & 0 & 0 & 0 & 0.0 & H5DTPA Lindsay \\
\hline 12700 & 9.24 & 50 & 1 & 148 & 1 & 0 & 0 & 0 & 0 & -3.2300 & $\mathrm{H} 3 \mathrm{BO} 3, \mathrm{~B} / \mathrm{M}$ \\
\hline 12701 & 9.11 & 50 & 1 & 148 & 2 & 0 & 0 & 0 & 0 & -1.8600 & $\mathrm{~B} 2 \mathrm{O}(\mathrm{OH}) 5(-), \mathrm{B} / \mathrm{M}$ \\
\hline 12702 & 20.68 & 50 & 1 & 148 & 3 & 0 & 0 & 0 & 0 & -10.2900 & $\mathrm{~B} 3 \mathrm{O} 3(\mathrm{OH}) 4(-), \mathrm{B} / \mathrm{M}$ \\
\hline 12703 & 20.66 & 50 & 1 & 148 & 4 & 0 & 0 & 0 & 0 & -19.9200 & B4O5(OH)4(2-) \\
\hline
\end{tabular}


THERMO.DAT Page 11 of 17

Thursday, July 13, 1995

\section{9:43:58 AM}

$\begin{array}{llllllllllll}12705 & 8.83 & 50 & 1 & 148 & 1 & 104 & 1 & 0 & 0 & -1.3800 & \text { BFx(OH)3-x(-),W2 } \\ 12706 & 16.87 & 50 & 2 & 148 & 1 & 104 & 2 & 0 & 0 & -1.6000 & \text { W2 } \\ 12707 & 22.91 & 50 & 3 & 148 & 1 & 104 & 3 & 0 & 0 & -4.8100 & \text { W2 } \\ 12708 & 29.52 & 50 & 4 & 148 & 1 & 104 & 4 & 0 & 0 & -5.0200 & \text { W2 } \\ 12710 & 13.09 & 50 & 1 & 112 & 1 & 0 & 0 & 0 & 0 & -4.6400 & \text { H3SiO4, gap, 9/82 } \\ 12720 & 22.92 & 50 & 2 & 112 & 1 & 0 & 0 & 0 & 0 & -10.7580 & \text { H4SiO4, gap } \\ 12722 & 53.10 & 50 & 6 & 112 & 1 & 104 & 6 & 0 & 0 & -27.0180 & \text { SiF6, W2 } \\ 13520 & 4.30 & 50 & 1 & 152 & 1 & 0 & 0 & 0 & 0 & 0.0000 & ? ? \\ 13530 & 3.70 & 50 & 1 & 153 & 1 & 0 & 0 & 0 & 0 & 0.0000 & ? ? \\ 13540 & 11.50 & 50 & 1 & 154 & 1 & 0 & 0 & 0 & 0 & 0.0 & \text { HAsO42-,B/M } \\ 13541 & 18.46 & 50 & 2 & 154 & 1 & 0 & 0 & 0 & 0 & 0.0 & \text { H2AsO4-,B/M } \\ 13542 & 20.70 & 50 & 3 & 154 & 1 & 0 & 0 & 0 & 0 & 0.0 & \text { H3AsO4, B/M } \\ 13551 & 28.42 & 162 & 1 & 50 & 4 & 0 & 0 & 0 & 0 & 0.0000 & ? ? \\ 13553 & 25.15 & 162 & 1 & 50 & 3 & 0 & 0 & 0 & 0 & 0.0000 & ? ? \\ 13555 & 21.33 & 162 & 1 & 50 & 2 & 0 & 0 & 0 & 0 & 0.0000 & ? ? \\ 13557 & 13.27 & 162 & 1 & 50 & 1 & 0 & 0 & 0 & 0 & 0.0000 & ? ? \\ 13561 & -5.67 & 163 & 1 & 50 & -1 & 0 & 0 & 0 & 0 & 0.0000 & ? ? \\ 13565 & -2.26 & 164 & 1 & 50 & -1 & 0 & 0 & 0 & 0 & 0.0000 & ? ? \\ 13567 & -5.85 & 164 & 1 & 50 & -2 & 0 & 0 & 0 & 0 & 0.0000 & ? ? \\ 13569 & -10.98 & 164 & 1 & 50 & -3 & 0 & 0 & 0 & 0 & 0.0000 & ? ? \\ 13570 & 8.50 & 50 & 1 & 156 & 1 & 0 & 0 & 0 & 0 & 0.0000 & ? ? \\ 13580 & 11.20 & 50 & 2 & 156 & 1 & 0 & 0 & 0 & 0 & 0.0000 & ? ? \\ 13595 & -13.99 & 50 & -1 & 0 & 0 & 0 & 0 & 0 & 0 & 13.3380 & \text { OH-, Robie } \\ & 8 & \text { following are type III } & & & & & & \\ 15000 & 13.01 & 6 & 1 & 7 & -1 & 99 & 1 & 0 & 0 & -9.7000 & \text { Fe(3)/Fe(2), Robie } \\ 15010 & 31.60 & 17 & 1 & 16 & -1 & 99 & 1 & 0 & 0 & 0.0000 & \text { Co(3)/Co(2) } \\ 15020 & -5.10 & 27 & 1 & 26 & -1 & 99 & 2 & 0 & 0 & 0.0000 & \text { Sn(IV)/Sn(II) } \\ 15030 & 2.70 & 9 & 1 & 33 & -1 & 99 & 1 & 0 & 0 & 0.0000 & \text { Cu(2)/Cu(l) } \\ 15040 & 20.72 & 102 & 1 & 108 & -1 & 50 & 8 & 99 & 8 & -48.0520 & \text { SO4/S2-, Robie } \\ 15050 & 9.22 & 32 & 1 & 50 & 4 & 99 & 2 & 36 & -1 & 0.0000 & \\ 15060 & 45.36 & 162 & 1 & 163 & -1 & 50 & 6 & 99 & 1 & 0.0000 & \\ 15070 & 51.07 & 162 & 1 & 164 & -1 & 50 & 99 & 2 & 0 & 0.0000 & \end{array}$

0 TYPE IV: No solids or gases autoclassified TYPE IV

0 TYPE V: No solids or gases autoclassified. TYPE V

217 TYPE VI: All solids \& gases autoclassified TYPE VI

$\begin{array}{llllllllllll}20000 & 8.48 & 1 & 1 & 101 & 1 & 0 & 0 & 0 & 0 & 2.2970 & \text { Calcite, pb82 } \\ 20002 & 8.34 & 1 & 1 & 101 & 1 & 0 & 0 & 0 & 0 & 2.5900 & \text { Aragonite, pb82 } \\ 20010 & 4.32 & 1 & 1 & 102 & 1 & 0 & 0 & 0 & 0 & 0.2700 & \text { Gypsum, Robie sign H } \\ 20012 & 4.12 & 1 & 1 & 102 & 1 & 0 & 0 & 0 & 0 & 4.3000 & \text { Anhydrite, Robie } \\ 20020 & 10.96 & 1 & 1 & 104 & 2 & 0 & 0 & 0 & 0 & -4.7100 & \text { Fluorite, Robie } \\ 20028 & 18.87 & 1 & 1 & 109 & 1 & 50 & 1 & 0 & 0 & 0.0000 & \text { Brushite, Garrels } \\ 20029 & 19.24 & 1 & 1 & 109 & 1 & 50 & 1 & 0 & 0 & 0.0000 & \text { Monetite, VT } 84 \\ 20030 & 57.54 & 1 & 5 & 50 & -1 & 109 & 3 & 0 & 0 & 0.0000 & \text { OH-apa, VT84, Bell } \\ 20035 & 59.74 & 1 & 5 & 104 & 1 & 109 & 3 & 0 & 0 & 0.0000 & \text { F-apa, VT84 } \\ 20040 & 48.20 & 1 & 4 & 50 & 1 & 109 & 3 & 0 & 0 & 0.0000 & \\ 20050 & 19.30 & 1 & 1 & 50 & 1 & 109 & 1 & 0 & 0 & 0.0000 & \\ 20070 & 8.70 & 1 & 1 & 112 & 1 & 0 & 0 & 0 & 0 & 0.0000 & \\ 20100 & 7.40 & 1 & 1 & 152 & 1 & 0 & 0 & 0 & 0 & 0.0000 & \\ 20110 & 22.90 & 1 & 3 & 154 & 2 & 0 & 0 & 0 & 0 & 0.0000 & \\ 20120 & 5.50 & 1 & 3 & 154 & 2 & 0 & 0 & 0 & 0 & 0.0000 & \\ 20130 & -22.68 & 1 & 1 & 50 & -2 & 0 & 0 & 0 & 0 & 34.9920 & \text { Portlandite, Robie } \\ 20140 & 8.20 & 2 & 1 & 101 & 1 & 0 & 0 & 0 & 0 & 7.3400 & \text { Magnesite, Rbie } \\ 20142 & 5.17 & 2 & 1 & 101 & 1 & 0 & 0 & 0 & 0 & -13.5700 & \text { Nesquehonite, Rbie } \\ 20143 & -9.59 & 2 & 2 & 101 & 1 & 50 & -2 & 0 & 0 & -3.7300 & \text { Artinite, Rbie } \\ 20144 & 9.72 & 2 & 5 & 101 & 4 & 50 & -2 & 0 & 0 & 19.3400 & \text { Hydromagnes, Robie } \\ 20145 & 17.02 & 2 & 1 & 1 & 1 & 101 & 2 & 0 & 0 & 8.2900 & \text { Dolomite, PHR } \\ & & & & & & & & & & & \end{array}$


THERNO.DAT Page 12 of 17

\section{Thursday, July 13, 1995 9:43:58 AM}

\begin{tabular}{|c|c|c|c|c|c|c|c|c|c|c|c|}
\hline 20146 & -41.62 & 2 & 3 & 1 & 1 & 101 & 4 & 0 & 0 & 29.2400 & Huntite, Rbie \\
\hline 20148 & 2.14 & 2 & 1 & 102 & 1 & 0 & 0 & 0 & 0 & -2.8200 & Epsomite, W2 \\
\hline 20150 & 8.00 & 2 & $\overline{1}$ & 104 & 2 & 0 & 0 & 0 & 0 & 0.0000 & \\
\hline 20160 & 28.40 & 2 & 3 & 109 & 2 & 0 & 0 & 0 & 0 & 0.0000 & \\
\hline 20180 & 24.40 & 2 & 3 & 154 & 2 & 0 & 0 & 0 & 0 & 0.0000 & \\
\hline 20190 & 4.90 & 2 & 1 & 156 & 1 & 0 & 0 & 0 & 0 & 0.0000 & \\
\hline 20200 & -16.76 & 2 & 1 & 50 & -2 & 0 & 0 & 0 & 0 & 14.3300 & Brucite, Robie \\
\hline 20210 & 9.27 & 3 & 1 & 101 & 1 & 0 & 0 & 0 & 0 & 0.0 & $\mathrm{SrCO} 3(\mathrm{c}), \mathrm{P} / \mathrm{B}$ \\
\hline 20220 & 6.50 & 3 & 1 & 102 & 1 & 0 & 0 & 0 & 0 & 0.5 & $\mathrm{SrSO} 4(\mathrm{c}) \mathrm{S} / \mathrm{M}$ \\
\hline 20230 & 8.60 & 3 & 1 & 104 & 2 & 0 & 0 & 0 & 0 & 0.0 & \\
\hline 20240 & 2.40 & 3 & 1 & 112 & 1 & 0 & 0 & 0 & 0 & 0.0 & \\
\hline 20260 & 22.80 & 3 & 3 & 154 & 2 & 0 & 0 & 0 & 0 & 0.0 & \\
\hline 20270 & 6.10 & 3 & 1 & 156 & 1 & 0 & 0 & 0 & 0 & 0.0 & \\
\hline 20280 & 25.80 & 6 & 1 & 109 & 1 & 0 & 0 & 0 & 0 & 0.0 & \\
\hline 20290 & 21.70 & 6 & 1 & 154 & 1 & 0 & 0 & 0 & 0 & 0.0 & Scorodite, Rmstidt \\
\hline 20300 & 31.60 & 6 & 2 & 156 & 3 & 0 & 0 & 0 & 0 & 0.0 & \\
\hline 20305 & 8.77 & 6 & 3 & 50 & -8 & 99 & 1 & 0 & 0 & 41.3700 & Magnetite, Robie \\
\hline 20310 & -2.71 & 6 & 1 & 50 & -3 & 0 & 0 & 0 & 0 & 0.0 & $\mathrm{Fe}(\mathrm{OH}) 3 \mathrm{am}$, gap \\
\hline 20312 & 1.68 & 6 & 1 & 50 & -3 & 0 & 0 & 0 & 0 & 14.5400 & Goethite, Robie \\
\hline 20313 & 3.84 & 6 & 2 & 50 & -6 & 0 & 0 & 0 & 0 & 31.0350 & Hematite, Robie \\
\hline 20314 & 11.20 & 6 & 3 & 50 & -6 & 5 & 1 & 102 & 1 & 36.1800 & $\mathrm{Na-jarosite,} \mathrm{W2}$ \\
\hline 20316 & 14.80 & 6 & 3 & 50 & -6 & 4 & 1 & 102 & 1 & 31.2800 & $\mathrm{~K}$-jarosite, W2 \\
\hline 20318 & 12.10 & 6 & 3 & 50 & -5 & 102 & 1 & 0 & 0 & 55.1500 & $\mathrm{H}$-jarosite, W2 \\
\hline 20320 & 10.50 & 7 & 1 & 101 & 1 & 0 & 0 & 0 & 0 & 6.9900 & $\mathrm{FeCO} 3(\mathrm{c})$, Robie \\
\hline 20330 & 16.83 & 7 & 1 & 108 & 1 & 0 & 0 & 0 & 0 & -10.2600 & ppt FeS, B67 \\
\hline 20331 & 17.56 & 7 & 1 & 108 & 1 & 0 & 0 & 0 & 0 & -11.3700 & Mackinawite, B67 \\
\hline 20332 & 18.96 & 7 & 1 & 108 & 1 & 0 & 0 & 0 & 0 & -10.7220 & Pyrrhotite, B67 \\
\hline 20338 & 44.32 & 7 & 1 & 108 & 2 & 99 & -2 & 0 & 0 & -35.4800 & Pyrite, Robie \\
\hline 20335 & 69.57 & 7 & 3 & 108 & 4 & 99 & -2 & 0 & 0 & -44.7840 & Greigite, B67 \\
\hline 20340 & 33.30 & 7 & 3 & 109 & 2 & 0 & 0 & 0 & 0 & 0.0 & \\
\hline 20350 & 16.40 & 7 & 1 & 112 & 1 & 0 & 0 & 0 & 0 & 0.0 & \\
\hline 20360 & -12.10 & 7 & 1 & 50 & -2 & 0 & 0 & 0 & 0 & 0. & $\mathrm{Fe}(\mathrm{OH}) 2, \mathrm{~B} / \mathrm{M}$ \\
\hline 20365 & -13.82 & 7 & 1 & 99 & 2 & 0 & 0 & 0 & 0 & 21.295 & Fe metal, Robie \\
\hline 20370 & 9.30 & 8 & 1 & 101 & $\overline{1}$ & 0 & 0 & 0 & 0 & 0.0 & $\mathrm{~S} / \mathrm{M} \mathrm{MnCO} 3(\mathrm{c})$ \\
\hline 20380 & 14.80 & 8 & 1 & 108 & 1 & 0 & 0 & 0 & 0 & 0.0 & \\
\hline 20400 & 10.70 & 8 & 1 & 112 & 1 & 0 & 0 & 0 & 0 & 0.0 & \\
\hline 20410 & 29.60 & 8 & 3 & 154 & 2 & 0 & 0 & 0 & 0 & 0.0 & \\
\hline 20420 & 7.30 & 8 & 1 & 156 & $\overline{1}$ & 0 & 0 & 0 & 0 & 0.0 & \\
\hline 20430 & -15.20 & 8 & 1 & 50 & -2 & 0 & 0 & 0 & 0 & 0.0 & $\mathrm{~B} / \mathrm{M}, \mathrm{Mn}(\mathrm{OH}) 2(\mathrm{ppt})$ \\
\hline 20440 & 5.92 & 9 & 2 & 50 & -2 & 101 & 1 & 0 & 0 & 0.0 & malachite, gap see lotus \\
\hline 20441 & 18.32 & 9 & 3 & 50 & -2 & 101 & 2 & 0 & 0 & 0.0 & azurite, gap see lotus \\
\hline 20450 & 38.30 & 9 & 1 & 108 & 1 & 0 & 0 & 0 & 0 & 0.0 & \\
\hline 20460 & 37.70 & 9 & 3 & 109 & 2 & 0 & 0 & 0 & 0 & 0.0 & \\
\hline 20480 & 39.80 & 9 & 3 & 154 & 2 & 0 & 0 & 0 & 0 & 0.0 & \\
\hline 20490 & 7.70 & 9 & 1 & 156 & 1 & 0 & 0 & 0 & 0 & 0.0 & \\
\hline 20500 & -7.62 & 9 & 1 & 50 & -2 & 0 & 0 & 0 & 0 & 0.0 & $\mathrm{CuO}(\mathrm{c}) \mathrm{B} / \mathrm{M}$ gap \\
\hline 20501 & -10.31 & 9 & 1 & 50 & -2 & 0 & 0 & 0 & 0 & 0.0 & $\mathrm{Cu}(\mathrm{OH}) 2(\mathrm{am})$ Gulens \\
\hline 20505 & 11.48 & 9 & 1 & 99 & 2 & 0 & 0 & 0 & 0 & -15.48 & $\mathrm{Cu}(2+)>\mathrm{Cu}$, Robie \\
\hline 20510 & 10.00 & 10 & 1 & 101 & 1 & 0 & 0 & 0 & 0 & 0.0 & \\
\hline 20520 & 9.95 & 10 & 1 & 102 & 1 & 0 & 0 & 0 & 0 & -6.281 & Barite, Robie sign $\mathrm{H}$ ? \\
\hline 20530 & 6.10 & 10 & 1 & 104 & 2 & 0 & 0 & 0 & 0 & 0.0 & \\
\hline 20550 & 54.80 & 10 & 3 & 154 & 2 & 0 & 0 & 0 & 0 & 0.0 & \\
\hline 20560 & 6.60 & 10 & 1 & 156 & 1 & 0 & 0 & 0 & 0 & 0.0 & \\
\hline 20570 & 12.00 & 11 & 1 & 101 & 1 & 0 & 0 & 0 & 0 & 0.0 & Stipp \\
\hline 20580 & 27.80 & 11 & 1 & 108 & 1 & 0 & 0 & 0 & 0 & 0.0 & \\
\hline 20600 & 37.40 & 11 & 3 & 154 & 2 & 0 & 0 & 0 & 0 & 0.0 & \\
\hline
\end{tabular}


THERMO.DAT Page 13 of 17

Thursday, July 13,1995

\section{9:43:58 AM}

\begin{tabular}{|c|c|c|c|c|c|c|c|c|c|c|c|}
\hline 20610 & 8.30 & 11 & 1 & 156 & 1 & 0 & 0 & 0 & 0 & 0.0 & \\
\hline 20620 & -13.65 & 11 & 1 & 50 & -2 & 0 & 0 & 0 & 0 & 0.0 & beta- $\mathrm{Cd}(\mathrm{OH}) 2 \mathrm{~B} / \mathrm{M}$ ? \\
\hline 20630 & 10.80 & 12 & 1 & 101 & 1 & 0 & 0 & 0 & 0 & 0.0 & \\
\hline 20640 & 23.00 & 12 & 1 & 108 & 1 & 0 & 0 & 0 & 0 & 0.0 & \\
\hline 20650 & 36.70 & 12 & 3 & 109 & 2 & 0 & 0 & 0 & 0 & 0.0 & \\
\hline 20660 & 18.50 & 12 & 1 & 112 & 1 & 0 & 0 & 0 & 0 & 0.0 & \\
\hline 20680 & 27.90 & 12 & 3 & 154 & 2 & 0 & 0 & 0 & 0 & 0.0 & \\
\hline 20690 & 7.70 & 12 & 1 & 156 & 1 & 0 & 0 & 0 & 0 & 0.0 & \\
\hline 20700 & -11.14 & 12 & 1 & 50 & -2 & 0 & 0 & 0 & 0 & 0.0 & $\mathrm{Zn}(\mathrm{OH}) 2, \mathrm{~B} / \mathrm{M}$ \\
\hline 20705 & -15.11 & 12 & 2 & 50 & -3 & 103 & 1 & 0 & 0 & 0.0 & $\mathrm{Zn} 2(\mathrm{OH}) 3 \mathrm{Cl} \mathrm{B} / \mathrm{M}$ \\
\hline 20710 & 8.20 & 13 & 1 & 101 & 1 & 0 & 0 & 0 & 0 & 0.0 & \\
\hline 20720 & 22.90 & 13 & 1 & 108 & 1 & 0 & 0 & 0 & 0 & 0.0 & \\
\hline 20730 & 30.20 & 13 & 3 & 154 & 2 & 0 & 0 & 0 & 0 & 0.0 & \\
\hline 20740 & 5.30 & 13 & 1 & 156 & 1 & 0 & 0 & 0 & 0 & 0.0 & \\
\hline 20750 & $-10-80$ & 13 & 1 & 50 & -2 & 0 & 0 & 0 & 0 & 0.0000 & $\mathrm{Ni}(\mathrm{OH}) 2 \mathrm{~B} / \mathrm{M}$ \\
\hline 20760 & 53.70 & 14 & 1 & 108 & 1 & 0 & 0 & 0 & 0 & 0.0 & \\
\hline 20770 & -1.87 & 14 & 1 & 50 & -2 & 0 & 0 & 0 & 0 & 0.0 & \\
\hline 20780 & 13.35 & 15 & 1 & 101 & 1 & 0 & 0 & 0 & 0 & 0.0000 & $\mathrm{PbCO} 3$, Bilinski \\
\hline 20790 & 19.34 & 15 & 3 & 50 & -2 & 101 & 2 & 0 & 0 & 0.0000 & $\mathrm{~Pb} 3(\mathrm{OH}) 2(\mathrm{CO} 3) 2$ \\
\hline 20800 & 7.70 & 15 & 1 & 102 & 1 & 0 & 0 & 0 & 0 & 0.0 & \\
\hline 20810 & 7.60 & 15 & 1 & 104 & 2 & 0 & 0 & 0 & 0 & 0.0 & \\
\hline 20820 & 27.90 & 15 & 1 & 108 & 1 & 0 & 0 & 0 & 0 & 0.0 & \\
\hline 20830 & 12.60 & 15 & 1 & 50 & 1 & 109 & 1 & 0 & 0 & 0.0 & \\
\hline 20840 & 43.00 & 15 & 3 & 109 & 2 & 0 & 0 & 0 & 0 & 0.0 & \\
\hline 20850 & 60.90 & 15 & 5 & 50 & -1 & 109 & 3 & 0 & 0 & 0.0 & \\
\hline 20860 & 3.50 & 15 & 2 & 50 & -2 & 112 & 1 & 0 & 0 & 0.0 & \\
\hline 20880 & 13.00 & 15 & 1 & 152 & 1 & 0 & 0 & 0 & 0 & 0.0 & \\
\hline 20890 & 36.30 & 15 & 3 & 154 & 2 & 0 & 0 & 0 & 0 & 0.0 & \\
\hline 20900 & 11.50 & 15 & 1 & 156 & 1 & 0 & 0 & 0 & 0 & 0.0 & \\
\hline 20910 & -12.72 & 15 & 1 & 50 & -2 & 0 & 0 & 0 & 0 & 0.0000 & $\mathrm{PbO}$ (red) $\mathrm{B} / \mathrm{M}$ \\
\hline 20920 & 10.12 & 16 & 1 & 101 & 1 & 0 & 0 & 0 & 0 & 4.6000 & Naumov \\
\hline 20921 & 9.98 & 16 & 1 & 101 & 1 & 0 & 0 & 0 & 0 & 4.6000 & $\mathrm{~S} / \mathrm{M}$ \\
\hline 20930 & 24.30 & 16 & 1 & 108 & 1 & 0 & 0 & 0 & 0 & 0.0 & \\
\hline 20940 & 32.80 & 16 & 3 & 154 & 2 & 0 & 0 & 0 & 0 & 0.0 & \\
\hline 20950 & 7.10 & 16 & 1 & 156 & 1 & 0 & 0 & 0 & 0 & 0.0 & \\
\hline 20960 & -12.28 & 16 & 1 & 50 & -2 & 0 & 0 & 0 & 0 & 21.5500 & inactpink, $\mathrm{B} / \mathrm{M}$ \\
\hline 20962 & -13.78 & 16 & 1 & 50 & -2 & 0 & 0 & 0 & 0 & 0.0 & act blue, $\mathrm{B} / \mathrm{M}$ \\
\hline 20970 & 3.70 & 17 & $i$ & 50 & -3 & 0 & 0 & 0 & 0 & 0.0 & \\
\hline 20980 & 10.90 & 18 & 2 & 101 & 1 & 0 & 0 & 0 & 0 & 0.0 & \\
\hline 20990 & 4.90 & 18 & 2 & 102 & 1 & 0 & 0 & 0 & 0 & 0.0 & \\
\hline 21000 & 9.90 & 18 & 1 & 103 & 1 & 0 & 0 & 0 & 0 & 0.0 & \\
\hline 21010 & 12.30 & 18 & 1 & 105 & 1 & 0 & 0 & 0 & 0 & 0.0 & \\
\hline 21020 & 15.90 & 18 & 1 & 106 & 1 & 0 & 0 & 0 & 0 & 0.0 & \\
\hline 21030 & 51.40 & 18 & 2 & 108 & 1 & 0 & 0 & 0 & 0 & 0.0 & \\
\hline 21040 & 16.00 & 18 & 3 & 109 & 1 & 0 & 0 & 0 & 0 & 0.0 & \\
\hline 21080 & 11.40 & 18 & 2 & 152 & 1 & 0 & 0 & 0 & 0 & 0.0 & \\
\hline 21090 & 11.20 & 18 & 2 & 153 & 1 & 0 & 0 & 0 & 0 & 0.0 & \\
\hline 21100 & 19.30 & 18 & 3 & 154 & 1 & 0 & 0 & 0 & 0 & 0.0 & \\
\hline 21110 & 14.90 & 18 & 2 & 156 & 1 & 0 & 0 & 0 & 0 & 0.0 & \\
\hline 21120 & -6.30 & 18 & 1 & 50 & -1 & 0 & 0 & 0 & 0 & 0.0 & \\
\hline 21130 & 20.90 & 19 & 1 & 154 & 1 & 0 & 0 & 0 & 0 & 0.0 & \\
\hline 21140 & -9.60 & 19 & 1 & 50 & -3 & 0 & 0 & 0 & 0 & 0.0 & \\
\hline 21150 & 22.50 & 20 & 1 & 109 & 1 & 0 & 0 & 0 & 0 & 0.0 & \\
\hline 21142 & 5.17 & 20 & 1 & 4 & 1 & 102 & 1 & 0 & 0 & -7.2200 & alum, W2 \\
\hline 21170 & 16.60 & 20 & 1 & 154 & 1 & 0 & 0 & 0 & 0 & 0.0 & \\
\hline 21180 & -8.11 & 20 & 1 & $50^{\circ}$ & -3 & 0 & 0 & 0 & 0 & 22.8 & Gibbs, DKN1984 \\
\hline
\end{tabular}


THERMO.DAT Page 14 of 17

Thursday, July 13, 1995

\section{9:43:58 AM}

\begin{tabular}{|c|c|c|c|c|c|c|c|c|c|c|c|}
\hline 21181 & -9.35 & 20 & 1 & 50 & -3 & 0 & 0 & 0 & 0 & 22.8 & Hem, Gibbs, DKN \\
\hline 21182 & -10.80 & 20 & 1 & 50 & -3 & 0 & 0 & 0 & 0 & 22.8 & Amorph, DKN \\
\hline 21190 & 11.23 & 20 & 2 & 50 & -3 & 109 & 1 & 0 & 0 & 0.0 & Augelite, Vie \\
\hline 21192 & 30.45 & 20 & 3 & 50 & -3 & 109 & 2 & 0 & 0 & 0.0 & Wavellite, Vie \\
\hline 21200 & 21.45 & 20 & 3 & 50 & -5 & 109 & 2 & 1 & 1 & 0.0 & Crandall, Vie \\
\hline 21202 & 19.03 & 20 & 1 & 109 & 1 & 0 & 0 & 0 & 0 & 0.0 & Variscite, Vie \\
\hline 21220 & 0.74 & 25 & 1 & 50 & -2 & 0 & 0 & 0 & 0 & 0.0 & am-Ti02 B/M edttd \\
\hline 21221 & 2.14 & 25 & 1 & 50 & -2 & 0 & 0 & 0 & 0 & 0.0 & rutile, Capi \\
\hline 21222 & 1.89 & 25 & 1 & 50 & -2 & 0 & 0 & 0 & 0 & 0.0 & anatase, Capi \\
\hline 21225 & -16.10 & 25 & 1 & 50 & -4 & 1 & 1 & 0 & 0 & 0.0 & a-perovskite, Capi \\
\hline 21226 & -15.91 & 25 & 1 & 50 & -4 & 1 & 1 & 0 & 0 & 0.0 & b-perovskite, Capi \\
\hline 21227 & -15.79 & 25 & 1 & 50 & -2 & 1 & 1 & 112 & 1 & 0.0 & sphene, Capi \\
\hline 21228 & -7.80 & 25 & 1 & 50 & -4 & 7 & 1 & 0 & 0 & 0.0 & ilmenite, Capi \\
\hline 21230 & 19.33 & 25 & 1 & 50 & 1 & 109 & 1 & 0 & 0 & 0.0 & TiHPO4, Einaga \\
\hline 21240 & 0.40 & 26 & 1 & 50 & -2 & 0 & 0 & 0 & 0 & 0.0 & \\
\hline 21250 & 1.00 & 27 & 1 & 50 & -4 & 0 & 0 & 0 & 0 & 0.0 & \\
\hline 21320 & 11.10 & 29 & 2 & 108 & 3 & 0 & 0 & 0 & 0 & 0.0 & \\
\hline 21330 & 22.10 & 29 & 1 & 109 & 1 & 0 & 0 & 0 & 0 & 0.0 & \\
\hline 21340 & 25.30 & 29 & 2 & 156 & 3 & 0 & 0 & 0 & 0 & 0.0 & \\
\hline 21350 & -21.00 & 29 & 1 & 50 & -3 & 0 & 0 & 0 & 0 & 0.0 & \\
\hline 21360 & 31.60 & 30 & 1 & 50 & -1 & 0 & 0 & 0 & 0 & 0.0 & \\
\hline 21370 & 20.50 & 31 & 1 & 156 & 2 & 0 & 0 & 0 & 0 & 0.0 & \\
\hline 21380 & -44.40 & 31 & 1 & 50 & -4 & 0 & 0 & 0 & 0 & 0.0 & \\
\hline 21385 & -5.55 & 32 & 1 & 50 & -2 & 0 & 0 & 0 & 0 & 0.0000 & schoep??, vjthesis \\
\hline 21388 & -5.40 & 32 & 1 & 50 & -2 & 0 & 0 & 0 & 0 & 12.0450 & schoep, Langmuir \\
\hline 21392 & 13.86 & 32 & 1 & 99 & 2 & 0 & 0 & 0 & 0 & 0.0 & uraninite \\
\hline 21393 & 53.15 & 32 & 2 & 1 & 1 & 155 & 2 & 0 & 0 & 0.0 & tyuyammite \\
\hline 21395 & 14.11 & 32 & 1 & 101 & 1 & 0 & 0 & 0 & 0 & 1.4400 & UO2CO3, vj thesis \\
\hline 21396 & 24.38 & 32 & 1 & 101 & 3 & 5 & 4 & 0 & 0 & 0.0000 & Na4UO2(CO3)3 OW 83 \\
\hline 21397 & 28.36 & 32 & 2 & 1 & 1 & 112 & 2 & 0 & 0 & 0.0 & uranophane \\
\hline 21398 & 56.55 & 32 & 2 & 4 & 2 & 155 & 2 & 0 & 0 & 0.0 & \\
\hline 21399 & 48.61 & 32 & 2 & 1 & 1 & 109 & 2 & 0 & 0 & 0.0 & \\
\hline 21400 & 51.32 & 32 & 2 & 4 & 2 & 109 & 2 & 0 & 0 & 0.0 & \\
\hline 21401 & 50.16 & 32 & 2 & 5 & 2 & 109 & 2 & 0 & 0 & 0.0 & \\
\hline 21402 & 48.09 & 32 & 2 & 50 & 2 & 109 & 2 & 0 & 0 & 0.0 & \\
\hline 21403 & 70.31 & 32 & 2 & 50 & 2 & 107 & 2 & 109 & 2 & 0.0 & \\
\hline 21404 & 47.58 & 32 & 2 & 2 & 1 & 109 & 2 & 0 & 0 & 0.0 & \\
\hline 21405 & 46.00 & 32 & 2 & 7 & 1 & 109 & 2 & 0 & 0 & 0.0 & \\
\hline 21406 & 33.77 & 32 & 2 & 9 & 1 & 109 & 2 & 0 & 0 & 0.0 & \\
\hline 21407 & 33.11 & 32 & 2 & 15 & $\hat{1}$ & 109 & 2 & 0 & 0 & 0.0 & \\
\hline 21408 & 48.31 & 32 & 2 & 3 & 1 & 109 & 2 & 0 & 0 & 0.0 & \\
\hline 21409 & 67.14 & 32 & 2 & 10 & 1 & 109 & 2 & 0 & 0 & 0.0 & \\
\hline 21410 & 25.00 & 32 & 1 & 50 & 1 & 109 & 1 & 0 & 0 & 0.0 & $\mathrm{vj}$ thesis \\
\hline 21411 & 50.96 & 32 & 3 & 109 & 2 & 0 & 0 & 0 & 0 & 0.0 & $\mathrm{vj}$ thesis \\
\hline 21413 & -4.82 & 36 & 1 & 50 & -4 & 0 & 0 & 0 & 0 & 0.0 & \\
\hline 21414 & 4.63 & 36 & 1 & 50 & -4 & 0 & 0 & 0 & 0 & 0.0 & \\
\hline 21415 & -21.05 & 36 & 3 & 50 & -16 & 99 & -4 & 0 & 0 & 0.0 & \\
\hline 21418 & 54.12 & 36 & 1 & 1 & 1 & 109 & 2 & 0 & 0 & 0.0 & \\
\hline 21420 & 51.50 & 36 & 1 & 50 & 2 & 109 & 2 & 0 & 0 & 0.0 & \\
\hline 21422 & 18.50 & 36 & 1 & 104 & 4 & 0 & 0 & 0 & 0 & 0.0 & \\
\hline 21424 & 27.58 & 36 & 1 & 104 & 4 & 0 & 0 & 0 & 0 & 0.0 & \\
\hline 21470 & -42.00 & 8 & 1 & 50 & -4 & 99 & -2 & 0 & 0 & 0.0 & \\
\hline 21480 & -61.70 & 8 & 3 & 50 & -8 & 99 & 1 & 0 & 0 & 0.0 & \\
\hline 21490 & -25.70 & 8 & 1 & 50 & -3 & 99 & -1 & 0 & 0 & 0.0 & \\
\hline 21500 & -49.20 & 15 & 1 & 50 & -4 & 99 & -2 & 0 & 0 & 0.0 & \\
\hline 21520 & 28.70 & 14 & 1 & 99 & 2 & 0 & 0 & 0 & 0 & 0.0 & \\
\hline
\end{tabular}




\begin{tabular}{llllllllllll}
\multicolumn{1}{l}{ THERMO.DAT } & \multicolumn{1}{l}{ Page 15 of 17 } \\
Thursday, July 13, 1995 & $\mathbf{9 : 4 3 : 5 8 ~ A M ~}$ & & & & & & \\
21417 & 51.50 & 36 & 1 & 50 & 2 & 109 & 2 & 0 & 0 & 0.0 & \\
21530 & 15.03 & 108 & 1 & 99 & -2 & 0 & 0 & 0 & 0 & 7.8870 & S(2-)>S(0),Robie \\
21550 & 82.15 & 162 & 2 & 50 & 8 & 99 & 2 & 0 & 0 & 0.0 & \\
21570 & 58.33 & 162 & 2 & 50 & 6 & 0 & 0 & 0 & 0 & 0.0 & \\
23900 & 26.92 & 50 & 2 & 112 & 1 & 0 & 0 & 0 & 0 & -17.3080 & Quartz, gap \\
23901 & 25.66 & 50 & 2 & 112 & 1 & 0 & 0 & 0 & 0 & -14.2260 & Amorph, gap \\
23902 & 26.65 & 50 & 2 & 112 & 1 & 0 & 0 & 0 & 0 & -16.9400 & Chalcedony, gap \\
23904 & 26.37 & 50 & 2 & 112 & 1 & 0 & 0 & 0 & 0 & -16.4130 & Cristobalite, gap \\
24000 & 16.29 & 20 & 2 & 1 & 3 & 112 & 3 & 50 & -6 & 70.5560 & Grossular, HH78 \\
24001 & 24.62 & 20 & 3 & 1 & 2 & 112 & 3 & 50 & -7 & 75.2180 & Clinozoisite \\
24200 & 38.58 & 5 & 1 & 20 & 1 & 112 & 2 & 0 & 0 & -0.2090 & Analcime, HH78 \\
24201 & 77.42 & 1 & 1 & 20 & 2 & 112 & 4 & 0 & 0 & 2.5670 & Laumontite, HH78 \\
24202 & 73.01 & 1 & 1 & 20 & 2 & 112 & 4 & 0 & 0 & 15.2680 & Wairakite, HH78 \\
24299 & 64.56 & 20 & 1 & 5 & 1 & 112 & 3 & 50 & 2 & -15.0490 & \\
24300 & 65.68 & 20 & 1 & 5 & 1 & 112 & 3 & 50 & 2 & -17.6820 & Albite, HH78 \\
24301 & 68.72 & 20 & 1 & 4 & 1 & 112 & 3 & 50 & 2 & -24.3500 & K-Spar, HH78 \\
24305 & 18.66 & 20 & 1 & 1 & 1 & 112 & 2 & 50 & -4 & 49.7310 & Anorthite, HH78 \\
24310 & 467.24 & 20 & 14 & 1 & 1 & 112 & 22 & 0 & 0 & 0.0000 & Ca-montmo, Vie \\
24311 & 870.5 & 20 & 22 & 1 & 3 & 112 & 60 & 2 & 11 & 0.0000 & Ca,Mg-SAz-1, M\&S \\
24400 & 38.21 & 20 & 2 & 50 & -2 & 112 & 2 & 0 & 0 & 13.862 & Kaolin2 Vie \\
24401 & 40.23 & 20 & 2 & 50 & -2 & 112 & 2 & 0 & 0 & 11.3550 & KaolinlHRK \\
24402 & 34.29 & 20 & 2 & 50 & -2 & 112 & 2 & 0 & 0 & 11.3550 & Halloysite, HRK \\
24410 & 54.23 & 4 & 1 & 20 & 3 & 112 & 3 & 50 & -4 & 24.5140 & Muscovite, HH78 \\
24450 & 106.50 & 2 & 4 & 50 & 4 & 112 & 6 & 0 & 0 & -18.1630 & Sepiolite, HH78 \\
24460 & 24.76 & 2 & 1 & 1 & 1 & 112 & 2 & 0 & 0 & 25.94 & Diopside, HH78 \\
24470 & 14.28 & 2 & 3 & 50 & -2 & 112 & 2 & 0 & 0 & 27.42 & Chrysotile, HH78 \\
24999 & 83.12 & 50 & -4 & 99 & -4 & 0 & 0 & 0 & 0 & -136.6300 & Oxygen gas, Robie \\
25000 & 18.14 & 50 & 2 & 101 & 1 & 0 & 0 & 0 & 0 & -0.9620 & CO2 gas, PB82 \\
& & & & & & & & & & &
\end{tabular}

Conventions:

$\operatorname{logK}$ and delta $\mathrm{H}$ for aqueous complexes retain sign formation reaction logK and delta $\mathrm{H}$ for solids: reverse sign found for dissolution reaction!!!

References and Sources of Data:

Bil Bilinski and Schindler, GCA 46,921-928

Bond Bond/Hefter IUPAC \# 271980

B67 Bemer, 1967 NOT checked to see that $\mathrm{Ka}$ for H2S is consistent Enthalpies estimated, see W2THRM binder

B/M BAES, C.F., AND MESMER, R.E.(1976) HYDROLYSIS OF CATIONS, WILEY-INTERSCIENCE, NEW YORK

CAUTION!!! symbol "<" means B/M say "less than"

Capi if Ti cmpd, then Capi's estimates; if phosphates, then Viellard Am Min 64626 (1979)

Chris Christensen/1zatt Handbook of metal ligand heats, 1983 for CaPhos cpxs, two agree with phr Einaga Einaga/Komatsu J. Inorg Nucl Chem 4324491981

gap G.A. Parks evaluated and selected from several sources, see W2THRM binder

Henly Henly et al., Fluid Mineral Equilibria, 1984

HRK Hemingway, B.S., Robie, R.A., AND Kittrick, J.A., REVISED VALUES FOR THE GIBBS FREE ENERGY OF FORMATION OF [AL $(\mathrm{OH}) 4-](\mathrm{AQ})$, DIASPORE, BOEHMITE, AND BAYERITE AT 298.15 K AND 1 BAR, THE THERMODYNAMIC PROPERTIES OF 


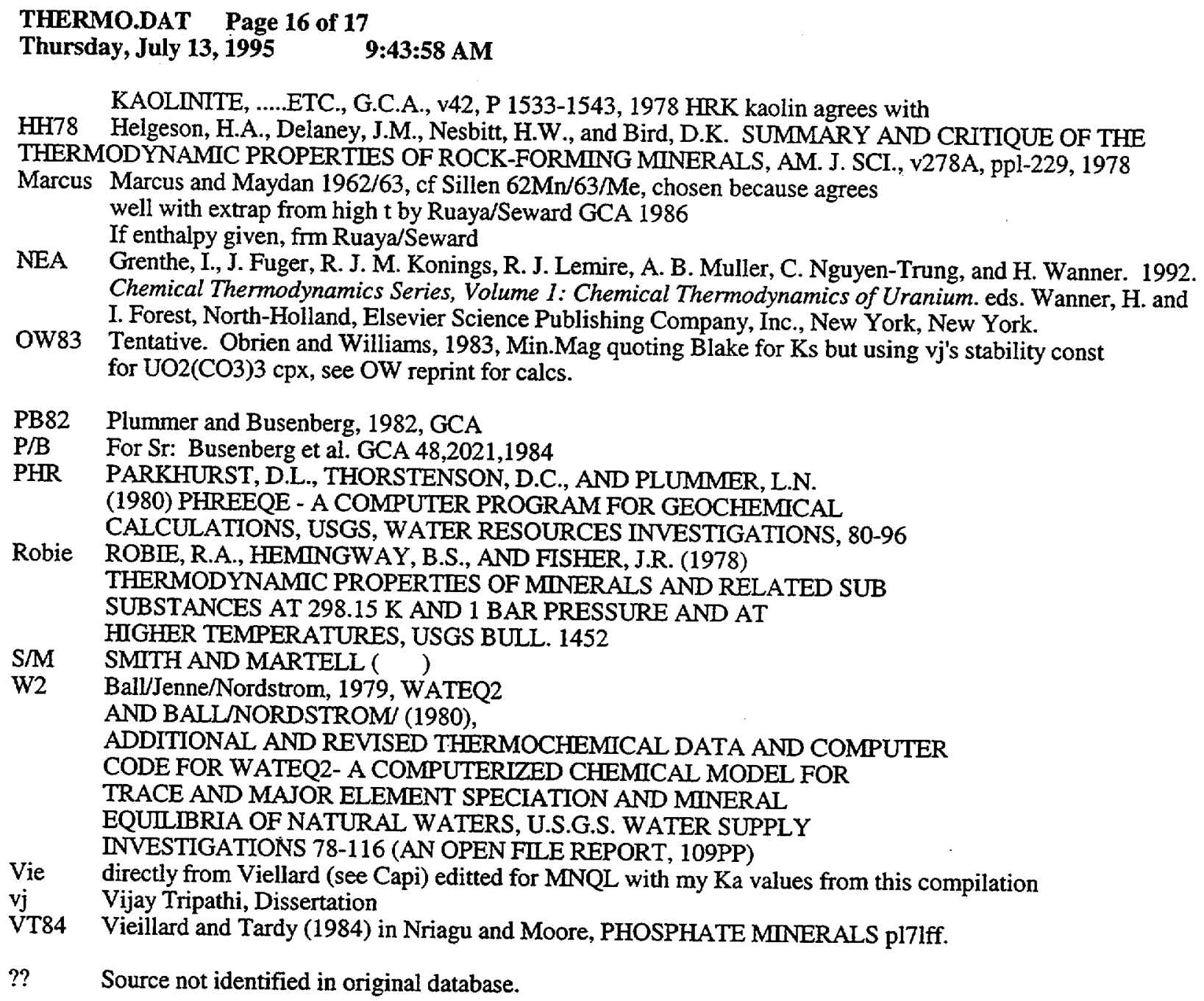

Falck, W. E. 1992. CHEM/VAL Project: Critical Evaluation of the CHEM/VAL Thermodynamic Database for the Aqueous Species, Gases, and Solids Containing Chromium, Mercury, Selenium, and Thallium. Report prepared for the U.S. Environmental Protection Agency the Pacific Northwest Laboratory, Richland, Washington.

Felmy, A. R., Rai, D., and R. W. Fulton. 1990. The Solubility of AmOHCO3 and the Aqueous Thermodynamics of the System Na+ - Am3 + - HCO3- - CO32- - OH- - H2O. Radiochim. Acta, 50, 193-204.

KC Various sources including S/M and analog estimates. 
THERMO.DAT Page 17 of 17

Thursday, July 13, 1995

9:43:58 AM

Lemire, R. J. and P. R. Tremaine. 1980. Uranium and Plutonium Equilibria in Aqueous Solutions to 200 C. J. of Chem. Eng. Data, 25, 361-370.

Lindsay, W. L. 1979. Chemical Equilibria in Soils.

Morel, F. M. M. 1983. Principals of Aquatic Chemistry.

Read, D. (ed.). 1991. CHEM/NAL Project. Report on Stages 3 and 4, Testing of Coupled Chemical Transport Models. Commission of the European Communities, Topical Report No. EUR13675EN, Luxembourg.

Rai, D., R. G. Strickert, D. A. Moore, and J. L. Ryan. 1983. Am(III) Hydrolysis Constants and Solubility of Am(III) Hydroxide. Radiochim. Acta, 33, 201-206.

Schwab, A. and A. Felmy. 1982. Review and Reevaluation of Pu Thermodynamic Data, PNL-SA-10731 (Draft Manuscript), Pacific Northwest Laboratory, Richland, Washington. 


\section{Appendix B}

\section{Kd Values $[\mathrm{mL} / \mathrm{g}]$ as a Function of $\mathrm{pH}$ for Batch Adsorption Experiments}

IOCS is iron coated sand. See Table 3.4 for other soil descriptions.

$\begin{array}{cccccc}\text { Metal Conc. } & \text { Kd (metal) } & \text { Ligand Conc. } & \text { Kd (ligand) } & \text { Adsorbent } & \text { pH } \\ 10 \mathrm{e}-5 \mathrm{Ni} & 0.0 & 0.0 & - & 1.2 \% \text { IOCS } & 4.40 \\ 10 \mathrm{e}-5 \mathrm{Ni} & 8.5 & 0.0 & - & 1.2 \% \text { IOCS } & 5.78 \\ 10 \mathrm{e}-5 \mathrm{Ni} & 35.8 & 0.0 & - & 1.2 \% \text { IOCS } & 6.58 \\ 10 \mathrm{e}-5 \mathrm{Ni} & 379.3 & 0.0 & - & 1.2 \% \text { IOCS } & 7.13 \\ 10 \mathrm{e}-5 \mathrm{Ni} & 2531.5 & 0.0 & - & 1.2 \% \text { IOCS } & 8.13 \\ 10 \mathrm{e}-5 \mathrm{Ni} & 6975.6 & 0.0 & - & 1.2 \% \text { IOCS } & 10.12 \\ 10 \mathrm{e}-5 \mathrm{Ni} & 1.7 & 10 \mathrm{e}-3 \mathrm{Pic} & 10.1 & 1.2 \% \text { IOCS } & 3.90 \\ 10 \mathrm{e}-5 \mathrm{Ni} & 4.1 & 10 \mathrm{e}-3 \mathrm{Pic} & 8.3 & 1.2 \% \text { IOCS } & 3.92 \\ 10 \mathrm{e}-5 \mathrm{Ni} & 0.0 & 10 \mathrm{e}-3 \mathrm{Pic} & 9.3 & 1.2 \% \text { IOCS } & 5.05 \\ 10 \mathrm{e}-5 \mathrm{Ni} & 0.0 & 10 \mathrm{e}-3 \mathrm{Pic} & 11.0 & 1.2 \% \text { IOCS } & 5.10 \\ 10 \mathrm{e}-5 \mathrm{Ni} & 0.0 & 10 \mathrm{e}-3 \mathrm{Pic} & 7.3 & 1.2 \% \text { IOCS } & 6.33 \\ 10 \mathrm{e}-5 \mathrm{Ni} & 0.0 & 10 \mathrm{e}-3 \mathrm{Pic} & 7.4 & 1.2 \% \text { IOCS } & 6.43 \\ 10 \mathrm{e}-5 \mathrm{Ni} & 0.0 & 10 \mathrm{e}-3 \mathrm{Pic} & 0.0 & 1.2 \% \text { IOCS } & 7.85 \\ 10 \mathrm{e}-5 \mathrm{Ni} & 0.0 & 10 \mathrm{e}-3 \mathrm{Pic} & 0.0 & 1.2 \% \text { IOCS } & 7.85 \\ 10 \mathrm{e}-5 \mathrm{Ni} & 0.0 & 10 \mathrm{e}-3 \mathrm{Pic} & 0.0 & 1.2 \% \text { IOCS } & 8.51 \\ 10 \mathrm{e}-5 \mathrm{Ni} & 0.0 & 10 \mathrm{e}-3 \mathrm{Pic} & 13.2 & 1.2 \% \text { IOCS } & 8.57 \\ 10 \mathrm{e}-5 \mathrm{Ni} & 0.0 & 10 \mathrm{e}-3 \mathrm{Pic} & 7.5 & 1.2 \% \text { IOCS } & 9.65 \\ & 0.0 & 10 \mathrm{e}-3 \mathrm{Pic} & 1.5 & 1.2 \% \text { IOCS } & 9.73 \\ 10 \mathrm{e}-5 \mathrm{Ni} & 11.8 & 10 \mathrm{e}-4 \mathrm{Pic} & 53.3 & 1.2 \% \text { IOCS } & 4.52 \\ 10 \mathrm{e}-5 \mathrm{Ni} & 7.5 & 10 \mathrm{e}-4 \mathrm{Pic} & 58 & 1.2 \% \text { IOCS } & 4.53 \\ 10 \mathrm{e}-5 \mathrm{Ni} & 0 & 10 \mathrm{e}-4 \mathrm{Pic} & 50.6 & 1.2 \% \text { IOCS } & 5.91 \\ 10 \mathrm{e}-5 \mathrm{Ni} & 6.7 & 10 \mathrm{e}-4 \mathrm{Pic} & 25.9 & 1.2 \% \text { IOCS } & 6.26 \\ 10 \mathrm{e}-5 \mathrm{Ni} & 3.5 & 10 \mathrm{e}-4 \mathrm{Pic} & 8.4 & 1.2 \% \text { IOCS } & 6.67 \\ 10 \mathrm{e}-5 \mathrm{Ni} & 9.3 & 10 \mathrm{e}-4 \mathrm{Pic} & 21.1 & 1.2 \% \text { IOCS } & 6.78 \\ 10 \mathrm{e}-5 \mathrm{Ni} & 9.5 & 10 \mathrm{e}-4 \mathrm{Pic} & 9.3 & 1.2 \% \text { IOCS } & 7.33 \\ 10 \mathrm{e}-5 \mathrm{Ni} & 6.5 & 10 \mathrm{e}-4 \mathrm{Pic} & 0.5 & 1.2 \% \text { IOCS } & 7.36 \\ 10 \mathrm{e}-5 \mathrm{Ni} & 2.6 & 10 \mathrm{e}-4 \mathrm{Pic} & 0 & 1.2 \% \text { IOCS } & 8.06 \\ 10 \mathrm{e}-5 \mathrm{Ni} & 1.2 & 10 \mathrm{e}-4 \mathrm{Pic} & 0 & 1.2 \% \text { IOCS } & 8.14 \\ 10 \mathrm{e}-5 \mathrm{Ni} & 24.2 & 10 \mathrm{e}-4 \mathrm{Pic} & 0 & 1.2 \% \text { IOCS } & 10.04 \\ 10 \mathrm{e}-5 \mathrm{Ni} & 14.9 & 10 \mathrm{e}-4 \mathrm{Pic} & 0 & 1.2 \% \text { IOCS } & 10.84 \\ 10 \mathrm{e}-5 \mathrm{Ni} & 6.9 & 10 \mathrm{e}-5 \mathrm{Pic} & 206.0 & 1.2 \% \text { IOCS } & 4.39 \\ 10 \mathrm{e}-5 \mathrm{Ni} & 14.6 & 10 \mathrm{e}-5 \mathrm{Pic} & 29.0 & 1.2 \% \text { IOCS } & 6.26 \\ 10 \mathrm{e}-5 \mathrm{Ni} & 37.3 & 10 \mathrm{e}-5 \mathrm{Pic} & 15.2 & 1.2 \% \text { IOCS } & 6.70 \\ 10 \mathrm{e}-5 \mathrm{Ni} & 57.3 & 10 \mathrm{e}-5 \mathrm{Pic} & 17.6 & 1.2 \% \text { IOCS } & 7.06 \\ 10 \mathrm{e}-5 \mathrm{Ni} & 151.7 & 10 \mathrm{e}-5 \mathrm{Pic} & 15.5 & 1.2 \% \text { IOCS } & 8.20\end{array}$


Metal Conc. Kd (metal) Ligand Conc. Kd (ligand)

Adsorbent $\quad$ pH

\begin{tabular}{|c|c|c|c|c|c|}
\hline $10 \mathrm{e}-5 \mathrm{Ni}$ & 2539.3 & $10 \mathrm{e}-5 \mathrm{Pic}$ & 25.7 & $1.2 \% \mathrm{IOCS}$ & 10.12 \\
\hline $10 \mathrm{e}-5 \mathrm{Ni}$ & 92039.1 & 10e-3 Pic & 1186.7 & Milford Soil & 4.24 \\
\hline $10 \mathrm{e}-5 \mathrm{Ni}$ & 2415456.7 & $10 \mathrm{e}-3 \mathrm{Pic}$ & 943.5 & Milford Soil & 4.26 \\
\hline $10 \mathrm{e}-5 \mathrm{Ni}$ & 20359.5 & 10e-3 Pic & 989.8 & Milford Soil & 4.84 \\
\hline $10 \mathrm{e}-5 \mathrm{Ni}$ & 20559.7 & 10e-3 Pic & 830.0 & Milford Soil & 4.91 \\
\hline $10 \mathrm{e}-5 \mathrm{Ni}$ & 2506.0 & $10 \mathrm{e}-3 \mathrm{Pic}$ & 542.1 & Milford Soil & 6.24 \\
\hline $10 \mathrm{e}-5 \mathrm{Ni}$ & 3836.5 & $10 \mathrm{e}-3 \mathrm{Pic}$ & 562.5 & Milford Soil & 6.34 \\
\hline $10 \mathrm{e}-5 \mathrm{Ni}$ & 82.1 & $10 \mathrm{e}-3 \mathrm{Pic}$ & 62.3 & Milford Soil & 6.38 \\
\hline $10 \mathrm{e}-5 \mathrm{Ni}$ & 506.4 & 10e-3 Pic & 273.4 & Milford Soil & 6.39 \\
\hline $10 \mathrm{e}-5 \mathrm{Ni}$ & 30.5 & 10e-3 Pic & 20.6 & Milford Soil & 6.96 \\
\hline $10 \mathrm{e}-5 \mathrm{Ni}$ & 31.1 & $10 \mathrm{e}-3 \mathrm{Pic}$ & 22.9 & Milford Soil & 6.97 \\
\hline $10 \mathrm{e}-5 \mathrm{Ni}$ & 22.6 & $10 \mathrm{e}-3 \mathrm{Pic}$ & 18.6 & Milford Soil & 6.98 \\
\hline $10 \mathrm{e}-5 \mathrm{Ni}$ & 18.4 & 10e-3 Pic & 15.6 & Milford Soil & 6.98 \\
\hline $10 \mathrm{e}-5 \mathrm{Ni}$ & 17.1 & 10e-3 Pic & 11.7 & Milford Soil & 7.46 \\
\hline $10 \mathrm{e}-5 \mathrm{Ni}$ & 18.8 & $10 \mathrm{e}-3 \mathrm{Pic}$ & 10.8 & Milford Soil & 7.51 \\
\hline $10 \mathrm{e}-5 \mathrm{Ni}$ & 13.9 & 10e-3 Pic & 10.6 & Milford Soil & 7.56 \\
\hline $10 \mathrm{e}-5 \mathrm{Ni}$ & 9.9 & $10 \mathrm{e}-3 \mathrm{Pic}$ & 3.9 & Milford Soil & 7.67 \\
\hline $10 \mathrm{e}-5 \mathrm{Ni}$ & 12.6 & $10 \mathrm{e}-3 \mathrm{Pic}$ & 6.9 & Milford Soil & 7.77 \\
\hline $10 \mathrm{e}-5 \mathrm{Ni}$ & 12.2 & $10 \mathrm{e}-3 \mathrm{Pic}$ & 3.2 & Milford Soil & 7.86 \\
\hline $10 \mathrm{e}-5 \mathrm{Ni}$ & 10.4 & $10 \mathrm{e}-3 \mathrm{Pic}$ & 3.9 & Milford Soil & 7.95 \\
\hline $10 \mathrm{e}-5 \mathrm{Ni}$ & 7.3 & $10 \mathrm{e}-3 \mathrm{Pic}$ & 0.0 & Milford Soil & 7.98 \\
\hline $10 \mathrm{e}-5 \mathrm{Ni}$ & 16.2 & $10 \mathrm{e}-3 \mathrm{Pic}$ & 3.2 & Milford Soil & 8.13 \\
\hline $10 \mathrm{e}-5 \mathrm{Ni}$ & 9.6 & $10 e-5 \mathrm{Pic}$ & 11.9 & Milford Soil & 4.11 \\
\hline $10 \mathrm{e}-5 \mathrm{Ni}$ & 17.7 & $10 \mathrm{e}-5 \mathrm{Pic}$ & 1.1 & Milford Soil & 4.19 \\
\hline $10 \mathrm{e}-5 \mathrm{Ni}$ & 7.5 & $10 \mathrm{e}-5 \mathrm{Pic}$ & 4.4 & Milford Soil & 5.16 \\
\hline $10 \mathrm{e}-5 \mathrm{Ni}$ & 7.9 & $10 \mathrm{e}-5 \mathrm{Pic}$ & 6.8 & Milford Soil & 5.17 \\
\hline $10 \mathrm{e}-5 \mathrm{Ni}$ & 13.7 & $10 \mathrm{e}-5 \mathrm{Pic}$ & 7.5 & Milford Soil & 6.47 \\
\hline $10 \mathrm{e}-5 \mathrm{Ni}$ & 1.8 & $10 \mathrm{e}-5 \mathrm{Pic}$ & 1.2 & Milford Soil & 6.47 \\
\hline $10 \mathrm{e}-5 \mathrm{Ni}$ & 1.3 & $10 \mathrm{e}-5 \mathrm{Pic}$ & 0.0 & Milford Soil & 7.97 \\
\hline $10 \mathrm{e}-5 \mathrm{Ni}$ & 12.1 & $10 \mathrm{e}-5 \mathrm{Pic}$ & 2.1 & Milford Soil & 8.14 \\
\hline $10 \mathrm{e}-5 \mathrm{Ni}$ & 9.2 & $10 \mathrm{e}-5 \mathrm{Pic}$ & 10.2 & Milford Soil & 8.48 \\
\hline $10 \mathrm{e}-5 \mathrm{Ni}$ & 1.0 & $10 e-5$ Pic & 0.0 & Milford Soil & 8.62 \\
\hline $10 \mathrm{e}-5 \mathrm{Ni}$ & 3.9 & $10 \mathrm{e}-5 \mathrm{Pic}$ & 0.5 & Milford Soil & 9.43 \\
\hline $10 \mathrm{e}-5 \mathrm{Ni}$ & 12.7 & $10 \mathrm{e}-5 \mathrm{Pic}$ & 0.0 & Milford Soil & 9.64 \\
\hline $10 \mathrm{e}-5 \mathrm{Ni}$ & 92039.1 & 10e-5 EDTA & 1186.7 & $1.2 \% \mathrm{IOCS}$ & 4.24 \\
\hline $10 \mathrm{e}-5 \mathrm{Ni}$ & 2415456.7 & 10e-5 EDTA & 943.5 & $1.2 \%$ IOCS & 4.26 \\
\hline $10 \mathrm{e}-5 \mathrm{Ni}$ & 20359.5 & 10e-5 EDTA & 989.8 & $1.2 \%$ IOCS & 4.84 \\
\hline $10 \mathrm{e}-5 \mathrm{Ni}$ & 20559.7 & 10e-5 EDTA & 830.0 & $1.2 \% \mathrm{IOCS}$ & 4.91 \\
\hline $10 \mathrm{e}-5 \mathrm{Ni}$ & 2506.0 & 10e-5 EDTA & 542.1 & $1.2 \% \mathrm{IOCS}$ & 6.24 \\
\hline $10 \mathrm{e}-5 \mathrm{Ni}$ & 3836.5 & 10e-5 EDTA & 562.5 & $1.2 \%$ IOCS & 6.34 \\
\hline $10 \mathrm{e}-5 \mathrm{Ni}$ & 82.1 & $10 \mathrm{e}-5$ EDTA & 62.3 & $1.2 \% \mathrm{IOCS}$ & 6.38 \\
\hline $10 \mathrm{e}-5 \mathrm{Ni}$ & 506.4 & 10e-5 EDTA & 273.4 & $1.2 \%$ IOCS & 6.39 \\
\hline $10 \mathrm{e}-5 \mathrm{Ni}$ & 30.5 & 10e-5 EDTA & 20.6 & $1.2 \% \mathrm{IOCS}$ & 6.96 \\
\hline
\end{tabular}




\begin{tabular}{|c|c|c|c|c|c|}
\hline Metal Conc. & Kd (metal) & Ligand Conc. & Kd (ligand) & Adsorbent & pH \\
\hline $10 \mathrm{e}-5 \mathrm{Ni}$ & 31.1 & 10e-5 EDTA & 22.9 & $1.2 \%$ IOCS & 6.97 \\
\hline $10 \mathrm{e}-5 \mathrm{Ni}$ & 22.6 & 10e-5 EDTA & 18.6 & $1.2 \% \mathrm{IOCS}$ & 6.98 \\
\hline $10 \mathrm{e}-5 \mathrm{Ni}$ & 18.4 & 10e-5 EDTA & 15.6 & $1.2 \% \mathrm{IOCS}$ & 6.98 \\
\hline $10 \mathrm{e}-5 \mathrm{Ni}$ & 17.1 & 10e-5 EDTA & 11.7 & $1.2 \% \mathrm{IOCS}$ & 7.46 \\
\hline $10 \mathrm{e}-5 \mathrm{Ni}$ & 18.8 & 10e-5 EDTA & 10.8 & $1.2 \%$ IOCS & 7.51 \\
\hline $10 \mathrm{e}-5 \mathrm{Ni}$ & 13.9 & 10e-5 EDTA & 10.6 & $1.2 \%$ IOCS & 7.56 \\
\hline $10 \mathrm{e}-5 \mathrm{Ni}$ & 9.9 & 10e-5 EDTA & 3.9 & $1.2 \%$ IOCS & 7.67 \\
\hline $10 \mathrm{e}-5 \mathrm{Ni}$ & 12.6 & 10e-5 EDTA & 6.9 & $1.2 \%$ IOCS & 7.77 \\
\hline $10 \mathrm{e}-5 \mathrm{Ni}$ & 12.2 & 10e-5 EDTA & 3.2 & $1.2 \%$ IOCS & 7.86 \\
\hline $10 \mathrm{e}-5 \mathrm{Ni}$ & 10.4 & 10e-5 EDTA & 3.9 & $1.2 \%$ IOCS & 7.95 \\
\hline $10 \mathrm{e}-5 \mathrm{Ni}$ & 7.3 & 10e-5 EDTA & 0.0 & $1.2 \%$ IOCS & 7.98 \\
\hline $10 \mathrm{e}-5 \mathrm{Ni}$ & 16.2 & 10e-5 EDTA & 3.2 & $1.2 \%$ IOCS & 8.13 \\
\hline $10 \mathrm{e}-5 \mathrm{Ni}$ & 190.6 & 10e-5 EDTA & 85.5 & Milford Soil & 4.51 \\
\hline $10 \mathrm{e}-5 \mathrm{Ni}$ & 191.3 & 10e-5 EDTA & 96.5 & Milford Soil & 4.56 \\
\hline $10 \mathrm{e}-5 \mathrm{Ni}$ & 195.9 & 10e-5 EDTA & 98.1 & Milford Soil & 4.97 \\
\hline $10 \mathrm{e}-5 \mathrm{Ni}$ & 191.4 & 10e-5 EDTA & 99.8 & Milford Soil & 4.98 \\
\hline $10 \mathrm{e}-5 \mathrm{Ni}$ & 110.3 & 10e-5 EDTA & 64.5 & Milford Soil & 5.59 \\
\hline $10 \mathrm{e}-5 \mathrm{Ni}$ & 131.8 & 10e-5 EDTA & 74.0 & Milford Soil & 5.64 \\
\hline $10 \mathrm{e}-5 \mathrm{Ni}$ & 60.1 & 10e-5 EDTA & 38.6 & Milford Soil & 5.86 \\
\hline $10 \mathrm{e}-5 \mathrm{Ni}$ & 57.1 & 10e-5 EDTA & 32.5 & Milford Soil & 5.97 \\
\hline $10 \mathrm{e}-5 \mathrm{Ni}$ & 27.7 & 10e-5 EDTA & 23.6 & Milford Soil & 6.75 \\
\hline $10 \mathrm{e}-5 \mathrm{Ni}$ & 35.4 & 10e-5 EDTA & 22.4 & Milford Soil & 6.78 \\
\hline $10 \mathrm{e}-5 \mathrm{Ni}$ & 21.5 & 10e-5 EDTA & 15.9 & Milford Soil & 6.85 \\
\hline $10 \mathrm{e}-5 \mathrm{Ni}$ & 24.4 & 10e-5 EDTA & 18.5 & Milford Soil & 6.89 \\
\hline $10 \mathrm{e}-5 \mathrm{Ni}$ & 21.7 & 10e-5 EDTA & 15.2 & Milford Soil & 6.97 \\
\hline $10 \mathrm{e}-5 \mathrm{Ni}$ & 15.4 & 10e-5 EDTA & 10.2 & Milford Soil & 6.98 \\
\hline $10 \mathrm{e}-5 \mathrm{Ni}$ & 22.2 & 10e-5 EDTA & 11.0 & Milford Soil & 7.00 \\
\hline $10 \mathrm{e}-5 \mathrm{Ni}$ & 13.7 & 10e-5 EDTA & 10.7 & Milford Soil & 7.02 \\
\hline $10 \mathrm{e}-5 \mathrm{Ni}$ & 15.9 & 10e-5 EDTA & 12.4 & Milford Soil & 7.95 \\
\hline $10 \mathrm{e}-5 \mathrm{Ni}$ & 9.5 & 10e-5 EDTA & 6.8 & Milford Soil & 7.96 \\
\hline $10 \mathrm{e}-5 \mathrm{Ni}$ & 13.7 & 10e-5 EDTA & 6.0 & Milford Soil & 7.98 \\
\hline $10 \mathrm{e}-5 \mathrm{Ni}$ & 11.0 & 10e-5 EDTA & 10.3 & Milford Soil & 8.11 \\
\hline $10 \mathrm{e}-5 \mathrm{Ni}$ & 10.5 & 10e-5 EDTA & 7.5 & Milford Soil & 8.85 \\
\hline $10 \mathrm{e}-5 \mathrm{Ni}$ & 11.8 & 10e-5 EDTA & 6.2 & Milford Soil & 9.03 \\
\hline $10 \mathrm{e}-5 \mathrm{Ni}$ & 28.5 & 10e-5 EDTA & 19.4 & LK-1 & 4.03 \\
\hline $10 \mathrm{e}-5 \mathrm{Ni}$ & 24.9 & 10e-5 EDTA & 17.6 & LK-1 & 4.34 \\
\hline $10 \mathrm{e}-5 \mathrm{Ni}$ & 20.5 & 10e-5 EDTA & 17.2 & LK-1 & 4.42 \\
\hline $10 \mathrm{e}-5 \mathrm{Ni}$ & 23.1 & 10e-5 EDTA & 17.0 & LK-1 & 4.56 \\
\hline $10 \mathrm{e}-5 \mathrm{Ni}$ & 13.2 & 10e-5 EDTA & 15.5 & LK-1 & 5.20 \\
\hline $10 \mathrm{e}-5 \mathrm{Ni}$ & 14.0 & 10e-5 EDTA & 14.9 & LK-1 & 5.22 \\
\hline $10 \mathrm{e}-5 \mathrm{Ni}$ & 6.3 & 10e-5 EDTA & 6.8 & LK-1 & 5.63 \\
\hline $10 \mathrm{e}-5 \mathrm{Ni}$ & 9.8 & 10e-5 EDTA & 10.9 & LK-1 & 5.74 \\
\hline $10 \mathrm{e}-5 \mathrm{Ni}$ & 4.3 & 10e-5 EDTA & 5.8 & LK-1 & 6.25 \\
\hline $10 \mathrm{e}-5 \mathrm{Ni}$ & 3.9 & 10e-5 EDTA & 4.1 & LK-1 & 6.32 \\
\hline
\end{tabular}


Metal Conc. Kd (metal) Ligand Conc. Kd (ligand) Adsorbent pH

\begin{tabular}{|c|c|c|c|c|c|}
\hline $10 \mathrm{e}-5 \mathrm{Ni}$ & 5.5 & 10e-5 EDTA & 5.9 & LK-1 & 6.36 \\
\hline $10 \mathrm{e}-5 \mathrm{Ni}$ & 3.3 & 10e-5 EDTA & 5.4 & LK-1 & 6.37 \\
\hline $10 \mathrm{e}-5 \mathrm{Ni}$ & 3.8 & 10e-5 EDTA & 4.6 & LK-1 & 6.39 \\
\hline $10 \mathrm{e}-5 \mathrm{Ni}$ & 4.1 & 10e-5 EDTA & 6.0 & LK-1 & 6.40 \\
\hline $10 \mathrm{e}-5 \mathrm{Ni}$ & 4.2 & 10e-5 EDTA & 4.2 & LK-1 & 6.45 \\
\hline $10 \mathrm{e}-5 \mathrm{Ni}$ & 5.1 & 10e-5 EDTA & 5.1 & LK-1 & 6.53 \\
\hline $10 \mathrm{e}-5 \mathrm{Ni}$ & 5.1 & 10e-5 EDTA & 6.8 & LK-1 & 6.61 \\
\hline $10 \mathrm{e}-5 \mathrm{Ni}$ & 4.8 & 10e-5 EDTA & 4.8 & LK-1 & 6.75 \\
\hline $10 \mathrm{e}-5 \mathrm{Ni}$ & 4.3 & 10e-5 EDTA & 3.8 & LK-1 & 7.01 \\
\hline $10 \mathrm{e}-5 \mathrm{Ni}$ & 2.1 & $10 \mathrm{e}-5 \mathrm{EDTA}$ & 0.9 & LK-1 & 8.02 \\
\hline $10 \mathrm{e}-5 \mathrm{Ni}$ & 5.2 & 10e-5 EDTA & 4.1 & LK-1 & 8.14 \\
\hline $10 \mathrm{e}-5 \mathrm{Ni}$ & 6.6 & 10e-5 EDTA & 4.0 & LK-1 & 8.15 \\
\hline $10 \mathrm{e}-5 \mathrm{Ni}$ & 16915.2 & 10e-5 EDTA & 423.8 & MNC-7 & 4.13 \\
\hline $10 \mathrm{e}-5 \mathrm{Ni}$ & 31158.4 & $10 \mathrm{e}-5$ EDTA & 574.9 & MNC-7 & 4.20 \\
\hline $10 \mathrm{e}-5 \mathrm{Ni}$ & 5308.0 & 10e-5 EDTA & 514.4 & MNC-7 & 4.76 \\
\hline $10 \mathrm{e}-5 \mathrm{Ni}$ & 11088.7 & 10e-5 EDTA & 575.1 & MNC-7 & 4.76 \\
\hline $10 \mathrm{e}-5 \mathrm{Ni}$ & 2649.3 & 10e-5 EDTA & 493.1 & MNC-7 & 4.99 \\
\hline $10 \mathrm{e}-5 \mathrm{Ni}$ & 2481.1 & 10e-5 EDTA & 516.4 & MNC-7 & 5.12 \\
\hline $10 \mathrm{e}-5 \mathrm{Ni}$ & 1399.4 & 10e-5 EDTA & 386.9 & MNC-7 & 5.62 \\
\hline $10 \mathrm{e}-5 \mathrm{Ni}$ & 1142.7 & 10e-5 EDTA & 371.7 & MNC-7 & 5.71 \\
\hline $10 \mathrm{e}-5 \mathrm{Ni}$ & 613.0 & 10e-5 EDTA & 248.3 & MNC-7 & 5.87 \\
\hline $10 \mathrm{e}-5 \mathrm{Ni}$ & 491.2 & 10e-5 EDTA & 268.4 & MNC-7 & 5.91 \\
\hline $10 \mathrm{e}-5 \mathrm{Ni}$ & 398.1 & 10e-5 EDTA & 223.8 & MNC-7 & 6.32 \\
\hline $10 \mathrm{e}-5 \mathrm{Ni}$ & 294.6 & 10e-5 EDTA & 175.2 & MNC-7 & 6.36 \\
\hline $10 \mathrm{e}-5 \mathrm{Ni}$ & 242.9 & 10e-5 EDTA & 154.3 & MNC-7 & 6.67 \\
\hline $10 \mathrm{e}-5 \mathrm{Ni}$ & 284.9 & 10e-5 EDTA & 160.1 & MNC-7 & 6.73 \\
\hline $10 \mathrm{e}-5 \mathrm{Ni}$ & 147.2 & 10e-5 EDTA & 112.5 & MNC-7 & 6.89 \\
\hline $10 \mathrm{e}-5 \mathrm{Ni}$ & 154.2 & 10e-5 EDTA & 117.9 & $\mathrm{MNC}-7$ & 6.92 \\
\hline $10 \mathrm{e}-5 \mathrm{Ni}$ & 107.3 & 10e-5 EDTA & 70.8 & $\mathrm{MNC}-7$ & 7.00 \\
\hline $10 \mathrm{e}-5 \mathrm{Ni}$ & 132.5 & 10e-5 EDTA & 89.0 & MNC-7 & 7.06 \\
\hline $10 \mathrm{e}-5 \mathrm{Ni}$ & 74.4 & 10e-5 EDTA & 53.8 & MNC-7 & 7.25 \\
\hline $10 \mathrm{e}-5 \mathrm{Ni}$ & 53.3 & 10e-5 EDTA & 28.4 & MNC-7 & 7.26 \\
\hline $10 \mathrm{e}-5 \mathrm{Ni}$ & 67.9 & 10e-5 EDTA & 52.6 & $\mathrm{MNC}-7$ & 7.33 \\
\hline $10 \mathrm{e}-5 \mathrm{Ni}$ & 40.1 & 10e-5 EDTA & 23.0 & MNC-7 & 7.56 \\
\hline $10 \mathrm{e}-5 \mathrm{Sm}$ & 36.1 & $10 \mathrm{e}-5 \mathrm{Pic}$ & 974.8 & $1.2 \%$ IOCS & 4.37 \\
\hline $10 \mathrm{e}-5 \mathrm{Sm}$ & 35.5 & $10 \mathrm{e}-5 \mathrm{Pic}$ & 975.4 & $1.2 \%$ IOCS & 4.38 \\
\hline $10 \mathrm{e}-5 \mathrm{Sm}$ & 78.1 & $10 e-5$ Pic & 451.2 & $1.2 \%$ IOCS & 5.37 \\
\hline $10 \mathrm{e}-5 \mathrm{Sm}$ & 105.6 & $10 \mathrm{e}-5 \mathrm{Pic}$ & 440.4 & $1.2 \%$ IOCS & 5.53 \\
\hline $10 \mathrm{e}-5 \mathrm{Sm}$ & 902.0 & $10 \mathrm{e}-5 \mathrm{Pic}$ & 139.3 & $1.2 \%$ IOCS & 6.04 \\
\hline $10 \mathrm{e}-5 \mathrm{Sm}$ & 968.1 & $10 \mathrm{e}-5 \mathrm{Pic}$ & 195.2 & $1.2 \%$ IOCS & 6.06 \\
\hline $10 \mathrm{e}-5 \mathrm{Sm}$ & 6923.0 & $10 \mathrm{e}-5 \mathrm{Pic}$ & 10.6 & $1.2 \% \mathrm{IOCS}$ & 7.89 \\
\hline $10 \mathrm{e}-5 \mathrm{Sm}$ & 221151.0 & $10 \mathrm{e}-5 \mathrm{Pic}$ & 8.7 & $1.2 \%$ IOCS & 8.01 \\
\hline $10 \mathrm{e}-5 \mathrm{Sm}$ & 5121.4 & $10 \mathrm{e}-5 \mathrm{Pic}$ & 6.5 & $1.2 \% \mathrm{IOCS}$ & 8.45 \\
\hline
\end{tabular}




\begin{tabular}{|c|c|c|c|c|c|}
\hline Metal Conc. & Kd (metal) & Ligand Conc. & Kd (ligand) & Adsorbent & pH \\
\hline $10 \mathrm{e}-5 \mathrm{Sm}$ & 2895.9 & 10e-5 Pic & 4.5 & $1.2 \%$ IOCS & 8.57 \\
\hline $10 \mathrm{e}-5 \mathrm{Sm}$ & 213428.5 & $10 \mathrm{e}-5 \mathrm{Pic}$ & 1.4 & $1.2 \%$ IOCS & 9.48 \\
\hline $10 \mathrm{e}-5 \mathrm{Sm}$ & 3535.4 & $10 \mathrm{e}-5 \mathrm{Pic}$ & 3.8 & $1.2 \% \mathrm{IOCS}$ & 9.67 \\
\hline $10 \mathrm{e}-8 \mathrm{Sm}$ & 0.0 & $10 e-5$ Pic & 58.3 & Milford Soil & 4.26 \\
\hline $10 \mathrm{e}-8 \mathrm{Sm}$ & 4.9 & $10 \mathrm{e}-5 \mathrm{Pic}$ & 55.5 & Milford Soil & 4.20 \\
\hline $10 \mathrm{e}-8 \mathrm{Sm}$ & 103.6 & $10 \mathrm{e}-5 \mathrm{Pic}$ & 65.3 & Milford Soil & 5.71 \\
\hline $10 \mathrm{e}-8 \mathrm{Sm}$ & 296.4 & $10 \mathrm{e}-5 \mathrm{Pic}$ & 54.0 & Milford Soil & 5.8 \\
\hline $10 \mathrm{e}-8 \mathrm{Sm}$ & 1993.0 & $10 \mathrm{e}-5 \mathrm{Pic}$ & 13.5 & Milford Soil & 7.24 \\
\hline $10 \mathrm{e}-8 \mathrm{Sm}$ & 1411.4 & $10 \mathrm{e}-5 \mathrm{Pic}$ & 20.9 & Milford Soil & 7.27 \\
\hline $10 \mathrm{e}-8 \mathrm{Sm}$ & 120.0 & $10 \mathrm{e}-5 \mathrm{Pic}$ & 0.0 & Milford Soil & 7.90 \\
\hline $10 \mathrm{e}-8 \mathrm{Sm}$ & 115.3 & 10e-5 Pic & 0.0 & Milford Soil & 7.92 \\
\hline $10 \mathrm{e}-8 \mathrm{Sm}$ & 487.8 & $10 \mathrm{e}-5 \mathrm{Pic}$ & 0.0 & Milford Soil & 8.34 \\
\hline $10 \mathrm{e}-8 \mathrm{Sm}$ & 1020.1 & $10 \mathrm{e}-5 \mathrm{Pic}$ & 0.0 & Milford Soil & 8.40 \\
\hline $10 \mathrm{e}-8 \mathrm{Sm}$ & 2740.6 & 10e-5 Pic & 0.0 & Milford Soil & 9.60 \\
\hline $10 \mathrm{e}-8 \mathrm{Sm}$ & 5396.6 & 10e-5 Pic & 0.0 & Milford Soil & 9.68 \\
\hline $10 \mathrm{e}-5 \mathrm{Sm}$ & 166.4 & $10 \mathrm{e}-5 \mathrm{Pic}$ & 92.9 & Milford Soil & 4.8 \\
\hline $10 \mathrm{e}-5 \mathrm{Sm}$ & 143.9 & 10e-5 Pic & 113.7 & Milford Soil & 4.85 \\
\hline $10 \mathrm{e}-5 \mathrm{Sm}$ & 194.9 & 10e-5 Pic & 294.5 & Milford Soil & 5.73 \\
\hline $10 \mathrm{e}-5 \mathrm{Sm}$ & 155.0 & $10 \mathrm{e}-5 \mathrm{Pic}$ & 505.0 & Milford Soil & 6.0 \\
\hline $10 \mathrm{e}-5 \mathrm{Sm}$ & 51.7 & 10e-5 Pic & 5583.0 & Milford Soil & 6.7 \\
\hline $10 \mathrm{e}-5 \mathrm{Sm}$ & 41.9 & $10 \mathrm{e}-5 \mathrm{Pic}$ & 4291.6 & Milford Soil & 6.8 \\
\hline $10 \mathrm{e}-5 \mathrm{Sm}$ & 5.4 & $10 \mathrm{e}-5 \mathrm{Pic}$ & 272368.7 & Milford Soil & 8.0 \\
\hline $10 \mathrm{e}-5 \mathrm{Sm}$ & 0.0 & $10 \mathrm{e}-5 \mathrm{Pic}$ & 283270.0 & Milford Soil & 8.13 \\
\hline $10 \mathrm{e}-5 \mathrm{Sm}$ & 1.2 & $10 \mathrm{e}-5 \mathrm{Pic}$ & 383.9 & Milford Soil & 8.7 \\
\hline $10 \mathrm{e}-5 \mathrm{Sm}$ & 6.8 & 10e-5 Pic & 362.3 & Milford Soil & 8.77 \\
\hline $10 \mathrm{e}-5 \mathrm{Sm}$ & 1.9 & $10 \mathrm{e}-5 \mathrm{Pic}$ & 950.2 & Milford Soil & 9.8 \\
\hline $10 \mathrm{e}-5 \mathrm{Sm}$ & 0.0 & $10 \mathrm{e}-5 \mathrm{Pic}$ & 1501.6 & Milford Soil & 9.9 \\
\hline $10 \mathrm{e}-5 \mathrm{Th}$ & 22.3 & $10 \mathrm{e}-5 \mathrm{Pic}$ & 213.5 & $1.2 \% \mathrm{IOCS}$ & 4.2 \\
\hline $10 \mathrm{e}-5 \mathrm{Th}$ & 32.1 & $10 \mathrm{e}-5 \mathrm{Pic}$ & 239.9 & $1.2 \%$ IOCS & 4.2 \\
\hline $10 \mathrm{e}-5 \mathrm{Th}$ & 74.6 & $10 \mathrm{e}-5 \mathrm{Pic}$ & 296.3 & $1.2 \%$ IOCS & 5.1 \\
\hline $10 \mathrm{e}-5 \mathrm{Th}$ & 86.1 & $10 \mathrm{e}-5 \mathrm{Pic}$ & 300.0 & $1.2 \% \mathrm{IOCS}$ & 5.1 \\
\hline $10 \mathrm{e}-5 \mathrm{Th}$ & 85.0 & $10 \mathrm{e}-5 \mathrm{Pic}$ & 141.1 & $1.2 \% \mathrm{IOCS}$ & 6.1 \\
\hline $10 \mathrm{e}-5 \mathrm{Th}$ & 88.7 & $10 \mathrm{e}-5 \mathrm{Pic}$ & 119.6 & $1.2 \% \mathrm{IOCS}$ & 6.2 \\
\hline $10 \mathrm{e}-5 \mathrm{Th}$ & 770.8 & $10 \mathrm{e}-5 \mathrm{Pic}$ & 30.1 & $1.2 \%$ IOCS & 7.9 \\
\hline $10 \mathrm{e}-5 \mathrm{Th}$ & 611.6 & $10 \mathrm{e}-5 \mathrm{Pic}$ & 32.1 & $1.2 \% \mathrm{IOCS}$ & 8.0 \\
\hline $10 \mathrm{e}-5 \mathrm{Th}$ & 1981.8 & $10 \mathrm{e}-5 \mathrm{Pic}$ & 21.7 & $1.2 \% \mathrm{IOCS}$ & 8.5 \\
\hline $10 \mathrm{e}-5 \mathrm{Th}$ & 1373.3 & $10 \mathrm{e}-5 \mathrm{Pic}$ & 22.4 & $1.2 \%$ IOCS & 8.6 \\
\hline $10 \mathrm{e}-5 \mathrm{Th}$ & 3544.0 & $10 \mathrm{e}-5 \mathrm{Pic}$ & 22.2 & $1.2 \% \mathrm{IOCS}$ & 9.6 \\
\hline $10 \mathrm{e}-5 \mathrm{Th}$ & 3844.5 & 10e-5 Pic & 18.0 & $1.2 \% \mathrm{IOCS}$ & 9.7 \\
\hline $10 \mathrm{e}-5 \mathrm{Th}$ & 201.0 & 10e-5 Pic & 196.1 & Milford Soil & 4.6 \\
\hline $10 \mathrm{e}-5 \mathrm{Th}$ & 202.3 & $10 \mathrm{e}-5 \mathrm{Pic}$ & 276.7 & Milford Soil & 4.7 \\
\hline $10 \mathrm{e}-5 \mathrm{Th}$ & 146.4 & $10 \mathrm{e}-5 \mathrm{Pic}$ & 184.0 & Milford Soil & 5.7 \\
\hline $10 \mathrm{e}-5 \mathrm{Th}$ & 128.7 & 10e-5 Pic & 164.7 & Milford Soil & 5.7 \\
\hline $10 \mathrm{e}-5 \mathrm{Th}$ & 1381.5 & $10 \mathrm{e}-5 \mathrm{Pic}$ & 136.9 & Milford Soil & 7.4 \\
\hline
\end{tabular}


Metal Conc. Kd (metal) Ligand Conc. Kd (ligand) Adsorbent pH

\begin{tabular}{|c|c|c|c|c|c|}
\hline $10 \mathrm{e}-5 \mathrm{Th}$ & 1449.2 & $10 \mathrm{e}-5 \mathrm{Pic}$ & 144.8 & Milford Soil & 7.46 \\
\hline $10 \mathrm{e}-5 \mathrm{Th}$ & 1278.2 & $10 \mathrm{e}-5 \mathrm{Pic}$ & 40.7 & Milford Soil & 8.29 \\
\hline $10 \mathrm{e}-5 \mathrm{Th}$ & 1671.5 & $10 \mathrm{e}-5 \mathrm{Pic}$ & 42.3 & Milford Soil & 8.40 \\
\hline $10 \mathrm{e}-5 \mathrm{Th}$ & 633.2 & $10 \mathrm{e}-5 \mathrm{Pic}$ & 38.6 & Milford Soil & 8.84 \\
\hline $10 \mathrm{e}-5 \mathrm{Th}$ & 1070.3 & $10 \mathrm{e}-5 \mathrm{Pic}$ & 35.2 & Milford Soil & 8.89 \\
\hline $10 \mathrm{e}-5 \mathrm{Th}$ & 2601.5 & $10 \mathrm{e}-5 \mathrm{Pic}$ & 34.7 & Milford Soil & 10.09 \\
\hline $10 \mathrm{e}-5 \mathrm{Th}$ & 3787.5 & $10 \mathrm{e}-5 \mathrm{Pic}$ & 38.6 & Milford Soil & 10.13 \\
\hline $6.7 \times 10 e-7 \mathrm{~Np}$ & 2.4 & 0.0 & - & $1.2 \% \mathrm{IOCS}$ & 4.12 \\
\hline $6.7 \times 10 e-7 \mathrm{~Np}$ & 1.1 & 0.0 & - & $1.2 \% \mathrm{IOCS}$ & 4.13 \\
\hline $6.7 \times 10 e-7 \mathrm{~Np}$ & 5.7 & 0.0 & - & $1.2 \% \mathrm{IOCS}$ & 5.10 \\
\hline $6.7 \times 10 \mathrm{e}-7 \mathrm{~Np}$ & 6.4 & 0.0 & - & $1.2 \% \mathrm{IOCS}$ & 5.16 \\
\hline $6.7 \times 10 \mathrm{e}-7 \mathrm{~Np}$ & 37.6 & 0.0 & - & $1.2 \% \mathrm{IOCS}$ & 6.14 \\
\hline $6.7 \times 10 \mathrm{e}-7 \mathrm{~Np}$ & 43.3 & 0.0 & - & $1.2 \% \mathrm{IOCS}$ & 6.16 \\
\hline $6.7 \times 10 \mathrm{e}-7 \mathrm{~Np}$ & 500.2 & 0.0 & - & $1.2 \% \mathrm{IOCS}$ & 7.85 \\
\hline $6.7 \times 10 \mathrm{e}-7 \mathrm{~Np}$ & 1327.0 & 0.0 & - & $1.2 \% \mathrm{IOCS}$ & 7.93 \\
\hline $6.7 \times 10 \mathrm{e}-7 \mathrm{~Np}$ & 969.8 & 0.0 & - & $1.2 \% \mathrm{IOCS}$ & 8.28 \\
\hline $6.7 \times 10 \mathrm{e}-7 \mathrm{~Np}$ & 2551.7 & 0.0 & - & $1.2 \%$ IOCS & 8.40 \\
\hline $6.7 \times 10 \mathrm{e}-7 \mathrm{~Np}$ & 9348.3 & 0.0 & - & $1.2 \%$ IOCS & 9.22 \\
\hline $6.7 \times 10 \mathrm{e}-7 \mathrm{~Np}$ & 1963.8 & 0.0 & - & $1.2 \%$ IOCS & 9.28 \\
\hline $6.7 \times 10 \mathrm{e}-7 \mathrm{~Np}$ & 2.8 & $10 \mathrm{e}-5 \mathrm{Pic}$ & 1072.6 & $1.2 \% \mathrm{IOCS}$ & 4.09 \\
\hline $6.7 \times 10 \mathrm{e}-7 \mathrm{~Np}$ & 3.0 & $10 \mathrm{e}-5 \mathrm{Pic}$ & 885.0 & $1.2 \%$ IOCS & 4.15 \\
\hline $6.7 \times 10 \mathrm{e}-7 \mathrm{~Np}$ & 10.5 & $10 \mathrm{e}-5 \mathrm{Pic}$ & 619.6 & $1.2 \%$ IOCS & 4.94 \\
\hline $6.7 \times 10 \mathrm{e}-7 \mathrm{~Np}$ & 9.8 & $10 \mathrm{e}-5 \mathrm{Pic}$ & 612.5 & $1.2 \% \mathrm{IOCS}$ & 5.30 \\
\hline $6.7 \times 10 \mathrm{e}-7 \mathrm{~Np}$ & 13.6 & $10 \mathrm{e}-5 \mathrm{Pic}$ & 72.6 & $1.2 \%$ IOCS & 6.16 \\
\hline $6.7 \times 10 \mathrm{e}-7 \mathrm{~Np}$ & 36.7 & $10 \mathrm{e}-5 \mathrm{Pic}$ & 120.1 & $1.2 \%$ IOCS & 6.16 \\
\hline $6.7 \times 10 \mathrm{e}-7 \mathrm{~Np}$ & 658.4 & $10 \mathrm{e}-5 \mathrm{Pic}$ & 12.7 & $1.2 \% \mathrm{IOCS}$ & 7.67 \\
\hline $6.7 \times 10 \mathrm{e}-7 \mathrm{~Np}$ & 696.0 & $10 \mathrm{e}-5 \mathrm{Pic}$ & 16.4 & $1.2 \% \mathrm{IOCS}$ & 7.89 \\
\hline $6.7 \times 10 \mathrm{e}-7 \mathrm{~Np}$ & 2226.6 & $10 \mathrm{e}-5 \mathrm{Pic}$ & 5.3 & $1.2 \%$ IOCS & 8.30 \\
\hline $6.7 \times 10 \mathrm{e}-7 \mathrm{~Np}$ & 1775.2 & $10 \mathrm{e}-5 \mathrm{Pic}$ & 0.0 & $1.2 \% \mathrm{IOCS}$ & 8.32 \\
\hline $6.7 \times 10 \mathrm{e}-7 \mathrm{~Np}$ & 9069.2 & $10 \mathrm{e}-5 \mathrm{Pic}$ & 3.9 & $1.2 \% \mathrm{IOCS}$ & 9.14 \\
\hline $6.7 \times 10 \mathrm{e}-7 \mathrm{~Np}$ & 4874.8 & $10 \mathrm{e}-5 \mathrm{Pic}$ & 5.2 & $1.2 \% \mathrm{IOCS}$ & 9.26 \\
\hline $6.7 \times 10 \mathrm{e}-7 \mathrm{~Np}$ & 1.8 & 0.0 & - & Milford Soil & 4.60 \\
\hline $6.7 \times 10 \mathrm{e}-7 \mathrm{~Np}$ & 0.0 & 0.0 & - & Milford Soil & 4.61 \\
\hline $6.7 \times 10 \mathrm{e}-7 \mathrm{~Np}$ & 2.6 & 0.0 & - & Milford Soil & 5.33 \\
\hline $6.7 \times 10 \mathrm{e}-7 \mathrm{~Np}$ & 7.1 & 0.0 & - & Milford Soil & 5.67 \\
\hline $6.7 \times 10 \mathrm{e}-7 \mathrm{~Np}$ & 21.1 & 0.0 & - & Milford Soil & 6.21 \\
\hline $6.7 \times 10 \mathrm{e}-7 \mathrm{~Np}$ & 17.5 & 0.0 & - & Milford Soil & 6.31 \\
\hline $6.7 \times 10 \mathrm{e}-7 \mathrm{~Np}$ & 122.2 & 0.0 & - & Milford Soil & 7.55 \\
\hline $6.7 \times 10 \mathrm{e}-7 \mathrm{~Np}$ & 122.5 & 0.0 & - & Milford Soil & 7.62 \\
\hline $6.7 \times 10 \mathrm{e}-7 \mathrm{~Np}$ & 248.3 & 0.0 & - & Milford Soil & 7.65 \\
\hline $6.7 \times 10 \mathrm{e}-7 \mathrm{~Np}$ & 301.1 & 0.0 & - & Milford Soil & 7.79 \\
\hline $6.7 \times 10 \mathrm{e}-7 \mathrm{~Np}$ & 748.0 & 0.0 & - & Milford Soil & 9.75 \\
\hline $6.7 \times 10 \mathrm{e}-7 \mathrm{~Np}$ & 740.8 & 0.0 & - & Milford Soil & 9.76 \\
\hline
\end{tabular}




\begin{tabular}{|c|c|c|c|c|c|}
\hline Metal Conc. & Kd (metal) & Ligand Conc. & Kd (ligand) & Adsorbent & $\mathbf{p H}$ \\
\hline $6.7 \times 10 \mathrm{e}-7 \mathrm{~Np}$ & 0.1 & 10e-5 Pic & 149 & Milford Soil & 4.63 \\
\hline $6.7 \times 10 \mathrm{e}-7 \mathrm{~Np}$ & 0 & $10 \mathrm{e}-5 \mathrm{Pic}$ & 141.2 & Milford Soil & 4.73 \\
\hline $6.7 \times 10 \mathrm{e}-7 \mathrm{~Np}$ & 5.8 & $10 \mathrm{e}-5 \mathrm{Pic}$ & 168.9 & Milford Soil & 5.61 \\
\hline $6.7 \times 10 \mathrm{e}-7 \mathrm{~Np}$ & 9.4 & $10 \mathrm{e}-5 \mathrm{Pic}$ & 132.8 & Milford Soil & 5.84 \\
\hline $6.7 \times 10 \mathrm{e}-7 \mathrm{~Np}$ & 15.4 & $10 \mathrm{e}-5 \mathrm{Pic}$ & 77.7 & Milford Soil & 6.3 \\
\hline $6.7 \times 10 \mathrm{e}-7 \mathrm{~Np}$ & 16.7 & $10 \mathrm{e}-5 \mathrm{Pic}$ & 56.8 & Milford Soil & 6.35 \\
\hline $6.7 \times 10 \mathrm{e}-7 \mathrm{~Np}$ & 107 & 10e-5 Pic & 10.2 & Milford Soil & 7.45 \\
\hline $6.7 \times 10 \mathrm{e}-7 \mathrm{~Np}$ & 121.3 & $10 \mathrm{e}-5 \mathrm{Pic}$ & 5.9 & Milford Soil & 7.48 \\
\hline $6.7 \times 10 \mathrm{e}-7 \mathrm{~Np}$ & 209.3 & $10 \mathrm{e}-5 \mathrm{Pic}$ & 1.7 & Milford Soil & 7.98 \\
\hline $6.7 \times 10 \mathrm{e}-7 \mathrm{~Np}$ & 217.1 & $10 \mathrm{e}-5 \mathrm{Pic}$ & 2.6 & Milford Soil & 8.05 \\
\hline $6.7 \times 10 \mathrm{e}-7 \mathrm{~Np}$ & 567.5 & $10 \mathrm{e}-5 \mathrm{Pic}$ & 1.4 & Milford Soil & 9.76 \\
\hline $6.7 \times 10 e-7 N p$ & 559.4 & 10e-5 Pic & 6 & Milford Soil & 9.85 \\
\hline $10 e-5 \mathrm{U}$ & 28.5 & 10e-3 Pic & 7.4 & $1.2 \%$ IOCS & 4.32 \\
\hline $10 e-5 \mathrm{U}$ & 37.8 & 10e-3 Pic & 6.4 & $1.2 \%$ IOCS & 4.35 \\
\hline $10 \mathrm{e}-5 \mathrm{U}$ & 218.2 & $10 \mathrm{e}-3 \mathrm{Pic}$ & 9.4 & $1.2 \%$ IOCS & 5.29 \\
\hline $10 \mathrm{e}-5 \mathrm{U}$ & 242.2 & $10 \mathrm{e}-3 \mathrm{Pic}$ & 14.8 & $1.2 \%$ IOCS & 5.30 \\
\hline $10 \mathrm{e}-5 \mathrm{U}$ & 825.4 & $10 \mathrm{e}-3 \mathrm{Pic}$ & 0.0 & $1.2 \%$ IOCS & 6.34 \\
\hline $10 \mathrm{e}-5 \mathrm{U}$ & 609.5 & 10e-3 Pic & 0.0 & $1.2 \% \mathrm{IOCS}$ & 6.37 \\
\hline $10 \mathrm{e}-5 \mathrm{U}$ & 1385.6 & 10e-3 Pic & 1.0 & $1.2 \% \mathrm{IOCS}$ & 6.82 \\
\hline $10 \mathrm{e}-5 \mathrm{U}$ & 3323.5 & 10e-3 Pic & 0.0 & $1.2 \%$ IOCS & 6.83 \\
\hline $10 e-5 U$ & 4527.1 & 10e-3 Pic & 0.0 & $1.2 \%$ IOCS & 7.30 \\
\hline $10 e-5 \mathrm{U}$ & 5379.7 & 10e-3 Pic & 0.0 & $1.2 \%$ IOCS & 7.38 \\
\hline $10 \mathrm{e}-5 \mathrm{U}$ & 3772.2 & 10e-3 Pic & 0.0 & $1.2 \%$ IOCS & 7.68 \\
\hline $10 \mathrm{e}-5 \mathrm{U}$ & 2468.8 & 10e-3 Pic & 0.0 & $1.2 \% \mathrm{IOCS}$ & 7.92 \\
\hline $10 \mathrm{e}-5 \mathrm{U}$ & 33.9 & $10 \mathrm{e}-3 \mathrm{Pic}$ & 4.6 & Milford Soil & 4.16 \\
\hline $10 \mathrm{e}-5 \mathrm{U}$ & 40.1 & $10 \mathrm{e}-3 \mathrm{Pic}$ & 0.0 & Milford Soil & 4.33 \\
\hline $10 \mathrm{e}-5 \mathrm{U}$ & 64.4 & $10 \mathrm{e}-3 \mathrm{Pic}$ & 0.0 & Milford Soil & 5.15 \\
\hline $10 \mathrm{e}-5 \mathrm{U}$ & 112.4 & 10e-3 Pic & 0.0 & Milford Soil & 5.24 \\
\hline $10 \mathrm{e}-5 \mathrm{U}$ & 160.8 & $10 \mathrm{e}-3 \mathrm{Pic}$ & 2.5 & Milford Soil & 6.29 \\
\hline $10 e-5 \mathrm{U}$ & 148.0 & 10e-3 Pic & 0.0 & Milford Soil & 6.30 \\
\hline $10 \mathrm{e}-5 \mathrm{U}$ & 598.4 & $10 \mathrm{e}-3 \mathrm{Pic}$ & 0.0 & Milford Soil & 7.15 \\
\hline $10 e-5 \mathrm{U}$ & 750.8 & 10e-3 Pic & 6.4 & Milford Soil & 7.29 \\
\hline $10 \mathrm{e}-5 \mathrm{U}$ & 625.9 & 10e-3 Pic & 0.0 & Milford Soil & 8.37 \\
\hline $10 \mathrm{e}-5 \mathrm{U}$ & 501.4 & 10e-3 Pic & 0.0 & Milford Soil & 8.50 \\
\hline $10 \mathrm{e}-5 \mathrm{U}$ & 1263.3 & 10e-3 Pic & 1.4 & Milford Soil & 9.17 \\
\hline $10 e-5 \mathrm{U}$ & 1245.5 & 10e-3 Pic & 11.7 & Milford Soil & 9.42 \\
\hline $10 \mathrm{e}-5 \mathrm{U}$ & 0.0 & 10e-5 EDTA & 614.0 & $1.2 \% \mathrm{IOCS}$ & 3.14 \\
\hline $10 e-5 U$ & 0.0 & 10e-5 EDTA & 539.1 & $1.2 \% \mathrm{IOCS}$ & 3.18 \\
\hline $10 \mathrm{e}-5 \mathrm{U}$ & 0.0 & 10e-5 EDTA & 528.2 & $1.2 \%$ IOCS & 3.24 \\
\hline $10 \mathrm{e}-5 \mathrm{U}$ & 0.0 & 10e-5 EDTA & 514.7 & $1.2 \%$ IOCS & 3.34 \\
\hline $10 \mathrm{e}-5 \mathrm{U}$ & 53.2 & 10e-5 EDTA & 253.3 & $1.2 \% \mathrm{IOCS}$ & 4.31 \\
\hline $10 \mathrm{e}-5 \mathrm{U}$ & 251.1 & 10e-5 EDTA & 196.4 & $1.2 \%$ IOCS & 4.9 \\
\hline $10 e-5 U$ & 6398.6 & 10e-5 EDTA & 115.1 & $1.2 \%$ IOCS & 5.33 \\
\hline $10 \mathrm{e}-5 \mathrm{U}$ & 12129.3 & 10e-5 EDTA & 74.1 & $1.2 \% \mathrm{IOCS}$ & 5.65 \\
\hline
\end{tabular}




\begin{tabular}{|c|c|c|c|c|c|}
\hline Metal Conc. & Kd (metal) & Ligand Conc. & Kd (ligand) & Adsorbent & $\mathbf{p H}$ \\
\hline $10 \mathrm{e}-5 \mathrm{U}$ & 71301.6 & 10e-5 EDTA & 34.8 & $1.2 \%$ IOCS & 7.28 \\
\hline $10 \mathrm{e}-5 \mathrm{U}$ & 19678.3 & 10e-5 EDTA & 42.5 & $1.2 \% \mathrm{IOCS}$ & 7.3 \\
\hline $10 e-5 U$ & 15244.1 & 10e-5 EDTA & 16.5 & $1.2 \% \mathrm{IOCS}$ & 7.33 \\
\hline $10 e-5 U$ & 19310.4 & 10e-5 EDTA & 28.6 & $1.2 \%$ IOCS & 7.44 \\
\hline $10 \mathrm{e}-5 \mathrm{U}$ & 8499.4 & 10e-5 EDTA & 10.8 & $1.2 \% \mathrm{IOCS}$ & 7.48 \\
\hline $10 \mathrm{e}-5 \mathrm{U}$ & 11692.5 & 10e-5 EDTA & 10.2 & $1.2 \% \mathrm{IOCS}$ & 7.51 \\
\hline $10 \mathrm{e}-5 \mathrm{U}$ & 25849.9 & 10e-5 EDTA & 20.2 & $1.2 \%$ IOCS & 7.52 \\
\hline $10 \mathrm{e}-5 \mathrm{U}$ & 17543.1 & 10e-5 EDTA & 19.4 & $1.2 \%$ IOCS & 7.58 \\
\hline $10 \mathrm{e}-5 \mathrm{U}$ & 3479.6 & 10e-5 EDTA & 6.2 & $1.2 \% \mathrm{IOCS}$ & 7.64 \\
\hline $10 e-5 \mathrm{U}$ & 3289.8 & 10e-5 EDTA & 6.7 & $1.2 \%$ IOCS & 7.69 \\
\hline $10 \mathrm{e}-5 \mathrm{U}$ & 2725.8 & 10e-5 EDTA & 1.6 & $1.2 \% \mathrm{IOCS}$ & 8.37 \\
\hline $10 e-5 U$ & 4417.4 & 10e-5 EDTA & 0.6 & $1.2 \% \mathrm{IOCS}$ & 8.64 \\
\hline $10 \mathrm{e}-5 \mathrm{U}$ & 9605.6 & 10e-5 EDTA & 0.0 & $1.2 \% \mathrm{IOCS}$ & 8.93 \\
\hline $10 \mathrm{e}-5 \mathrm{U}$ & 6626.2 & 10e-5 EDTA & 1.2 & $1.2 \%$ IOCS & 9.17 \\
\hline $10 \mathrm{e}-5 \mathrm{U}$ & 81.2 & 10e-5 EDTA & 29.6 & Milford Soil & 4.55 \\
\hline $10 \mathrm{e}-5 \mathrm{U}$ & 76.1 & 10e-5 EDTA & 24.5 & Milford Soil & 4.61 \\
\hline $10 e-5 \mathrm{U}$ & 165.4 & 10e-5 EDTA & 30.2 & Milford Soil & 4.96 \\
\hline $10 \mathrm{e}-5 \mathrm{U}$ & 88.2 & 10e-5 EDTA & 29.7 & Milford Soil & 5.01 \\
\hline $10 \mathrm{e}-5 \mathrm{U}$ & 213.9 & 10e-5 EDTA & 26.4 & Milford Soil & 5.67 \\
\hline $10 \mathrm{e}-5 \mathrm{U}$ & 328.4 & 10e-5 EDTA & 29.3 & Milford Soil & 5.67 \\
\hline $10 \mathrm{e}-5 \mathrm{U}$ & 2026.2 & 10e-5 EDTA & 24.3 & Milford Soil & 5.98 \\
\hline $10 \mathrm{e}-5 \mathrm{U}$ & 1454.5 & 10e-5 EDTA & 22.8 & Milford Soil & 5.99 \\
\hline $10 \mathrm{e}-5 \mathrm{U}$ & 1837.9 & 10e-5 EDTA & 18.8 & Milford Soil & 6.69 \\
\hline $10 \mathrm{e}-5 \mathrm{U}$ & 3064.0 & 10e-5 EDTA & 17.2 & Milford Soil & 6.72 \\
\hline $10 \mathrm{e}-5 \mathrm{U}$ & 3927.5 & 10e-5 EDTA & 13.4 & Milford Soil & 6.84 \\
\hline $10 e-5 \mathrm{U}$ & 4544.8 & 10e-5 EDTA & 13.4 & Milford Soil & 6.84 \\
\hline $10 \mathrm{e}-5 \mathrm{U}$ & 5148.6 & 10e-5 EDTA & 10.0 & Milford Soil & 6.94 \\
\hline $10 \mathrm{e}-5 \mathrm{U}$ & 2978.3 & 10e-5 EDTA & 8.7 & Milford Soil & 6.95 \\
\hline $10 \mathrm{e}-5 \mathrm{U}$ & 2179.2 & 10e-5 EDTA & 6.3 & Milford Soil & 7.04 \\
\hline $10 \mathrm{e}-5 \mathrm{U}$ & 1265.9 & 10e-5 EDTA & 5.8 & Milford Soil & 7.05 \\
\hline $10 e-5 U$ & 481.2 & 10e-5 EDTA & 2.5 & Milford Soil & 7.95 \\
\hline $10 \mathrm{e}-5 \mathrm{U}$ & 599.2 & 10e-5 EDTA & 3.1 & Milford Soil & 7.97 \\
\hline $10 \mathrm{e}-5 \mathrm{U}$ & 488.5 & 10e-5 EDTA & 0.7 & Milford Soil & 8.16 \\
\hline $10 \mathrm{e}-5 \mathrm{U}$ & 436.9 & 10e-5 EDTA & 2.3 & Milford Soil & 8.23 \\
\hline $10 \mathrm{e}-5 \mathrm{U}$ & 2026.1 & 10e-5 EDTA & 0.0 & Milford Soil & 9.12 \\
\hline $10 \mathrm{e}-5 \mathrm{U}$ & 1835.2 & 10e-5 EDTA & 0.3 & Milford Soil & 9.16 \\
\hline $10 \mathrm{e}-5 \mathrm{U}$ & 821.2 & 10e-5 EDTA & 22.6 & LK-1 & 4.04 \\
\hline $10 \mathrm{e}-5 \mathrm{U}$ & 844.3 & 10e-5 EDTA & 23.3 & LK-1 & 4.06 \\
\hline $10 e-5 U$ & 992.9 & 10e-5 EDTA & 19.8 & LK-1 & 4.12 \\
\hline $10 e-5 \mathrm{U}$ & 900.0 & 10e-5 EDTA & 24.0 & LK-1 & 4.14 \\
\hline $10 \mathrm{e}-5 \mathrm{U}$ & 4644.6 & 10e-5 EDTA & 20.3 & LK-1 & 4.67 \\
\hline $10 e-5 U$ & 5162.2 & 10e-5 EDTA & 19.7 & LK-1 & 4.73 \\
\hline $10 e-5 U$ & 52827.3 & 10e-5 EDTA & 29.3 & LK-1 & 5.50 \\
\hline
\end{tabular}




\begin{tabular}{|c|c|c|c|c|c|}
\hline Metal Conc. & Kd (metal) & Ligand Conc. & Kd (ligand) & Adsorbent & $\mathbf{p H}$ \\
\hline $10 \mathrm{e}-5 \mathrm{U}$ & 23433.7 & 10e-5 EDTA & 24.7 & LK-1 & 5.53 \\
\hline $10 \mathrm{e}-5 \mathrm{U}$ & 32382.4 & 10e-5 EDTA & 13.9 & LK-1 & 6.37 \\
\hline $10 \mathrm{e}-5 \mathrm{U}$ & 55035.1 & 10e-5 EDTA & 7.3 & LK-1 & 6.44 \\
\hline $10 \mathrm{e}-5 \mathrm{U}$ & 32976.5 & 10e-5 EDTA & 15.1 & LK-1 & 6.50 \\
\hline $10 \mathrm{e}-5 \mathrm{U}$ & 61528.2 & 10e-5 EDTA & 8.3 & LK-1 & 6.55 \\
\hline $10 \mathrm{e}-5 \mathrm{U}$ & 26013.7 & 10e-5 EDTA & 5.3 & LK-1 & 6.60 \\
\hline $10 \mathrm{e}-5 \mathrm{U}$ & 9077.8 & 10e-5 EDTA & 1.2 & LK-1 & 6.71 \\
\hline $10 \mathrm{e}-5 \mathrm{U}$ & 68238.0 & 10e-5 EDTA & 17.9 & LK-1 & 6.76 \\
\hline $10 \mathrm{e}-5 \mathrm{U}$ & 29014.4 & 10e-5 EDTA & 6.7 & LK-1 & 6.80 \\
\hline $10 \mathrm{e}-5 \mathrm{U}$ & 4613.1 & 10e-5 EDTA & 8.3 & LK-1 & 6.97 \\
\hline $10 \mathrm{e}-5 \mathrm{U}$ & 2524.5 & 10e-5 EDTA & 1.6 & LK-1 & 7.00 \\
\hline $10 \mathrm{e}-5 \mathrm{U}$ & 5995.8 & 10e-5 EDTA & 4.5 & LK-1 & 7.16 \\
\hline $10 e-5 \mathrm{U}$ & 6946.1 & 10e-5 EDTA & 7.9 & LK-1 & 7.18 \\
\hline $10 \mathrm{e}-5 \mathrm{U}$ & 8157.7 & 10e-5 EDTA & 8.0 & LK-1 & 7.48 \\
\hline $10 \mathrm{e}-5 \mathrm{U}$ & 9593.1 & $10 \mathrm{e}-5$ EDTA & 7.9 & LK-1 & 7.55 \\
\hline $10 e-5 \mathrm{U}$ & 18.2 & 10e-5 EDTA & 153.0 & MNC-70 & 4.23 \\
\hline $10 \mathrm{e}-5 \mathrm{U}$ & 20.1 & $10 \mathrm{e}-5 \mathrm{EDTA}$ & 136.9 & MNC-70 & 4.25 \\
\hline $10 \mathrm{e}-5 \mathrm{U}$ & 144.2 & 10e-5 EDTA & 159.6 & MNC-70 & 4.71 \\
\hline $10 \mathrm{e}-5 \mathrm{U}$ & 109.7 & $10 \mathrm{e}-5$ EDTA & 150.2 & MNC-70 & 4.72 \\
\hline $10 e-5 U$ & 717.3 & 10e-5 EDTA & 159.2 & MNC-70 & 5.16 \\
\hline $10 \mathrm{e}-5 \mathrm{U}$ & 595.5 & 10e-5 EDTA & 154.5 & MNC-70 & 5.17 \\
\hline $10 \mathrm{e}-5 \mathrm{U}$ & 2204.7 & 10e-5 EDTA & 151.4 & MNC-70 & 5.63 \\
\hline $10 \mathrm{e}-5 \mathrm{U}$ & 2340.3 & 10e-5 EDTA & 141.0 & MNC-70 & 5.74 \\
\hline $10 \mathrm{e}-5 \mathrm{U}$ & 5246.4 & 10e-5 EDTA & 144.0 & MNC-70 & 5.97 \\
\hline $10 \mathrm{e}-5 \mathrm{U}$ & 6978.3 & $10 \mathrm{e}-5$ EDTA & 153.5 & MNC-70 & 5.99 \\
\hline $10 \mathrm{e}-5 \mathrm{U}$ & 8925.4 & 10e-5 EDTA & 136.2 & MNC-70 & 6.31 \\
\hline $10 \mathrm{e}-5 \mathrm{U}$ & 12808.9 & 10e-5 EDTA & 131.7 & MNC-70 & 6.34 \\
\hline $10 \mathrm{e}-5 \mathrm{U}$ & 8372.9 & 10e-5 EDTA & 109.9 & MNC-70 & 6.55 \\
\hline $10 \mathrm{e}-5 \mathrm{U}$ & 7715.3 & 10e-5 EDTA & 81.9 & MNC-70 & 6.56 \\
\hline $10 \mathrm{e}-5 \mathrm{U}$ & 9311.1 & 10e-5 EDTA & 89.7 & MNC-70 & 6.56 \\
\hline $10 \mathrm{e}-5 \mathrm{U}$ & 13769.7 & 10e-5 EDTA & 96.9 & MNC-70 & 6.79 \\
\hline $10 e-5 \mathrm{U}$ & 5203.1 & 10e-5 EDTA & 62.6 & $\mathrm{MNC}-70$ & 6.95 \\
\hline $10 \mathrm{e}-5 \mathrm{U}$ & 7963.8 & 10e-5 EDTA & 81.2 & MNC-70 & 6.99 \\
\hline $10 \mathrm{e}-5 \mathrm{U}$ & 3529.4 & 10e-5 EDTA & 42.8 & MNC-70 & 7.13 \\
\hline $10 e-5 \mathrm{U}$ & 3852.6 & 10e-5 EDTA & 47.4 & MNC-70 & 7.16 \\
\hline $10 \mathrm{e}-5 \mathrm{U}$ & 775.1 & 10e-5 EDTA & 18.0 & MNC-70 & 7.45 \\
\hline $10 \mathrm{e}-5 \mathrm{U}$ & 1390.7 & 10e-5 EDTA & 19.1 & MNC-70 & 7.75 \\
\hline $6.7 \times 10 \mathrm{e}-7 \mathrm{Pu}$ & 0 & 0.0 & - & Milford Soil & 4.86 \\
\hline $6.7 \times 10 \mathrm{e}-7 \mathrm{Pu}$ & 0 & 0.0 & - & Milford Soil & 4.91 \\
\hline $6.7 \times 10 \mathrm{e}-7 \mathrm{Pu}$ & 0 & 0.0 & - & Milford Soil & 6.05 \\
\hline $6.7 \times 10 \mathrm{e}-7 \mathrm{Pu}$ & 0 & 0.0 & - & Milford Soil & 6.08 \\
\hline $6.7 \times 10 \mathrm{e}-7 \mathrm{Pu}$ & 3 & 0.0 & - & Milford Soil & 7.47 \\
\hline $6.7 \times 10 \mathrm{e}-7 \mathrm{Pu}$ & 0.7 & 0.0 & - & Milford Soil & 7.52 \\
\hline $6.7 \times 10 \mathrm{e}-7 \mathrm{Pu}$ & 8.7 & 0.0 & - & Milford Soil & 7.86 \\
\hline
\end{tabular}

B. 9 


$\begin{array}{lcccll}\text { Metal Conc. } & \text { Kd (metal) } & \text { Ligand Conc. } & \text { Kd (ligand) } & \text { Adsorbent } & \text { pH } \\ 6.7 \times 10 \mathrm{e}-7 \mathrm{Pu} & 2.1 & 0.0 & - & \text { Milford Soil } & 7.89 \\ 6.7 \times 10 \mathrm{e}-7 \mathrm{Pu} & 36.1 & 0.0 & - & \text { Milford Soil } & 8.39 \\ 6.7 \times 10 \mathrm{e}-7 \mathrm{Pu} & 49.2 & 0.0 & - & \text { Milford Soil } & 8.58 \\ 6.7 \times 10 \mathrm{e}-7 \mathrm{Pu} & 53.3 & 0.0 & - & \text { Milford Soil } & 9.30 \\ 6.7 \times 10 \mathrm{e}-7 \mathrm{Pu} & 45.5 & 0.0 & - & \text { Milford Soil } & 9.34 \\ 6.7 \times 10 \mathrm{e}-7 \mathrm{Pu} & 0 & - & - & \text { Milford Soil } & 4.78 \\ 6.7 \times 10 \mathrm{e}-7 \mathrm{Pu} & 0 & - & - & \text { Milford Soil } & 4.74 \\ 6.7 \times 10 \mathrm{e}-7 \mathrm{Pu} & 0.2 & - & - & \text { Milford Soil } & 6.27 \\ 6.7 \times 10 \mathrm{e}-7 \mathrm{Pu} & 0 & - & - & \text { Milford Soil } & 6.28 \\ 6.7 \times 10 \mathrm{e}-7 \mathrm{Pu} & 1.5 & - & - & \text { Milford Soil } & 7.63 \\ 6.7 \times 10 \mathrm{e}-7 \mathrm{Pu} & 2.6 & - & - & \text { Milford Soil } & 7.67 \\ 6.7 \times 10 \mathrm{e}-7 \mathrm{Pu} & 9.7 & - & - & \text { Milford Soil } & 7.97 \\ 6.7 \times 10 \mathrm{e}-7 \mathrm{Pu} & 9.9 & - & - & \text { Milford Soil } & 7.98 \\ 6.7 \times 10 \mathrm{e}-7 \mathrm{Pu} & 52.9 & - & - & \text { Milford Soil } & 8.47 \\ 6.7 \times 10 \mathrm{e}-7 \mathrm{Pu} & 46.7 & - & - & \text { Milford Soil } & 8.74 \\ 6.7 \times 10 \mathrm{e}-7 \mathrm{Pu} & 64.9 & - & - & \text { Milford Soil } & 9.61 \\ 6.7 \times 10 \mathrm{e}-7 \mathrm{Pu} & 84 & - & - & \text { Milford Soil } & 9.69 \\ 1.0 \times 10 \mathrm{e}-8 \mathrm{Pu} & 18.5 & 10 \mathrm{e}-5 \mathrm{Pic} & 126.8 & \text { Milford Soil } & 4.52 \\ 1.0 \times 10 \mathrm{e}-8 \mathrm{Pu} & 16.8 & 10 \mathrm{e}-5 \mathrm{Pic} & 153.2 & \text { Milford Soil } & 4.54 \\ 1.0 \times 10 \mathrm{e}-8 \mathrm{Pu} & 87.5 & 10 \mathrm{e}-5 \mathrm{Pic} & 169.2 & \text { Milford Soil } & 6.61 \\ 1.0 \times 10 \mathrm{e}-8 \mathrm{Pu} & 109.7 & 10 \mathrm{e}-5 \mathrm{Pic} & 114.4 & \text { Milford Soil } & 6.88 \\ 1.0 \times 10 \mathrm{e}-8 \mathrm{Pu} & 512.2 & 10 \mathrm{e}-5 \mathrm{Pic} & 57.4 & \text { Milford Soil } & 7.45 \\ 1.0 \times 10 \mathrm{e}-8 \mathrm{Pu} & 547.5 & 10 \mathrm{e}-5 \mathrm{Pic} & 71.3 & \text { Milford Soil } & 7.58 \\ 1.0 \times 10 \mathrm{e}-8 \mathrm{Pu} & 600.1 & 10 \mathrm{e}-5 \mathrm{Pic} & 7.4 & \text { Milford Soil } & 7.99 \\ 1.0 \times 10 \mathrm{e}-8 \mathrm{Pu} & 569.0 & 10 \mathrm{e}-5 \mathrm{Pic} & 14.9 & \text { Milford Soil } & 8.00 \\ 1.0 \times 10 \mathrm{e}-8 \mathrm{Pu} & 515.7 & 10 \mathrm{e}-5 \mathrm{Pic} & 0.7 & \text { Milford Soil } & 8.48 \\ 1.0 \times 10 \mathrm{e}-8 \mathrm{Pu} & 829.1 & 10 \mathrm{e}-5 \mathrm{Pic} & 0.0 & \text { Milford Soil } & 8.51 \\ 1.0 \times 10 \mathrm{e}-8 \mathrm{Pu} & 490.1 & 10 \mathrm{e}-5 \mathrm{Pic} & 0.0 & \text { Milford Soil } & 9.52 \\ 1.0 \times 10 \mathrm{e}-8 \mathrm{Pu} & 852.9 & 10 \mathrm{e}-5 \mathrm{Pic} & 0.0 & \text { Milford Soil } & 9.64\end{array}$


(See instructions on the reverse)

2. TITLE AND SUBTITLE

NUREG/CR-6758

Radionuclide - Chelating Agent Complexes in Low-Level

Radioactive Decontamination Waste; Stability, Adsorption

And Transport Potential

5. AUTHOR(S)

R.J. Serne, K.J. Cantrell, C.W. Lindenmeier, A.T. Owen,

I.V. Kutnyakov, R.D. Orr, and A.R. Felmy
DATE REPORT PUBLISHED

MONTH

4. FIN OR GRANT NUMBER

L1155

6. TYPE OF REPORT

NUREG/CR

7. PERIOD COVERED (Imc/usive Dates)

$3 / 31 / 96$ to $12 / 31 / 01$

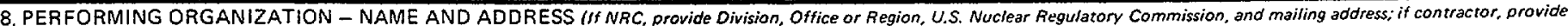
name and mailing address.)

Pacific Northwest National Laboratory

Environmental Technology Division

P.O. Box 999 MS. K6-81; Richland, WA 99352

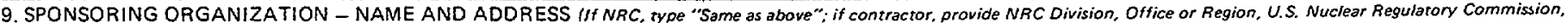
and maising address.)

Division of Systems Analysis and Regulatory Effectiveness

Office of Nuclear Regulatory Research

U.S. Nuclear Regulatory Commission, Washington, DC 20555-0001

10. SUPPLEMENTARY NOTES

P.R. Reed, NRC Project Manager

11. ABSTRACT (200 words or jess)

Speciation calculations were done to determine whether organic complexants facilitate transport of radionuclides leached from waste buried in soils. EDTA readily mobilizes divalent transitions metals and moderately impacts trivalent actinides. Picolinate readily mobilizes only $\mathrm{Ni}^{2+}$ and $\mathrm{Co}^{2+}$. These speciation predictions ignore the influence of soil adsorption and biodegradation that break apart the complexes. In adsorption studies, picolinate concentrations have to be $>10^{-4} \mathrm{M}$ to lower the adsorption on $\mathrm{Ni}$ and $\mathrm{Co}$. For $\mathrm{Sm}^{3+}, \mathrm{Th}^{4+}, \mathrm{NpO}^{2+}, \mathrm{UO}_{2}{ }^{2+}$, and $\mathrm{Pu}$, the picolinate concentration must be $>10^{-3} \mathrm{M}$ before adsorption decreases. EDTA forms strong complexes with divalent transition metals and can stop adsorption of $\mathrm{Ni}$ and $\mathrm{Co}$ when EDTA solution concentrations are $\geq 10^{-5} \mathrm{M}$. EDTA complexes with $\mathrm{NpO}_{2}^{+}, \mathrm{UO}_{2}{ }^{2+}$, and $\mathrm{Pu}$ are much weaker; EDTA concentrations would have to be $>10^{-3} \mathrm{M}$ to adversely effect non-transition metal/radionuclide adsorption. Most picolinate and ETDA-metal complexes appear to readily dissociate during interactions with soils. The enhanced migration of radionuclide-organic complexes may be limited to a few unique conditions. We recommend that mixtures of metal/radionuclides and EDTA should not be solidified or co-disposed with high $\mathrm{pH}$ materials such as cement. For weaker binding organic complexants, picolinate, citrate and oxalante, co-disposal of decontamination wastes and concrete should be acceptable.

12. KEY WORDS/DESCR!PTORS (List words or phrases that will assist researchers in locating the report.)

13. AVAILABILITY STATEMENT

unlimited

radionuclide-chelate complex aqueous complexation of radionuclides adsorption of radionuclides, organic ligands, and complexes spent-resin leachates
14. SECURIYY CLASSIFICATION

TThis Pagel

unclassified

(This Reoont)

unclassified

15. NUMBER OF PAGES

16. PRICE 


\section{UNITED STATES}

NUCLEAR REGULATORY COMMISSION

WASHINGTON, DC 20555-0001

OFFICIAL BUSINESS

PENALTY FOR PRIVATE USE, $\$ 300$ 